\title{
BNWL-122 \\ HANFORD BIOLOGY RESEARCH ANNUAL REPORT FOR 1964
}

AEC

RESEARCH

and

DEVELOPMENT

REPORT

JANUARY, 1965
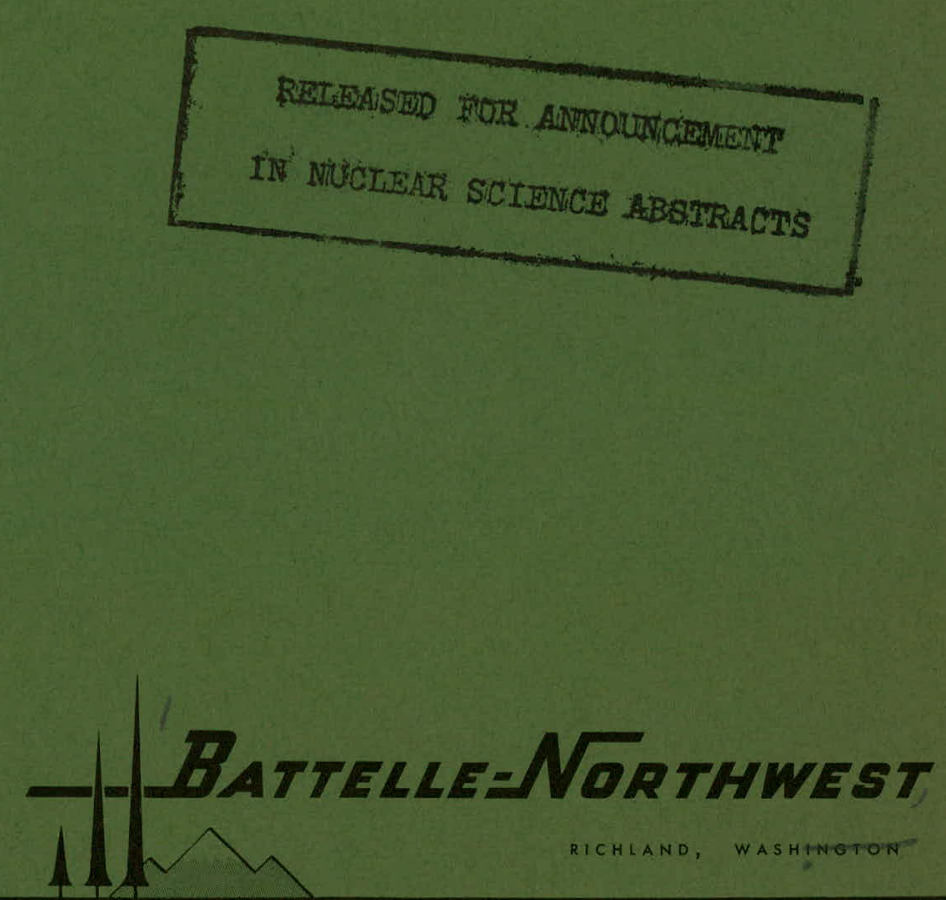

2 PACIFIC NORTHWEST LABORATORY operated by BATTELLE MEMORIAL INSTITUTE 


\section{DISCLAIMER}

This report was prepared as an account of work sponsored by an agency of the United States Government. Neither the United States Government nor any agency Thereof, nor any of their employees, makes any warranty, express or implied, or assumes any legal liability or responsibility for the accuracy, completeness, or usefulness of any information, apparatus, product, or process disclosed, or represents that its use would not infringe privately owned rights. Reference herein to any specific commercial product, process, or service by trade name, trademark, manufacturer, or otherwise does not necessarily constitute or imply its endorsement, recommendation, or favoring by the United States Government or any agency thereof. The views and opinions of authors expressed herein do not necessarily state or reflect those of the United States Government or any agency thereof. 


\section{DISCLAIMER}

Portions of this document may be illegible in electronic image products. Images are produced from the best available original document. 


\section{LEGAL NOTICE}

This report was prepared as an account of Government sponsored work. Neither the United States, nor the Commission, nor any person acting on behalf of the Commission:

A. Makes any warranty or representation, expressed or implied, with respect to the accuracy, completeness, or usefulness of the information contained in this report, or that the use of any information, apparatus, method, or process disclosed in this report may not infringe privately owned rights; or

B. Assumes any liabilities with respect to the use of, or for damages resulting from the use of any information, apparafus, method, or process disclosed in this report.

As used in the above, "person acting on behalf of the Commission" includes any employee or contractor of the Commission, or employee of such contractor, to the extent that such employee or contractor of the Commission, or employee of such contractor prepares, disseminates, or provides access to, any information pursuant to his employment or contract with the Commission, or his employment with such contractor.

\section{PACIFIC NORTHWEST LABORATORY \\ RICHLAND, WASHINGTON \\ operated by \\ BATTELLE MEMORIAL INSTITUTE}

for the

UNITED STATES ATOMIC ENERGY COMMISSION UNDER CONTRACT AT(45-1)-1830 


\section{LEGAL NOTICE}

This report was prepared as an account of Government sponeored

A. Makes any warranty or represerson acting on behalf of the Cork. Nelther the United racy, completeness, or usefulness of thention, expresised or implined Commission:

of any Information, apparatus, of the information contained in this th respect to the accu-

privately ouned rights; or

B. Assumes any liabilities with respect to the disclosed in this report may not infringe
use of any information

As used in the above, "fpers, method, or process of, or for damages resulting from the ployee or contractor of the Corson acting on behalf of the Comming the report.

dish employee ur contractor of the com, or cmpluyee of such contraction "inoludes any em-

with the $\mathrm{Cos}$, or provides access to any

With the Commission, or his employm any information pursuant to his eontractor prepares,

\begin{abstract}
with such contractor.
\end{abstract}
BNWL- 122

$\mathrm{UC}-48$, Biology and Medicine

FIRST

TID-4500

UNRESTRICTED

JAN $14^{\circ} 66$

DISTRIBUTION

MADE
$47 \mathrm{TH}$

EDITION

\section{HANFORD BIOLOGY RESEARCH}

ANNUAL REPORT FOR 1964

By

The Staff

of the Biology Department

Edited by

R. C. Thompson and S. W. Woods

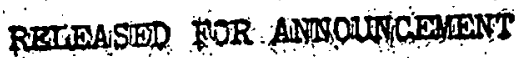

IN NUTCLEAR SICIDNCA ABSTHACTS

Janüäry, 1965 
ii

BNWL - 122

This is the fourteenth Annual Report of the Hanford Biology

Laboratory. Previous volumes are: HW-25021 (1951), HW-28636 (1952), HW-30437 (1953), HW-35917 (1954), HW-41500 (1955), HW-47500 (1956), HW-53500 (1957), HW-59500 (1958), HW-65500 (1959), HW-69500 (1960), HW -72500 (1961), HW-76000 (1962), and HW-80500 (1963).

Printed in USA. Price \$6:00. Available from the Clearinghouse for Federal Scientific and Technical Information

National Bureau of Standards

U.S. Department of Commerce Springfield, Virginia 


\section{INTRODUCTION :}

This fourteenth Annual Report of the Hanford Biology Laboratory will be the last to appear under such title. The Hanford Laboratories, operated by the General Electric Company for the U.S. Atomic Energy Commission, became, on January 4, 1965, the Pacific Northweot Laboratory, with administrative responsibility assumed by Battelle Memorial Institute. This report, issued by the Biology Department of the Pacific Northwest Laboratory describes work done in 1964 by the Biology Laboratory of the Hanford Laboratories.

The change of contractors involved no personnel changes in Biology. Another event of late 1964 was traumatic, however. On the evening of November 3 , the building that housed all of our aquatic biology, and much of our ecology laboratories was destroyed by fire. With the help of the Division of Biology and Medicine, by mid-1965 some of the more critical aquatic biology facilities were back in operation and the remainder of the aquatic and ecology program was housed in temporary facilities. The ensuing disruptions may to some extent excuse the late appearance of this report. Topical summaries of many of the papers in this report follow.

Of 40 dogs that were experimentally exposed to $\mathrm{Pu}^{239} \mathrm{O}_{2}$ aerosols, 10 succumbed two to five years postexposure, and five of these showed bronchiolo-alveolar carcinomas. Plutonium burdens at death ranged from 1-3 $\mu \mathrm{Ci}$ with 40-75\% remaining in the lungs and 20-50\% in bronchial and mediastinal lymph nodes.

Of particular interest in other inhalation studies was the observation that uranium and thorium activities from inhaled uranium ore dust are handled biologically in very different fashions and must, therefore, be separately considered in hazard evaluations.

In basic work on lung biochemistry, it was demonstrated that fatty acids can be synthesized by pulmonary tissue, and some knowledge was obtained of the mechanisms with which this occurs. These fatty acids 
iv

BNW L -122

are probably constituents of surfactants. which are needed to reduce surface tension for maintaining proper physical characteristics of the alveoli.

Of considerable interest and potential is the observation that leukemia can be induced in miniature swine by radiation. Two to four years after initiation of daily feedings of $\mathrm{Sr}^{90}$ tho the animals, five of them developed neoplasia of hematopoietic tissues--four of these were on a $125 \mu \mathrm{Ci}$ per day intake, one on a $25 \mu \mathrm{Ci}$ per day intake. No effects on bone have as yet been observed, and no effects of any kind at intake levels of $5 \mu \mathrm{Ci}$ per day, or less.

The major experiment in feeding $\mathrm{I}^{131}$ daily to sheep, begun over 15 years ago, is drawing to a close. Present efforts are principally concerned with peripheral studies, such as $I^{131}$ content of milk, absorption of $I^{131}$ through the skin, and analog computer studies of the metabolic kinetics of the $\mathrm{Te}^{132}-\mathrm{I}^{132}$ system. In a cooperative study with personnel of the Radiation Protection Department, the passage of $I^{131}$ from cows to man via milk was measured, especially noting the effect of inert iodine intake.

Factors that influence $\mathrm{Cs}^{137}$ concentration in rumen contents of sheep relative to that in feed were studied to aid in the interpretation of observations made on wild ruminants (caribou, reindeer, moose) in our Alaskan studies. Thermoluminescent dosimeters were successfully employed to measure the in vivo gamma radiation dose from internally deposited $\mathrm{Cs}^{137}$ in sheep.

Subcutaneously administered $\mathrm{Pu}^{239} \mathrm{O}_{2}$ in the miniature swine was much less mobile than similarly administered plutonium nitrate. Such translocation as occurred was principally to the regional lymph nodes. Efforts to influence the acute toxicity of $\mathrm{Pu}^{238}$ or $\mathrm{Pu}^{239}$ in rats by prior splenectomy. were without success.

Of particular interest is the description of a new method for ultrahigh-speed gross alpha autoradiography. Using a $\mathrm{ZnS}$ intensifier and high-speed Polaroid film, exposure time can be reduced to $1 / 1000$ 
of that required by conventional methods. This technique may have many important applications where time, rather than the ultimate in resolution, is the critical factor.

Several different systems for removing internal emitters were studied--desferoxamine on plutonium, sulfhydryl compounds and chelating agents on ruthenium, and NTPA on inhalcd $\mathrm{Ce}^{144}-\mathrm{PP}^{144}$ oxide.

Further studies on the involvement of bile in the intestinal radiation syndrome showed that $1500 \mathrm{R}$ to the abdomen of a rat reduced bile salt reabsorption in the small intestine by $50 \%$, with a resultant increased excretion of this bile via the large intestine. The effect of bile in promoting the loss of mucus, particularly, from the large intestine, was demonstrated in autoradiographic studies employing $\mathrm{S}^{35}$-labelling of the sulfomucopolysaccharides.

Effects of X ray, fast neutrons, DDT, and dimethylsulfoxide on flour beetles are described. These insects offer many advantages for the study of population effects.

Several interesting observations are reported from cytological studies of the liver of radiation chimeras. The hepatomegaly character:istic; of these chimeras seems to arise from an. increase in all functional elements of the liver. The parenchymal cells, which constitute 60-70\% of the total mouse liver cells, showed a shift to a lower DNA content population following foreign tissue injection. Leucocytic infiltrates were shown to provide a sensitive early indication of graft-host interaction.

In the microbiological area, evidence is reported for a specific role for methionine in the regulation of RNA synthesis. Certain hitherto unexplained peculiarities in the tryptophan requirements of Neurospora were clarified by demonstrating that indolepyruvic acid may be reversibly accumulated and serve as an ancillary source of tryptophan for tryptophan autotrophs.

The effect of many variables on the foliar deposition, root uptake, and translocation of such ions as $\mathrm{Rb}^{+}, \mathrm{I}^{-}, \mathrm{K}^{+}, \mathrm{Ca}^{++}, \mathrm{Sr}^{++}$, and $\mathrm{Cs}^{+}$are described. 
vi

BNWL-122

Results are reported from a third survey of radioactivity in northern Alaskan natives and their foods: Eskimo Cs ${ }^{137}$ levels in the summer of 1964 were about double those measured in 1963, but still well below any level which should be cause for concern. Seasonal fluctuations as determined by caribou hunting patterns, and caribou feeding patterns can now be fairly clearly defined. Food chain, precipitation, and radionuclide deposition interrelationships are also described for a continuing general survey in the State of Washington and in a carefully studied chèatgrass community.

Looking toward a broadened study of the dynamic balance of radionuclides in the Columbia River, preliminary results are reported on the role of plankton and periphyton in the accumulation and transport of $\mathrm{P}^{32}$ and $\mathrm{Zn}^{65}$.

Further studies of the economically important columnaris disease in fish have led to the demonstration of anti-columnaris titers in fish exposed to the organism. A sampling program showed that such titers exist in the majority of Columbia River fish. Application of immunological techniques in this area opens many exciting possibilities for study and control.

The third Hanford Biology Symposium, on Inhaled Radioactive Particles and Gases, was held on May 4-6, 1964, and was attended by some 170 visitors, 20 representing seven foreign countries. The complete proceedings of this symposium were published as the December 1964 issue of Health Physics. The 1965 symposium will be on Radiation and Terrestrial Ecosystems, and planned for 1966 is a symposium on Gastrointestinal Radiation Effects.

H. A. Kornberg 


\section{BIOLOGY LABORATORY STAFF \\ (as of December 31, 1964)}

\author{
H. A. Kornberg - Manager, Biology \\ P. M. Potter - Financial \\ Representative
}

\section{AQUATIC BIOLOGY}

R. E. Nakatani - Manager.
J. M. Dean
- Biol. Scientist
D. H. W. Liu - Biol. Scientist
P. A. Olson - Sr. Scientist

\section{BIOLOGICAL AN ALYSES}

R. F. Palmer - Manager

J. D. Berlin - Biol. Scientist

A. C. Case - Chemist

W. J. Clarke - Sr. Scientist

J. P. Herring - Chemist

R. F. Keough - Chemist

J. L. Palotay - Sr. Scientist

L. A. Temple - Biol. Scientist Glenda S. Vogt- Biol. Scientist
Evelyn G. Swezea - Secretary

Marguerite S. Stack - Secretary

Corinne H. Breazeale - Adm. Clerk

Patricia C. Lee - Secretary
R. G. Genoway
- Biol. Tech.
J. D. Maulsby
- Biol. Téch.
C. O'Malley
- Biol. Tech.

Gertrude G. Haggard - Adm. Clerk

R. R. Adee - Biol. Tech.

T. K. Andrews - Biol. Tech.

Juanita S. Barnett - Biol. Tech.

Donna B. Demers - Biol. Analyst

B. T. Didway - Biol. Analyst

Eugenia T.

Edinteson - Biol. Tech.

V. T. Faubert - Biol. Tech.

Ruth E. Gates - Biol. Analyst

Daphne S. Harrah - Biol. Analyst

Alys M. Harty - Biol. Tech.

Yvonne $\mathrm{W}$.

Hendrickson - Biol. Analyst

R. F. Howard - Biol. Tech.

Darlene H. Hunter - Biol. Analyst

Dona G. Kruger - Biol. Analyst

Patty Jo Nordahl - Biol. Tech.

Martha C. Perkins - Biol. Analyst

G. J. Powers - Biol. Tech.

Patricia H. Ray - Biol. Analyst

Sarah K. Richards - Biol. Tech.

Dorothy A.

Ricketts - Biol. Tech.

W. W. Roberts - Biol. Analyst

Helen M. Robinson - Biol. Analyst

R. L. Tramel - Biol. Analyst 
viii

BNWL- 122

BIOLOGY LABORATORY STAFF. (Continued)

EXPERIMENTAL ANIMAL FARIM

L. K. Bustad - Manager

Nelda B. Brown - Secretary

V. G. Horstman- Biol. Scientist

Beatrice'J.

B. L. Anderson - Biol. Analyst McClanahan - Biol. Scientist

R. O.

McClellan - Sr. Scientist

J. L. Beamer

- Biol. Tech.

W. W. Coleman

- Biol. Tech.

W. L. Daniels

- Biol. Tech.

R. C. Joyce - Biol. Tech.

J. R. McKenney- Biol. Scientist

J. C. Pekas - Biol. Scientist

H. A. Ragan - Biol. Scientist

\section{INHALATION TOXICOLOGY}

\section{W. J. Bair - Manager}

J. V. Dilley - Biol. Scientist

J. F. Park - Sr. Scientist

B. O. Stuart - Biol. Scientist

E. G.

Turrbrupuilos Sr. Scientiet

D. H. Willard - Biol. Scientist

\section{METABOLISM}

R. C. Thompson - Manager

Patricia L.

Hackett - Biol. Scientist

D. D. Mahlum - Sr. Scientist

V. H. Smith - Biol. Scientist

M. F. Sullivan - Sr. Scientist

E. M. Uyeki - Sr. Scientist
M. E. Kerr - Biol. Tech. Leader

W. B. Peterson - Biol. Analyst

K. L. Scherbarth - Biol. Analyst

P. L. Sheldon - Biol. Analyst

Ruby B. Shelton - General Clerk

V. D. Tyler - Biol. Tech.

W. A. Zimmerman- Biol. Tech.

Bernice L. Armstrong - Clerk

P. E. Bergam - Biol. Tech:

M. G. Brown - Biol. Tech.

D. L. Catt - Biol. Tech.

J. C. Gaven - Biol. Tech.

T. C. Kinnas - Biol. Analyst

K. E. McDonald - Biol. Tech.

W. Skinner - Biol. Tech.

M. D. Snyder - Biol. Tech.

D. A. Taff - Biol. Tech.

Sandra W. Woods - Secretary

Alma L. Crosby - Biol. Tech.

Joan O. Hess - Biol. Tech.

L. R. Richardson - Biol. Analyst

Linda G. Smith - Biol. Tech. 


\section{BIOLOGY LABORATORY STAFF (Continued)}

\section{RADIOECOLOGY}

F. P. Hungate - Manager

J. F. Cline - Biol. Scientist

C. E.Cushing - Biol. Scientist

I.. T.. Eberhardt Sr. Scientist

H. E. Erdman - Biol. Scientist

M. P. Fujihara - Biol:. Scientist

W. C. Hanson - Sr. Scientist

J. J.C.Hsieh - Biol. Scientist

W. H. Matchett - Biol. Scientist

W. H. Rickard - Sr. Scientist

R. L. Uhler - Sr. Scientist

D. G. Watson - Sr. Scientist
Jesse M. Bowelle - Secretary

Linda S. Collisson - Biol. Analyst

Frances A. Demers- Risl. Tech.

Ethel H. Jaschek - Biol. Analyst

I. L. Newcomb - Biol. Analyst

H. A. Sweany - Biol. Tech.

Dorothy D. Wade - Biol. Tech.

Laura S. Winn - Biol. Tech.

EDUCATIONAL LEAVE OF ABSENCE

J. E. Ballou - University of Rochester, Rochester, New York

MISCELLANEOUS SERVICES .

\begin{tabular}{|c|c|}
\hline Electrical & - T. J. Halloran \\
\hline Glassblower & - W. D. Leach \\
\hline Instruinerits & $\begin{array}{l}\text { - D. W. Findley } \\
\text { - R. D. Tucker } \\
\text { - S.A. A. Wilson }\end{array}$ \\
\hline Janitors & $\begin{array}{l}\text { - T.C. Abbey } \\
\text { - B. T. Didway } \\
\text { - T. L. Jackson } \\
\text { - L. Moore } \\
\text { - W. A. Orr } \\
\text { - O. O. Sions }\end{array}$ \\
\hline $\begin{array}{l}\text { Librarian } \\
\text { Radiation }\end{array}$ & - Elizabeth H. Groff \\
\hline Monitoring & $\begin{array}{l}\text { - G. M. Rolph } \\
\text { - W. W. King } \\
\text { - H. E. Frestun }\end{array}$ \\
\hline
\end{tabular}

SUMMER EMPLOYEES

I. L. Jacques - Experimental Animal Farm

$\mathrm{H}$. H. Jones - Radioecology

R.E. Kane - Experimental Animal Farm

R.C.Rall - Inhalation Toxicology

J.J.Reardon - Metabolism 


\section{BIOLOGY LABORATORY STAF́F (Continued)}

\section{SPECIAL ASSIGNMENT}

Capt. J. L. Murray, U.S. Air Force (Veterinary Corps)

- Experimental Animal Farm

Capt. R. O. Shannon, U.S. Air Force (Veterinary Corps)

- Experimental Animal Farm

Capt. D.H. Wood, U.S.A.ir Force (Veterinary Corps)

- Experimental Animal Farm

R. C. Erickson, AEC Richland Graduate Fellow

C. W. Fort, AEC Health Physics Fellow

- Aquatic Biology

K. R. Price, AEC Predoctoral Fellow.

- Radioecology

C. R. Watson, AEC Health Physics Fellow

- Experimental Animal Farm

J. Eapen, Atomic Energy Establishment, India

- Assigned to Biology for a one year period on a Fellowship sponsored by the International Atomic Energy Agency and supported by the National Academy of Sciences

\section{CONSULTANTS}

D. C. England, Oregon State University, Corvallis, Oregon

M. E. Ensminger, Consultants - Agriservices, Clovis, California 
TABLE OF CONTENTS

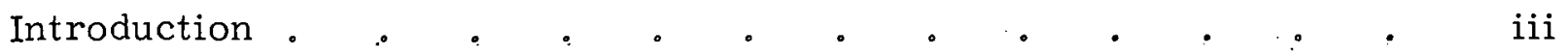

Biology Laboratory Staff . • . • • . • . . • • vii

TOXICITY AND METABOLISM OF RADIOELEMENTS

Inhalation Studies

Chronic Effects of Inhaled $\mathrm{Pu}^{239} \mathrm{O}_{2}$ in Dogs-Pregfess Report-

J. F. Park, W。 J. Clarke, and W.J. Bair . •

Whole-Body Retention and Biological Effects of Inhaled Ce ${ }^{144}-\mathrm{Pr}^{144}$ and $\mathrm{Ru} 106-\mathrm{Rh}{ }^{106}$ Oxides in Beagles

B. O. Stuart

Selective Tissue Accumulation of Uranium and Thorium in Rats After Inhalation of Uranium Ore Dust

B. O. Stuart and T. M. Beasley . . . . . . . . . 21

Experimental Beagle Colony - Breeding and Animal Care Program

M. G. Brown and J. F. Park • 。 • • • • • •

Improved Respiratory Valves for Inhalation Studies

B. O. Stuart, M. D. Snyder, W. J. Bair, and N. S. P.orter :

A. Versatile Iodine Vapor and Particle Sampler

IVI. D. Snyder and W. J. Bair.

Strontium

Biological Effects of $\mathrm{Sr}^{90}$ in Miniature Swine - Fifth Progress

Report

R. O. McClellan, W. J. Clarke, J. L. Palotay, H. A. Ragan, and Glenda S. Vogt

Cycling of $\mathrm{Sr}^{90}$ in Molting, Crayfish

J. M. Dean .

Radioiodine

Biological Effects of $\mathrm{I}^{131}$ in Sheep and Cattle

H. A. Ragan, B. J. McClanahan, V. G. Horstman,

R. O.Shannon, and L.K. Bustad . . . . . .

Sheep Milk Production and Its $\mathrm{I}^{131}$. Content

H. A. Ragan, V。G. Horstman, B. J. McClanahan, and L. K. Bustad . .. . . . . . . 。

Thyroid Uptake of $\mathrm{I}^{131}$ from Skin Exposure

J. L. Murray . • . • • . • • : ,

Analog Computer Evaluation of Tellurium-Iodine Contamination Events

E. C. Watson, R. A. Harvey, and L. K. Bustad . . . 
xii

BNWL-12்

\section{Cesium}

Relationship of $\mathrm{Cs}^{137}$. Concentration in Feed and Rumen Contents

R. O. Shannon, H. A. Ragan, and L.K. Bustad : .

Radiation Dosimetry of $\mathrm{Cs}^{137}$ in Sheep Evaluated with Thermoluminescent Dosimeters

R. O. McClellan and C. R. Watson . . . . . .

Metabolism of $\mathrm{Cs}^{137}$ in Trout

J. M. Dean, J. Eapen, and R. E. Nakatani . . . .

Transuranium and Rare Earth Elements

Liver Damage from $\mathrm{Np}^{237}$ in Sheep , $19: 40350$

D. H. Wood, J. L. Murray, and J. L. Palotay . . .

Effect of Dietary and Hormonal Manipulations on $\mathrm{Np}^{237}$-Induced

Fatty Livers

D. D. Mahlum . . . . . . . . . . .

Translocation of Subcutaneously Administered $\mathrm{Pu}^{239} \mathrm{O}_{2}$

Effect of Splenectomy on Acute Plutonium Toxicity

J. E. Ballou

Gastrointestinal Absorption of $\mathrm{Ce}^{144}$ and $\mathrm{Pm}^{147}$ in Miniature Swine

R. O. McClellan, L. K. Bustad, and R. F. Keough . . .

Chemical Carcinogens and Radionuclide Metabolism

D. D. Mahlum . . . . . . . . . . . . .

\section{Other Elements}

Milk Secretion of $\mathrm{Zn}^{65}$ and. $\mathrm{Cd}^{115 \mathrm{~m}}$ in Sheep

B. J. McClanahan and H. A. Ragan . . . . . . . 94

Toxicity of Stable Zinc and Stable Cadmium in Sheep

B. J.McClanahan, W. J. Clarke, and H. A. Ragan. . . 99

Effect of Chronic Ingestion of $\mathrm{Zn}^{65}$ in Trout

R. E. Nakatani, D. H.W. Liu, and W. J. Clarke . . . 101

Toxicity of Copper and $\mathrm{X}$ Rays in Rats

P. L. Hackett, W. J. Clarke, and J. L. Palotay . . . 107

Ultrahigh-Speed Gross Alpha Autoradiography

J. J. C. Hsieh, F. P. Hungate, and S. A. Wilson . . . 110 


\section{MODIFICATION OF RADIOELEMENT DEPOSITION AND RADIATION: RES PONSE $:$}

Effect of $I^{127}$ on Passage of $I^{131}$ from Cows to Man via Milk

E. C. Watson, I. C. Nelson, D. H. Wood, R. O. MicClellan, and L. K. Bustad

Removal of Internally Deposited Plutonium from Rats

V. H.'Smith

Kemoval of Internally Deposited Ruthenium from Rats

V. H. Smith

The Effect of DTPA on Translocation and Excretion of Inhaled

$\mathrm{Ce} 144-\mathrm{Pr}^{144}$ Oxide in Dogs

E. G. Tombropoulos, W. J.. Bair, and K. E. McDonald

\section{ANIMAL AND CELLULAR PHYSIOLOGY}

Bile Salt Absorption from the Irradiated Rat Intestine

M. F. Sullivan . . . . . . . . • .

The Effect of Bile on $\mathrm{S}^{35}$ Incorporation into Intestinal Mucopolysaccharides

M. F. Sullivan . . . . . . . . . . . .

Influence of Fission Neutrons on Rat Reproduction

$\mathrm{X}$-Ray and Fast. Neutron Effects on Productivity of Flour Beetles

H. E. Erdman . . . . . . . . . . .

DDT Toxicity in Flour Beetles

H. E. Erdman

140

Effects of a Sulfoxide Compound on Flour Beetles Exposed to X Rays

H. E. Erdman

Cytophotometric DNA Studies on Livers of Xenogeneic Chimeras

E. M. Uyeki

Liver Infiltrates in Radiation Chimeras

E. M. Uyeki and J. L. Palotay . . . . : . . . . 146

The Synthesis of RNA in Escherichia Coli

W. H. Matchett and R. T. O'Brien . . . . . . 150

The Role of Indolepyruvic Acid in the Metabolism of Tryptophan

in Neurospora

W. H. Matchett . . . . . . . . . . . . . 154

Incorporation of Acetate-1-C 14 into Long-Chain Fatty Acids

by Lung Mitochondria

E. G. Tombropoulos. . . . . . . . . . 160 
xiv

BNWL- 122

\section{PLANT PHYSIOLOGY}

Absorption and Translocation of $\mathrm{Rb}^{+}$and $\mathrm{I}^{-}$by Intact Plants

R. L. Uhler . • . • • . . • • •

Effects of Moisture and Air Temperature on Deposition and

Retention of $1 \frac{1}{2} 1$ on Plants and Soil

J. F. Cline and F. P. Hungate . . . . . . . . $166^{\prime}$

Influence of Soil Sodium on Plant Uptake of $\mathrm{Ca}^{45}, \mathrm{Sr}^{85}$, and $\mathrm{Cs}^{137}$

J. F. Cline and W. H. Rickard .. . . . . . . . 168

Effect of Root Temperatures on Plant Uptake of Potassium and

Calcium

J. F. Cline . . . . . . 170

\section{ECOLOGY}

Radioactivity in Northern Alaskan Natives and Their Foods During 1964

W. C. Hanson, H. E. Palmer, L. A. Braby, and

B. I. Griffin . . • . . . . • • • .

Radioactivity in Alaskan Animals and Forage Plants

D. G. Watson, L. L. Eberhardt, and W. C. Hanson . . 176

Studies of Fallout Nuclides in Plants and Browsing Animals of

Washington

L. L. Eberhardt and W. H. Rickard • • • • • . 181

Relationship of Annual Forage Yield and Fallout Deposition in a

Cheatgrass Community

W. H. Rickard . . . . . . . . . . . 184

Radionuclide Accumulation and Transport by Plankton in the

Columbia River

C. E. Cushing . . . . . . . . . .

Radionuclide Accumulation and Productivity of Periphyton in the

Columbia River

C. E. Cushing . . . . . . . . . . . . . 190

Antibody Production and Irrmune Response of Fish to $\mathrm{C}$. Columnaris

M. P. Fujihara, P. A. Olson, and R. E. Nakatani . . • 194

Chinook Salmon Spawning Near Hanford - 1964

Reactor Effluent Monitoring - 1964

P. A. Olson and R. E. Nakatani . . . . . . . 198 


\section{PUBLICATIONS}

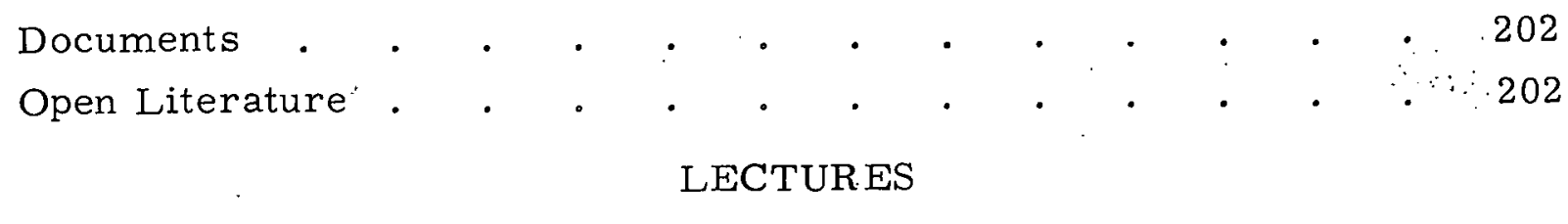

Papers Presented at Society Meetings and Symposia $\quad 206$

Orf-Site and Local Seminars $\quad \therefore \quad . \quad . \quad . \quad . \quad . \quad .210$

Biology Department Seminars .

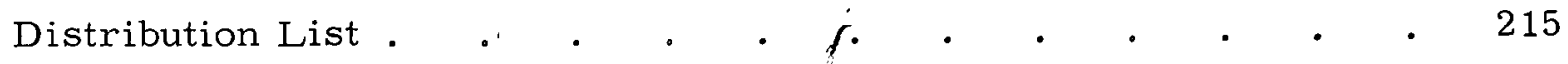




\title{
CHRONIC EFFECTS OF INHALED Pu ${ }^{239} \mathrm{O}_{2}$ IN DOGS- PROGRES:S-REPERT
}

\author{
J. F. Park, W. J. Clarke, and W. J. Bair
}

Inhalation of $\mathrm{Pu}^{239} \mathrm{O}_{2}$ particles by 40 beagle digs saused death in 10 animals 29 to 56 months postexposure. The body burdens at death ranged from 1 to $3 \mu \mathrm{Ci}$ with 40 to $75 \%$ of the body burden in the lungs, and 20 to $50 \%$ in the bronchial and mediastinal lymph nodes. The liver contained 2 to $15 \%$, and the skeleton, 1 to 5\%. Cardiopulmonary insufficiency and lymphopenia were the primary clinical signs. Pathologic effects in the lungs consisted primarily of severe fibrosis followed by alveolar cell hyperplasia, and bronchiolar and squamous types of metaplasia. Five of the animals showed bronchiolo-alveolar carcinomas, an incidence of $13 \%$ as compared to a primary lung tumor incidence of $0.2 \%$ in canine ? necropsy material. The bronchial lymph nodes were composed of dense sclerotic connective tissue devoid of any lymphoid element. Metastases of the pulmonary tumor to the bronchial lymph nodes were seen in one dog.

To study the long-term translocation and biological effects of inhaled $\mathrm{Pu}^{239} \mathrm{O}_{2}, 40$ beagle dogs were given a single 10 to $30 \mathrm{~min}$ exposure to $\mathrm{Pu}^{239} \mathrm{O}_{2}$ aerosols. The count median particle diameter of the aerosol ranged from 0.1 to $0.5 \mu$. Aerosol preparation, exposure methods, and clinical and pathology procedures were described in previous reports.

This report summarizes the tissue distribution of plutonium and biological effects in those dogs five years postexposure.

Mortality and Body Burden

'l'en dogs died or were sacrificed when death was imminent during the three to five year postinhalation period. The body burden at death ranged from 1 to $3 \mathrm{\mu Ci}$. Four additional dogs were sacrificed during this period to determine the tissue distribution of plutonium. The body burden at sacrifice in these dogs ranged from 0.01 to $0.9 \mathrm{MCi}$. One control dog was also sacrificed during this time period. Twenty-six exposed and 23 control dogs still alive three to five years postexposure are being maintained for long-term effects studies. 
BNWL- 122

\section{Distribution of Plutonium}

The body burden and distribution of plutonium at death are shown in Table 1. The lungs and bronchial and mediastinal lymph nodes contained 76 to $95 \%$ of the body burden, while the livers ranged from 1 to $15 \%$, and the skeleton 1 to $5 \%$. The bronchial and mediastinal lymph nodes had the highest concentration of plutonium at death, accounting for as much as 40 to $50 \%$ of the body burden in some dogs.

\section{Clinical Signs}

The first indication of a pathologic change in the exposed arimals was a lymphopenia. Lymphocyte counts, approximately one-half of control values 33 weeks postexposure, decreased to one-third before. death (Figure 1). There was no associated decrease in eosinophils, and the monocytes and basophils were within normal range. Total leukocytes decreased proportionally to the decrease in lymphocytes, while neutrophils were not significantly different from the control values (Figure 2). The lymphocyte counts of six exposed animals and their approximate body burdens at death are shown in Figure 3. Dogs 158 and 64 (body burdens less than $0.1 \mathrm{MCi}$ ) did not show lymphopenia. Packed cell volume, hemoglobin, erythrocyte counts, and blood urea nitrogen were normal. During the week before death there were elevated leukocyte and erythrocyte counts associated with dehydration and hemoconcentration and the absolute neutrophil counts increased.

Three to 24 months before death respiratory rates progressively increased from the normal of 20 to $40 / \mathrm{min}$ to over $150 / \mathrm{min}$ the week before death. As tidal volume decreased, three to 12 months prior to death, arterial blood $\mathrm{CO}_{2}$ increased and $\mathrm{O}_{2}$ and hemoglobin saturation decreased. A.s respiratory insufficiently progressed, the dogs showed intermittent anorexia, occasional vomiting, dehydration, cyanosis, and 20 to $30 \%$ body weight loss.

Thoracic radiographs showed lung fibrosis, mild cardiac enlargement, and slight dorsal deviation of the trachea six to 12 months prior to 
TABLE 1. Mortality and Tissue Distribution of $\mathrm{Pu} 239^{\circ}$ in Dogs After Inhalation of $\mathrm{Pu}^{239} \mathrm{O}_{2}$

\begin{tabular}{|c|c|c|c|c|c|c|c|c|c|c|}
\hline \multirow[b]{2}{*}{ Dog no. } & \multirow[b]{2}{*}{$\begin{array}{c}\text { Time of death } \\
\text { (months after } \\
\text { exposure) }\end{array}$} & \multirow[b]{2}{*}{$\begin{array}{l}\text { Pu }(\mu \mathrm{Ci}) \\
\text { body burden } \\
\text { at death }\end{array}$} & \multicolumn{4}{|c|}{$\begin{array}{c}\text { Distribution of Pu at death } \\
\text { (\% cf body burden) }\end{array}$} & \multicolumn{4}{|c|}{$\begin{array}{c}\text { Concentration of } \mathrm{Pu} \text { at death } \\
(\mathrm{nCi} / \mathrm{g})^{\text {;r }}\end{array}$} \\
\hline & & & Lungs & $\begin{array}{l}\text { Bronchial } \\
\text { lymph } \\
\text { nodes }\end{array}$ & Liver & Skeleton & Lung ${ }^{* * x}$ & $\begin{array}{l}\text { Bronchial } \\
\text { lymph } \\
\text { nodes }\end{array}$ & Liver & Skeleton \\
\hline
\end{tabular}

DIED or sacrificed when death was imminent.

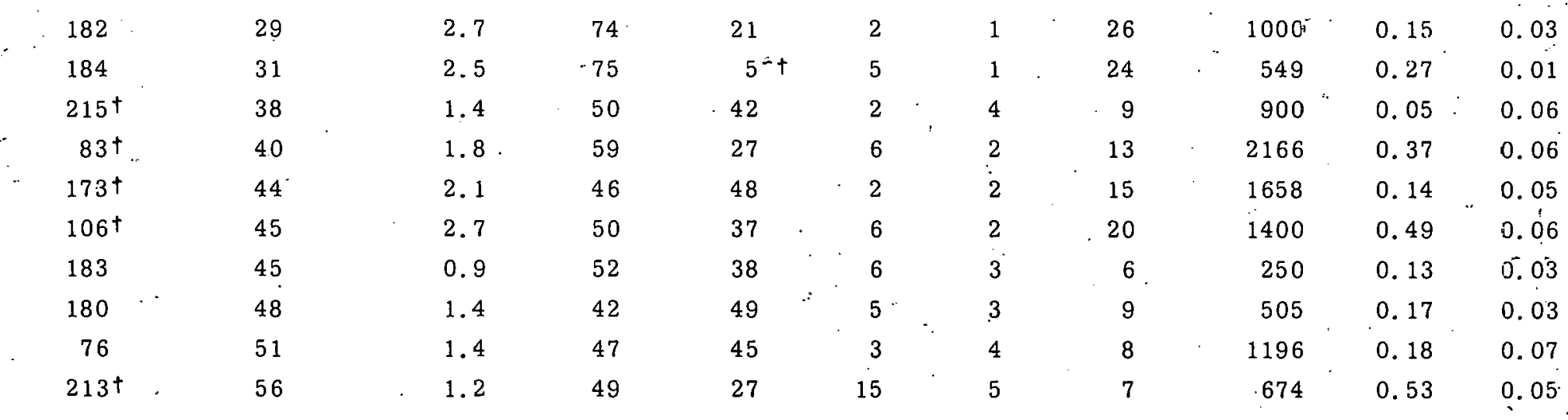

SACRIFICED for tissue distribution study.

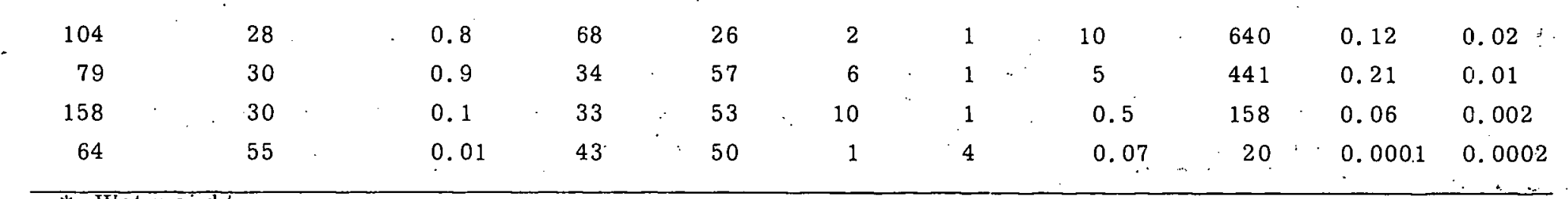

Wet weight

Estimated lung weights were used for calculating concentration since the lungs of the dogs that died were heavy due to pathological changes.

** Total nanocuries in $2-4$ nodes divided by wet weight.

$\dagger$ Pulmonary tumors.

t† A bronchial lymph node of this dog was accidently analyzed with the muscle. Separate analysis of muscle tissue indicated the nuscle content should be $1 \%$ of the body burden; therefore, the lymph node content is $17 \%$. 
BN.WL- 122

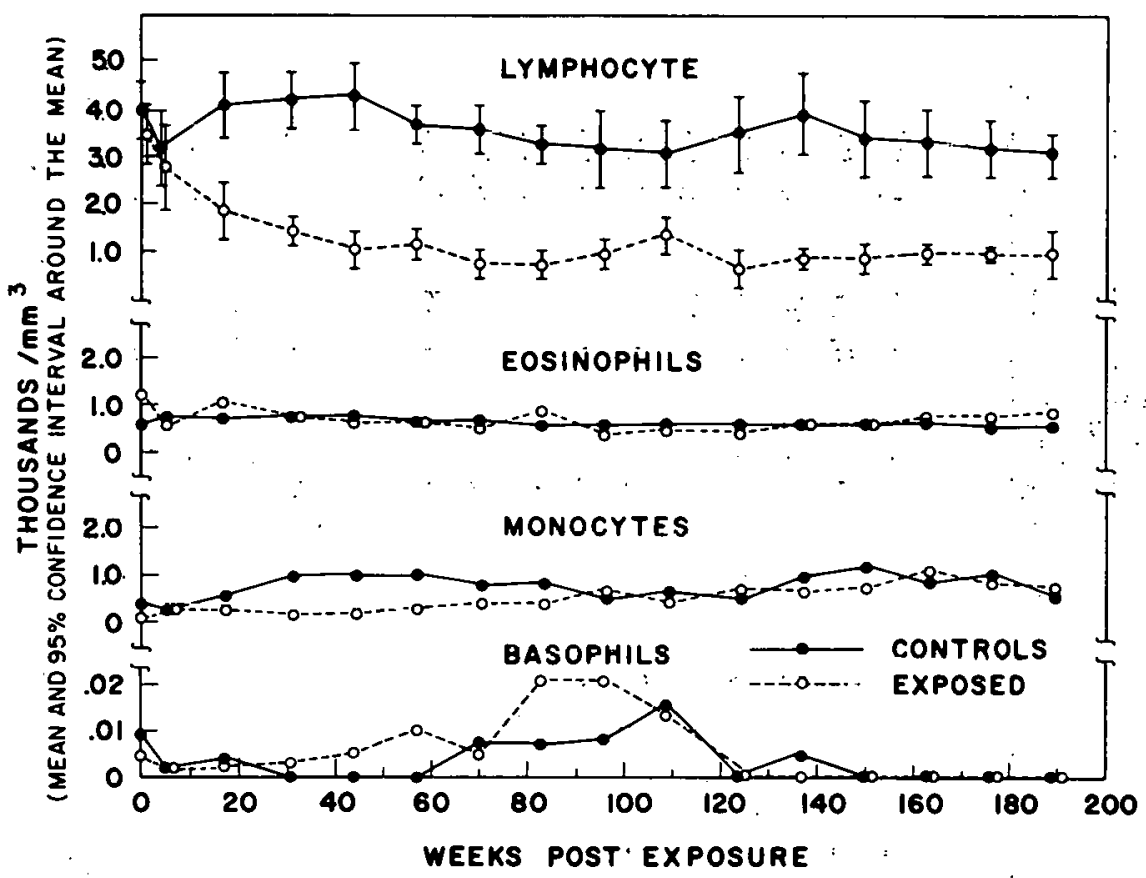

FIGURE 1. Lymphocyte, Eosiniphil, Monocyte, and Basophil Counts of the Chronic Inhalation Study

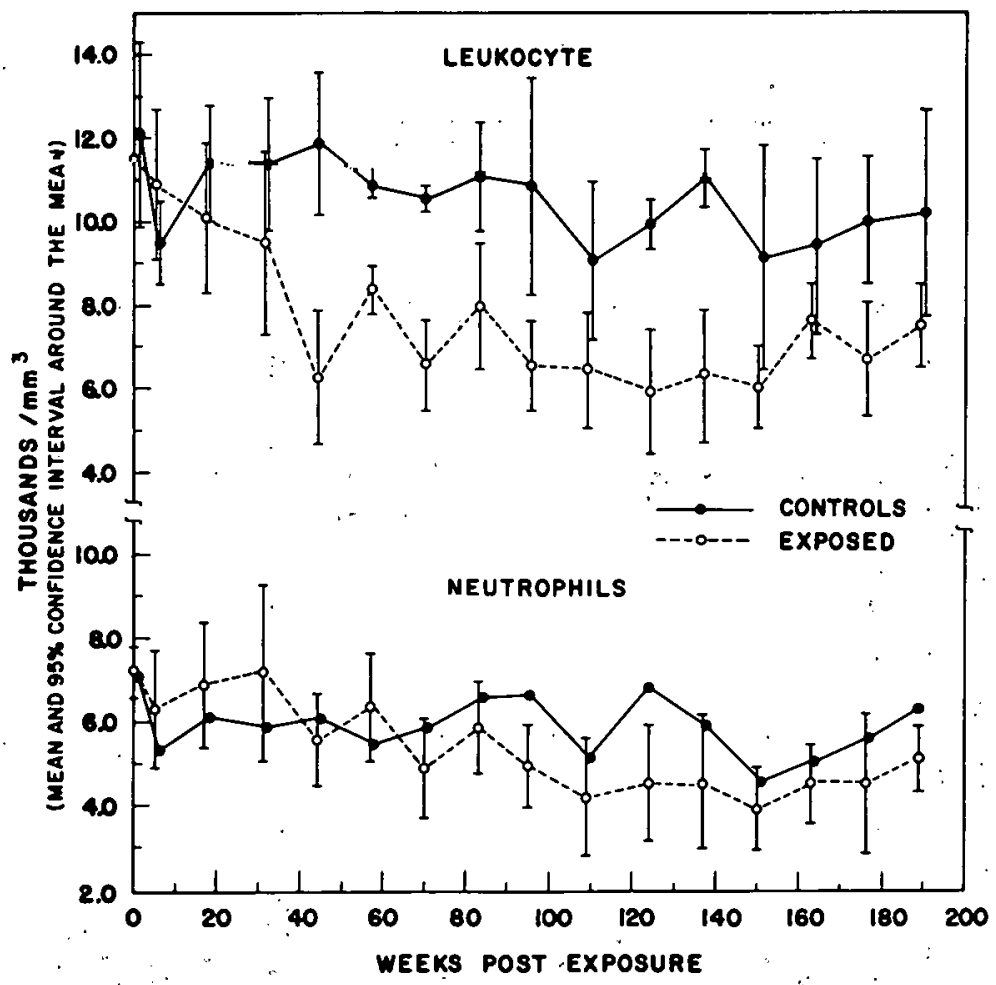

FIGURE 2. Total Leukocyte and Neutrophil Counts of the Chronic Inhalation Study 
BNWL-122

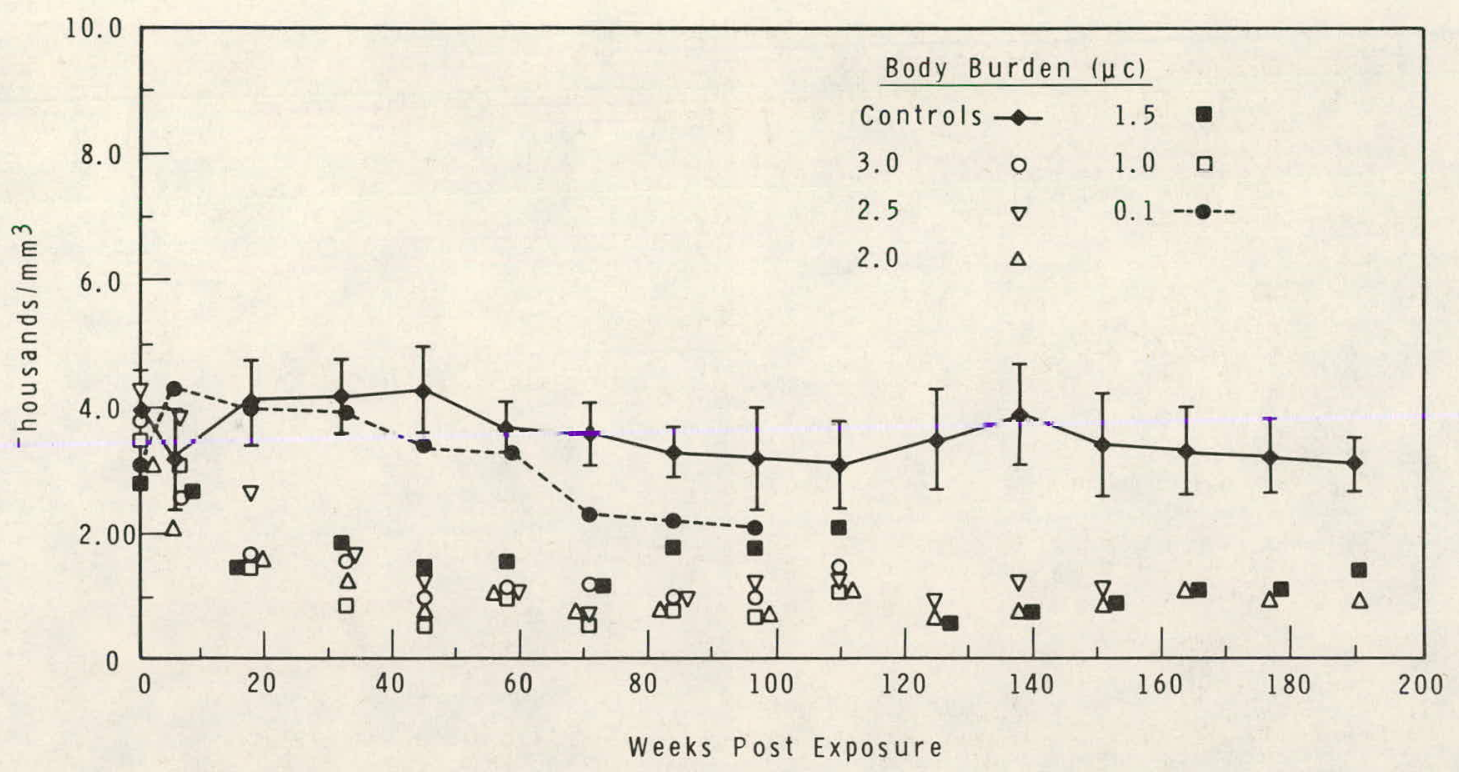

FIGURE 3. Lymphopenia in Dogs After $\mathrm{Pu}^{239} \mathrm{O}_{2}$ Inhalation

death. Lung densities become more diffuse, the heart continued to enlarge, and the trachea showed positive dorsal deviation during the month prior to death. Figures 4 and 5 show the thoracic radiograph changes in dog 213 and indicate the location and growth rate of the pulmonary tumor. Radiograph of the disarticulated skeletons showed no abnormalities.

Lymphopenia was the only clinical abnormality seen in the dogs sacrificed for plutonium distribution studies.

\section{Gross Pathology}

Gross pathologic changes were seen in the lung, bronchial and mediastinal lymph nodes, heart, and liver of the dogs that died.

The lungs were firm, uncollapsed, did not pit with pressure, and were not buoyant in formalin. Their surfaces were dark red and showed many small, creamy-white spots extending from 1 to $5 \mathrm{~mm}$ into the parenchyma. The cut surfaces were firm, dark red, and exuded serosanguineous fluid. The bronchi contained clear or blood-tinged fluid and froth. All the lungs were two to three times normal weight. The anterior dorsal part of the left diaphragmatic lobe of dog 83 and 213 and the right diaphragmatic lobe of dog 106 contained dense, white, well defined areas, 2 to $5 \mathrm{~cm}$ 
BNWL-122
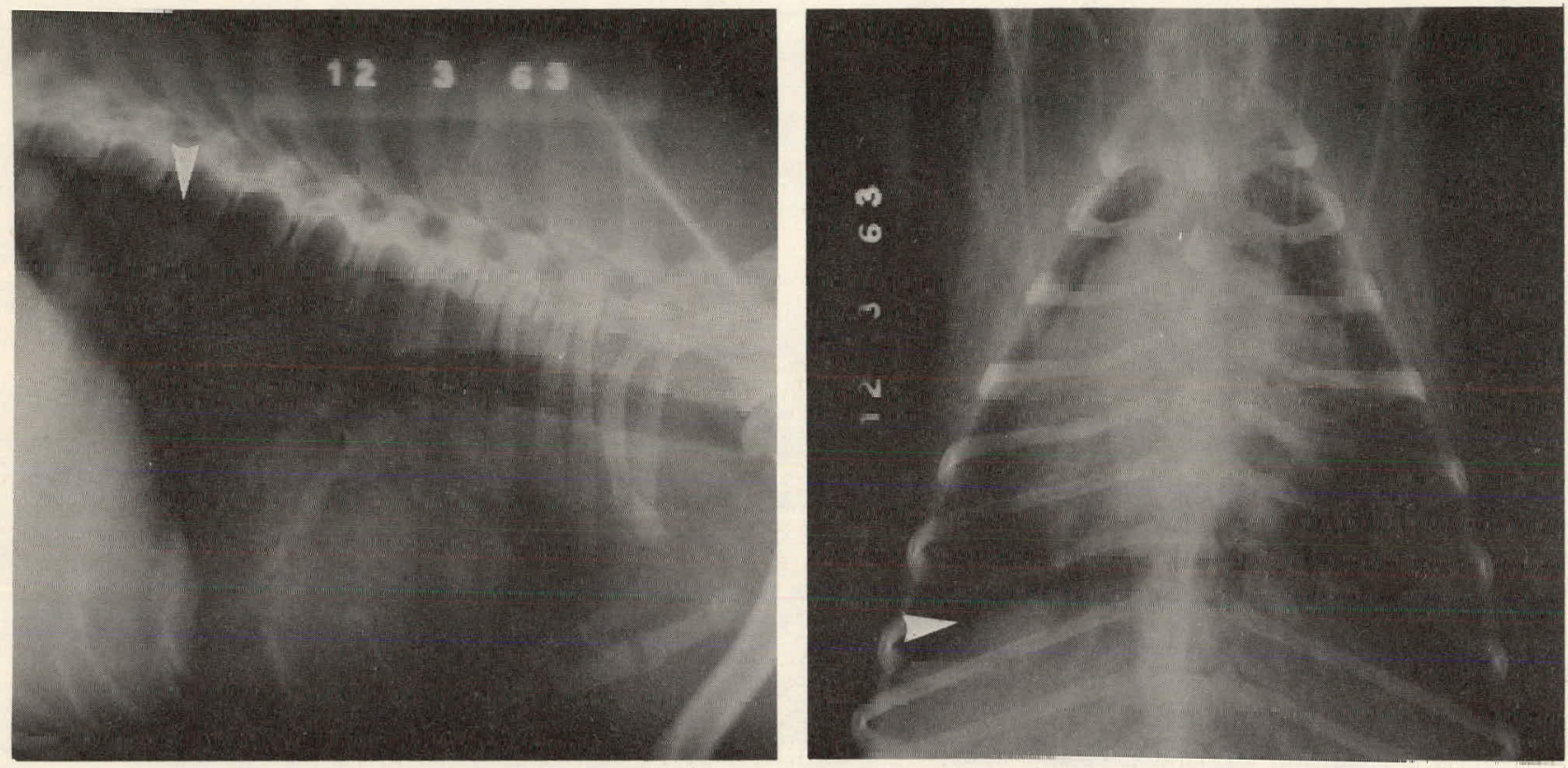

FIGURE 4. Thoracic Radiographs of Dog 213 (48 months postexposure) Showing Cardiac Enlargement, Increased Density in the Lung, and Early Indication of a Pulmonary Tumor in the Left

Diaphragmatic Lobe
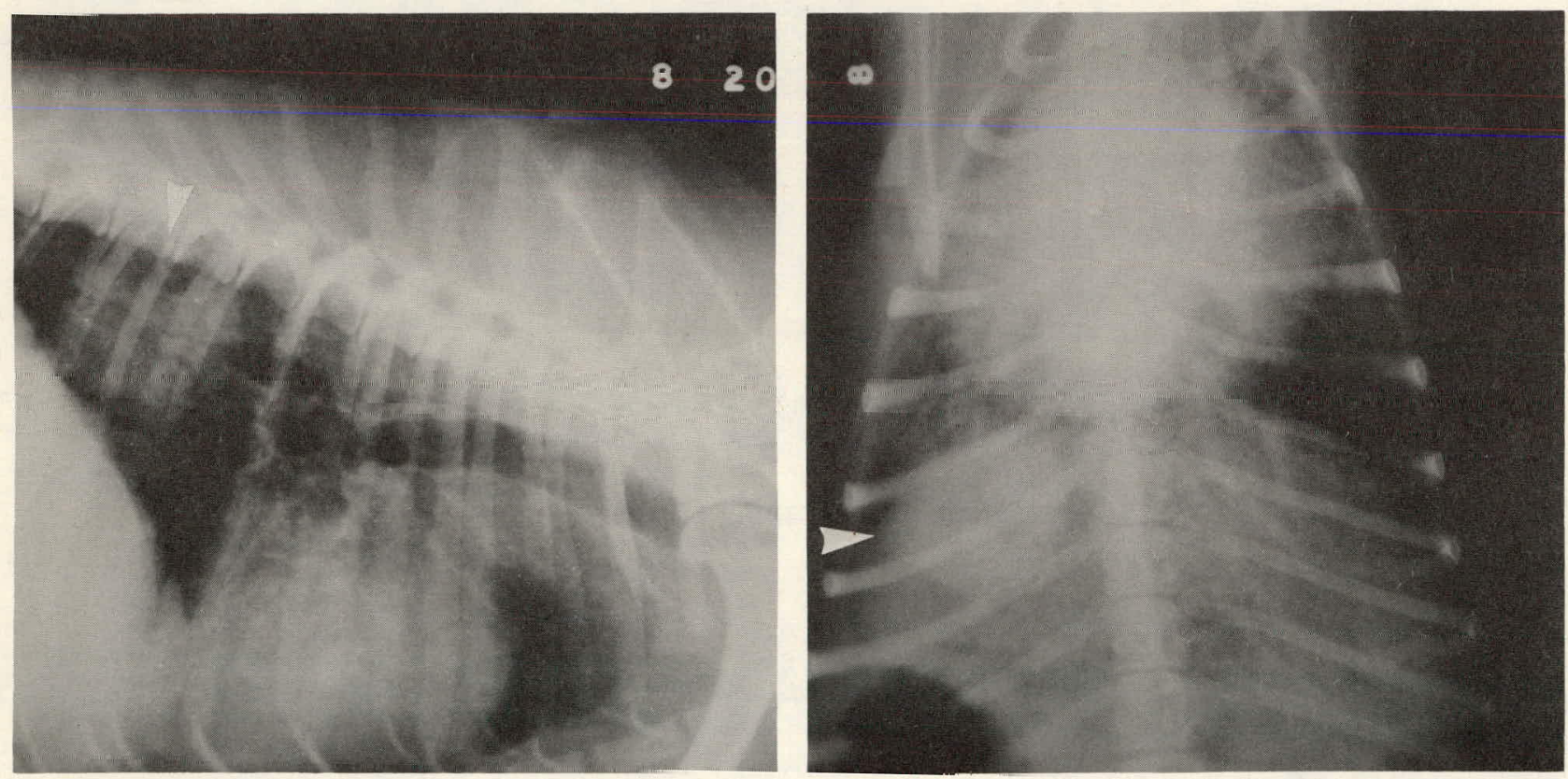

FIGURE 5. Thoracic Radiographs of Dog 213 (56 months postexposure) Showing Cardiac Enlargement, Dorsal Deviation of the Trachea, Diffuse Increased Density in the Lung, and a Pulmonary Tumor in the Left Diaphragmatic Lobe 
diameter, with necrotic centers (Figure 6). Both the right apical lobe of dog 173 and the left diaphragmatic lobe of dog 106 contained a peripherally located, poorly encapsulated, firm white nodule $1 \mathrm{~cm}$ in diameter that protruded slightly above the surface of the lung (Figure 7). Dog 213 had several small, white, firm, poorly defined nodules less than $0.5 \mathrm{~cm}$ in diameter scattered throughout the lung parenchyma.

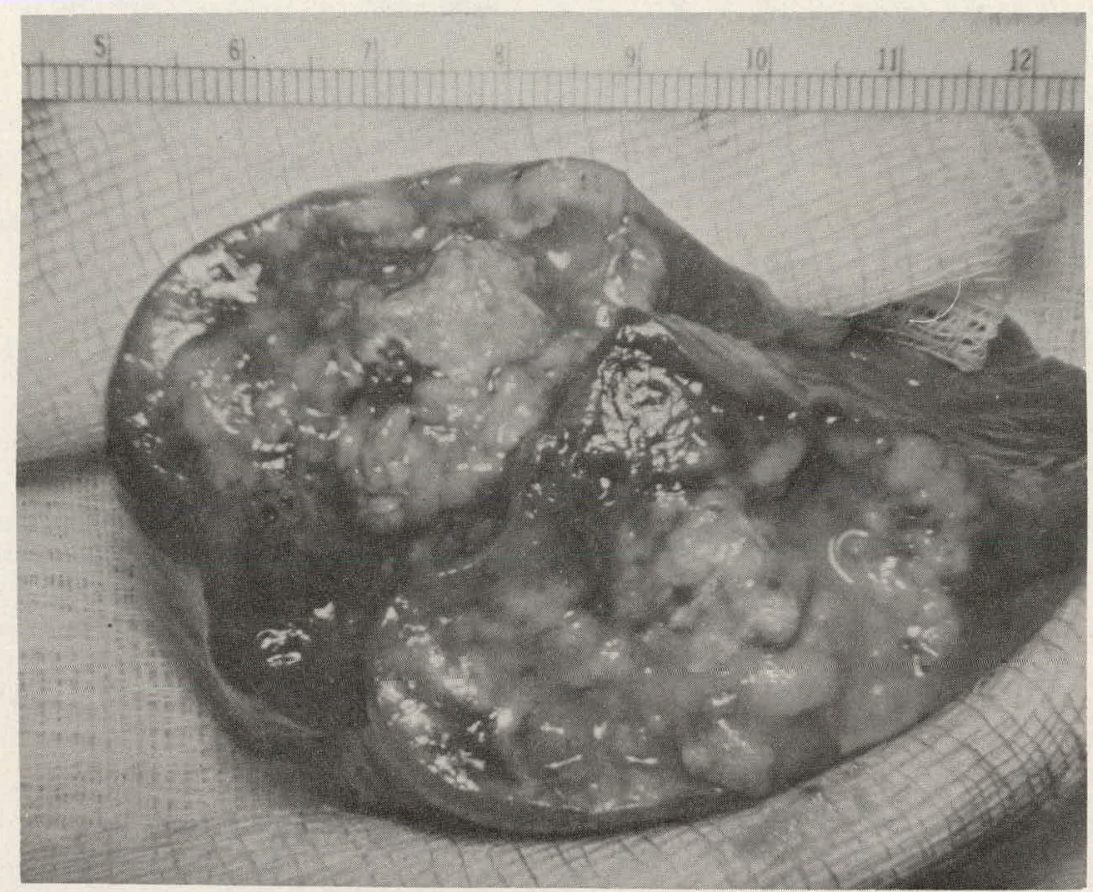

FIGURE 6. Primary Pulmonary Tumor in the Anterior, Dorsal, Lateral Area of the Left Diaphragmatic Lobe of Dog 213 Showing Necrotic Center

The bronchial lymph nodes were small, indurated, and had dark centers, while the mediastinal nodes appeared hypertrophied and congested.

The right ventricular wall of the heart in all dogs appeared flabby and the chambers dilated. Right ventricular wall thickening, however, was not apparent.

The livers of all the animals were markedly congested.

The dogs that were sacrificed showed similar changes in the bronchial and mediastinal lymph nodes, while their lungs, except for the few 
white spots on the surface, were relatively normal. No other gross abnormalities were seen in these animals. The control dog was normal.

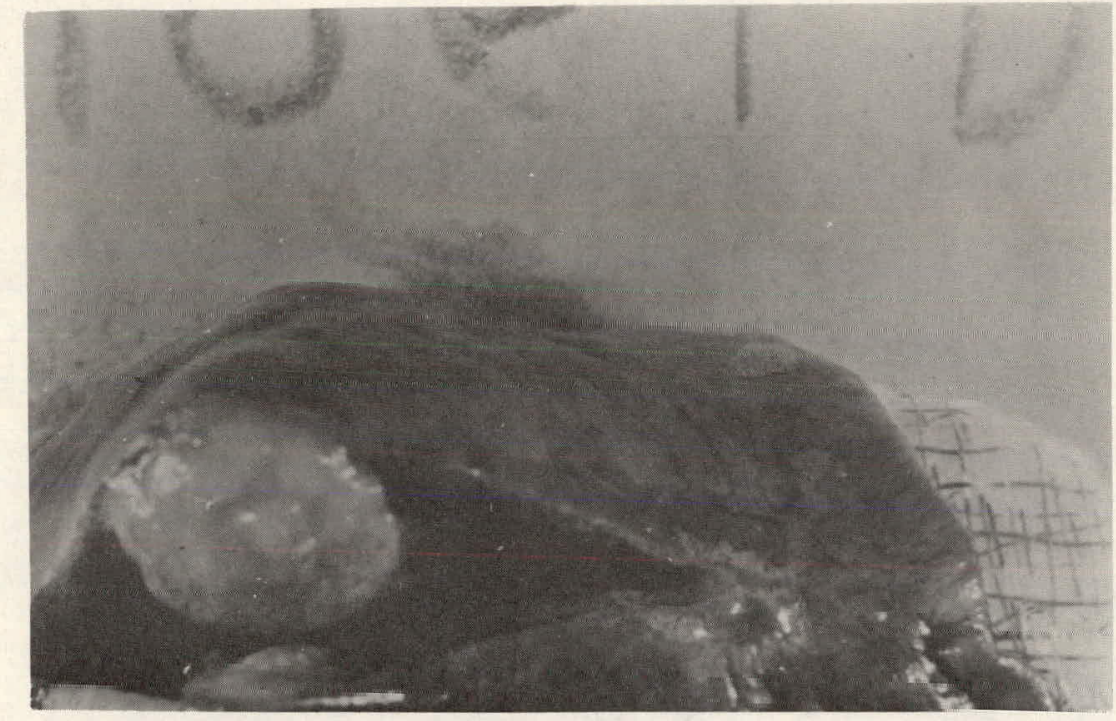

FIGURE 7. Primary Pulmonary Tumor in the Left Diaphragmatic Lobe of Dog 106 Showing a Well Defined Nodule

\section{Microscopic Pathology}

The lungs of the 10 animals dying during this three to five year postexposure period showed marked pleural, subpleural, parenchymal, and alveolar septal fibrosis and sclerosis (Figure 8). Scattered throughout, in association with some of these fibrosed and sclerotic areas, were numerous foci of alveolar and bronchiolar type metaplasia (Figures 9 and 10). In addition to the above changes, five of the dogs $(215,83,173,106$, and 213) had bronchiolo-alveolar tumors. The tumors were peripheral or subpleural in location, and all were multicentric in origin, except dog 173 where only one neoplasm in the right apical lobe was observed. The neoplasms were associated with scarring and numerous foci of alveolar and bronchiolar metaplasia, some of which showed transition to anaplastic and neoplastic cell forms. Infiltrating pleomorphic cells in these regions assumed epithelioid or squamous characteristics, formed frond-like papillary projections, or took the appearance of bronchiolar or acinar 
BNWL- 122

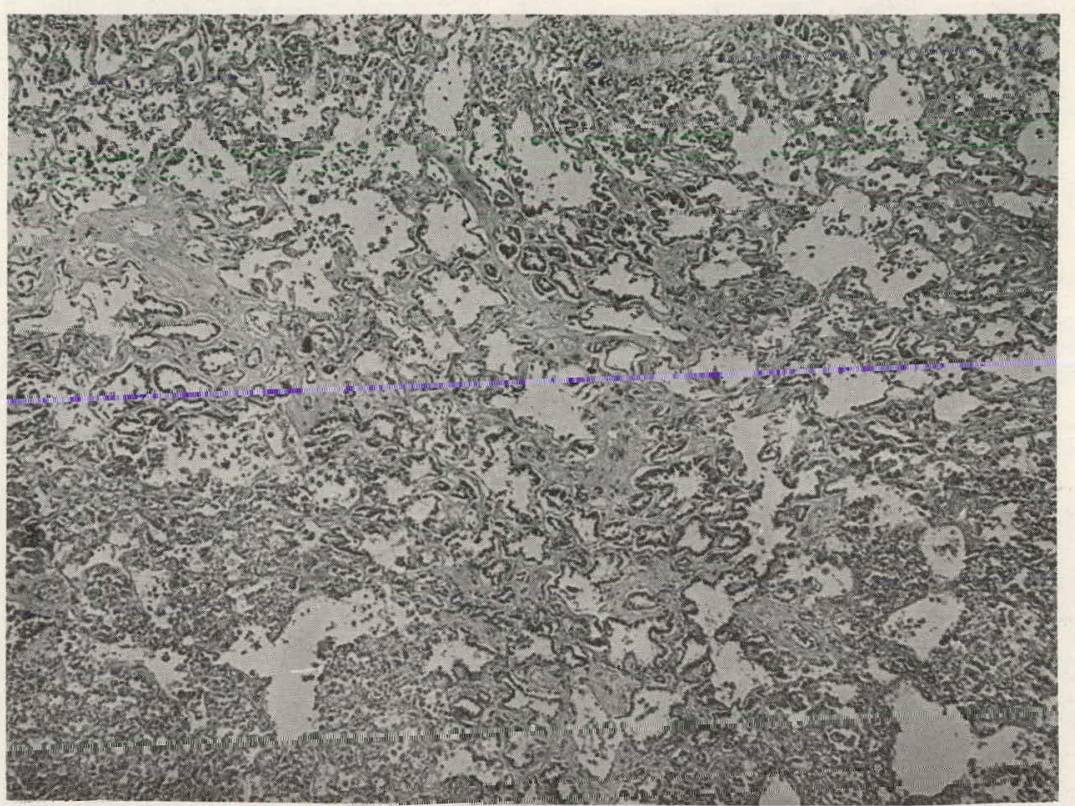

FIGURE 8. Marked Parenchymal Fibrosis of the Lung (H\&E 40X)

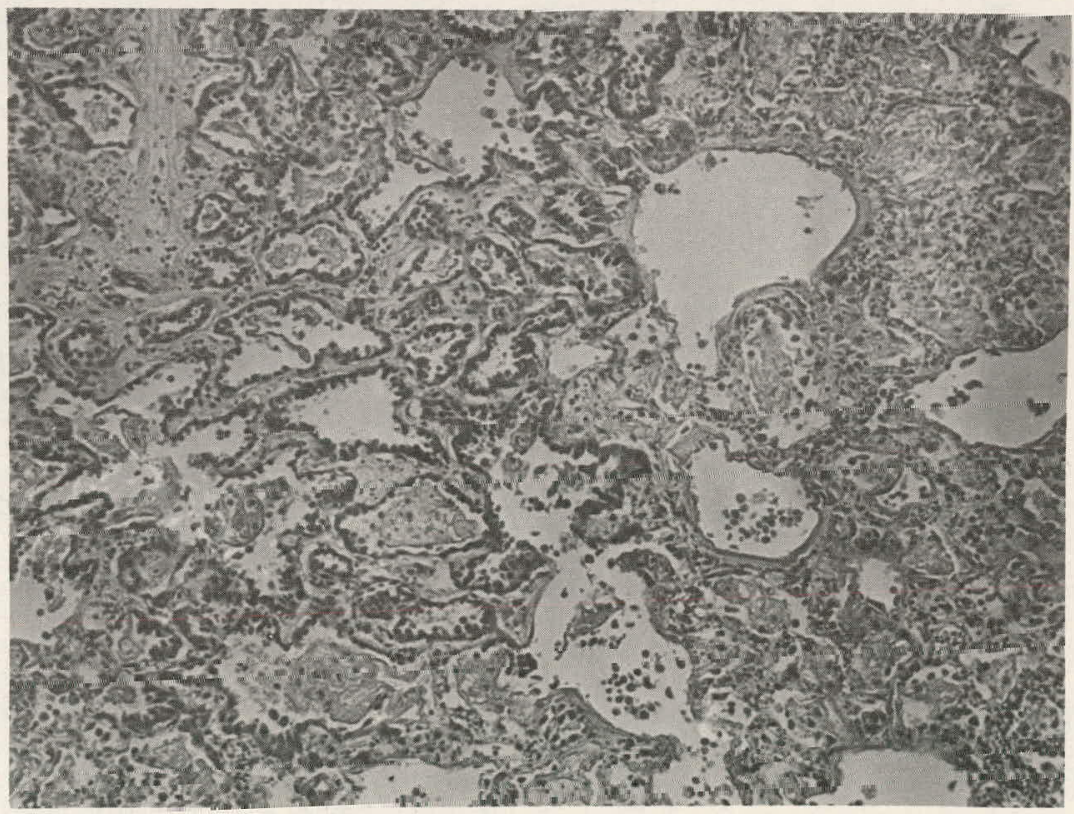

FIGURE 9. Alveolar Septal and Bronchiolar Fibrosis and Metaplasia

(H\&E 100X) 
10

BNWL- 122

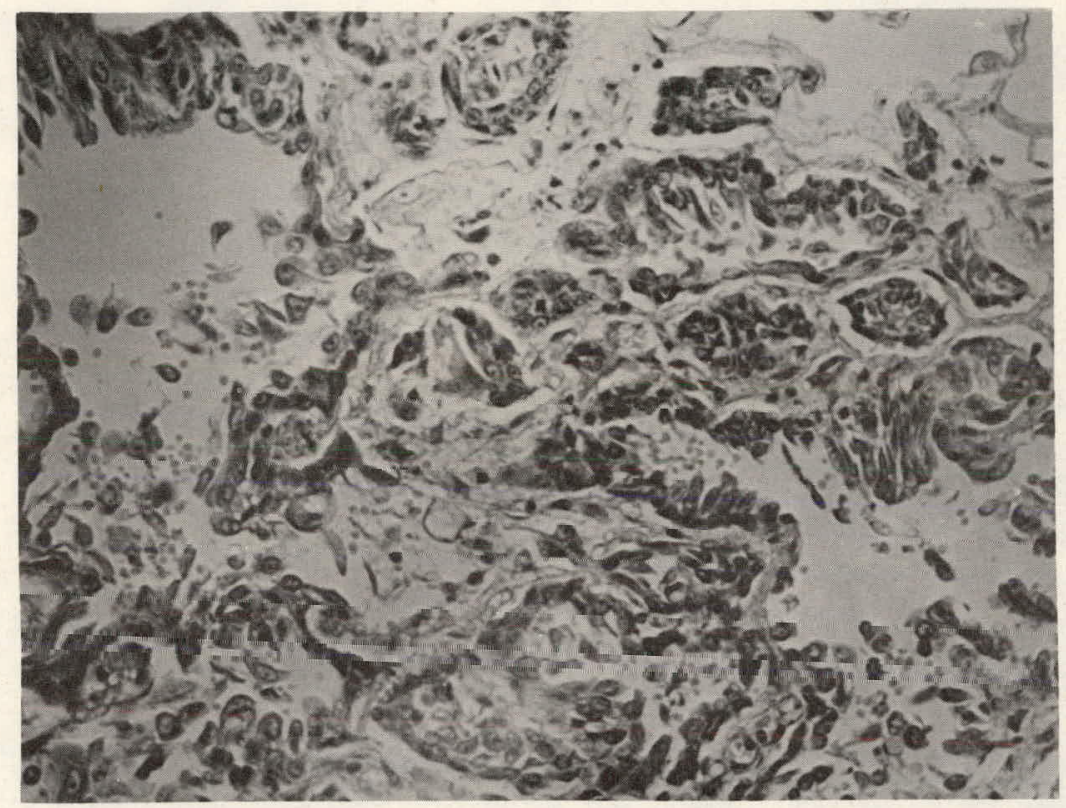

FIGURE 10. Alveolar and Bronchiolar Metaplasia (H\&E 256X)

structures (Figures 11 and 12). Mitotic figures, though not numerous, were present in all neoplasms. Although local invasiveness was apparent in all of these tumors, metastases were found only in one animal, dog 213. In this animal, metastatic foci from the primary lung tumors were seen in the middle and left bronchial lymph nodes. Extension to other tissues or organ systems, however, was not apparent.

The origin of these bronchiolo-alveolar tumors appeared to be from the bronchiolar and/or alveolar epithelium in all cases. In no instance could derivation be associated with bronchial epithelium or bronchial glands.

Serial autoradiographs of these lung sections showed moderate numbers of radioactive particles associated with the desmoplastic and metaplastic processes, especially in the subpleural and peripheral parenchymal regions (Figure 13). All neoplasms originated in areas of plutonium retention, fibrosis, and bronchiolo-alveolar metaplasia in the lung periphery. The irradiated proliferating cells, comprising the metaplastic response to lung scarring, appeared to be the nidus of tumor formation. 
BNWL-122

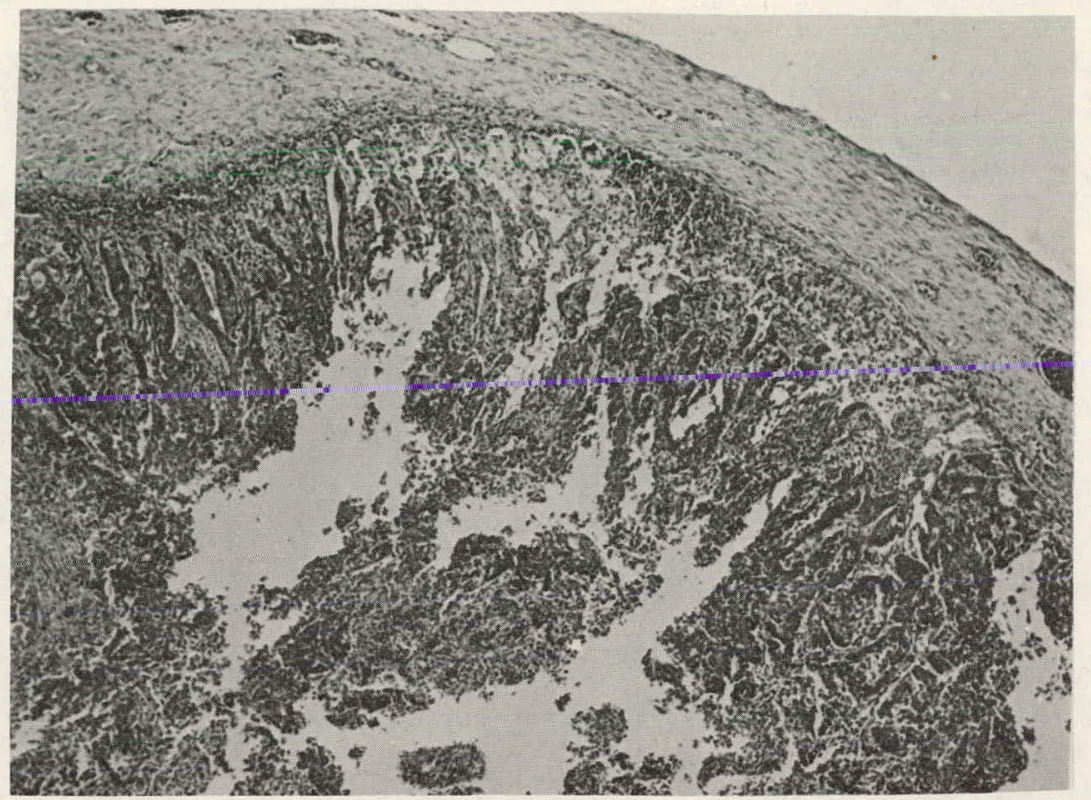

FIGURE 11. Bronchiolo-Alveolar Tumor with Papillary Structure in Periphery of Left Apical Lobe of Dog 83

(H\&E 40X)

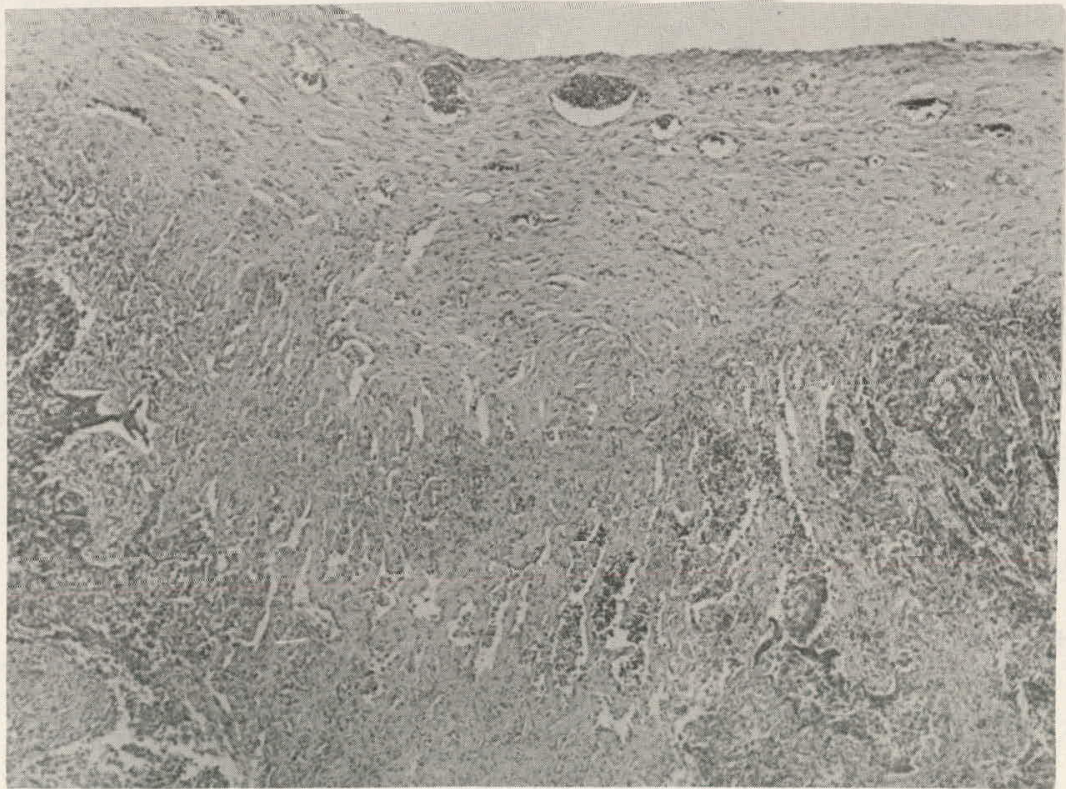

FIGURE 12. Bronchiolo-Alveolar Tumor in an Area of Severe Subpleural and Parenchymal Scarring (H\&E 40X) 


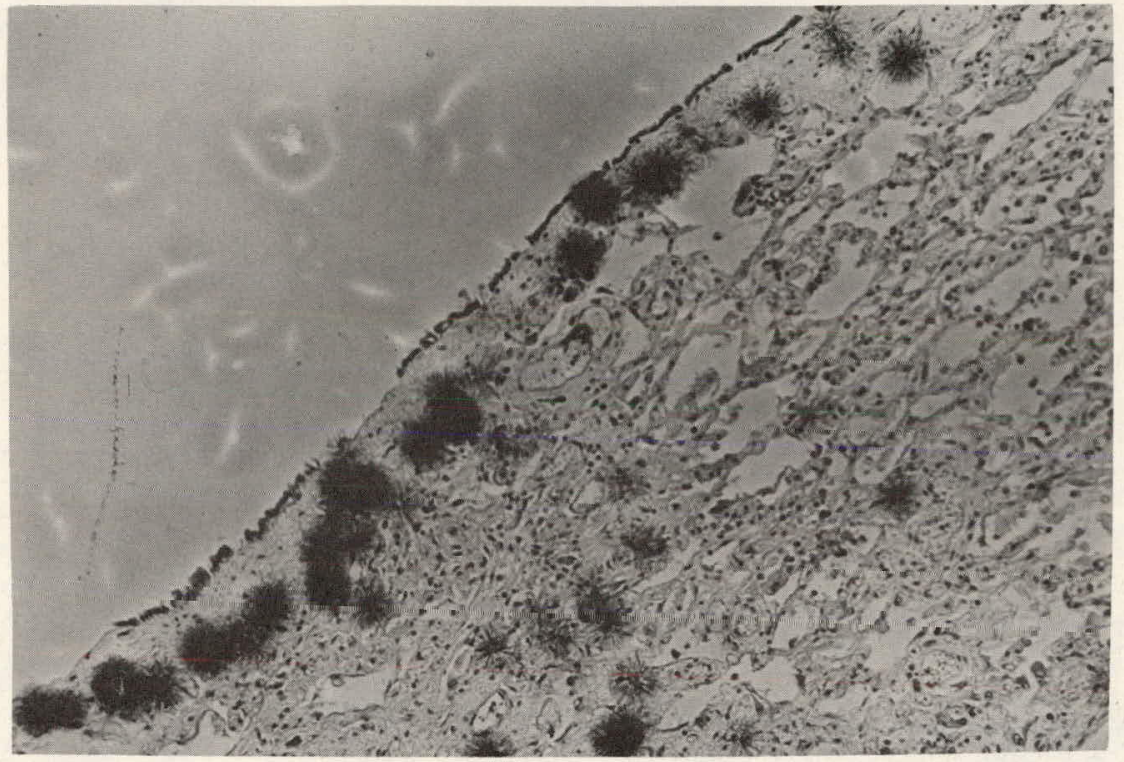

FIGURE 13. Autoradiograph Showing Preponderance of Plutonium Particles Associated with the Subpleural and Parenchymal Scarring

(H\&E 100X)

The lung lesions in the sacrificed dogs were similar to those in the dogs that died, but were considerably less diffuse and neoplasia was not detected. The lung sections from dog 64 (lung burden $0.005 \mu \mathrm{Ci}$ ) appeared normal and particles were not seen in autoradiographs.

The bronchial lymph nodes of these animals were composed of dense, sclerotic connective tissue and were devoid of any lymphoid elements (Figure 14). Serial autoradiographs of these sections showed a heavy, diffuse distribution of radioactivity throughout the scarred parenchyma (Figure 15). The mediastinal nodes, on the other hand, evidenced varying degrees of fibrosis and sclerosis, dependent on their radioactive particle content.

The lesions in the lymph nodes of the sacrificed dogs were similar but less severe and functional lymphatic tissue was evident in the bronchial lymph nodes. Dog 64 (lymph node burden $0.006 \mu \mathrm{Ci}$ ) showed only minimal lesions. 


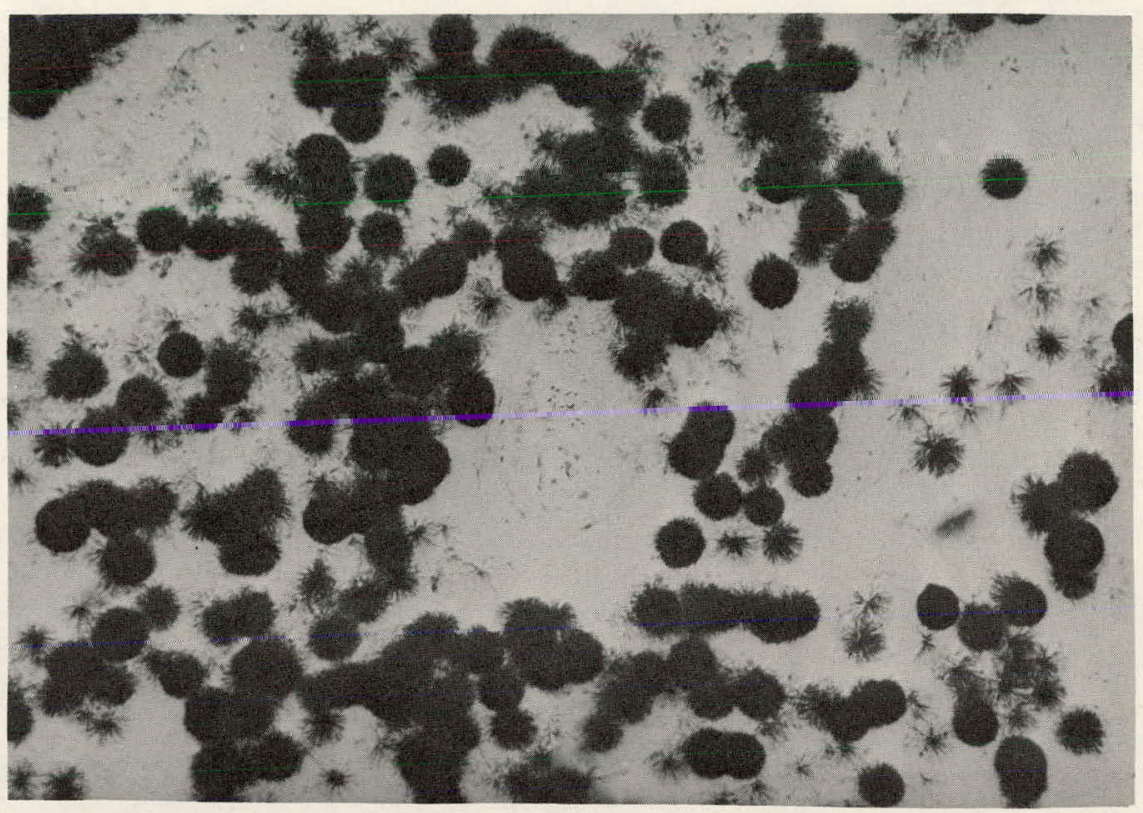

FIGURE 14. Complete Replacement with Dense Fibrous Connective Tissue in a Bronchial Lymph Node (H\&E 100X)

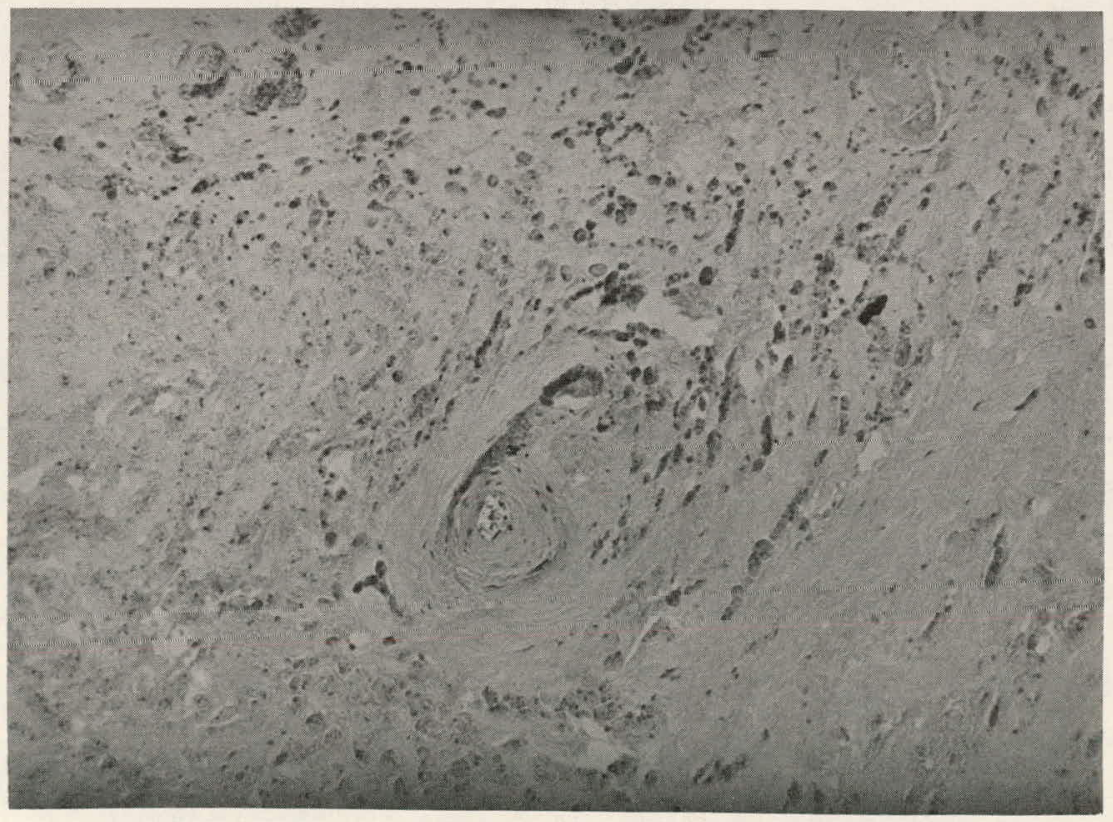

FIGURE 15. Autoradiograph of Figure 14 Showing Plutonium Deposition in a Damaged Area of a Bronchial Lymph Node (H\&E 88X) 
In the heart, there was a loss of cross striations in some of the cardiac fibers, along with the appearance of vacuolation and hyalinization of muscle cells in others.

Livers of these dogs all showed chronic passive congestion with extreme dilatation of the central veins and sinusoids. Concurrent with this congestion were varying degrees of parenchymal cell degeneration and necrosis, and increased amounts of connective tissue in the periportal regions.

The hearts and livers of the sacrificed dogs appeared normal.

\section{DISCUSSION}

The plutonium content of the lung correlated with the pulmonary pathology and clinical cardiopulmonary insufficiency indicated that the lung was the critical organ causing death in the animals studied thus far. The highest concentration of plutonium, however, was in the bronchial lymph nodes which contained $50 \%$ of the body burden in some dogs. There is no indication that the severe pathology in the bronchial lymph nodes was a concomitant cause of death; however, it is possible that obstruction of lymphatic drainage from the lung contributed to the pulmonary pathology.

Five of the 40 dogs had primary pulmonary tumors, an incidence of $13 \%$. Since the control animals on this study have not been sacrificed, complete pathologic comparisons are not available at the present time. Histopathologic examinations of over 100 dogs in this laboratory on various experiments over the past eight years, however, have revealed only one other animal with neoplasia of the lung. This dog had $19 \mu \mathrm{Ci}$ of plutonium in the lung at necropsy 150 days postexposure (Clark, et al., Am. Rev. Resp. Dis. 90: 963, 1964). The incidence of naturally occurring primary pulmonary neoplasms in the dog averages $0.2 \%$ in necropsy material surveys from other institutions (Nielsen, S. W and A. Horava, Am. J. Vet. Res. 21: 813,1960$)$.

In attempting to extrapolate these results to man it is pertinent to note that the highest concentration of plutonium reported for analyzed autopsy 
tissues of plutonium workers dying of natural causes was in the lymph nodes draining the lung, followed in decreasing order by the lungs, liver, and bone (Langham, W. H., et al; Health Physics 8: 753, 1962). Although the organ distribution is similar, plutonium deposition in these workers was probably via chronic low-level exposure, while the dogs received only a single exposure. The lungs of the tumor-bearing dogs at death contained 200 to 500 times, and the bronchial lymph nodes 40 to 50 thousand times the amount of $\mathrm{Pu}^{239}$ at equilibrium which would result in a mean dose of $0.3 \mathrm{rem} /$ week to the tissue, assuming uniform distribution. In the case of bone and liver the levels. were 10 to 40 times the maximum permissible organ burden for dogs, calculated from the values given for man by ICRP..

$\because$ : Results of the low level dogs are too limited to draw conclusions. However, in this study 55 months postexposure the minimum tissue burdens at time of sacrifice causing pathology (dog 158) were approximately 15 times the $0.3 \mathrm{rem} /$ week dose levels for lungs and 7000 times for lymph nodes. No significant lesions were seen in dog 64 with a lung burden equivalent to twice the $0.3 \mathrm{rem} /$ week level and a lymph node burden 600 times the $0.3 \mathrm{rem} /$ week level (assuming uniform distribution of plutonium in the lungs). 
WHOLE-BODY RETENTION AND BIOLOGICAL EFFECTS OF INHALED Ce $\mathrm{Ce}^{144}-\mathrm{Pr}^{144}$ AND Ru ${ }^{106}-\mathrm{Rh}^{106}$ OXIDES IN BEAGLES

\author{
B. O. Stuart
}

In beagle dogs one-half to one-third of inhaled peroxidepreparcd $\mathrm{Ce}{ }^{144}-\mathrm{Pr}^{141} \mathrm{U}_{2}$, calcined Ce ${ }^{144}-\mathrm{Pr}^{144} \mathrm{O}_{2}$, or calcined $\mathrm{Ru}{ }^{106}-\mathrm{Rh}^{106} \mathrm{O}_{2}$ was rapidly cleared within $7-20$ days. The remaining cerium and ruthenium were retained with biological half-lives of several years. Calcined Ce ${ }^{144}$ $\mathrm{Pr}^{144} \mathrm{O}_{2}$ translocated to the liver and skeleton more slowly than $\mathrm{Ce}^{144}-\mathrm{Pr}^{144} \mathrm{O}_{2}$ precipitated with peroxide; calcined - $\mathrm{Ru}{ }^{106}-\mathrm{Rh}^{106} \mathrm{O}_{2}$ has remained in the region of the lungs for more than one year postexposure. One dog died ejght months after depositing $2 \mathrm{mCi}$ of peroxide-prepared $\mathrm{Ce}{ }^{144}-\mathrm{Pr}^{144} \mathrm{O}_{2}$; the remaining animals show varying degrees of lymphocyte depression.

The isotope pairs $\mathrm{Ce}^{144}-\mathrm{Pr}^{144}$ and $\mathrm{Ru}{ }^{106}-\mathrm{Rh}^{106}$ are fission products of relatively high yield with comparable half-lives (290 and 365 days, respectively) and maximum beta energies ( 3.0 and $3.5 \mathrm{MeV}$, respectively). They might. therefore prçent simildr inhälation hazards, depending upon their pulmonary retention and translocation to other tissues. The data presented below are drawn from continuing studies on dogs which inhaled $\mathrm{Ce}^{144}-\mathrm{Pr}^{144} \mathrm{O}_{2}$ prepared by chemical precipitation or calcination and on dogs which inhaled $\mathrm{Ru}{ }^{106}-\mathrm{Rh}^{106} \mathrm{O}_{2}$ particles prepared by calcination of the hydroxide at $480^{\circ} \mathrm{C}$. Single exposures were performed in all cases.

Wholc-body counting rates for the 140 day postexposure period were previously reported for nine dogs exposed to either calcined or chemically prepared Ce ${ }^{144}-\mathrm{Pr}^{144} \mathrm{O}_{2}$ (Hanford Biology Report for 1963). Table 1 summarizes the whole-body retention data and gives the count median diameters for $\mathrm{Ce}^{144}-\mathrm{Pr}^{144} \mathrm{O}_{2}$ and $\mathrm{Ru}{ }^{106}-\mathrm{Rh}^{106} \mathrm{O}_{2}$ exposures. There appears to be no correlation between particle size and retention within the size range studied. The long biological half-lives of both isotope pairs are quantitatively similar, and indicate very low rates of clearance. Whole-body counting data for over 500 days postexposure for dogs exposed to calcined or peroxide-prepared $\mathrm{Ce}^{144}-\mathrm{Pr}^{144} \mathrm{O}_{2}$ showed essentially only radioactive decay beyond 80 to 160 days. 
TABLE 1. Biological Half-Liyes* and Count Median Diameters of Inhaled $\mathrm{Ce}^{144}-\mathrm{Pr}^{14} \mathrm{O}_{2}$ and $\mathrm{Ru}^{106}-\mathrm{Rh}^{106} \mathrm{O}_{2}$

\begin{tabular}{|c|c|c|c|c|c|c|c|}
\hline \multicolumn{4}{|c|}{$\mathrm{Ce} e^{144}-\mathrm{Pr}^{144} \mathrm{O}_{2}$} & \multicolumn{4}{|c|}{$\mathrm{Ru}^{106}-\mathrm{Rh}^{106} \mathrm{O}_{2}$} \\
\hline $\begin{array}{l}\text { Dog } \\
\text { no. }\end{array}$ & Preparation & $\begin{array}{c}\mathrm{T}_{1 / 2} \text { biological } \\
\text { (days) }\end{array}$ & CMD & $\begin{array}{l}\text { Dog } \\
\text { no. }\end{array}$ & Preparation & $\mathrm{T}_{1 / 2} \begin{array}{l}\text { biological } \\
\text { (days) }\end{array}$ & $\mathrm{CMD}$ \\
\hline 1 & $\begin{array}{l}\text { Chemical } \\
\text { precipitation }\end{array}$ & 570 & 0.52 & 21 & Calcination & 1300 & 0.07 \\
\hline 2 & $\begin{array}{l}\text { Chemical } \\
\text { precipitation }\end{array}$ & 960 & 0.67 & 22 & Calcination & 1150 & 0.08 \\
\hline 3 & $\begin{array}{l}\text { Chemical } \\
\text { precipitation }\end{array}$ & 540 & 1.40 & 23 & Calcination & 1200 & 0.10 \\
\hline 4 & $\begin{array}{l}\text { Chemical } \\
\text { precipitation }\end{array}$ & 1520 & 0.59 & 24 & Calcination & 900 & 0.11 \\
\hline 7 & $\begin{array}{l}\text { Chemical } \\
\text { precipitation }\end{array}$ & 740 & 0.18 & 25 & Calcination & 1410 & 0.09 \\
\hline 8 & $\begin{array}{l}\text { Chemical } \\
\text { precipitation }\end{array}$ & 1910 & 0.37 & 26 & Calcination & 1540 & 0.12 \\
\hline 10 & Calcination & 1520 & 0.21 & & & & \\
\hline 11 & Calcination & 1740 & 0.26 & & & & \\
\hline 12 & Calcination & 690 & 0.09 & & & & \\
\hline
\end{tabular}

* Calculated for 10-140 days postexposure.

Our earher report indicated that $\mathrm{C}^{144}-\mathrm{Pr}^{144} \Omega_{2}$ prepared with peroxide cleared the lungs of dogs with a half-life of about four months. In contrast, other work (Tombropoulos, E. G., this report) showed lung burdens of calcined $\mathrm{Ce}^{144}-\mathrm{Pr}^{144} \mathrm{O}_{2}$ at four months postexposure to be $75 \%$ of the total body burden. Figure 1 illustrates longitudirial whole-body scans of representative dogs 12 months after exposure to calcined $\mathrm{Ce}^{144}-\mathrm{Pr}^{144} \mathrm{O}_{2}$ and $\mathrm{Ru}^{106}-\mathrm{Rh}^{106} \mathrm{O}_{2}$. At one year postexposure a large amount of the calcined $\mathrm{Ce}^{144}-\mathrm{Pr}^{144^{2}}$ was translocated posteriorly towards the region of liver, with a broadening of the peak which may indicate more generalized distribution, i.e. in the skeleton (tissue analyses of one dog showed $14 \%$ in the bone). By comparison calcined $\mathrm{Ru}^{106}-\mathrm{Rh}^{106} \mathrm{O}_{2}$ seemed to be retained almost exclusively in the lung area, as indicated by the much narrower peak, confined principally to the thorax. Earlier work from this laboratory using mice also suggested high lung retention for $\mathrm{Ru}^{106} \cdot \mathrm{Rh}^{106} \mathrm{O}_{2}$ 
BNWL-122

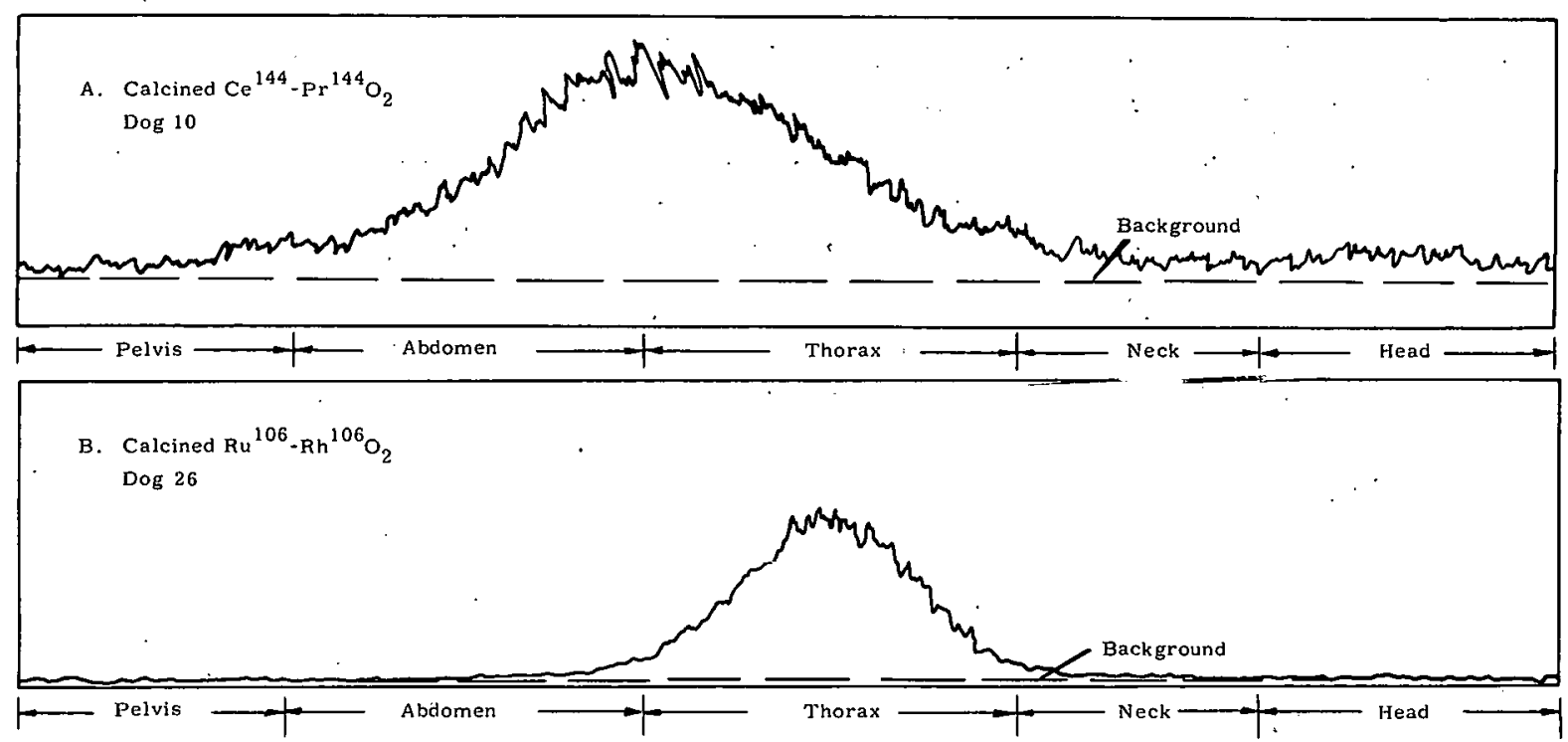

FIGURE 1. Whole-Body Longitudinal Scans of Beagles After Inhalation of Calcined $\mathrm{Ce}^{144}-\mathrm{Pr}^{144}$ Oxide or Calcined $\mathrm{Ru} 106-\mathrm{Rh}^{106}$ Oxide

With the exception of $\operatorname{dog} 3$ which died eight months after depositing $2 \mathrm{mCi} \mathrm{Ce} \mathrm{C}^{144}-\mathrm{Pr}^{144}$, none of the animals have shown significant changes in blnod-gas constitueils, general physical condition, body weight, or blood serum enzymes. However, the levels of circulating white blood cells generally dropped in inverse proportion to the quantity of isotope inhaled. Table 2 shows the percent pre-exposure levels of lymphocytes and neutrophils for experimental and control dogs at eight months postexposure. Dogs 1 through 3 showed greatly depressed lymphocyte levels after depositions of several hundred $\mu \mathrm{Ci}$ 's of peroxide-prepared $\mathrm{Ce}^{144}-\mathrm{Pr}^{144} \mathrm{O}_{2}$ in their lungs, but there was little or no effect in dogs which deposited $90 \mu \mathrm{Ci}$ or below. Dogs 1 and 2 had very low neutrophil levels, but a neardeath pneumonitis may have elevated the neutrophil counts in dog 3 . One hundred to $300 \mu \mathrm{Ci}$. of calcined $\mathrm{Ce}^{144}-\mathrm{Pr}^{144} \mathrm{O}_{2}$ (dogs 10 through 15) lowered lymphocyte levels markedly, but neutrophil levels. in exposed dogs were at least as high as in controls. The comparatively small amounts of initially deposited $\mathrm{Ru}^{106}-\mathrm{Rh}^{106} \mathrm{O}_{2}$ had little effect on leukocyte levels at eight months postexposure. 
TABLE 2. Leukocyte Levels; in Beagle Dogs Eight Months After Inhalation of $\mathrm{Ce}^{144}-\mathrm{Pr}^{144}$ or Ru ${ }^{106}-\mathrm{Rh}^{106}$ Oxides

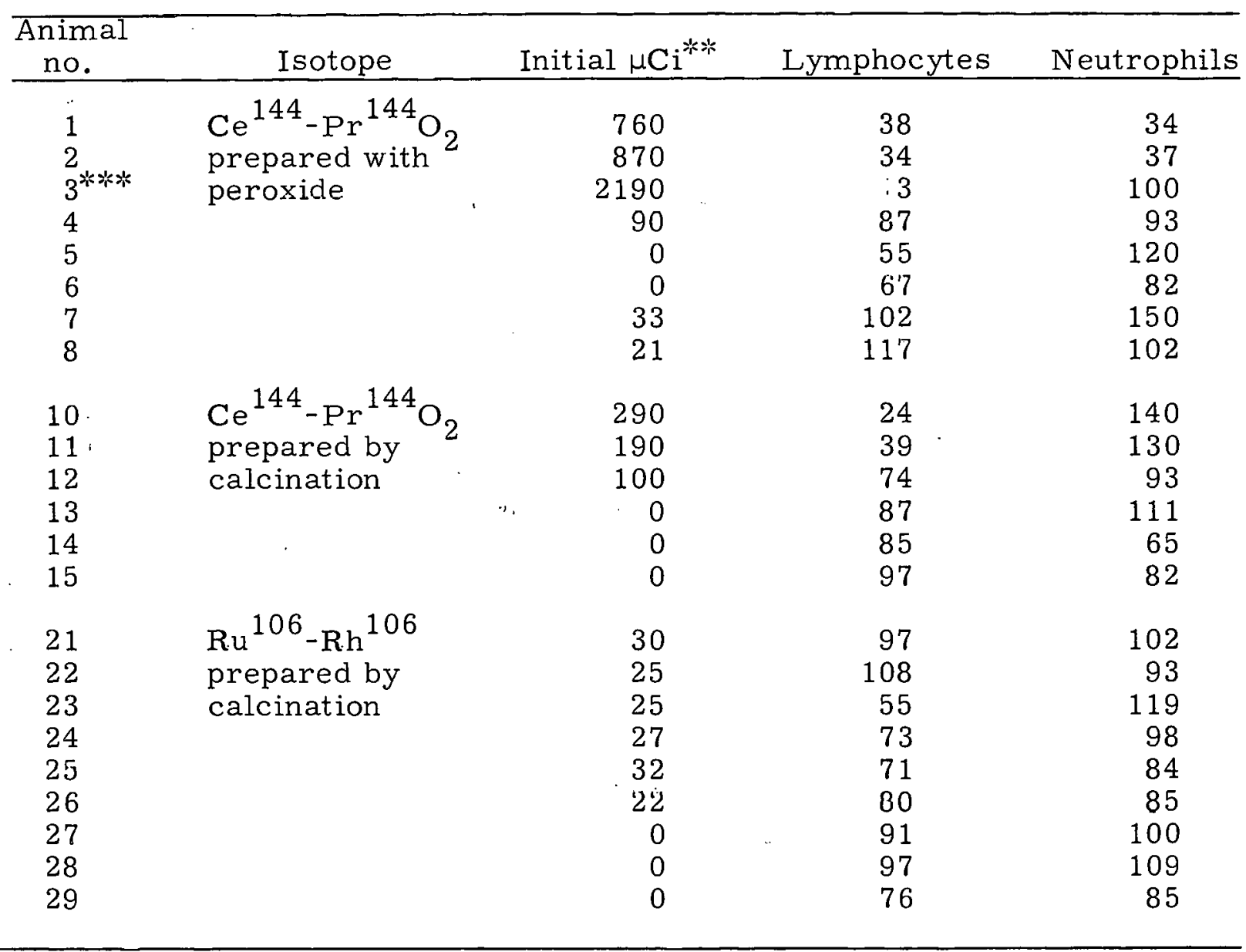

* Percent pre-exposure levels.

** Estimated initial deposition.

$* * *$ Death at eight months due to pulmonary insufficiency; pneumonitis involved.

Findings to date indicate that the oxides of the fission product isotope pairs $\mathrm{Ce}^{144}-\mathrm{Pr}^{144}$ and $\mathrm{Ru}^{106}-\mathrm{Rh}^{106}$ have very long retention times for that fraction, $40 \%$ or more, which is not excreted within the first 20 days. postexposure. Although whole-body retention of these three insoluble materials is similar, their rates of translocation from the lungs are quite different. $\mathrm{Ce}{ }^{144}-\mathrm{Pr}^{144} \mathrm{O}_{2}$ prepared by precipitation with peroxide is accumulated more rapidly in the liver and skeleton than is calcined $\mathrm{Ce}^{144}-\mathrm{Pr}^{144} \mathrm{O}_{2}$. After a year whole-body scans show that both forms of $\mathrm{Ce}^{144}-\mathrm{Pr}^{144} \mathrm{O}_{2}$ 
apparently translocated to tissues outside of the thorax, but calcined $\mathrm{Ru}^{106}$. $\mathrm{Rh}^{106} \mathrm{O}_{2}$ remained almost entirely in the lung area. . More detailed distribution studies are in progress. With the exception of one dog which died eight months after exposure to about $2 \mathrm{mCi} \mathrm{Ce}^{144}-\mathrm{Pr}^{144}$, the only observed effects of these isotopes to date has been a reduction in leukocyte levels, primarily due to lymphocyte depression. 
SELECTIVE TISSUE ACCUMULATION OF URANIUM AND THORIUM IN RATS AFTER INHALATION OF URANIUM ORE DUST

\author{
B. O. Stuart and T. M. Beasley
}

Groups of rats inhaled uranium ore aerosols semiweekly for two months $\mathrm{Th}^{230}$ activity levels in the lungs were twice those of $\mathrm{U}^{238}$ by the end of exposures, increasing to nine times after four months due to selective removal of uranium. Levels of $\mathrm{Th}^{230}$ in tracheo-bronchial lymph nodes were also higher than $\mathrm{U}^{238}$. Uranium levels in the kidneys and femurs were initially higher than thorium, but by two months postexposure thorium activities were equal to or greater than those of uranium. This rapid in vivo separation of uranium and thorium is important for permissible limit considerations.

The maximum permissible level of dust $\left(75 \mu \mathrm{g} / \mathrm{m}^{3}\right)$ in uranium ore mining and milling facilities is based on natural uranium content, assuming that retentions of the daughter radionuclides are governed by the 120 day biological half-life of uranium. However, if the daughter, $\mathrm{Th}^{230}$, were present in secular equilibrium and were retained independently of the uranium, its reported four year pulmonary half-life would restrict:levelis. to $27 \mu \mathrm{g} / \mathrm{m}^{3}$. Hill (Health Physics $\underline{8}, 17,1962$ ) has reported a higher level of thorium than uranium in a lung. sample from a uranium miner, suggesting a selective removal of uranium. Preliminary findings (Hanford Biology Report for 1963) from this laboratory using single inhalation exposures of rats to dust from high grade uranium ore indicated gradually increasing $\mathrm{Th}^{230} / \mathrm{U}^{238}$ ratios with time postexposure. The data presented here are from a study involving repeated exposures of rats to this ore.

Thirty-six rats were exposed to aerosols of ground pitchblende ore (25\% uranium) twice weekly for two months. The count median diameter of these particles was $0.2 \mu$, which is comparable to that of airborne dust in operating and Colorado mines. Groups of six experimental animals and two unexposed controls were sacrificed on the first, second, and eighth weeks of exposure, and on the first,..ninth, and seventeenth weeks after cessation of exposures. Highly sensitive analytical techniques were developed to measure the small amounts of uranium and thorium present 
in the lungs, lymph nodes, kidneys, and femurs: By chemical separation and subsequent $\alpha$-energy analyses, approximately $3 \%$ accuracy could be obtained on $2 \mathrm{\mu g}$ of parent uranium.

Figure 1 shows the uranium and thorium levels in the lungs and tracheo-bronchial lymph nodes at various times after the start of exposures. Although all animals were repeatedly exposed to fresh ore in secular equilibrium, thorium levels in the lungs became significantly higher than uranium by the second week of exposure. At the conclusion of the exposures the $\mathrm{Th}^{230} / \mathrm{U}^{238}$ ratios had increased to about two; a ratio of unity would indicate secular equilibrium. Thorium levels in the lungs decreased about one-half at nine weeks after conclusion of the exposures, and then remained constant until sacrifice of the remaining rats after

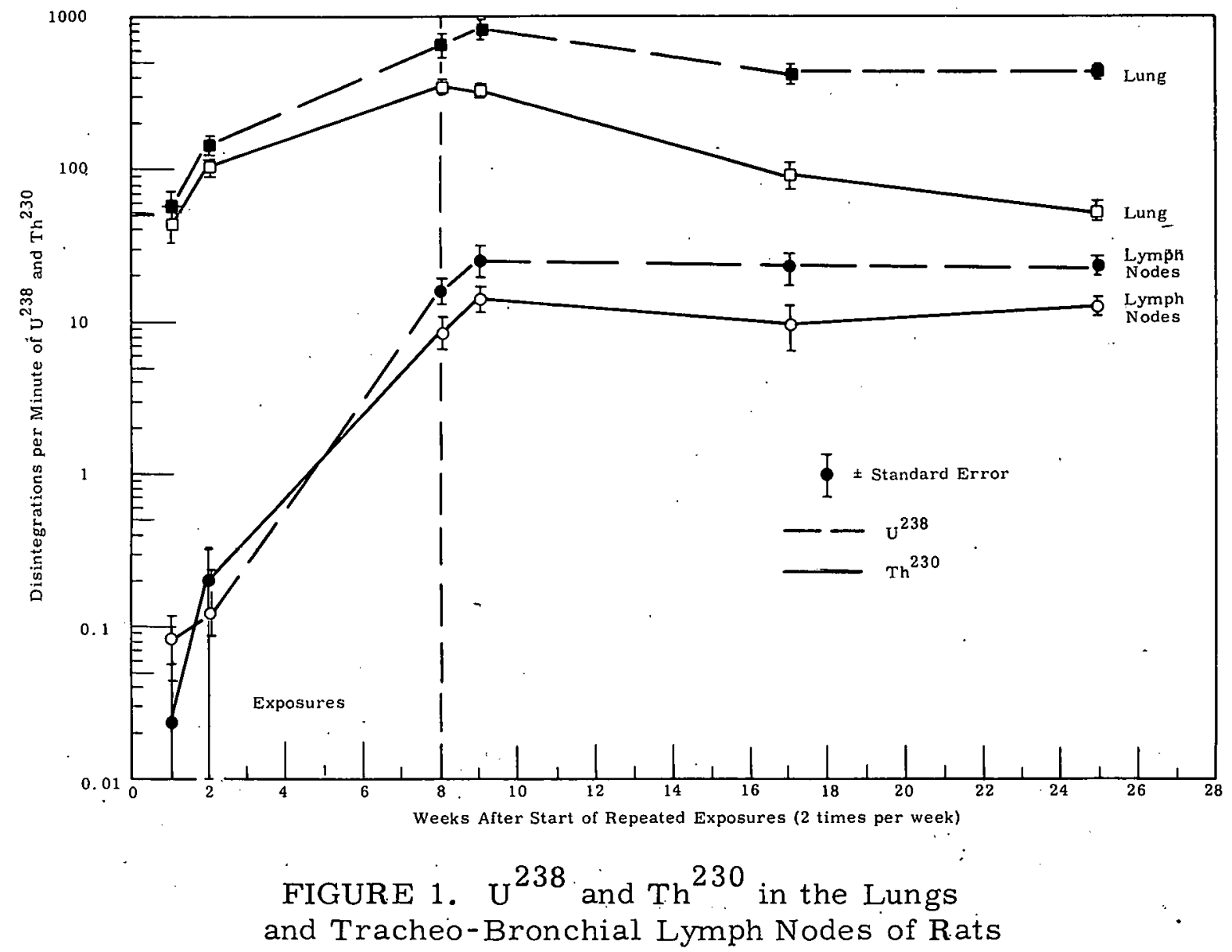


17 weeks, consistent with previously reported long pulmonary retention times for pure thorium dioxide. Uranium was cleared more rapidly from the lungs with an estimated half time of 85 to 140 days, which is in general agreement with values reported for pure uranium dioxide. At 17 weeks after exposure there was 9.2 times more thorium than uranium radioactivity in the lungs. Thorium and uranium in the tracheo-bronchial lymph nodes rose over two orders of magnitude from very low initial levels to about $2 \%$ of those in the lungs at the eighth week of exposure. As in the lungs, the thorium levels were significantly greater than those of uranium. The $\mathrm{Th}^{230} / \mathrm{U}^{238}$ ratios remained at two or three for the duration of the experiment.

If the uranium was being preferentially solubilized in the lungs and absorbed by the blood, rapid accumulations would be expected in the kidneys. Figure 2 shows uranium levels in this organ 10 times greater than those of thorium during the first two weeks of exposure. However, by the end of

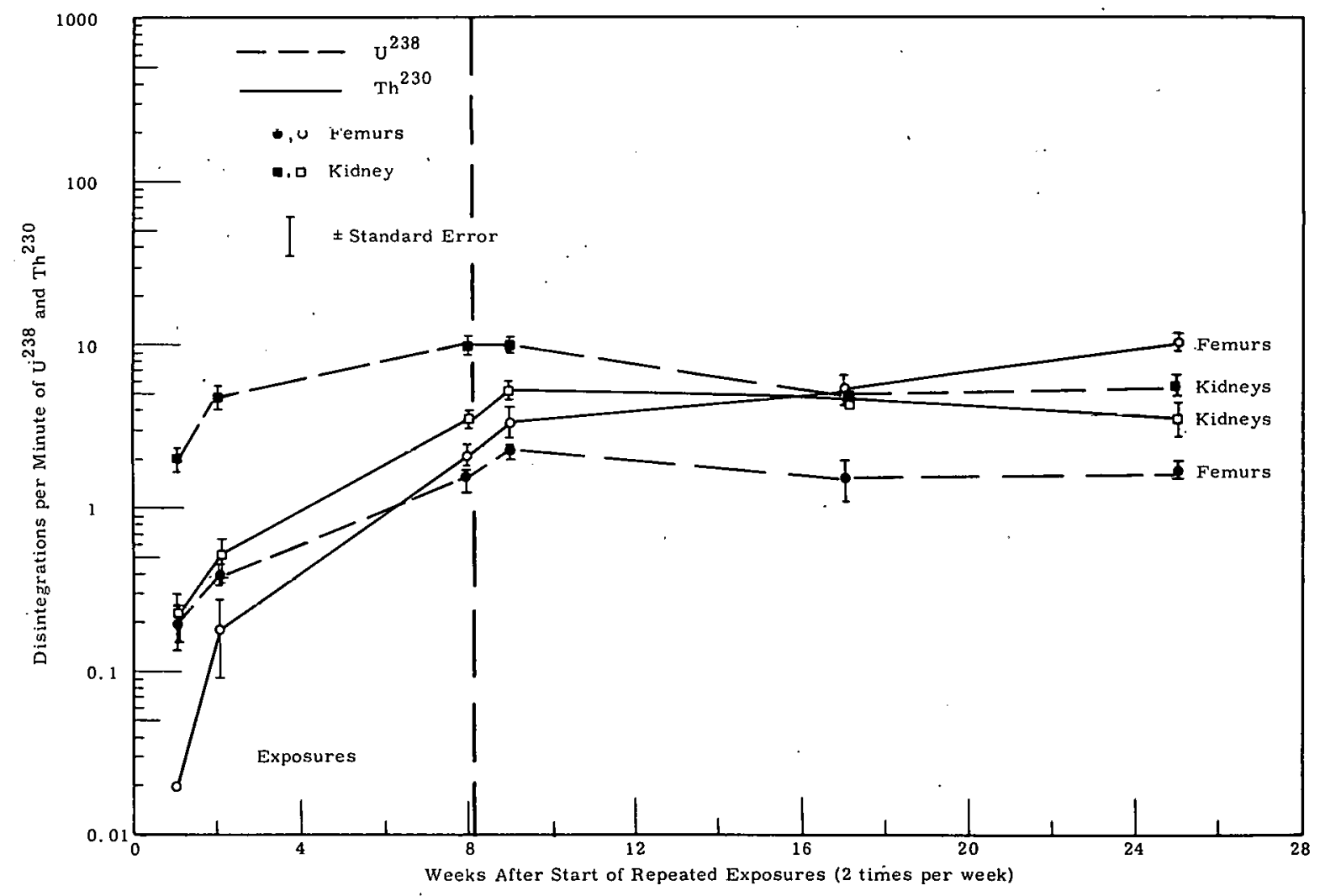

FIGURE 2. $\mathrm{U}^{238}$ and $\mathrm{Th}^{230}$ in the Kidneys and Femurs of Rats 
the eighth exposure week, thorium increased to one-third to one-half of the uranium levels, and remained nearly constant. The uranium content of the kidney dropped one-half two months postexposure and remained about equal to the thorium content.

Initial levels of uranium in the femurs were at least twice those of thorium, but shortly after the end of exposure this was reversed with the thorium rising to three times the uranium two months after exposure.

These findings indicate that uranium and thorium become dissociated in the lung shortly after inhalation, each showing retentions similar to those of their pure oxides. The tracheo-bronchial lymph nodes also showed higher thorium concentrations, while both kidneys and femur accumulated uranium preferentially during the first weeks of exposure, followed by equal or higher thorium buildups when exposures were discontinued. It is evident that thorium and uranium inhaled as constituents of pitchblende undergo vastly different biological fates and should be considered individually in respect to hazard evaluation. 


\section{EXPERIMENTAL BEAGLE COLONY - BREEDING AND ANIMAL CARE PROGRAM}

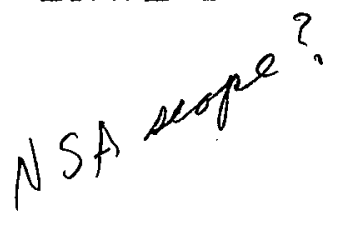

M. G. Brown and J. F. Park

The breeding colony produced 106 puppies with an average. litter size of 6.6 and $91.5 \%$ survival. Internal parasitism in the puppies, otitis externa and ocular changes in the aging dogs, and bite wounds accounted for $90 \%$ of the clinical cases in the colony. No contagious or respiratory diseases were encountered.

Our dogs are used primarily for inhalation studies. The demands of the research require dogs of uniform type and conformation, free of congenital and acquired diseases, and docile in temperament. The quality and quantity of dogs required necessitates the maintenance of a breeding colony and program providing animal care and clinical support for investigators using these dogs.

The breeding colony consists of purebred Beagles derived from stock procured from the University of California (Davis line), University of Washington (Pullman line), and locally (Hanford line). "Closed line" breeding is used most frequently. Breeding dogs are selected from matings within the lines which produce litters satisfying our criteria for experimental animals and for reproduction efficiency. When suitable males of a line are not available the females are occasionally cross-bred to selected males from another line.

The breeding colony consisted of 18 females and seven males in December, 1963. Three males were culled during the past year. Two dogs were not aggressive breeders and one dog was culled due to convulsions. Six females were culled primarily due to a history of dystocia and stillborn offspring. Nineteen females were bred and 16 animals whelped 106 puppies during the past year. Unsuccessful matings were due to infertility in the males that were eventually culled and to late detection of estrus. The litters ranged from five to 10 puppies, the mean was 6.6 (Table 1). Nine and one-half percent of the puppies died. Four 
of the stillborn deaths were from a cesarean birth, and one due to entanglement in fetal membranes. Four puppies died prior to weaning, three due to trauma, and one due to unexplained anorexia.

TABLE 1. Breeding Colony Production

(December 31, 1963-December 31, 1964)

\begin{tabular}{|c|c|c|c|c|c|c|c|c|c|c|}
\hline & \multicolumn{2}{|c|}{$\begin{array}{c}\text { No. of } \\
\text { fertile matings }\end{array}$} & \multirow{2}{*}{\multicolumn{2}{|c|}{$\begin{array}{c}\text { No. of } \\
\text { pups whelped }\end{array}$}} & \multicolumn{4}{|c|}{ Losses } & \multirow{2}{*}{\multicolumn{2}{|c|}{$\begin{array}{c}\text { No. of } \\
\text { pups weaned }\end{array}$}} \\
\hline & \multirow{2}{*}{$\begin{array}{l}\text { No. } \\
\text { bred }\end{array}$} & \multirow{2}{*}{$\begin{array}{l}\text { No. of } \\
\text { litters }\end{array}$} & & & \multicolumn{2}{|c|}{ Neonatal } & \multicolumn{2}{|c|}{ Preweaning } & & \\
\hline & & & Male & Female & Male & Female & Male & F'emale & $\overline{\text { Male }}$ & Female \\
\hline Total in category & 19 & 16 & \multicolumn{2}{|c|}{106} & \multicolumn{2}{|c|}{5} & \multicolumn{2}{|c|}{4} & \multicolumn{2}{|c|}{97} \\
\hline No. of each sox & - & - & 49 & 57 & 3 & 2 & 1 & 3 & 45 & 52 \\
\hline $\begin{array}{l}\text { Percent of } \\
\text { category }\end{array}$ & 100 & 100 & 46 & 54 & 50 & 40 & 25 & 75 & 46 & 54 \\
\hline Percent of total & \multicolumn{2}{|c|}{84} & \multicolumn{2}{|c|}{100} & \multicolumn{2}{|c|}{4.7} & \multicolumn{2}{|c|}{3.8} & \multicolumn{2}{|c|}{91.5} \\
\hline
\end{tabular}

The two litters of 10 puppies were associated with production problems, a cesarean section in one case, and the other bitch developed postpuerperal metritis with agalactia.

The mean weight, $\pm 95 \%$ confidence interval around the mean, for 127 colony raised dogs more than one year old was $12.33 \pm 0.57 \mathrm{~kg}$ for the males, and $10.20 \pm 0.36 \mathrm{~kg}$ for the females.

Five congenital or hereditary conditions have appeared in colony produced dogs during the past three years. Approximately $20 \%$ of the dogs lack one or more premolars. Seven dogs had prognathic or brachynathic jaw conditions. Two dogs have shown convulsions. Two litters had abnormally torturous ear canals that seem to be prone to recurring otitis. Four dogs had retained testicles.

There have been no contagious diseases. Monthly parasitological examination (fecal flotation) indicated internal parasitism was confined to Toxocara canis and occurred in only eight of the 16 litters produced in 1964 .

The animal care unit consists of three animal technicians, an animal care leader, and a veterinarian providing routine animal care and veterinary service for the breeding colony and experimental dog colony. Two hundred and forty-eight dogs were in the colony in 1964, ranging from one day to - eight years old, and consisting of procured and colony produced dogs. The routine animal care program consists of feeding, sanitizing, grooming, 
parisitological examination, physical examinations, immunizatıons, diagnosis, treatment, breeding program, daily observation of all dogs, recording observations, and reporting changes and procedures to the investigator. The unit provides investigators with dog weights, sample collections, anesthesia, physical examinations, necropsies, radiography, surgery, diagnosis, and treatment. Table 2 summarizes the activities of the animal care unit in 1964.

TABLE 2. Animal Care Activities

(December 31, 1963-December 31, 1964)

Body weights

Parasitological examinations

Hematology, samples

Immunizations

Special physical examinations

Anesthetics given

Routine physical examinations

Radiographs (films)

Eye examinations

Dog production (breeding colony)

Tattoos

Necropsies

Surgery
5,537

1,060

626

400

286

252

248

238

110

97

65

21

15

Table 3 lists the 1964 clinical observations which apparently were not associated with experimentally produced effects. Isolation and treatment have controlled the spread of Toxocaracanis from the breeding colony. One dog showed Ancylostoma caninum in fecal flotation and at necropsy., Bite wounds usually required only inspection, clipping, and cleaning of the affected area; however, 45 cases required additional topical, surgical or systemic treatment. Thirty animals received treatment for otitis externa. These cases, were primarily confined to older animals and to two litters with apparent congenital tendency to ear infection which became obvious at two years of age. Eye changes in the older 
animals consisted of cataracts, retinal degeneration, and vitreous bodies. Future reports will describe the eye changes in detail. Dermatitis and conjunctivitis cases were primarily associated with chronic ear conditions. Dental conditions were confined to retained deciduous canine teeth and two cases of loose teeth with tartar accumulation in adult dogs. Tartar accumulation is minimal due to weekly feeding of oxtails.

TABLE 3. Clinical Observations in the Beagle Colony (December 31, 1963-December 31, 1964)

\begin{tabular}{lc}
\hline \multicolumn{1}{c}{ Condition } & $\begin{array}{c}\text { No. of } \\
\text { cases }\end{array}$ \\
\hline Internal parasitism & 65 \\
Wounds & 45 \\
Otitis & 30 \\
Eye changes & 28 \\
Dermatitis & 7 \\
Eye inflamation & 7 \\
Dental & 7 \\
Nervnus system (convulsions) & 5 \\
Inguinal hernia and umbilical hernia & 1 \\
Pseudocyesis & 2 \\
Metritis & 2 \\
Allergy & 2 \\
Mammary tumor & 2 \\
Interdigital cyst & 2 \\
Lymphoid hyperplasia of third eyelid & 1 \\
Dystocia (cesarean) & 1 \\
\hline
\end{tabular}

Care of the colony is based primarily on preventive medicine. Therapeutic treatment when necessary is initiated and followed according to routine and acceptable veterinary procedures. There were no contagious diseases in the colony. Ninety percent of clinical observations concerned internal parasitism in the puppies, otitis externa in the aging dogs, and bite wounds. Since the animals are used for inhalation studies it is particularly significant that respiratory disease has not been a problem. 
BNWL-122

\section{IMPROVED RESPIRATORY VALVES FOR INHALATION STUDIES}

B. O. Stuart, M. D. Snyder, W. J. Bair, and N. S. Porter

Two new types of respiratory valves were developed for use in inhalation deposition studies with large experimental animals. The first uses a cylindrical slide driven by a lincar actuator; the second is a compact, rotary-action valve actuated by a rotary solenoid. Both units have operated with minimal air leakage and vibration during several animal experiments.

Evaluation of the hazards of inhaling a particular aerosol requires information as to the percent of the inhaled material deposited in the respiratory tract and particle size analyses of the inspired and expired aerosols. Such studies with experimental animals can only be made using a valve that effectively separates inspired and expired air; it must operate rapidly, be reasonably quiet and free from vibration, and must be compact in order to reduce deposition in the mechanism itself.

A sliding valve was constructed similar to that developed by the University of Rochester (UR 308, 1955), but it was found that the multiple $90^{\circ}$ surfaces of this mechanism introduced frictional problems and binding. Consequently, two other valves were developed to provide fast, air-tight switching between inspiration and expiration air passages.

The first of these is shown disassembled in Figure 1, mounted with a linear activator (bidirectional) to drive the valve proper. This valve was fabricated with a slide (either brass or nylon) in the shape of a cylinder, thus minimizing surface contact area and allowing much closer machining tolerances. The resulting valve operated with much less friction and was found to be virtually air-tight when used in subsequent animal experiments. An external guide was incorporated to eliminate any tendency of the slide to rotate.

Figure 2 shows a rotary-action respiratory valve designed to further reduce the surface-to-surface area and to provide a minimum of moving weight during operation. The valve interior rotates through $62^{\circ}$ upon actuation of the rotary solenoid mounted above it; at the end of 
expiration a scroll-type spring returns it to the inspiratory position. This valve is less than 6 in. high and can be positioned either horizontally or vertically with respect to the aerosol chamber and animal.

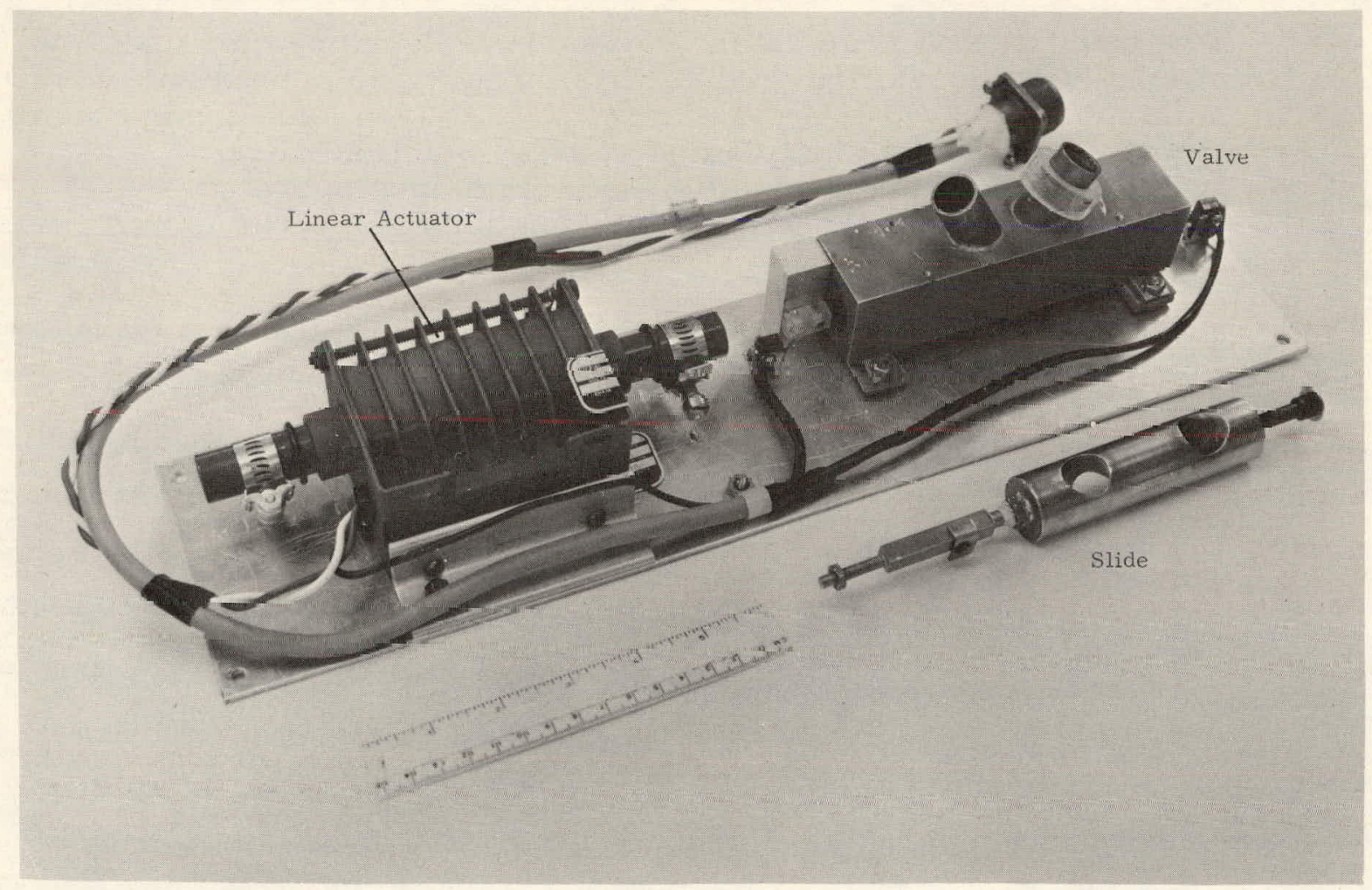

FIGURE 1. Linear Action Respiratory Valve

Figure 3 is a schematic design of an electronic switch and control unit that was developed to operate these valves in response to the animals' breathing. The sensor of transient inspiratory or expiratory pressures is a variable inductance transducer coupled directly to the animals' face mask. The coil consists of 520 turns of 6 mil copper wire on a plastic coil form. A ferrite slug attached to a rubber diaphragm moves in and out of the coil with breathing pressure changes. This transducer forms the frequency dependent component of the Hartley oscillator. The changing direct current from the diode pump is used to bias transistor Q2 to On or Off, which then causes the Schmitt trigger to activate the relay controlling the respiratory valve. Similar valves with larger diameter (3/4 in.) air passages are being developed. 

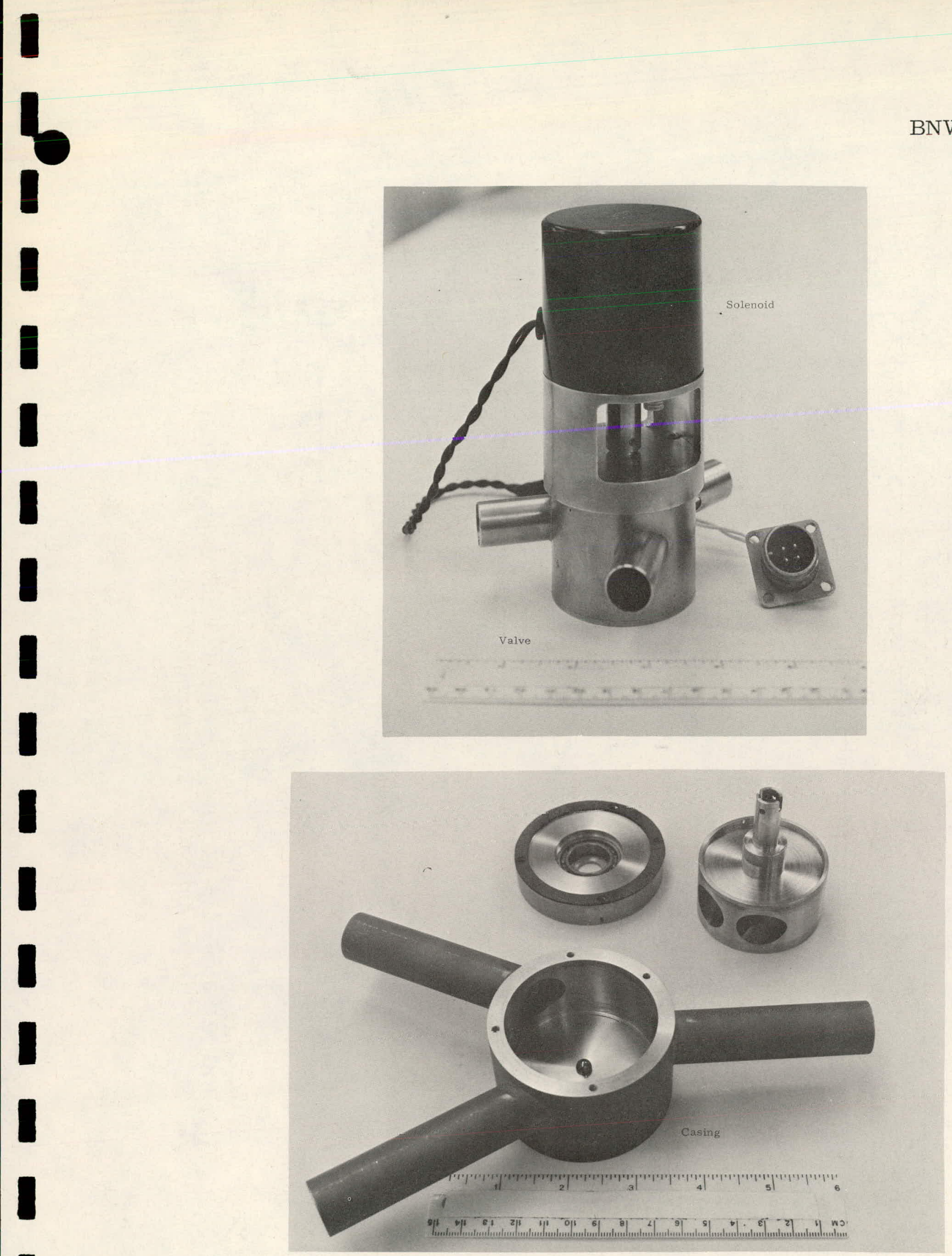

FIGURE 2. Rotary-Action Respiratory Valve 

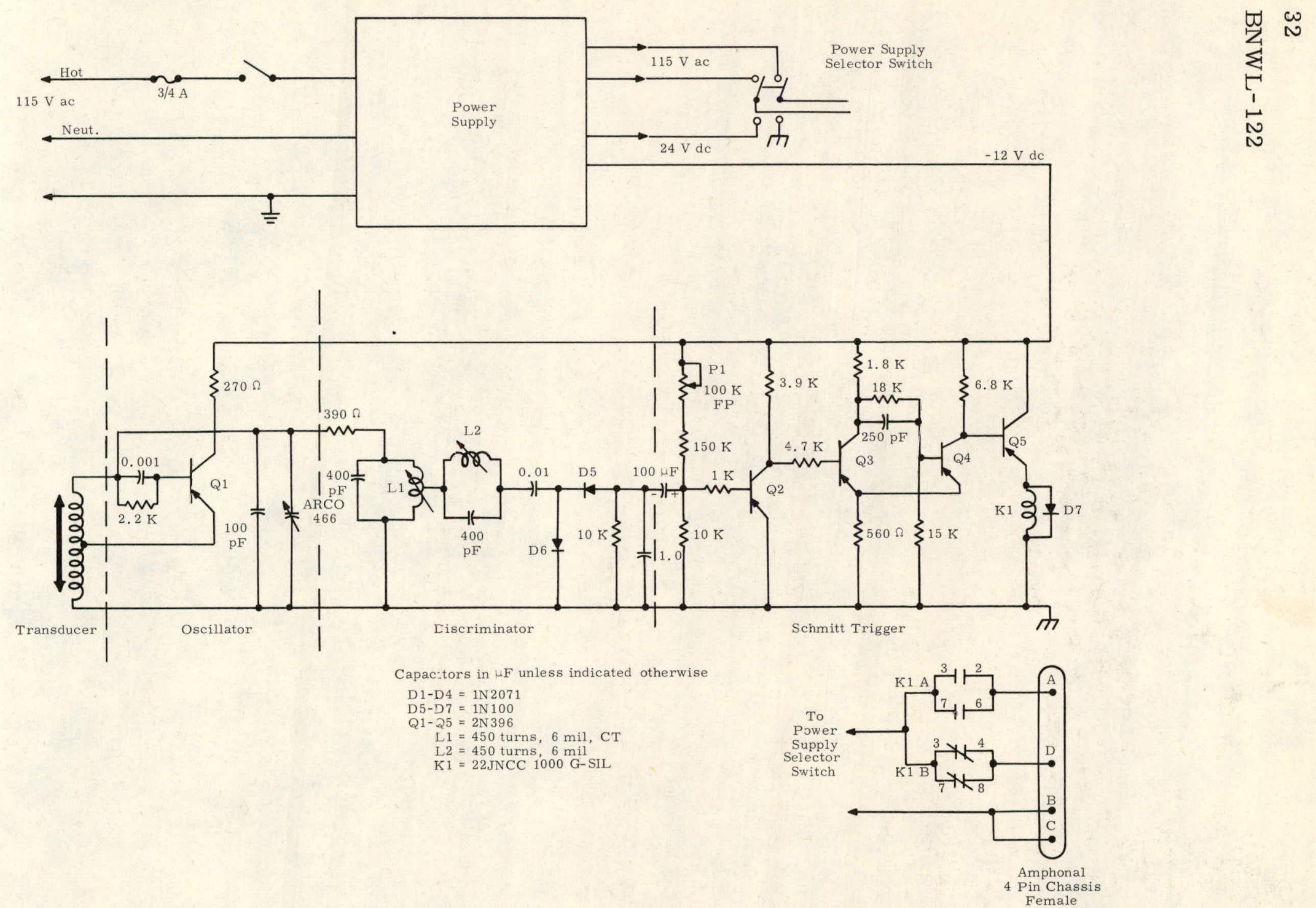

FIGURE 3. Schematic Diagram of Switch and Control Unit for Operation of Respiratory Valves 
BNWL-122

\title{
A VERSATILE IODINE VAPOR AND PARTICLE SAMPLER
}

\author{
M. D. Snyder and W. J. Bair
}

\begin{abstract}
A compact, versatile air sampler pack for collection of iodine vapor and particles is described. Particles are collected on membrane filters and vapors are collected on charcoal or copper turnings in one dram vials for direct radioiodine cuunting in well-type counters. Iodine collected on membrane filters and copper turnings can be also analyzed by chemical methods.
\end{abstract}

In a study of inhaled iodine in rats and dogs it was necessary to sample the air in the exposure chamber for both stable and radioactive iodine which were released from separate sources. Conventional methods employing activated charcoal granules or charcoal impregnated filters were not feasible because the stable iodine which adsorbed on charcoal could not be removed for chemical analyses. A sampler pack described by Megaw and May (J. Nuclear Energy, A/B 16: 427, 1962) containing a membrane filter, acid-etched copper gauzes, charcoal impregnated paper, and finally activated charroal, seented suitable for our purpose, since iodine collected on the membrane filter or copper gauze could be removed for both chemical and radiochemical analysis.

For use in our studies certain modifications of the Megaw and May sampler pack were necessary because of the small volume of the aerosol chamber to be sampled, the desire to collect the radioiodine in a container which could be rapidly counted in well-type crystal counters, and the need to rapidly interchange various parts of the sampler pack. This report describes a compact, versatile sampler composed of four or more individual sections containing the different collecting media.

The samplers were machined from lucite rod and are composed of four separate elements (Figures 1 and 2). The cap (number 1 on the drawing) holds one-inch membrane or other type filters. The body sections, 2 and 3 , contain one-dram vials which can be packed with copper turnings or activated charcoal. The one-dram vials are modified by cutting a hole in the bottom to allow air to be drawn through the collecting media. 


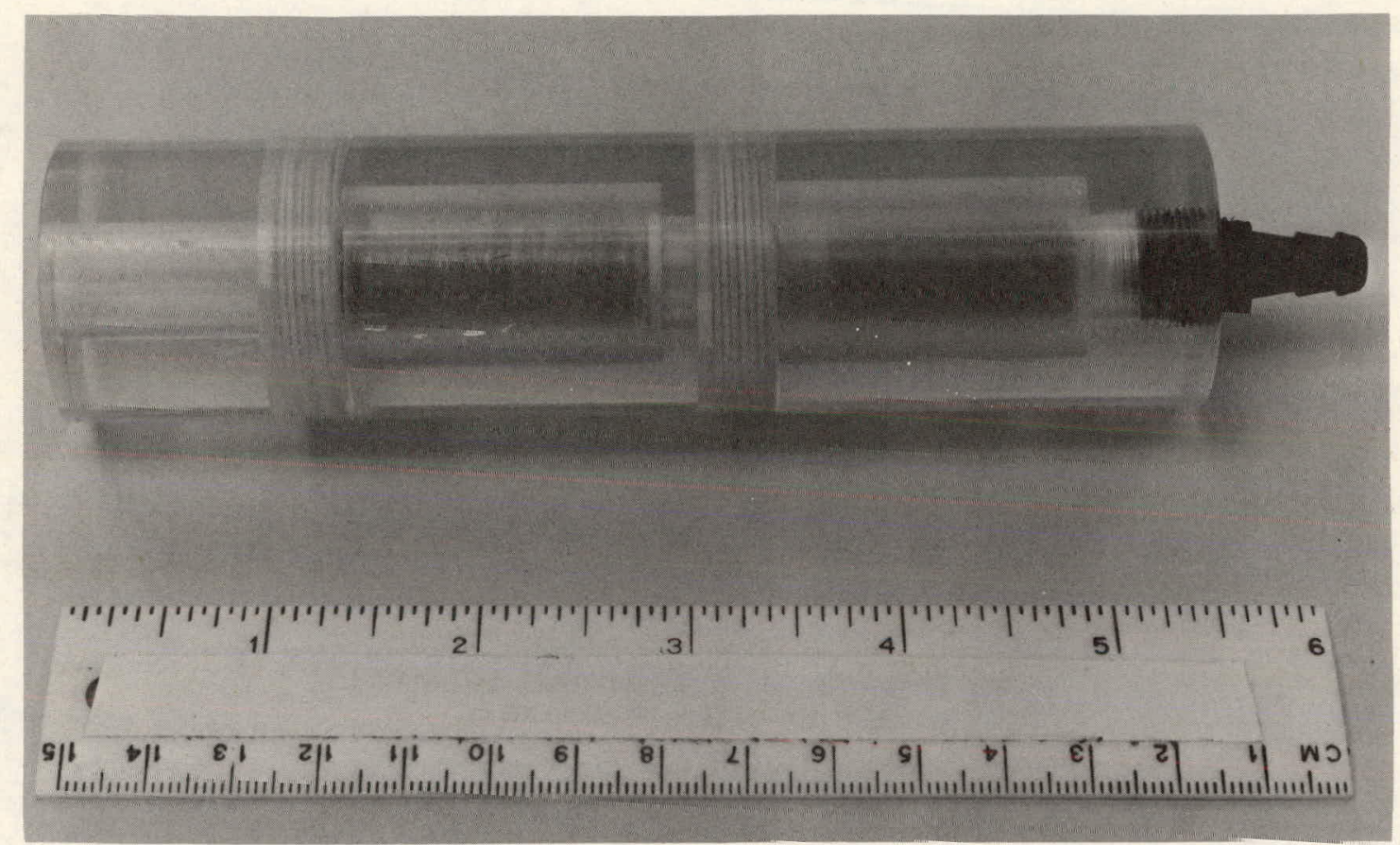

FIGURE 1. Assembled Iodine Air Sampler

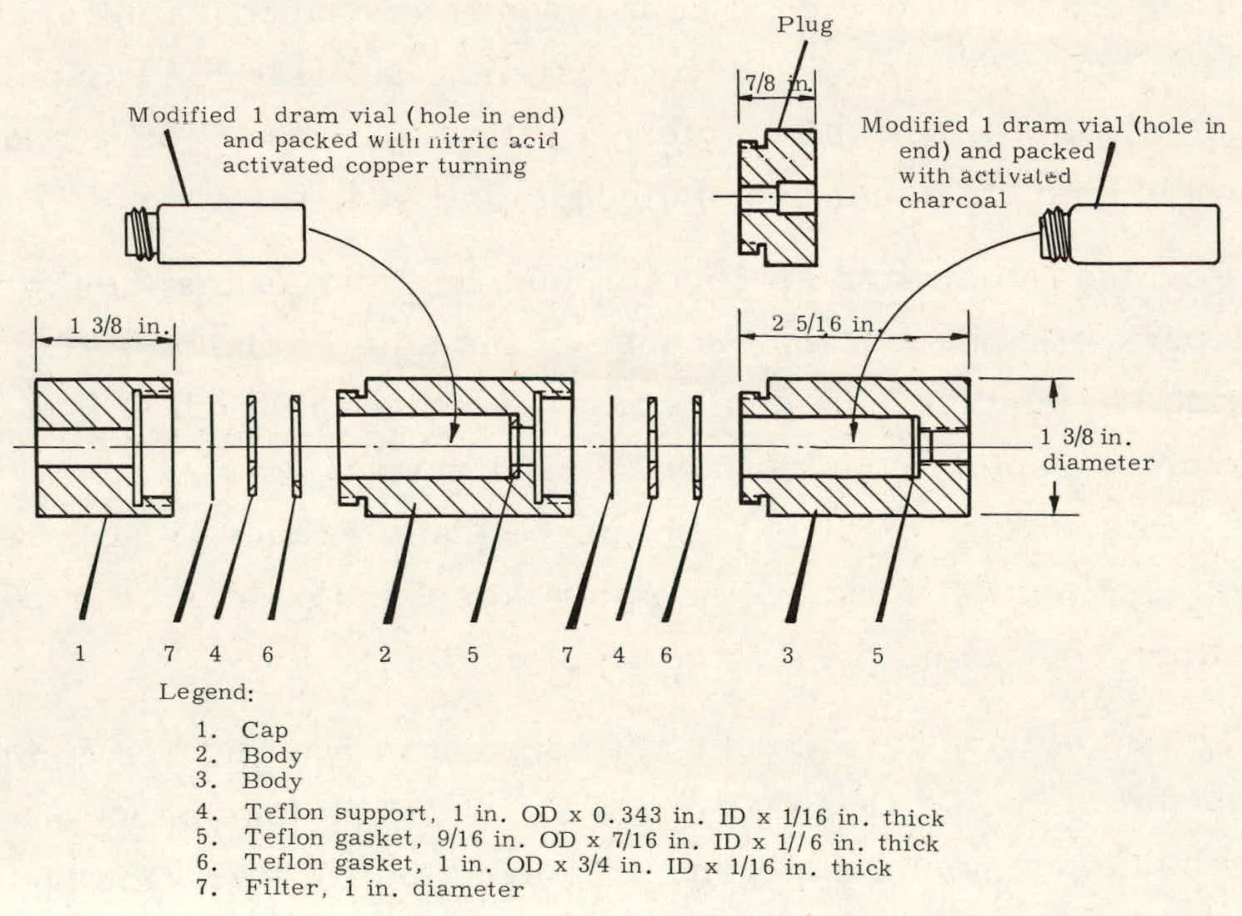

FIGURE 2. Iodine Air Sampler 
BNWL- 122

Several number 2 body sections can be in series followed by a number 4 body or a plug. The number 3 body and plug are drilled and tapped for an air hose fitting. Membrane filters can be inserted between sections. Also, the cap and plug can be used together as a filter paper sampling unit. Teflon supports and gaskets are used between sections to make an airtight seal.

The sampler was used to collect air from an animal exposure chamber in which stable iodine and radioiodine were dispersed. Typical. results are shown in Table 1 . A one-inch membrane filter in the cap was backed up with about $10 \mathrm{~g}$ copper turnings or one-half inch disks of 100 mesh copper freshly etched with $0.5 \mathrm{~N} \mathrm{HNO}_{3}$ and washed with distilled water in one body section, $2.5 \mathrm{~g}$ activated charcoal in a second body section, and a one-inch $\mathrm{AgNO}_{3}$-impregnated asbestos filter in the plug section. Air was drawn through the samplers at a rate of $100 \mathrm{~cm}^{3} / \mathrm{min}$ for $20 \mathrm{~min}$. All samples were counted in a well-type NaI crystal with a single channel gamma analyzer. More than $99 \%$ of the iodine.. was collected on the copper, and less than $1 \%$ of the total collecled $I^{131}$ was found on the walls of the disassembled sampler.

One criticism of most iodine vapor samplers is the difficulty in determining how much of the iodine is reversibly adsorbed on particles. The "quick-change" features of this sampler were utilized to determine the rate at which iodine was desorbed from partioles first collected on the membrane filters. Backup sampler sections containing copper were replaced periodically as fresh clean air was pulled through the membrane filter. Results are shown in Figure 3.

Although this sampler does not solve all of the problems associated with the sampling of iodine contaminated air it does offer several advantages over previously described samplers. These include:

- Versatility-choice of several collecting media and sequence of collection.

- Quick assembly and disassembly for analysis, decontamination, or exchange of sampling sections.

- Useful for small volume sampling. The design can be scaled up for larger volume sampling. 
- Compact and can be prepackaged for field use.

- Use of copper as an adsorbing media makes it possible to analyze for both stable iodine and radioiodine.

TABLE 1. Examples of air sample data

\begin{tabular}{|c|c|c|c|c|c|c|c|c|}
\hline \multirow{4}{*}{ Sample stage } & \multicolumn{8}{|c|}{ Percent of total $\mathrm{I}^{131}$ or $\mathrm{I}^{127}$ collected } \\
\hline & \multicolumn{4}{|c|}{ Experiment 10} & \multicolumn{4}{|c|}{ Experiment 11} \\
\hline & \multicolumn{2}{|c|}{$\mathrm{I}^{131}$} & \multicolumn{2}{|c|}{$I^{127}$} & \multicolumn{2}{|c|}{$\mathrm{I}^{131}$} & \multicolumn{2}{|c|}{$I^{127}$} \\
\hline & $a^{*}$ & $b^{*}$ & $\mathrm{a}$ & $\mathrm{b}$ & a & $\mathrm{b}$ & $\mathrm{a}$ & $b$ \\
\hline Membrane filter & 0.9 & 0.73 & 0.98 & 0.92 & 0.26 & 0.15 & 0.18 & .0 .23 \\
\hline Copper screen & 99.0 & 99.2 & 99.0 & 99.0 & 99.4 & 99.2 & 99.8 & 99.7 \\
\hline Charcoal & 0.05 & 0.02 & - & - & 0.14 & 0.28 & - & - \\
\hline AgNO $_{3}$ asbestos filter & 0.05 & 0.03 & - & - & 0.18 & 0.35 & - & - \\
\hline Total iodine collected & $\begin{array}{r}0.37 \\
(\mu \mathrm{Ci})\end{array}$ & $\begin{array}{r}0.45 \\
(\mu \mathrm{Ci})\end{array}$ & $\begin{array}{c}5.1 \\
(\mathrm{mg})\end{array}$ & $\begin{array}{c}7.7 \\
(\mathrm{mg})\end{array}$ & $\begin{array}{r}0.26 \\
(\mu \mathrm{Ci})\end{array}$ & $\begin{array}{r}0.21 \\
(\mu \mathrm{Ci})\end{array}$ & $\begin{array}{l}11 \\
(\mathrm{mg})\end{array}$ & $\begin{array}{c}8.8 \\
(\mathrm{mg})\end{array}$ \\
\hline
\end{tabular}

* Duplicate, 2-1. Air samples were collected during each experiment.

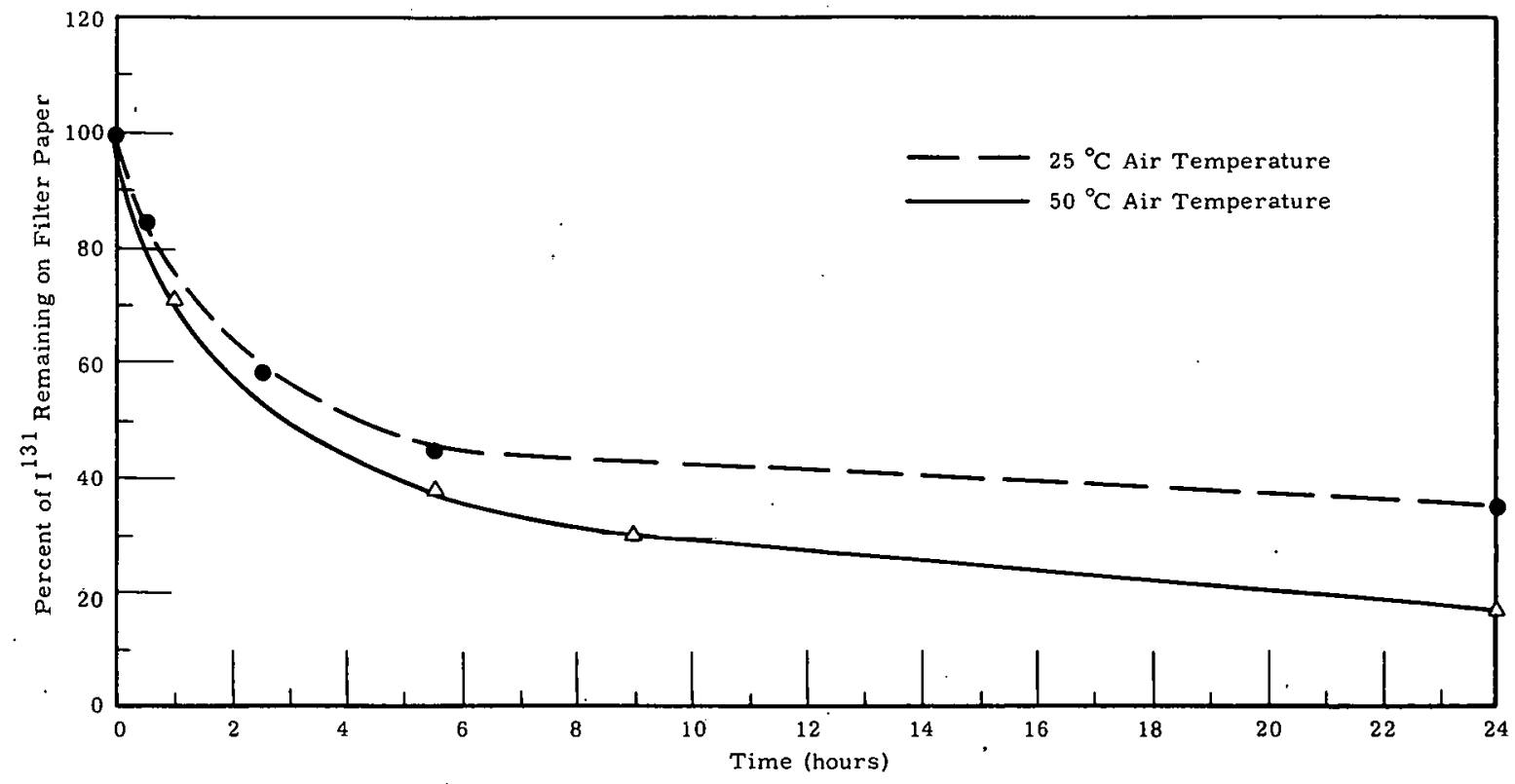

FIGURE 3. The Effect of Air Temperature on Desorption of $\mathrm{I}^{131}$ from Dust Particles Deposited on the Filter of an Air Sampler (from J. F.. Cline) 
BIOLOGICAL EFFECTS OF $\mathrm{Sr}^{90}$ IN MINIATURE SWINEFIFTH PROGRESS REPORT

.' '

R. O. McClellan, ${ }^{*}$ W. J. Clarke, J. L. Palotay,
H. A. Ragan, and Glenda S. Vogt

Rinlogical effccts of dally ingestion of $\mathrm{Sr}^{90}$ are being studied in miniature swine fed from 1 to $3100 \mu \mathrm{Ci} \mathrm{Sr} 90 /$ day. Approximately 300 animals are presently being maintained for lifetime observation. A total of five cases of neoplasia of the hematopoietic tissues have now been observed in 2.5 to 4.5 year old miniature swine with chronic exposure to $\mathrm{Sr} 90$; four cases at the $125 \mu \mathrm{Ci} \mathrm{Sr} 90 /$ day level and one case at the $25 \mu \mathrm{Ci} \mathrm{Sr} 90 /$ day level. Three of these cases have been diagnosed as lymphosarcoma and two as myelogenous leukemia. Other animals at the $125 \mu \mathrm{Ci} \mathrm{Sr} 90 /$ day level continue to have a moderate neutropenia, lymphopenia, and thrombocytopenia. Other animals at the $25 \mathrm{MC} \mathrm{Sr}^{90} /$ day have hematological values that are within the normal range. Effects related to $\mathrm{Sr}^{90}$ ingestion have not yet been observed in animals fed 1 or $5 \mu \mathrm{Ci} \mathrm{Sr} 90 /$ day.

This paper summarizes certain aspects of the progress made since the last report (Hanford Biology Report for 1963) on the long term studies initiated in March 1959. In this study, levels of $0,1,5,25,125,625$, or $3100 \mu \mathrm{Ci} \mathrm{Sr}^{90} /$ day are being fed to young females starting at nine months of age. Two generations of their offspring are being fed levels of $0,1,5$, 25 , or $125 \mu \mathrm{Ci} \mathrm{Sr} 90 /$ day and one generation of offspring has been maintained at the $625 \mu \mathrm{Ci} \mathrm{Sr} 90 /$ day level. Young animals receive less $\mathrm{Sr}^{90}$ in proportion to their lower feed intake.

In Table 1 are summarized the number of animals at each of the $\mathrm{Sr}^{90}$ feeding levels. A number of the original animals in the experiment are now over six years old and have ingested $\mathrm{Sr}^{90}$ daily for over 69 months. Some of their offspring, which have been exposed since conception, are nearly 5.5 years old. An additional group of six young females were started during the past year at the $125 \mu \mathrm{Ci} \mathrm{Sr} 90 /$ day level. The addition of these six animals results in a total of 11 original females that have been exposed to $\mathrm{Sr}^{90}$ daily starting at nine months of age. Two young females were added to the $625 \mu \mathrm{Ci} \mathrm{Sr} 90 /$ day level to provide more offspring for use in studies on the myeloproliferative lesions seen at this level.

* Present Address: Division of Biology and Medicine, United States Atomic Energy Commission, Washington, D.C. 
BNWL-122

TABLE 1. Number of Animals at Each $\mathrm{Sr}^{90}$ Feeding Level as of January 1, 1965

\begin{tabular}{|c|c|c|c|c|c|c|}
\hline $\begin{array}{c}\mathrm{Sr}^{90} \\
\text { feeding level } \\
\text { ( } \mathrm{MCi} \text { day) }\end{array}$ & \multicolumn{2}{|c|}{$\begin{array}{c}\text { Original } \\
\text { group }\end{array}$} & \multicolumn{2}{|c|}{$\begin{array}{l}F_{1} \text { and } F_{2} \\
\text { off spring }\end{array}$} & \multicolumn{2}{|c|}{ Total } \\
\hline 3100 & $5^{*}$ & $(0)^{* * *}$ & & & 5 & (0) \\
\hline 625 & 6 & (1) & 38 & $(4)^{* ; 2 * 2 \cdot k}$ & 44 & (5) \\
\hline 125 & 12 & (10) & 72 & (25) & 84 & (35) \\
\hline 25 & 18 & (11) & 117 & (32) & 135 & (43) \\
\hline 5 & 6 & $(6)^{* ; * k * k}$ & 98 & (24) & 104 & (30) \\
\hline 1 & 24 & 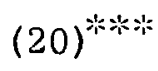 & 242 & (52) & 260 & (72) \\
\hline \multirow[t]{2}{*}{0} & 42 & (38) & 285 & $(54)$ & 327 & $(92)$ \\
\hline & & & Gra & Total & 965 & (277) \\
\hline
\end{tabular}

*n Total number of animals used

$* *(\mathrm{n})$ Animals alive and on experiment as of January 1, 1965

*** Removed from $\mathrm{Sr}^{90}$ feeding and held for lifetime observation

Five cases of neoplasia of the hematopoietic system have been observed in miniature swine ingesting $\mathrm{Sr}^{90}$ (Table 2). The clinical course in all five animals was relativcly acute. T retharg.y and inappetence were the first indications of an animals impending death. Examination of blood

TABLE 2. Neoplasms of the Hematopoietic Tissue in Miniature Swine Chronically Irradiated with $\mathrm{Sr}^{90}$

\begin{tabular}{|c|c|c|c|c|c|c|}
\hline $\begin{array}{c}\text { Case } \\
\text { Number } \\
\end{array}$ & $\begin{array}{c}\mathrm{Sr}^{90} \text { exposure } \\
\text { ( } \mathrm{\mu Ci} / \text { day) }\end{array}$ & $\begin{array}{c}\text { Estimated cumula } \\
\text { radiation dose } \\
\text { (rad) }\end{array}$ & e & Age & $\begin{array}{l}\text { e at death } \\
\text { (years) }\end{array}$ & Diagnosis \\
\hline 1 & 125 & 16,000 & & & 2.5 & $\begin{array}{c}\text { Myelogenous } \\
\text { Leukemia }\end{array}$ \\
\hline 2 & 125 & 16,000 & $\cdot$ & & 2.5 & Lymphosarcoma \\
\hline 3 & 125 & 18,500 & & & 3.0 & Lymphosarcoma \\
\hline 4 & 125 & 18,500 & & . & 3.0 & Lymphosarcoma \\
\hline 5 & 25 & 3,000 & & & 4.5 & $\begin{array}{c}\text { Myelogenous } \\
\text { Leukemia }\end{array}$ \\
\hline
\end{tabular}

* All exposures started in utero, except number 5 which started ingesting $\mathrm{Sr}^{90}$ at nine months of age. 
samples at this time revealed abnormal leukocytes. In both cases of myelogenous leukemia there was a pronounced increase of leukocytes in the peripheral blood. In case 5 the peak leukocyte count was $33 \times 10^{3} / \mathrm{mm}^{3}$ the majority being basophils. In case 1 , the peak. leukocyte count was $33 \times 10^{3} / \mathrm{mm}^{3}$ with the majority.being immature myeloid forms. Selected hematological values for this animal are shown. in Figure 1 . In all cuses there was a progressive thrombocytopenia and anemia.

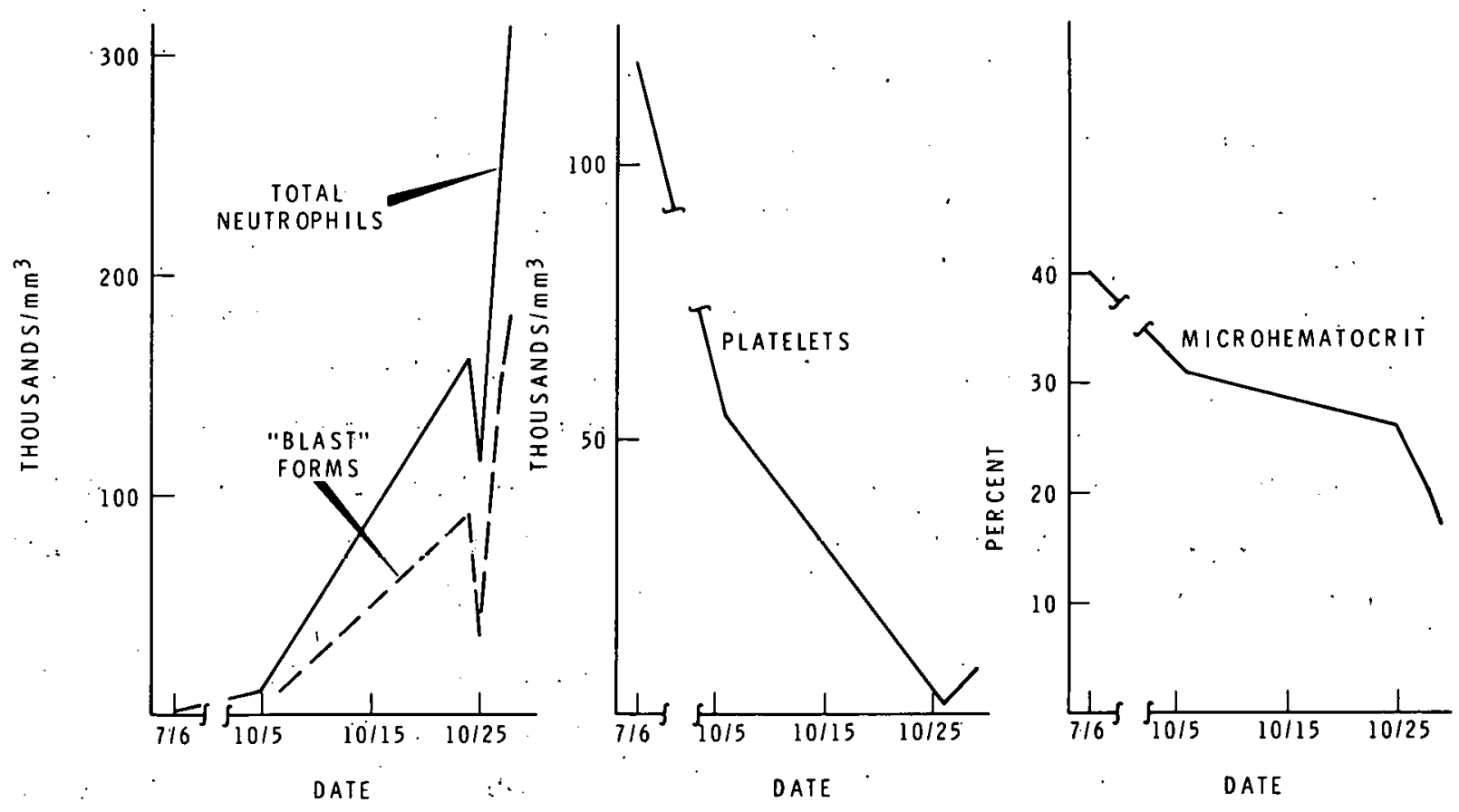

FIGURE 1. Hematological Values in Ácute Leukemia of a. Miniature Swine Irigesting $125 \mu \mathrm{Ci} \mathrm{Sr} 90 / \mathrm{Day}$

Affected animals were killed when death appeared to be imminent. The most prominent and consistent gross lesions observed were hemorrhage throughout the body and marked enlargement of lymph nodes. The number of lymph nodes showing enlargement ranged from relatively few, in localized areas, to enlargement of all lymph nodes. In some cases the lymph nodes were enlarged and retained their normal color and gross architecture; in others the nodes contained foci of bright pink or red tissue that sharply contrasted with the normal gray color. Other nodes had a rough granular texture. 
In four of the five animals there was enlargement of the spleen. Splenic weights ranged: from 170-790 g compared to control weights of 100-150 g. In three of the five animals there were distinct grayish white foci, up to $1 \mathrm{~cm}$ in diameter, in the cortex of the kidney. Smaller foci were observed in the liver. The bone marrow of four of the five animals was pale pink as contrasted to the normal pink color of active marrow. The color of this marrow was not unlike that seen in chronically irradiated animals. This coloration may also have been due, in part, to the invasion of neoplastic tissue.

Both hemorrhage and an accumulation of neoplastic cells were evident histologically in the cell poor sinuses of most of the lymph nodes (Figure 2a). In four of the animals, neoplastic cells replaced much of the splenic tissue. In the kidney, foci of neoplastic cells were often associated with the blood vascular system (Figure 2b). Neoplastic involvement of the liver was usually found associate with an accumulation of cells in the interlobular connective tissue (Figure 2c). In the lung (Figure 2d) neoplastic cells were found scattered diffusely throughout the alveoli, in close apposition to blood vascular structures and in nodular foci.

The cytological characteristics of the neoplastic cells varied somewhat between the five cases. For the sake of classification they were categorized into myelogenous leukemia and lymphosarcoma (several types). It is highly suggestive that a very immature type cell (reticulum cell or hemocytoblast) has become neoplastic. In many cases, mature forms of both the leucocytic and erythrocytic series could be found intimately associated with the neoplastic process. Histochemical and differential staining techniques are being used to further delineate cellular morphology.

It is of interest that seven other cases of hematopoietic tissue neoplasia have been observed in animals following chronic exposure to $\mathrm{Sr} 90$. Five cases were lymphosarcoma or reticulum cell sarcoma observed in dogs ingesting $\mathrm{Sr}^{90}$ as part of the continuous study at the University of California, Davis. Two cases of myelogenous leukemia were observed in dogs at Argonne National Laboratory. These animals had received multiple injections of $\mathrm{Sr}^{90}$ over the period of one year starting either soon after birth or at six months of age. 


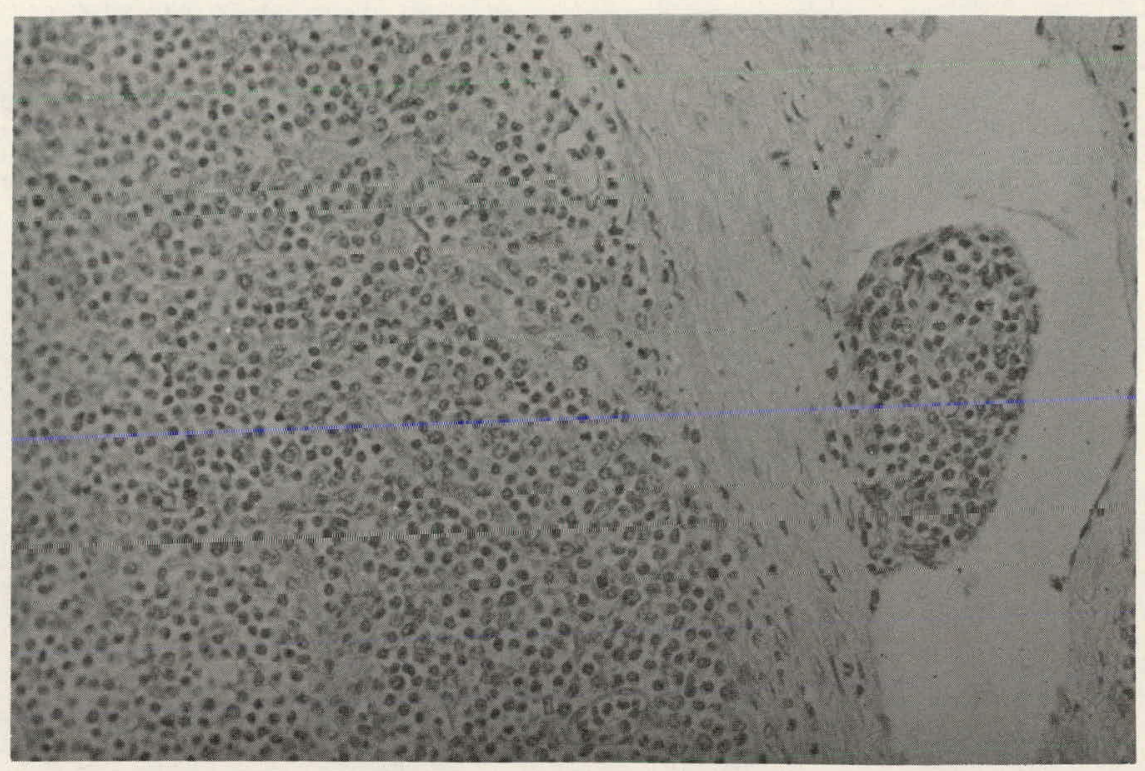

FIGURE 2a. Lymph Node: Replacement of Tissue with Neoplastic Cells

(Notice metastatic nodule in lumen of vessel.) (H\&E 256X)

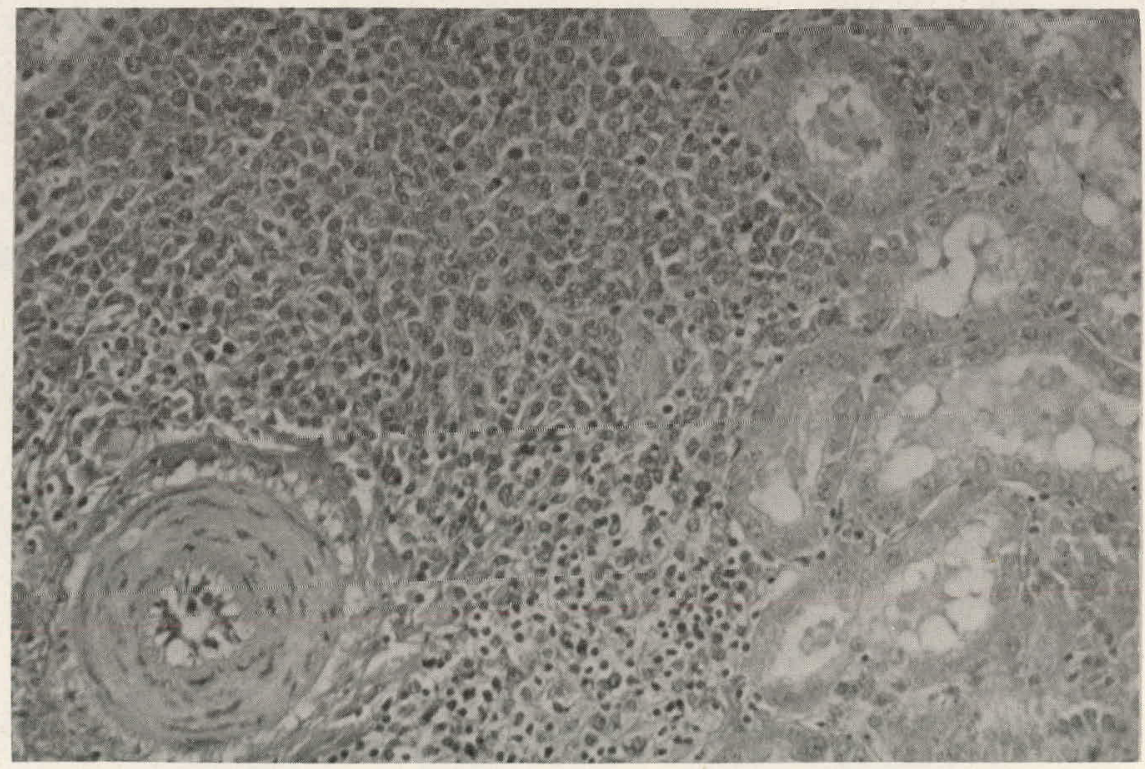

FIGURE 2b. Kidney: Foci of Neoplastic Cells in Close Apposition

to Artery and Between Tubules (H\&E 256X) 
BNWL- 122

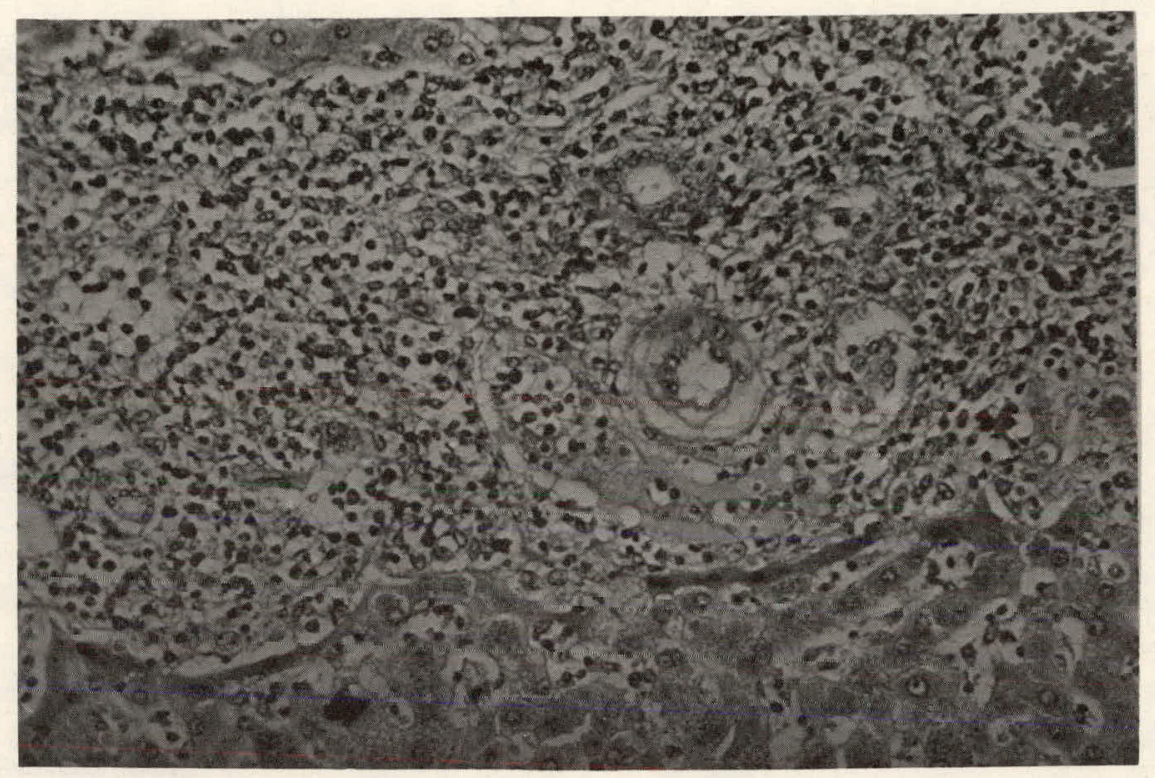

FIGURE 2c. Liver: Infiltration of Cells Within the Interlobular Connective Tissue (H\&E 256X)

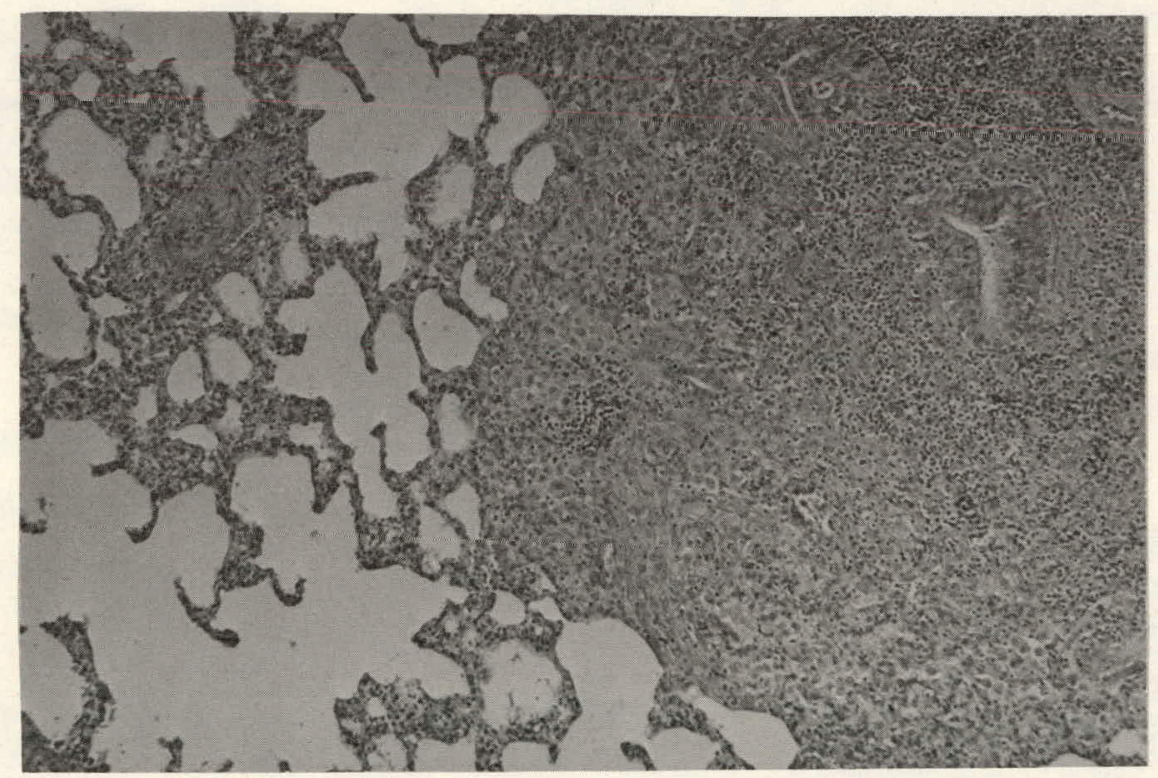

FIGURE 2d. Lung: Nodule of Neoplastic Cells Between Small Artery and Bronchiole

(H\&E 100X) 
In Table 3 are summarized data on animal experiments in which hematopoietic and bone neoplasms have been observed. Data are included for three groups of dogs at the University of Utah. These dogs have had a high incidence of bone neoplasms rather than hematopoietic tissue neoplasms. All groups except the Davis group 1, have a large number of animals surviving. It must be emphasized that the data do not represent the actual incidence of a given condition, and are very preliminary in nature.

TABLE 3. Neoplasms of Bone and Hematopoietic Tissue in Animals Exposed to $\mathrm{Sr}^{9}$

\begin{tabular}{|c|c|c|c|c|c|c|c|c|c|c|c|c|}
\hline \multirow[b]{3}{*}{ Group } & \multirow{3}{*}{\multicolumn{2}{|c|}{$\begin{array}{c}\text { Species } \\
\text { and references }\end{array}$}} & \multirow[b]{3}{*}{$\mathrm{Sr}^{90}$ exposure } & \multirow{3}{*}{\multicolumn{2}{|c|}{$\begin{array}{l}\text { Present age(a) } \\
\text { of animals (yr) }\end{array}$}} & \multirow{3}{*}{$\begin{array}{l}\text { No. of } \\
\text { animals }\end{array}$} & \multicolumn{6}{|c|}{ Deaths to date } \\
\hline & & & & & & & \multirow{2}{*}{$\begin{array}{l}\text { From } \\
\text { No. }\end{array}$} & \multirow{2}{*}{\multicolumn{3}{|c|}{$\begin{array}{r}\text { osteosarcoma } \\
\text { Age at(a) } \\
\text { death (yr) }\end{array}$}} & \multirow{2}{*}{\multicolumn{2}{|c|}{$\begin{array}{r}\begin{array}{c}\text { From neoplasia of } \\
\text { hematopoietic tissue } \\
\text { Age at } \\
\text { No. death (yr) }\end{array} \\
\text { Nor }\end{array}$}} \\
\hline & & & & & & & & & & & & \\
\hline Hanford & -1 & Swine & $125 \mu \mathrm{Ci} /$ day-ingested & & $5-3.5$ & 16 & 0 & & & - & 4 & $2.5-3.0$ \\
\hline Hanford & -2 & Swine & $25 \mathrm{\mu Ci} /$ day-ingested & & $5-6$ & 22 & 0 & & & - & 1 & 4.5 \\
\hline Davis & -1 & $\operatorname{Dogs}(1,2,3)$ & $13 \mu \mathrm{Ci} /$ day-ingested & & - & 4 & 2 & & & $2-5.5$ & 2 & $0.5-1.2$ \\
\hline Davis & -2 & Dogs & $10 \mu \mathrm{Ci} /$ day-ingested & & $5-3.3$ & 30 & 0 & & & - & 3 & $1.5-2.3$ \\
\hline Argonne & -1 & Dogs $(4,5)$ & $15 \mu \mathrm{Ci} / \mathrm{kg}^{(\mathrm{b})}$ & 5 & -7 & 24 & 0 & & - & - & $\cdot 1$ & 2.3 \\
\hline Argonne & -2 & Dogs & $15 \mu \mathrm{Ci} / \mathrm{kg}^{(\mathrm{c})}$ & 4 & -5 & 14 & 0 & $A$ & & - & 1 & 2.4 \\
\hline Argonne & -3 & Dogs & $150 \mu \mathrm{Ci} / \mathrm{kg}^{(\mathrm{d})}$ & 4 & & 38 & 22 & & 1 & -6 & 0 & - \\
\hline Argonne & -4 & Dogs & $10-250 \mu \mathrm{Ci} / \mathrm{kg}^{(\mathrm{c})}$ & & -11 & 17 & 4 & & 3 & 1 & - & - \\
\hline Utah & -1 & Dogs (6) & $100 \mu \mathrm{Ci} / \mathrm{kg}^{(\mathrm{f})}$ & 6. & & 12 & 6 & & & $8-7.6$ & 0 & - \\
\hline Utah & -2 & Dogs & $33 \mu \mathrm{Ci} / \mathrm{kg}^{(\mathrm{g})}$ & & $5-11$ & 12 & 0 & & & - & 0 & - \\
\hline
\end{tabular}

(a) For the Argonne dogs the value shown for age is the time after injection.

(b) Multiple. injections starting shortly after birth.

(c) Multiple injections starting at six months of age.

(d) Multiple injections.

(e) Single injection.

(f) Single injection at 17 months of age.

References:

1. A.C. Anderson, and associates, personal communication.

2. A. C. Anderson and D. H. MCKelvie; UCD-472: 10,1964 .

3. A. C. Anderson, M. Goldman, T. F. Dougherty, W. S. S. Gee, C. W. Mays and B. J. Stover; Some aspects of internal irradiation. Pergamon Press, London, Engláid, p. 319.

4. M. F. Finkel and B. O. Biskis, personal communication.

5. B. O. Biskis, M. P. Finkel, and I. L. Greco; (Abstr.) Radiation Research 22: $169,1964$.

6. T. F. Dougherty; Editor-Research in Radiobiology, COO-119, 1964.

Ages of the animals differ between groups and within groups, making comparisons difficult. Furthermore, in Table $3, \mathrm{Sr}^{90}$ exposure for each of the animals is shown as a quantity injected or ingested. Differences in size of the animals, uptake, retention and distribution of the $\mathrm{Sr}^{90}$ will influence the actual radiation dose rate. Significant numbers of hematopoietic tissue neoplasms have been observed in animals exposed to moderate radiation dose rates starting early in life (Hanford groups 1 and 2, Davis 
groups 1 and 2, and.Argonne groups 1 and 2). During the early portions of the experiments, bone neoplasms have not been a major cause of death among groups with cases of hematopoietic tissue neoplasms. Bone tumors have been observed only in the two Davis group 1 dogs that survived for 3.2 and 5.5 years, having outlived their experimental mates who succumbed to hematopoietic tissue neoplasms.

In contrast to the above animals, only bone neoplasms have appeared in Argonne groups 3 and 4 and Utah groups 1 and 2. The Utah dogs and the Argonne group 4 dogs were given $\mathrm{Sr}^{90}$ as a single injection when the skeleton was nearly mature. In these animals the radiation dose declined as $\mathrm{Sr}^{90}$ was excreted and exposure of the bone marrow followed a similar pattern. Total radiation dose exposure to the skeleton of the Utah dogs was similar to or higher than that noted for the Davis dogs or Argonne groups 1 and 2 dogs that showed hematopoietic tissue neoplasms and not bone neoplasms. The Argonne group 3 dogs received multiple injections of $\mathrm{Sr}^{90}$ with *. resultant total radiation doses 5-10 times higher than the Davis dogs or Argonne groups 1 and 2 dogs.

On the one hand, animals with chronic expusure to modorate radjation dose rates from $\mathrm{Sr}^{90}$ starting early in life have developed hematopoietic tissue neoplasms, but as yet they have not developed many bone neoplasms. Animals with acute exposure to $\mathrm{Sr}^{90}$ and resultant declining radiation dose rate exposures, (or with high radiation dose rates) have shown, : on the other.hand, a large number of bone neoplasms but no hematopoietic tissue neoplasms. Although these statements emphasize the differences in radiation dose and radiation dose rate, other factors, such as differences in radiation dose distribution, may be important. In the animals receiving single injections, the $\mathrm{Sr}^{90}$ is unevenly distributed which will result in less uniform irradiation of the bone marrow than when $\mathrm{Sr}^{90}$ is distributed evenly throughout the bone, as occurs with chronic administration. The difference in age at initial exposure may be of significance, particularly in comparing the Utah dogs to the others. These preliminary results might also be explained on the basis of possible 
differences in the latent period for the two types of neoplasia. If the latent period for induction of bone neoplasms is considerably longer than that for hematopoietic tissue neoplasms, then it might be expected that during early life hematopoietic tissue neoplasms would predominate over bone neoplasms as noted in this report.

Comparablc carly results from three long term studies (Argonne, Davis, and Hanford) are mutually supporting and emphasize the potential importance of hematopoietic tissue neoplasms as well as bone neoplasms as sequelae to chronic exposure to $\mathrm{Sr}^{90}$. These changes must be considered in evaluating the potential hazard of $\mathrm{Sr}^{90}$. The suggested relationship between type of effect and mode of $\mathrm{Sr}^{90}$ exposure will be evaluated further as these continuing studies progress. 


\section{CYCLING OF Sr ${ }^{90}$ IN MOLTING CRAYFISH}

\section{J. M. Dean}

Crayfish injected with $\mathrm{Sr}^{90}-\mathrm{Y}^{90}$ while in the premolt stage concentrated the isotope in the gastrolith and fixed it in the exoskeletur.. Al molt the $\mathrm{Sr}^{90}-\mathrm{Y}^{00}$ in the gastrolith was mobilized and deposited in the postmolt exoskeleton.

Crayfish can be induced to molt by eyestalk extirpation. This operation releases the hormonal inhibition of molt and the animals assume a physiological state of constant molting activity. During the premolt stage, the crayfish resorbs calcium from the old exoskeleton and fixes it in the gastroliths, a pair of structures in the walls of the cardiac stomach that concentrate calcium. Calcium actively taken up from the external environment is also deposited in the gastrolith. At the time the old exoskeleton is being resorbed, a new integument forms beneath it. This integument is soft and pliable and does not have a large deposition of calrium sälts unitil postmolt.

Schurr and Stamper (Limnology and Oceanography, 1: 474, 1962) proposed a model for the accumulation of $\mathrm{Sr}^{85}$ by crayfish from the environment. However, they neither considered the molt stage in their model nor was the molt stage defined in their experiment. Since the metabolism of calcium and strontium in.Crustacea is dependent upon the stage of the molt cycle, the model is not generally applicable.

Crayfish, Pacifastacus trowbridgi, were acclimated to $15{ }^{\circ} \mathrm{C}$ and held as a group for three weeks in running river water in the laboratory. The eyestalks were removed and the animals isolated. Each week for five weeks $1.0 \mu \mathrm{Ci}$ of $\mathrm{Sr}^{90}-\mathrm{Y}^{90}$ was injected into a sinus at the base of the last walking leg. Individuals were collected at different stages of the molt cycle. Their molt stage was estimated from, the gastrolith length to carapace length, (GL/CL) ratio. This ratió is used as a convenient physiological time scale which allows stratification of animals by their physiological stage rather than by time, per se. Samples were taken of exoskeleton I (ESI) and exoskeleton II (ESII). ESI is the initial exoskeleton 
observed and ESII is the integument formed during premolt which becomes the newly hardened exoskeleton, postmolt. Tail muscle and the gastroliths were also sampled.

The results, as shown in Figure 1, represent an average of two animals at each point. A rapid and heavy deposition of the $\mathrm{Sr} 90-\mathrm{Y}^{90}$ occurred in the gastroliths during premolt which reached a peak just prior to molt. The salts in the gastroliths are mobilized and the gastroliths disappear at postmolt as the new exoskeleton becomes hardened. Interestingly however, the ESI, which had undergone a rapid loss of calcium by resorption also fixed the $\mathrm{Sr}^{90}-\mathrm{Y}^{90}$ and there was appreciable radioactivity in the freshly molted ESI: The activity in the exoskeleton for 30 animals at the first molt averaged $: \because 68 \mathrm{nCi} / \mathrm{mg}$ dry weight. Thus, a dynamic turnover occurs in this tissue. Muscle had a low level of radioactivity and reflects the level in the circulating blood. After the first artifically induced molt, the animal

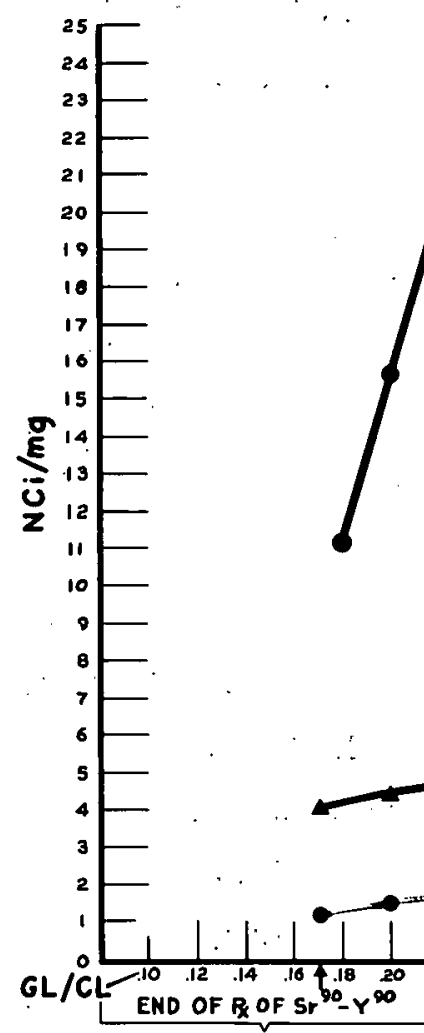

PREMOLT
GASTROLITH ACTIVITY

- ES II

- tall muscle

- ACTIVITY OF MOLTED ESI

- ACTIVITY OF MOLTED ESI

FIGURE 1. Shifts in $\mathrm{Sr}^{90}$ During the Molt Cycle $\therefore \quad$. of the Crayfish Pacifastacus trowbridgi 
is abnormal and the second molt is unnatural. However, those animals that succeeded in completing a second molt shifted the $\mathrm{Sr}^{90}-\mathrm{Y}^{90}$ in the same manner as the first molt group.

On the average, the total retained in whole body for premolt animals was $91 \%$ of the total activity injected compared with $82 \%$ for the molt and postmolt animals, thus demonstrating the very cfficient regulatory mechanism of these animals. About $10 \%$ of the activity was lost in the first and second molted exoskeletons. After the first molt, and complete hardening of the exoskeleton had taken place, the animals immediately proceeded into premolt. As they resorbed salts from the exoskeleton, $\mathrm{Sr}^{90}-\mathrm{Y}^{90}$ in the carapace was mobilized and concentrated in the new gastrolith, thus completing the cycle. 


\section{BIOLOGICAL EFFECTS OF I ${ }^{131}$ IN SHEEP AND CATTLE}

H. A. Ragan, B. J. McClanahan, V. G. Horstman; R. O. Shannon, and L. K. Bustad

Peak thyroid uptake of $\mathrm{I}^{131}$ in a group of ewes fed a single oral dooc of 3 mini I ${ }^{131}$ seven years ago was not greatly different than results obtained two years ago (mean about $11 \%)$. Tissue 131 concentrations in three cows are lower than those seen in sheep chronically fed I ${ }^{131}$. $\mathrm{I}^{131}$ is present in detectable amounts in the distal colon of sheep within 20 min after receiving the isotope orally. Stable iodine administered to ewes several days prior to parturition reduced neonatal thyroid uptake of I 131 about $40 \%$ from that seen in control lambs. Continuing long term studies on the biological effects of ${ }^{131}$ in sheep are summarized.

Daily feeding of $\mathrm{I}^{131}$ to sheep began 15 years ago and is continuing. The number of ewes remaining in the various groups is shown in Table 1. During the past 15 years, 1 fibrosarcoma, 4 probable carcinomas, and 19 adennmas have been detccted histulugically in the thyroids of a total of 45 sheep over four years of age fed daily quantities of ${ }^{131}$ ranging from 0.5 to $5 \mu \mathrm{Ci}$. Eight thyroid adenomas and 5 chromophobe adenomas of the pituitary were also observed in 16 sheep which received a single $3 \mathrm{mCi}$ oral dose of $\mathrm{I}^{131}$.

TABLE 1. Sheep Remaining in Groups Receiving $\mathrm{I}^{131}$ Daily

\begin{tabular}{|c|c|c|c|c|c|}
\hline & \multicolumn{5}{|c|}{$\mathrm{I}^{131 / \mathrm{day}(\mathrm{uC} i)}$} \\
\hline & 5.0 & 1.5 & 0.5 & 0.15 & Control \\
\hline No. of animals & -- & - & 13 & 4 & 11 \\
\hline $\begin{array}{l}\text { No. weaned from above ewes } \\
\text { and held for lifetime observation }\end{array}$ & 18 & 10 & 13 & 3 & 10 \\
\hline
\end{tabular}

* An additional 88 animals are kept in a control flock, serving as controls and a source of replacement animals.

Six ewes remain in a group given single doses of $3 \mathrm{mCi} \mathrm{I}^{131}$ in 1957 or 1958. Mean peak thyroid uptake (TU) of a tracer test dose of $\mathrm{I}^{131}$ in these hypothyroid ewes was $11 \%$, which is similar to that described in our Annual Report two years ago; however, in the control group mean peak uptake fell from $48 \%$ two years ago to 38\% this year. The results obtained in 1962 
and 1964 on PBI are compared in Table 2 along with recently obtained TSH levels. The decrease in TU of the control group is also reflected in depressed PBI values.

TABLE 2. Serum Protein Bound Iodine, Plasma TSH Levels, and Peak I 131 Thyroid Uptake in Ewes

Which Received $3 \mathrm{mCi} \mathrm{I}^{131}$ Seven Years Ago

\begin{tabular}{|c|c|c|c|c|c|}
\hline \multirow{2}{*}{$\begin{array}{l}\text { Animal } \\
\text { No. }\end{array}$} & \multicolumn{2}{|c|}{$\begin{array}{c}\text { Serum PBI } \\
(\mu \mathrm{g} / 100 \mathrm{mi} \text { serum })\end{array}$} & \multicolumn{2}{|c|}{$\begin{array}{l}\text { Maximum percentage } \\
\text { uptake of } 131 \text { tracer }\end{array}$} & \multirow{2}{*}{$\begin{array}{c}\text { Plasma TSH } \\
\left(\mathrm{mu}^{*} / \mathrm{ml} \text { plasma }\right) \\
1964\end{array}$} \\
\hline & 1962 & 1964 & 1962 & 1964 & \\
\hline 1 & 0.9 & 1.4 & 11 & 7 & 1.28 \\
\hline 2 & 1.9 & 3.1 & 13. & 9 & 0.37 \\
\hline 3 & 1.8 & 2.6 & 17 & 12 & 0.39 \\
\hline 4 & 1.2 & 2.4 & 14 & 13 & 2.18 \\
\hline 5 & 1.0 & 2.0 & 12 & 13 & 0.31 \\
\hline 6 & .1 .4 & 2.2 & 11 & 15 & 0.17 \\
\hline Controls & & & & & \\
\hline .7 & 2.0 & 2.9 & 41 & 31 & $<0.04$ \\
\hline 8 & 3.7 & 2.2 & 48 & 34 & $<0.04$ \\
\hline 8 & 2,9 & .4 .3 & 52. & 51 & $<0.04$ \\
\hline
\end{tabular}

* $\mathrm{mu}=$ milliunits

In an attempt to determine the ausorption of $\mathrm{I}^{131}$ from the gastrointestinal tract and its excretion into the same system, a series of male sheep received $I^{131}$ orally and were killed at varying time intervals. Sections of the GI tract were then isolated, ligated and removed for radioanalysis. In this preliminary study it was possible to detect the isotope as far posterior as the distal colon in approximately $20 \mathrm{~min}$ and in the thyroid in approximately $10 \mathrm{~min}$ post-feeding.

To determine the efficacy of $\mathrm{I}^{127}$ in reducing the thyroid burden of $\mathrm{I}^{131}$ in the neonate, a group of ewes were administered $100 \mathrm{mg} \mathrm{I}^{127} 3-10$ days prior to parturition. At birth; the newborn lambs received $5 \mu \mathrm{Ci}$ $\mathrm{I}^{131}$ orally as an aqueous solution. These lambs had a peak $\mathrm{I}^{131}$ thyroid uptake $60 \%$. of that in a group of control lambs.

The study utilizing $I^{131}$ in Holstein dairy cattle was terminated and the three cows sacrificed. These cows had received $5 \mu \mathrm{Ci} \mathrm{I}{ }^{131}$ daily via 
the feed for nine months and then $50 \mu \mathrm{Ci} /$ day for five weeks prior to sacrifice. A comparison of maternal and term fetal thyroid wejghts and $I^{131}$ concentrations appear in Table 3. These maternal thyroid weights compare favorably with a mean of $33 \pm 13$ (SD) observed in 78 adult cattle thyroids collected locally.

TABLE 3, Milk PBI, Maternal and Fetal Thyroid Weights, and $\mathrm{I}^{131}$ Concentrations of Holstein Cattle

\begin{tabular}{|c|c|c|c|c|c|c|}
\hline $\begin{array}{c}\text { Animal } \\
\text { No. }\end{array}$ & $\begin{array}{c}\text { Milk PBI } \\
(\mu \mathrm{g} / 100 \mathrm{ml})\end{array}$ & $\begin{array}{l}\text { Mat } \\
\text { (g) }\end{array}$ & $\begin{array}{l}\text { thyroid } \\
\text { sht } \\
(\mu \mathrm{Ci} / \mathrm{g})\end{array}$ & $\begin{array}{l}\mathrm{Fe} \\
(\mathrm{g})\end{array}$ & $\begin{array}{l}\text { thyroid } \\
\text { ight } \\
\text { ( } \mathrm{MCi} / \mathrm{g})\end{array}$ & $\begin{array}{c}\text { Fetal/maternal } \\
\text { ratio } \\
\left(\mu \mathrm{Ci} \mathrm{I}^{131} / \mathrm{g}\right) \\
\end{array}$ \\
\hline 1 & 2.6 & 38 & 0.21 & 56 & 0.02 & 0.1 \\
\hline 2 & 1. 6 & 21 & 0.5 & 11 & 0.9 & 1.8 \\
\hline 3 & 25 & 42 & 0.1 & 29 & 0.06 & 0.6 \\
\hline
\end{tabular}

The thyroid from fetus No. 1 was grossly enlarged and goitrous, which probably accounts for the low $I^{131}$ concentration. Since these cows were receiving identical amounts of stable iodine ( $3 \mathrm{mg} /$ day), the reason for the high PBI value for milk in animal 3 is not obvious but was probably due to stable iodine contamination after milking. In Table 4 is shown a comparison of $I^{131}$ concentration in the tissues of cattle and those of sheep fed $5 \mu \mathrm{Ci}$ of $\mathrm{I}^{131}$ per day.

TABLE 4. Bovine and Ovine Tissue Concentrations Following Chronic Daily Ingestion of $\mathrm{I}^{131}$ ( $\%$ of daily dose per gram of tissue $\times 10^{4}$ )

\begin{tabular}{|c|c|c|c|c|c|c|c|c|c|c|c|c|}
\hline Animal. & Blood & Muscle & Spleen & Pancreas & Kidney & Liver & Dvary & $\begin{array}{l}\text { Parotid } \\
\text { gland }\end{array}$ & $\begin{array}{c}\text { Mandible } \\
\text { salivary } \\
\text { gland }\end{array}$ & Feces & Milk & Thyroid \\
\hline \multicolumn{13}{|l|}{ Cattle } \\
\hline 1 & 2.0 & 0.3 & 1.1 & 0.8 & 1.6 & 1.7 & 1.4 & 1.0 & 1.0 & 6.2 & 3.4 & 30,000 \\
\hline 2 & 1.9 & 0.2 & 0.8 & 0.9 & 1.6 & 1.7 & 1.4 & 1.4 & 1.3 & 6.2 & 5.2 & 46,000 \\
\hline 3 & 1.1 & 0.1 . & 0.4 & 0.4 & 0.9 & 0.6 & 0.5 & 0.5 & 0.5 & 3.2 & 5.6 & 19,000 \\
\hline mean & 1.7 & 0.2 & 0.8 & 0.7 & $1: 3$ & 1.4 & 1.1 & 1.0 & 0.9 & 5.2 & 4.7 & 32,000 \\
\hline \multicolumn{13}{|l|}{ Sheep } \\
\hline mean & 1.5 & 1.0 & 1.4 & 1.5 & 3.0 & 3.0 & 2.0 & 6.0 & 18.0 & 22.0 & 35.0 & 15,000 \\
\hline
\end{tabular}




\section{SHEEP MILK PRODUCTIONON AND ITS I ${ }^{131}$ CONTENT}

H. A. Ragan, V. G. Horstman, B. J. McClanahan, and L. K. Bustad

Milk secretion in the groups of ewes studied appears to be linear over a $24 \mathrm{hr}$ period with a daily secretion of about $1000 \mathrm{mll}$. Peak milk I ${ }^{131}$ values occur near $5 \mathrm{hr}$ postadministration and fall rapidly, whereas plasma I ${ }^{131}$ levels have a diphasic pattern with a rapid peak, a decline and then gradual rise again. Posterior pituitary extract apparently increases protein-bound iodine concentrations in milk when given intravenously shortly before sampling.

A study was undertaken in sheep to determine the secretion rate of milk as influenced by the time interval between milkings. Determined concurrently was the secretion of $\mathrm{I}^{131}$ in milk following a single oral dose, the plasma levels of $\mathrm{I}^{131}$, and the influence of intravenously administered posterior pituitary extract on the protein-bound iodine (PBI) content of milk。

To detcrmine milk volumes at the various time intervals $(1,3,5$, 9,13 , and $24 \mathrm{hr}$ ) the lambs were allowed to nurse until the udder was empty and were then removed from the dam's pen. At the specified time intervals, the ewes were given 20 USP units of posterior pituitary extract (Pitocin) to stimulate milk "let down" and were then milked by hand to remove the accumulated milk and the volume was measured. Milk secretion averaged $42 \mathrm{ml} / \mathrm{hr}$ over the $24 \mathrm{hr}$ period. When plotted at the time intervals involved, this resulted in a linear secretion rate; the average daily secretion was slightly less than 1 liter.

At the conclusion of the milk volume portion of this study, each ewe was given a single feed pellet containing $500 \mu \mathrm{Ci} \mathrm{I}{ }^{131}$. Milk and plasma samples were obtained over a $96 \mathrm{hr}$ period. Results of $\mathrm{I}^{131}$ determinations on these samples are illustrated in Figure 1. Plasma values rose sharply to a peak near $3 \mathrm{hr}$, fell quite rapidly for the next 6-9 $\mathrm{hr}$, and then began increasing again:; : approaching a plateau at $1-3$ days after $I^{131}$ ingestion. Milk values rose rapidly to peak near $5 \mathrm{hr}$ after dosing and fell quite rapidly during the next $40 \mathrm{hr}$. 


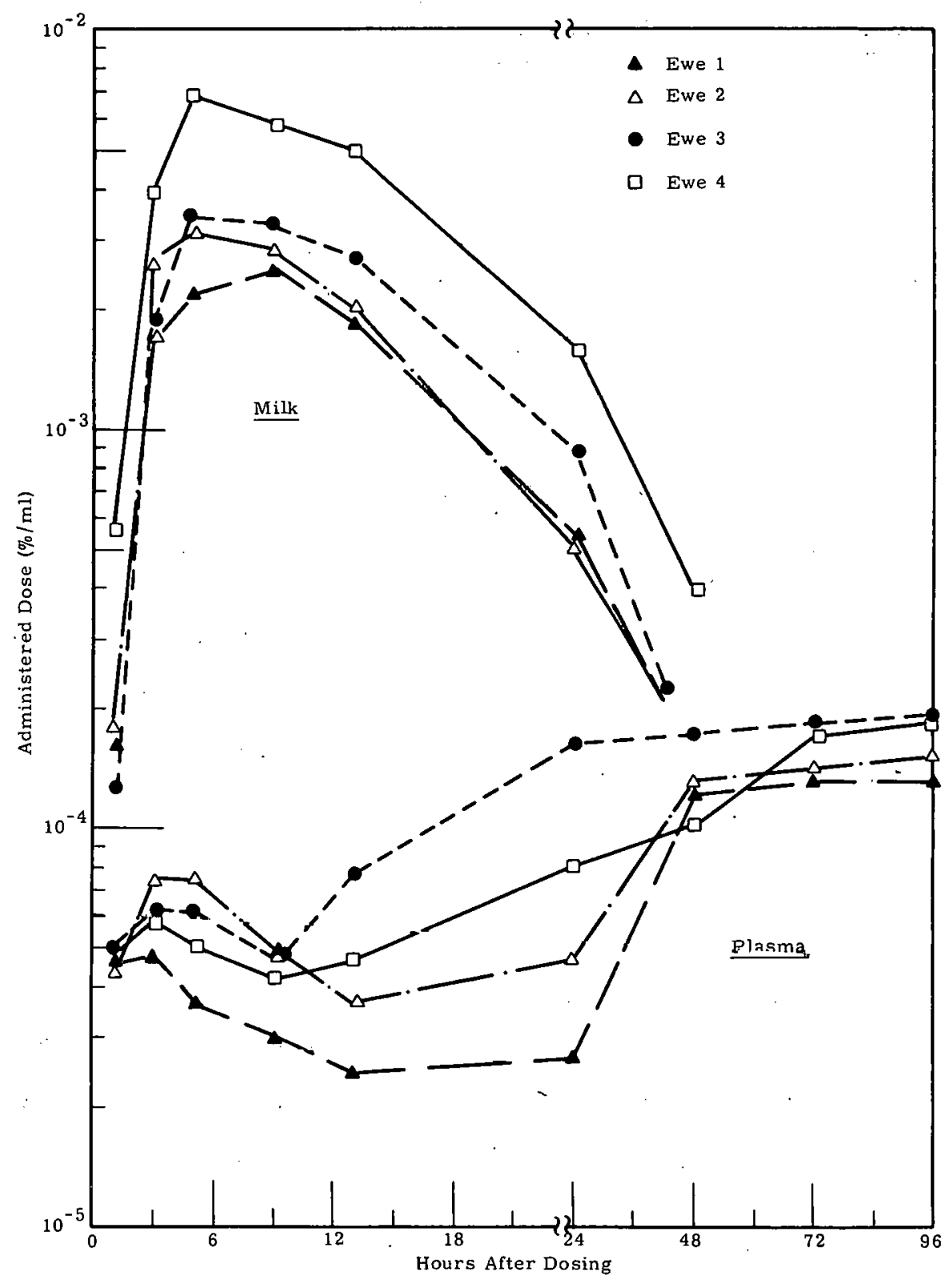

FIGURE 1. Plasma and Milk I ${ }^{131}$ Levels in Lactating Ewes Following a Single Oral Dose of $500 \mu \mathrm{Ci}$

It is probable that during the first few hours the $\mathrm{I}^{131}$ is circulating in an unbound form and will readily concentrate in the mammary gland. The fall in plasma levels occurs as the circulating $\mathrm{I}^{131}$ is removed by various organs and tissued, particularly the thyroid, where it is bound. 
$I^{131}$-labeled thyroid hormone is then released into the peripheral blood, increasing the plasma I ${ }^{131}$ levels (chiefly protein-bound $I^{131}$ ). The PBI ${ }^{131}$ is, however, not as readily concentrated by the mammary system as I 131 and milk values continue to fall.

Protein-bound iodine values were obtained for serum and for milk from each half of the under, with and without the use of intravenous Pitocin. The results are illustrated in Table 1. There was considerable variation between the two halves of the udder with regard to PBI values. With a singlc exception, the PBI values obtained following Pitocin administration were higher than those prior to Pitocin, which might result from a decreased fluid content and a relatively higher solid constituent content following Pitocin administration. The left half of the udder in most of these animals had palpable evidence of induration, which may account for the generally lower PBI values on that side. The difference between the two halves is not as great following Pitocin administration and the reason for this is open to speculation. In most instances, milk PBI values were higher than serum PBI valucs.

TABLE 1。 Protein-Bound Iodine Values $(\mu \mathrm{g} / 100 \mathrm{ml})$ of Serum and Milk from. Right and Left Halves of Udder with or Without the Use of Pitocin Prior to Milking

\begin{tabular}{|c|c|c|c|c|c|}
\hline \multirow{2}{*}{$\begin{array}{c}\text { Sheep } \\
\text { No. }\end{array}$} & \multirow[b]{2}{*}{ Serum } & \multicolumn{2}{|c|}{$\begin{array}{c}\text { Milk } \\
\text { (no Pitocin) }\end{array}$} & \multicolumn{2}{|c|}{$\begin{array}{c}\text { Milk } \\
\text { (Pitócin) }\end{array}$} \\
\hline & & $\mathrm{R}$ & $\mathrm{L}$ & $\mathrm{R}$ & L \\
\hline 1 & 3.4 & 5.0 & 3.4 & 6.2 & 4.7 \\
\hline 2 & 3.7 & 5.8 & 3.2 & 3.5 & 4.6 \\
\hline 3 & 3.3 & 4.2 & 2.5 & 1.0 & 4.5 \\
\hline 4 & 4.1 & 3.9 & 4.4 & 4.4 & 4.6 \\
\hline
\end{tabular}




\title{
THYROID UPTAKE OF I $I^{131}$ FROM SKIN EXPOSURE
}

\author{
J. L. Murray*
}

a. The maximum thyroid uptake in young swine following exposure of $150 \mathrm{~cm}$ area of swine skin to I 131 vapor was about $0.2-0.4 \%$ of the deposited dose and occurred un the fifth day. Fullowing application of solution containing $I^{131}$ to a comparable area, allowing it to dry and then washing the area, peak thyyroid concentrations of $0.1 \%$ of the total dose deposited occurred by the second day. Over $95 \%$ of the radioiodine was removed by washing.

This study was undertaken to determine the uptake of $I^{131}$ vapor and solution through the skin of Hanford miniature swine and to compare these results with those from reports on human exposures.

Young swine, 2-9 months of age and weighing 10-30 kg, were used in this study because of their sparse hair coat and a skin comparable in thickness to that of man. Abdominal skin areas exposed were approximately $1.2 \mathrm{~mm}$ thick which is comparable to that on a man's forearm. H'lank skin varied from 2-10 mm thick.

Skin areas were clipped and washed one day prior to exposure. A.ll vapor exposures were conducted on anesthetized swine in a gloved box which also housed the generator apparatus and a 12 liter cylindrical lucite vapor chamber with a $150 \mathrm{~cm}^{2}$ opening for skin exposure. During each exposure of 20-25 min, three air samples were taken from the vapor chamber to estimate the $\mathrm{I}^{131}$ air concentrations. While in the gloved box, animals breathed room air through a tube in the gloved box wall.

. Some animals were exposed to $\mathrm{I}^{131}$ solution which was $85 \% \mathrm{I}_{2}^{131}$ and $15 \% \mathrm{NaI}^{131}$. The solution was spread over a $150 \mathrm{~cm}^{2}$ area of abdominal skin and allowed to dry. All skin areas, thyroid glands, and urine samples. were monitored with a scintillation probe containing a 2 in. $x 2$ in. NaI crystal. The skin areas were monitored immediately for initial deposiat tion;:" and daily thereafter... An air sample taken 6 in. over the neck of one

* Captain, USAF, VC, assigned to Hanford Laboratories. 
incumbent animal for $4 \mathrm{hr}$ following exposure to $\mathrm{I}^{131}$. vapor indicated a timeintegrated air concentration of $1.1 \times 10^{-6} \mu \mathrm{c}-\mathrm{sec} / \mathrm{cm}^{3}$. Even if this concentration were breathed for $24 \mathrm{hr}$, it still would not add significantly to the thyroid uptake from the skin exposure.

The exposure conditions are summarized in Table 1. Table 2 shows the results of the various exposures and treatments, and Figure 1 shows the changes in $\mathrm{I}^{131}$ activity with time for the group exposed to $\mathrm{I}^{131}$ vapor and the treated group exposed to $\mathrm{I}^{131}$ solution. The four animals exposed to $I^{131}$ vapor were not washed so that maximum uptake values would be obtained and sufficient thyroidal $\mathrm{I}^{131}$ was obtaired for accurate monitoring. Without washing, the peak thyroid uptakes were only $0.2-0.4 \%$ of the initial skin deposit. Other animals were washed to simulate human exposure conditions.

TABLE 1. Exposure Conditions

\begin{tabular}{lcccc}
\hline $\begin{array}{c}\text { Animal } \\
\text { No. }\end{array}$ & $\begin{array}{c}\text { Exposure } \\
\text { time } \\
(\mathrm{min})\end{array}$ & $\begin{array}{c}\text { I131 air } \\
\text { concentration } \\
\left(\mu \mathrm{c} / \mathrm{cm}^{3}\right)\end{array}$ & $\begin{array}{c}\text { Carrier } \mathrm{I}^{127} \\
(\mu \mathrm{gg} / \mathrm{\mu c})\end{array}$ & $\begin{array}{c}\% \mathrm{I}^{131} \\
\text { as vapor }\end{array}$ \\
\hline 1 & 20 & $1.2 \times 10^{-3}$ & 2.7 & 80 \\
2 & 23 & $1.2 \times 10^{-3}$ & 2.5 & 89 \\
3 & 25 & $2.4 \times 10^{-3}$ & 2.1 & 81 \\
4 & 25 & $1.9 \times 10^{-3}$ & 2.4 & 78 \\
\hline
\end{tabular}

* Percent of sample activity passing through the Type AA millipore filter.

The estimated loss of $\mathrm{I}^{131}$ from unwashed skin exposed to the vapor was over $80 \%$ during the first 7 days, probably due primarily to vaporization. Most noteworthy were the thyroid uptake curves which were almost identical at day one. While the thyroids of the washed animals reached peak uptake in 1-2 days, the thyroids of the unwashed animals continued to take up the $I^{131}$ through the fifth day, indicating a slow, gradual absorption of surface contamination. The thyroid uptakes in animals 6 and 9 agree favorably with a report of comparable human exposures by Harrison (Health Physics 9: 993,1963 ) which showed peak thyroid uptakes of $0.1 \%$ or less in all cases except one when a large amount of carrier $1^{127}$ was added. 
TABBLE 2. Results of $I^{131}$ Skin Exposures

\begin{tabular}{|c|c|c|c|c|c|}
\hline $\begin{array}{l}\text { Animal } \\
\text { No. }\end{array}$ & $\begin{array}{l}\text { Type of } \\
\text { exposure }\end{array}$ & $\begin{array}{l}\text { Site of } \\
\text { exposure }\end{array}$ & $\begin{array}{c}\text { Initial } \\
\text { deposit } \\
(\mu c)\end{array}$ & Treatment & $\begin{array}{l}\text { Peak thyroid } \\
\text { uptake (\% of } \\
\text { initial deposit) }\end{array}$ \\
\hline 1 & Vapor & Flank & 69 & None & 0.25 \\
\hline 2 & Vapor & Flank & 41 & None & 0.37 \\
\hline 3 & Vapor & Flank & 74 & None & 0.43 \\
\hline 4 & Vapor & Flank & 86 & None & 0.33 \\
\hline 5 & $\begin{array}{l}85 \% \mathrm{I}_{2}^{131} \\
\text { solution }\end{array}$ & Abdomen & 83 & $\begin{array}{l}\text { Washed at } 2 \mathrm{hr} \\
\text { (no soap) }\end{array}$ & 0.59 \\
\hline 6 & $\begin{array}{l}85 \% I_{2}^{131} \\
\text { solution }\end{array}$ & Abdomen & 91 & $\begin{array}{c}\text { Washed with soap } \\
\text { at } 2 \mathrm{hr}\end{array}$ & 0.15 \\
\hline 7 & $\begin{array}{l}85 \% \mathrm{I}_{2}^{131} \\
\text { solution }\end{array}$ & Abdomen & 77 & $\begin{array}{l}\mathrm{AgNO}_{3} \text { solution at } 2 \mathrm{hr} \\
\text { flushed with water }\end{array}$ & 0.30 \\
\hline 8 & $\begin{array}{l}85 \% \mathrm{I}_{2}^{131} \\
\text { solution }\end{array}$ & Abdomen & 89 & $\begin{array}{l}\text { None } \\
\text { (area covered with gauze) }\end{array}$ & 2.1 \\
\hline 9 & $85 \% \mathrm{I}_{2}^{131}$ & Abdomen & 93 & $\begin{array}{l}\mathrm{AgNO}_{3} \text { solution at } 2 \mathrm{hr} \\
\text { (washed with soap) }\end{array}$ & 0.15 \\
\hline
\end{tabular}

To evaluate the possible hazard of skin exposure to $I^{131}$ in air in the proper perspective, it should be compared with the hazard of inhaling that same air. It can be shown mathematically that the thyroid uptake from skin deposition will be approximately one-tenth of that from inhalation when the $I^{131}$ is primarily in the vapor form. This factor would apply to people working and residing in the vicinity of a nuclear facility. In a fallout situation, where $75 \%$ of the $\mathrm{I}^{131}$ is expected to be in particulate form, the factor would be much smaller.

Eisenbud and Wrenn (Health Physics 9: 1133, 1963) evaluated the exposure from a passing cloud of particulate $\mathrm{I}^{131}$ and estimated a person's thyroid burden from drinking milk produced in the same area would be approximately 50 times that from inhalation. Wehman (Health Physics 9: 1221 , 1963) made a similar comparison on two test releases, and calculated the ingestion dose to be at least 100 times the inhalation dose. On the basis of these comparisons, a skin exposure would be expected to contribute only $1 / 500-1 / 1000$ of the total thyroid burden following an atmospheric release of $I^{131}$. 


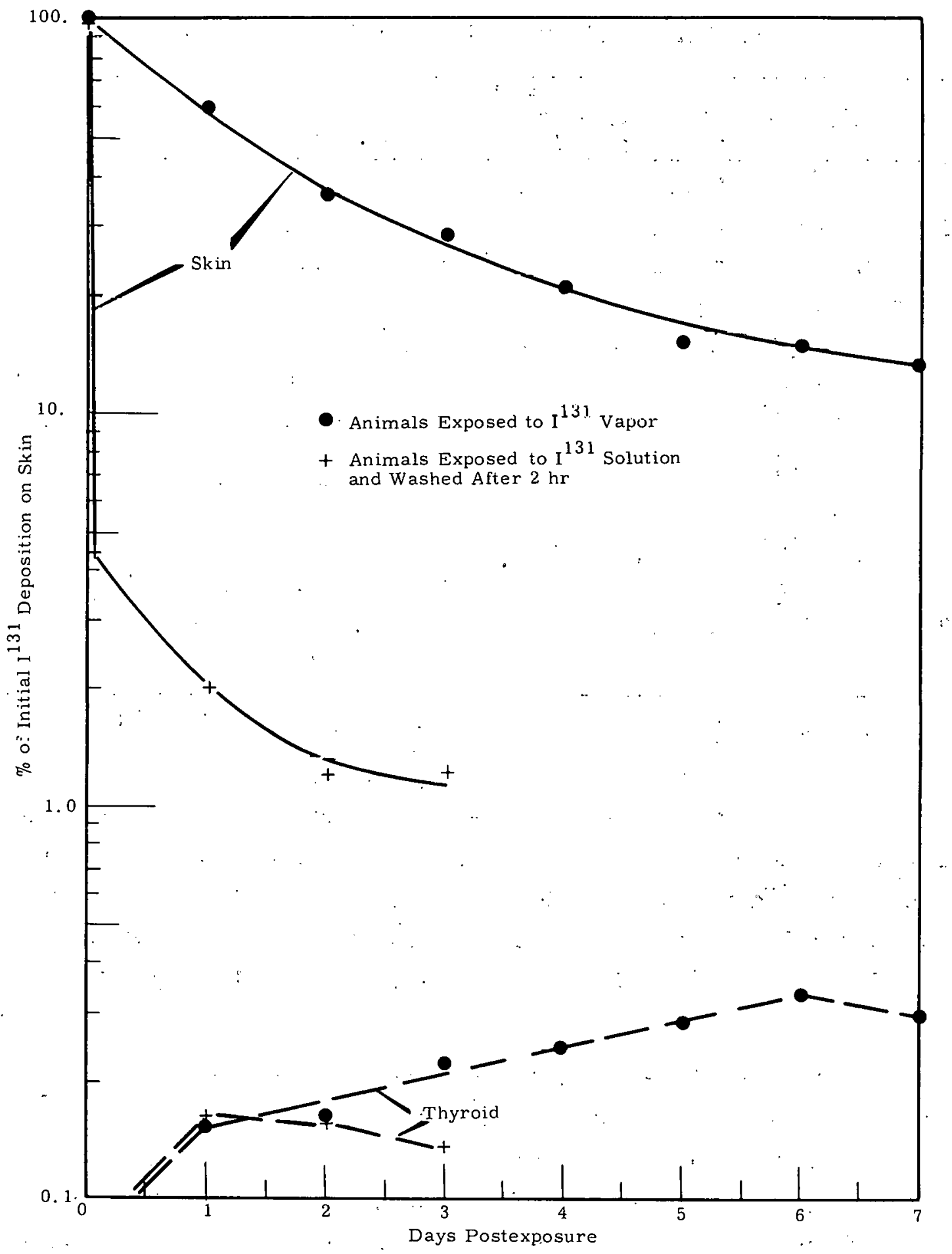

FIGURE 1. I ${ }^{131}$ Concentrations in Animals Exposed to $I^{131}$ Vapor with no Further Treatment, and Animals Exposed to $\mathrm{I}^{13}$ Solution and Washed After $2 \mathrm{hr}$ 


\title{
ANALOG COMPUTER EVALUATION OF TELLURIUM-IODINE
}

\section{CONTAMINATION EVENTS}

\author{
E. C. Watson, R. A. Harvey, ${ }^{* *}$ and L. K. Bustad
}

\begin{abstract}
Applications of analog computing for evaluating radinnuclide kinetics especially tollowing contamination events are discussed. A model was established limiting the compartments to total body, skin, lungs, gastrointestinal tract (stomach, small intestines, and large intestines), muscle, bone, thyroid, liver, and kidneys. These compartments would satisfy the needs of all of the elements that result from the fission of $\mathrm{U}^{235}$.
\end{abstract}

The study of radionuclide kinetics, especially parent-daughter relationships following a contamination event may be very complex. With the availability of an EASE' analog computer, however, we felt some of the complexities could be circumvented. Using this system, one can test the output in a few seconds, and vary both the initial assumptions and approximate parameters of the initial differential equations until a reasonable fit with experimental data is obtained. This analog computer is a differential analyzer with 200 operational amplifiers, 72 of which are integrators, so that under ideal conditions 72 independent variables can be handled simultaneously. Additional variables that are algebraically related to the independent variables can also be handled simultaneously with the above. In this report we summarize the application of the system to tellurium-iodine radionuclides kinetics following single and multiple administrations. Multiple administration consisted of daily intakes of both constant and decaying amounts. The compartments of the model are diagrammed in Figure 1.

The transfer coefficients for tellurium and iodine utilized in this model are listed in Table 1. Figure 2 shows the computer derived

* Radiation Protection Department

** Physics and Instruments Department

† Electronic Analog Simulation Equipment-2133, Beckman Instrument, Inc. 
$\mathrm{Te}^{132}-\mathrm{I}^{132}$ burdens in the several organs following a single intake by ingestion of $100 \mu \mathrm{Ci} \mathrm{Te}^{132}$, only, allowing the daughter $\mathrm{I}^{132}$ to build up as the parent decays.

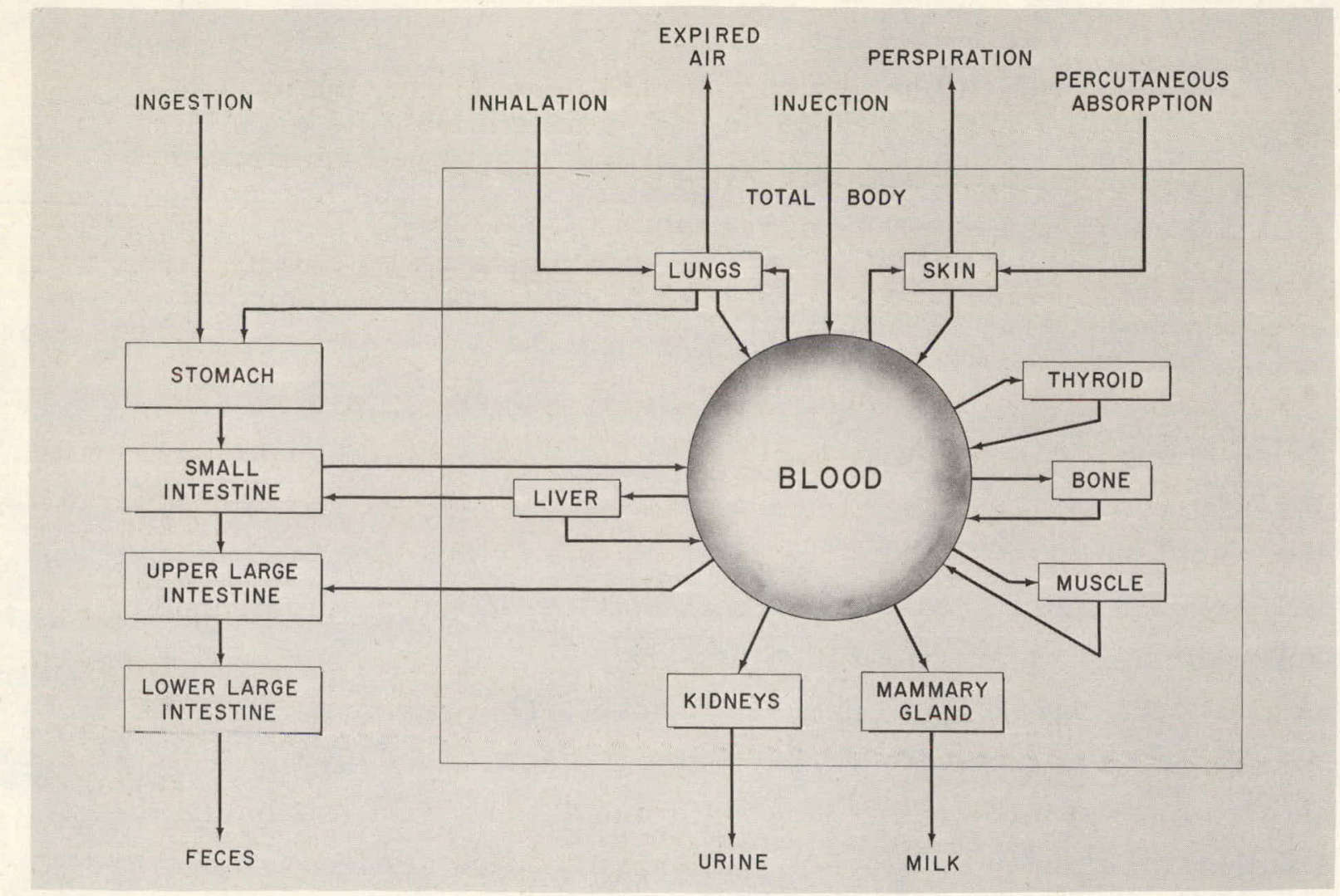

FIGURE 1. Analog Simulation Scheme for Mammals

One of the primary features of the model is the ability to accept multiple intakes either at a constant or a decaying rate. Figure 3 shows the time dependence of organ burdens as man ingests $\mathrm{Te}^{132}-\mathrm{I}^{132}$ (equilibrium) twice daily. The initial feeding is $100 \mu \mathrm{Ci} \mathrm{Te}{ }^{132}$ and $100 \mu \mathrm{Ci} \mathrm{I}{ }^{132}$; subsequent feedings both $\mathrm{Te}^{132}$ and $\mathrm{I}^{132}$ are decayed by the radiological half-life of $\mathrm{Te}^{132}$.

This model was designed as a general case for mammals. In the case of man the compartments include most of the organs of interest and all but two of those which the ICRP consider as the critical organs, 
i.e., testis and spleen. These two are the critical organs when the intake consists of the isotopes of sulfur or iron. In either case, adjustments can be made in the parametric values which will permit the model to be used for these organs.

TABLE 1. Fractional Transfer Rates in Man Following Ingestion of 'l'ellurium and Iodine*' (per hour)

\begin{tabular}{|c|c|c|}
\hline From blood to & Organs & To blood \\
\hline $\begin{array}{l}\text { N. A. } \\
\text { N.A. }\end{array}$ & Small intestine & $\begin{array}{l}0.0625 \\
0.75\end{array}$ \\
\hline $\begin{array}{l}0.00686 \\
0.00173\end{array}$ & Lungs & $\begin{array}{l}0.231 \\
0.231\end{array}$ \\
\hline $\begin{array}{l}0.00866 \\
0.00347\end{array}$ & Skin & $\begin{array}{l}0.632 \\
0.0253\end{array}$ \\
\hline $\begin{array}{l}0.000175 \\
0.0347\end{array}$ & Thyroid & $\begin{array}{l}0.00321 \\
0.000516\end{array}$ \\
\hline $\begin{array}{l}0.0156 \\
0.0121\end{array}$ & Bone & $\begin{array}{l}0.000966 \\
0.00207\end{array}$ \\
\hline $\begin{array}{l}0.0433 \\
0.0693\end{array}$ & Muscle & $\begin{array}{l}0.000292 \\
0.000292\end{array}$ \\
\hline $\begin{array}{l}0.0121 \\
0.00693\end{array}$ & Kidney & $\begin{array}{l}0.0 \\
0.0\end{array}$ \\
\hline $\begin{array}{l}0.00866 \\
0.0208\end{array}$ & Liver & $\begin{array}{l}0.000483 \\
0.00207\end{array}$ \\
\hline $\begin{array}{l}0.000175 \\
0.00173\end{array}$ & Upper large intestine & $\begin{array}{l}\text { N.A. } \\
\text { N.A. }\end{array}$ \\
\hline From stomach to & & $\begin{array}{c}\text { To upper } \\
\text { large intestine }\end{array}$ \\
\hline $\begin{array}{l}1.00 \\
1.00\end{array}$ & Small intestine & $\begin{array}{l}0.187 \\
0.0\end{array}$ \\
\hline From liver to & & $\begin{array}{c}\text { To lower } \\
\text { large intestine }\end{array}$ \\
\hline $\begin{array}{l}0.00048 \\
0.00207\end{array}$ & Small intestine & $\begin{array}{l}0.125 \\
0.125\end{array}$ \\
\hline
\end{tabular}

* First number of each pair is rate of Te transfer; second is rate of I transfer. 

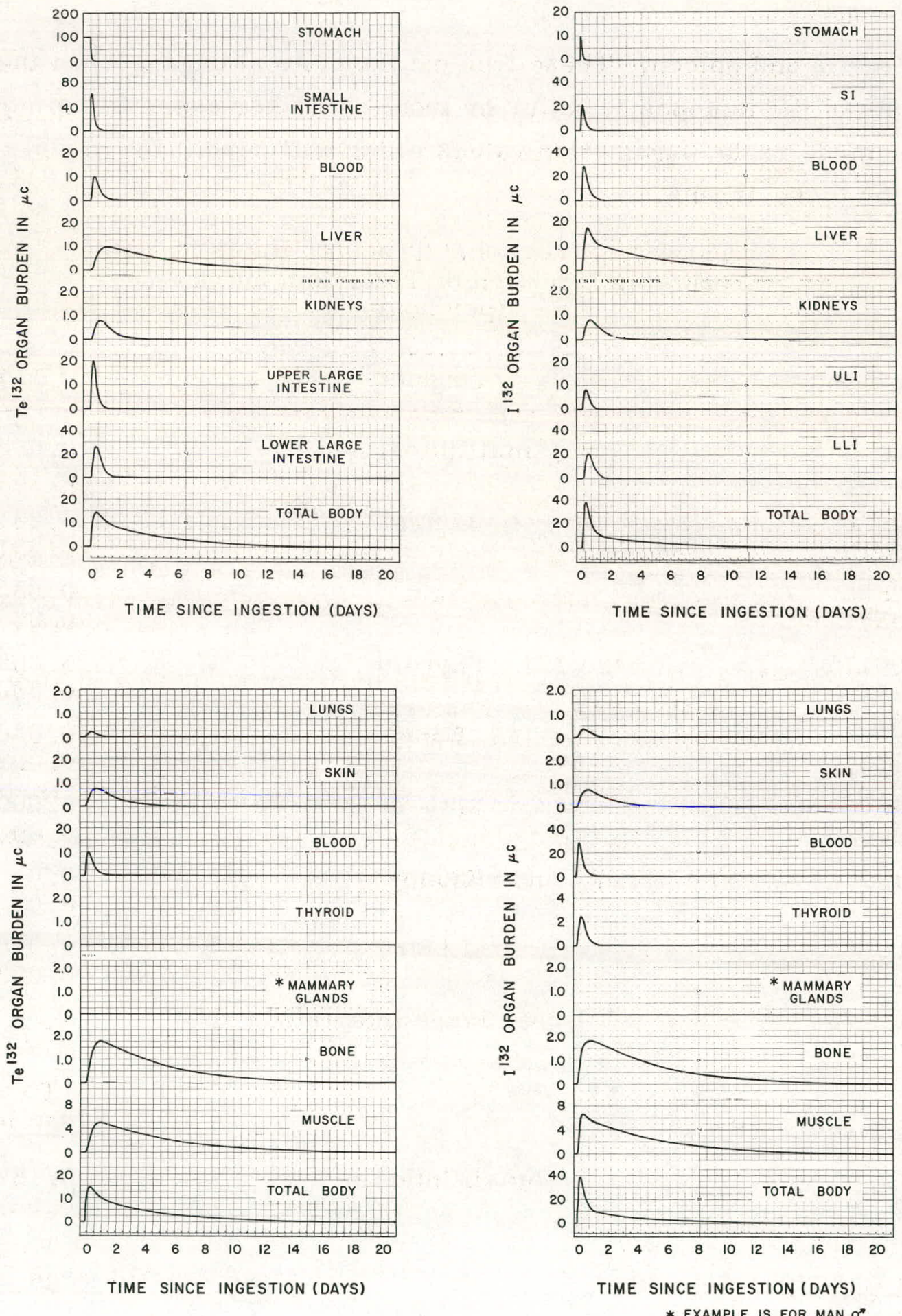
FIGURE 2. $\mathrm{Te}^{132}-\mathrm{I}^{132}$ Burdens of Selected Organs in Man
Following Ingestion of $100 \mathrm{MCi} \mathrm{Te}^{132}$ 


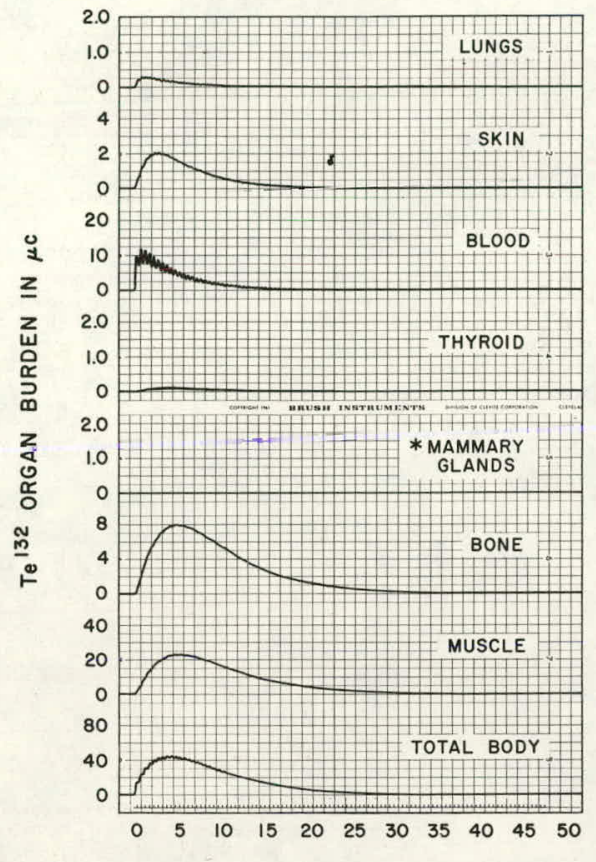

TIME SINCE INITIAL FEEDING (DAYS)

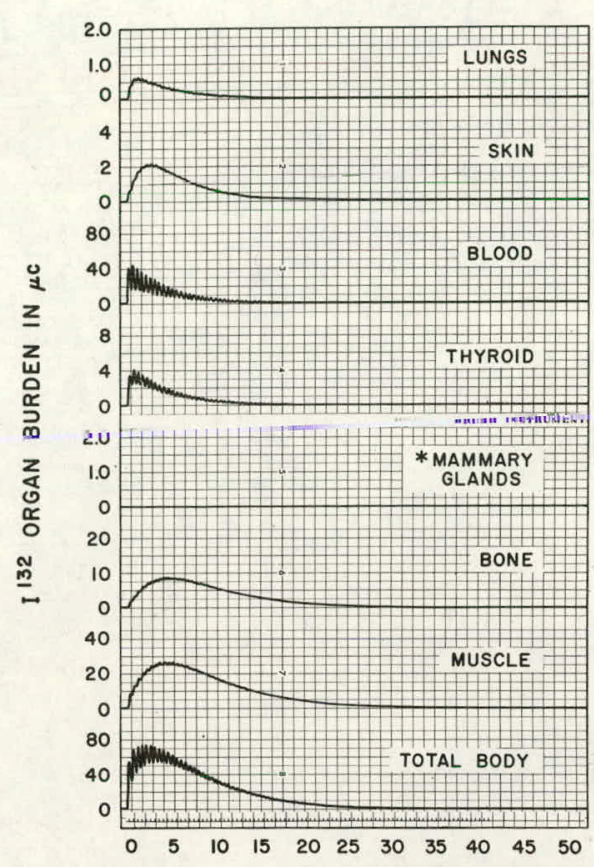

TIME SINCE INITIAL FEEDING (DAYS) * EXAMPLE IS FOR MAN o

FIGURE 3. $T \mathrm{Te}^{132}-\mathrm{I}{ }^{132}$ Burdens of Selected Organs in Man During Multiple Feedings
(Initial Feeding $100 \mu \mathrm{Ci} \mathrm{Te}$
Tw

It is anticipated that the model will be especially useful in studying the organ distribution of parent-daughter radionuclides such as cesiumbarium, strontium-yttrium, and ruthenium-rhodium. 


\section{RELATIONSHIP OF $\mathrm{Cs}^{137}$ CONCENTRATION} IN FEED AND RUMEN CONTENTS

R. O. Shannon, H. A. Ragan, and L. K. Bustad

A series of four studies were conducted with sheep to compare the $\mathrm{Cs} 137$ concentration in the rumen contents with that in the feed ingested. The $\mathrm{Cs}^{137}$ concentration in the rumen exceeded that in the feed in only those animals that received water on a regulated basis.

Recently the Radioecology Section found that the Cs ${ }^{137}$ concentrations of the rumen ingesta of wild ruminants (caribou, reindeer, moose) exceeded that of their diet. To explore this observation, a series of studies were initiated in sheep. Rumen fistulas were established in the paralumbar fossa of adult female Suffolk sheep. A solution of $\mathrm{Cs}^{137}$ was incorporated into a portion of the daily ration which consisted of chopped alfalfa hay. The $\mathrm{Cs}^{137}$ concentration was determined on a dry weight basis.

In the first study, two sheep were given feed containing $0.033 \mu \mathrm{Ci}$ of $\mathrm{Cs}^{137} / \mathrm{g}$ each morning. Rumen sampling was conducted $7 \mathrm{hr}$. after each daily feeding. Water was available at all times. At no time during this study did the $\mathrm{Cs}^{137}$ concentration in the rumen exceed that of the feed. The variation observed in the $\mathrm{Cs}^{137}$ concentration in the rumen contents is shown in Figure 1.

The second study utilized two sheep and resembled the first study except the animals were fed twice a day (morning and afternoon) and rumen samples were taken at varying time intervals. The results are compared with those from the first study in Figure 1. At no time during this experiment did the $\mathrm{Cs}^{137}$ concentration in the rumen exceed that in the feed.

In the third study, three sheep were given feed containing $0.025 \mu \mathrm{Ci}$ of $\mathrm{Cs}^{137} / \mathrm{g}$ feed each morning. Rumen sampling was conducted at the time of feeding and $7 \mathrm{hr}$ later. Water was available only during the period of rumen sampling. The results of the study are shown in Figure 2. It will be noted that on several occasions the $\mathrm{Cs}^{137}$ concentration in the rumen exceeded that in the feed. 
To evaluate the sampling method, one sheep was fed $\mathrm{Cs}^{137}$ spiked feed each morning. No rumen sampling procedures were conducted during. the feeding period and water was available at all times. The animal was euthanatized on the fourth day, $41 / 2 \mathrm{hr}$ after feeding. The rumen contents was thoroughly mixed and five representative samples were extracted. The $\mu \mathrm{Ci} \mathrm{Cs}{ }^{137} / \mathrm{g}$ rumen content did not exceed the $\mu \mathrm{Ci} \mathrm{Cs}^{137} / \mathrm{g}$ feed in any of the five samples.

It appears that restricted water intake exerts considerable influence on the $\mathrm{Cs}^{137}$ i concentration in the rumen. Only in the third study, where water intake was regulated, did the $\mathrm{Cs}^{137}$ concentration of rumen exceed that of the feed and then only in the afternoon samples ( $7 \mathrm{hr}$ after the last feed or water was consumed).

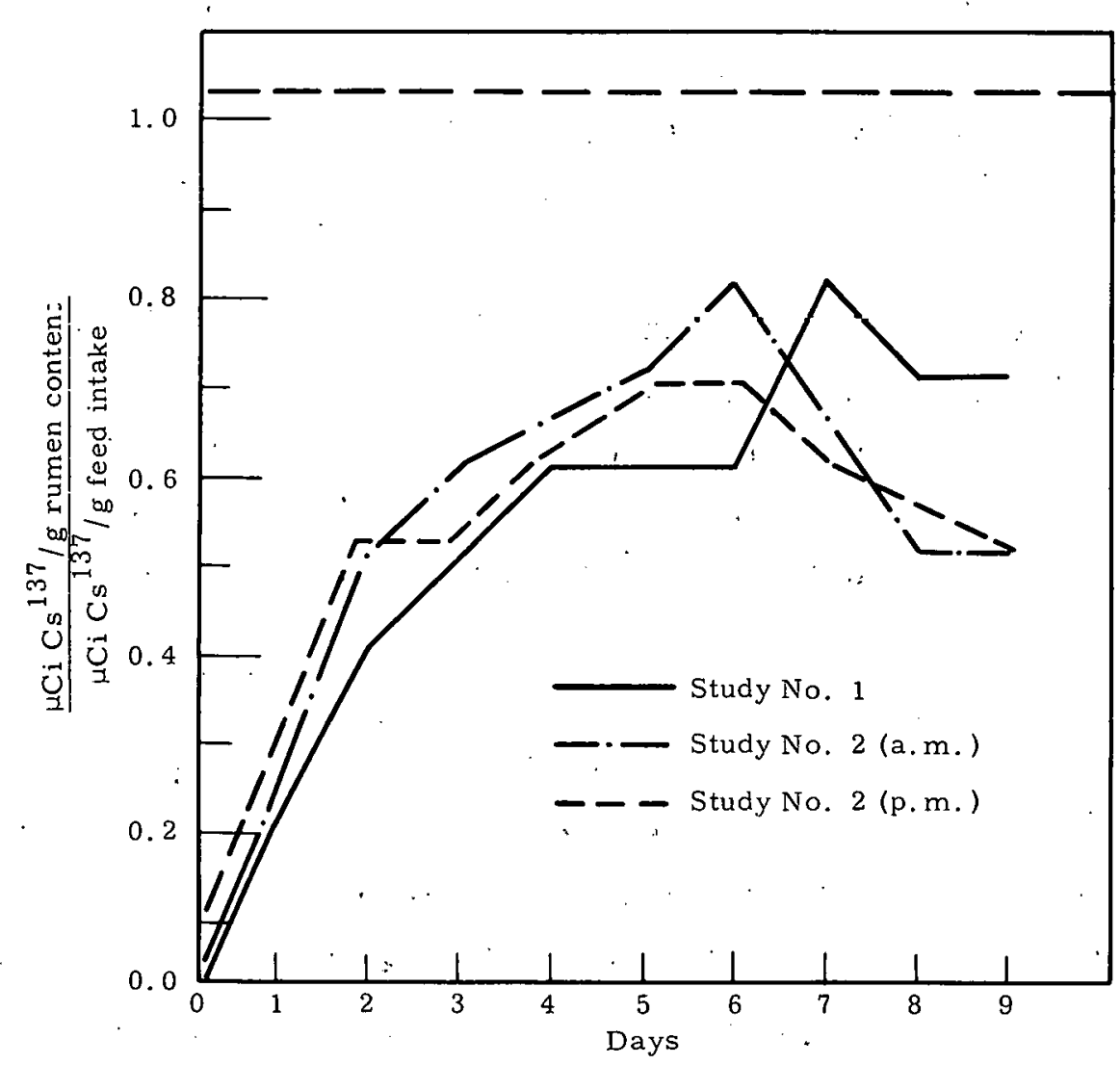

FIGURE 1. Ratio of Average $\mu \mathrm{Ci} \mathrm{Cs}^{137} / \mathrm{g}$ Rumen Content per $\mu \mathrm{Ci} \mathrm{Cs}{ }^{137} / \mathrm{g}$ Feed for Two Sheep Fed Once Daily (a.m.) and Sampled 7 hr later and Two Sheep Fed Twice Daily (12 hr intervals) and Sampling Conducted at Varying Time Intervals 


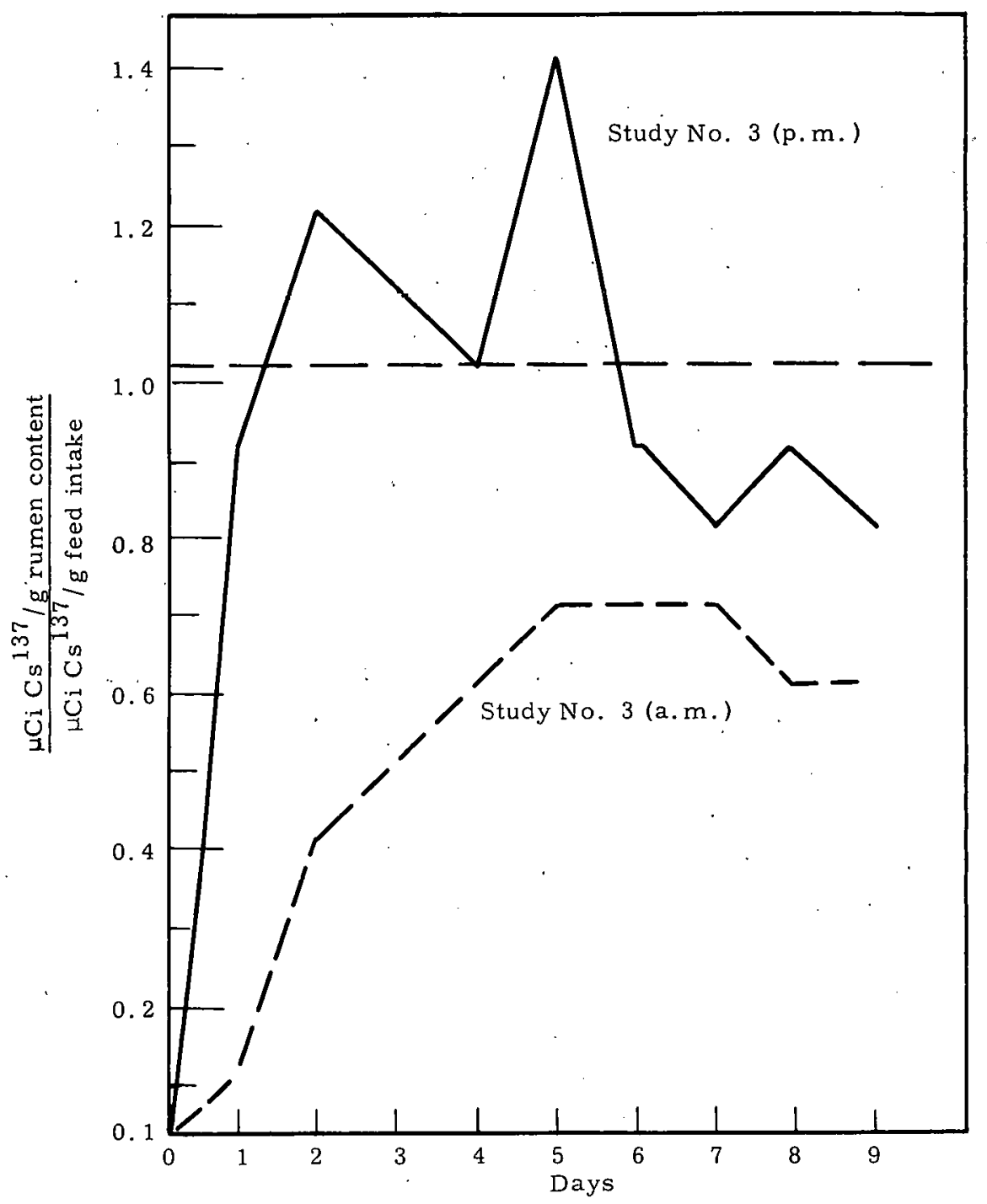

FIGURE 2. Average $\mu \mathrm{Ci} \mathrm{Cs}^{137} / \mathrm{g}$ Rumen Contents as Compared with $\mu \mathrm{Ci} \mathrm{Cs}_{\mathrm{s}} 137 / \mathrm{g}$ Feed in Three Sheep Fed Once Daily (a.m.) and Sampled Twice Daily (a.m. and $7 \mathrm{hr}$ later)

(Water was available twice daily.) 


\title{
RADIATION DOSIMETRY OF Cs ${ }^{137}$ IN SHEEP EVALUATED WITH THERMOLUMINESCENT DOSIMETERS
}

\author{
R. O. McClellan* and C. R. Watson
}

A thermnluminescent dosinetry system employing powdered lithium fluoride in Teflon capsules was evaluated and used to measure gamma radiation in vivo. Dose rates of less than $50 \mathrm{mr} /$ day were successfully measured in sheep ingesting $25 \mu \mathrm{Ci} \mathrm{Cs}{ }^{137 / d a y ~ w i t h ~ b o d y ~ b u r d e n s ~ a r o u n d ~} 400 \mu \mathrm{C} \dot{\text { }}$.

Preliminary observations have been made on the use of a thermoluminescent dosimetry system to obtain in vivo gamma radiation dose measurements. Lithium fluoride was used as the thermoluminescent material because of its energy independence, tissue-like quality and low fading rate. Specially constructed Teflon capsules were used to contain $55 \mathrm{mg}$ of LiF powder. The capsules have a wall thickness of $0.32 \mathrm{~cm}$ to effectively shield the LiF from the beta radiation of $\mathrm{Cs}^{137}$. Preliminary studies had indicated that it was difficult to calibrate thinner-walled capsules for use in measuring both gamma and beta radiation dose. Teflon was used for the capsules since it is well "tolerated when surgically implanted and has a tissue-like gamma cross section.

To provide animals that had equilibrium body burdens of $\mathrm{Cs}^{137}$, sheep were fed $25 \mu \mathrm{Ci}$ of $\mathrm{Cs}^{137} /$ day for more than a year. Body burdens of $\mathrm{Cs}^{137}$ were measured frcquently prior to and during the exposure using a whole body, counter (Figure 1).

The dosimeter capsules were surgically implanted in the abdomen and muscles 15 days, and attached to the skin 10 days, before the sheep were killed. The dosimeters ready for implanting, and in situ, are shown in Figure 2. Relatively little tissue reaction was apparent.

* Present address: Medical Research Branch, Division of Biology and Medicine, U.S. Atomic Energy Commission, Washington, D.C. 


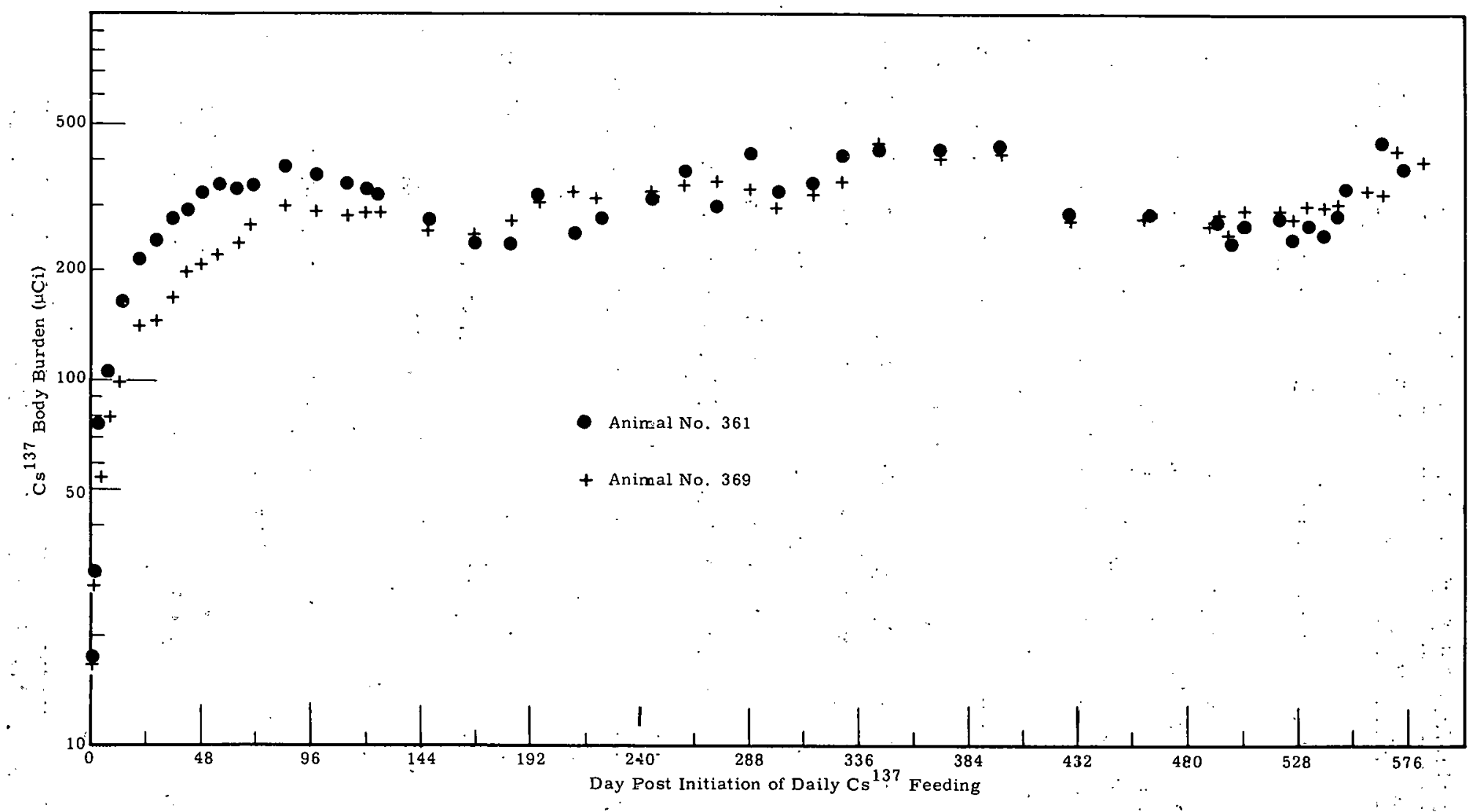

FIGURE 1. Whole Body $\mathrm{Cs}^{137}$ Measurements of Sheep Fed $25 \mu \mathrm{Ci} \mathrm{Cs}^{137}$ Daily (In vivo dosimetry measurements were made during the 15 days prior to the animals' sacrifice.) 

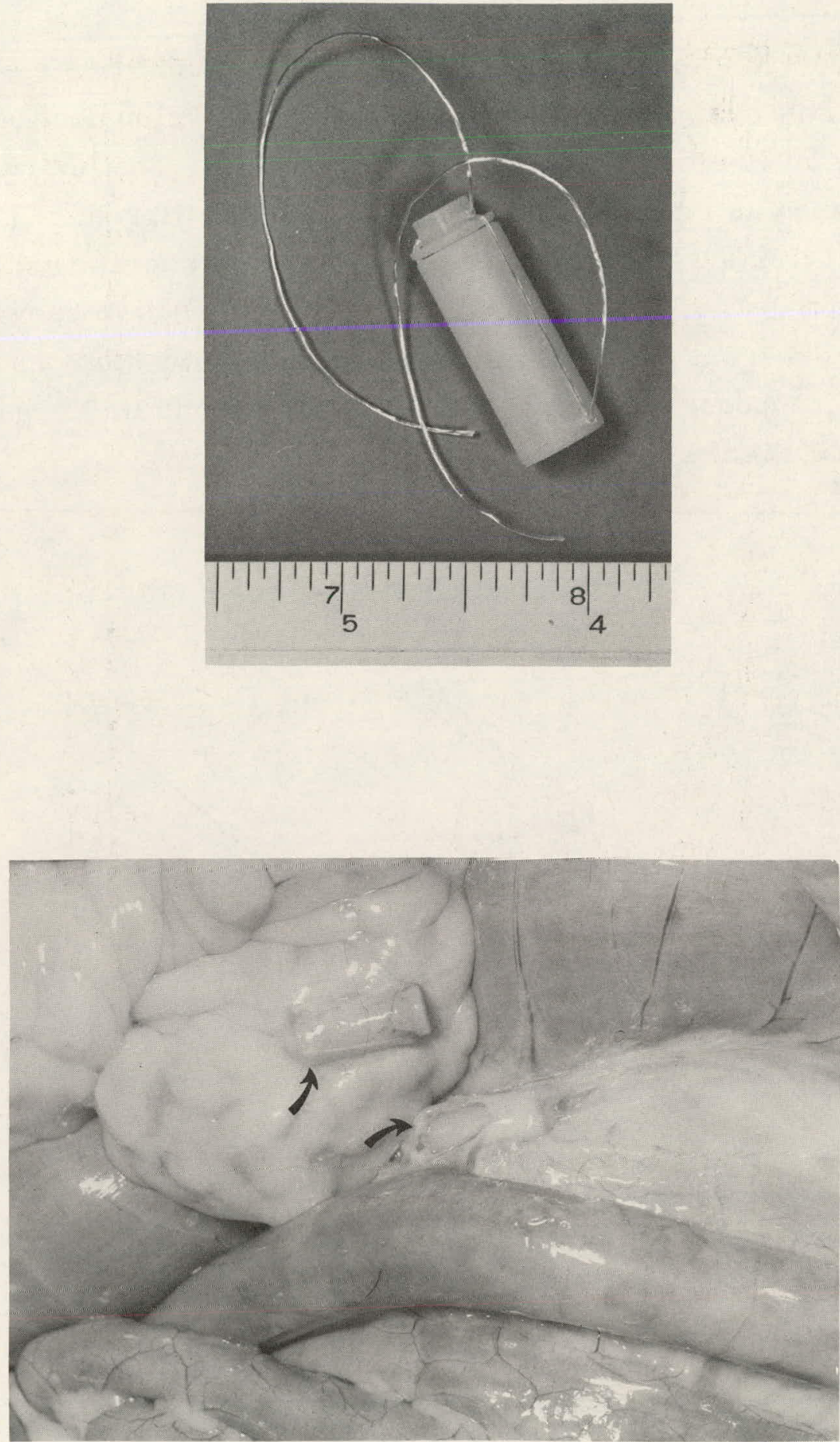

FIGURE 2. (Above) Teflon Dosimeter Containing LiF Ready for Surgical Implantation with $0.4 \mathrm{~mm}$ Vetafil Suture Attached (Below) Dosimeters in situ in the Mesentery (Note the minimal tissue reaction even though the dosimeters have been in place for 15 days.) 
BNWL-122

A "Controls for Radiation" Thermoluminescent Dosimetry System, modified to study low doses by the Radiological Development and Calibrations section at Hanford was used for LiF readout. The instrument results were expressed as integrated "Light Units" per milligram of LiF. Background corrections were made with readings from nonexposed samples of the same batch. Calibration dosimeters were exposed to known gamma radiation doses from a $\mathrm{Ra}^{226}$ source. A preliminary study had indicated that the $\mathrm{LiF}$ response was similar for both $\mathrm{Cs}^{137}$ and $\mathrm{Ra}^{226}$ gamma radiation. Typical results are shown in Figure 3.

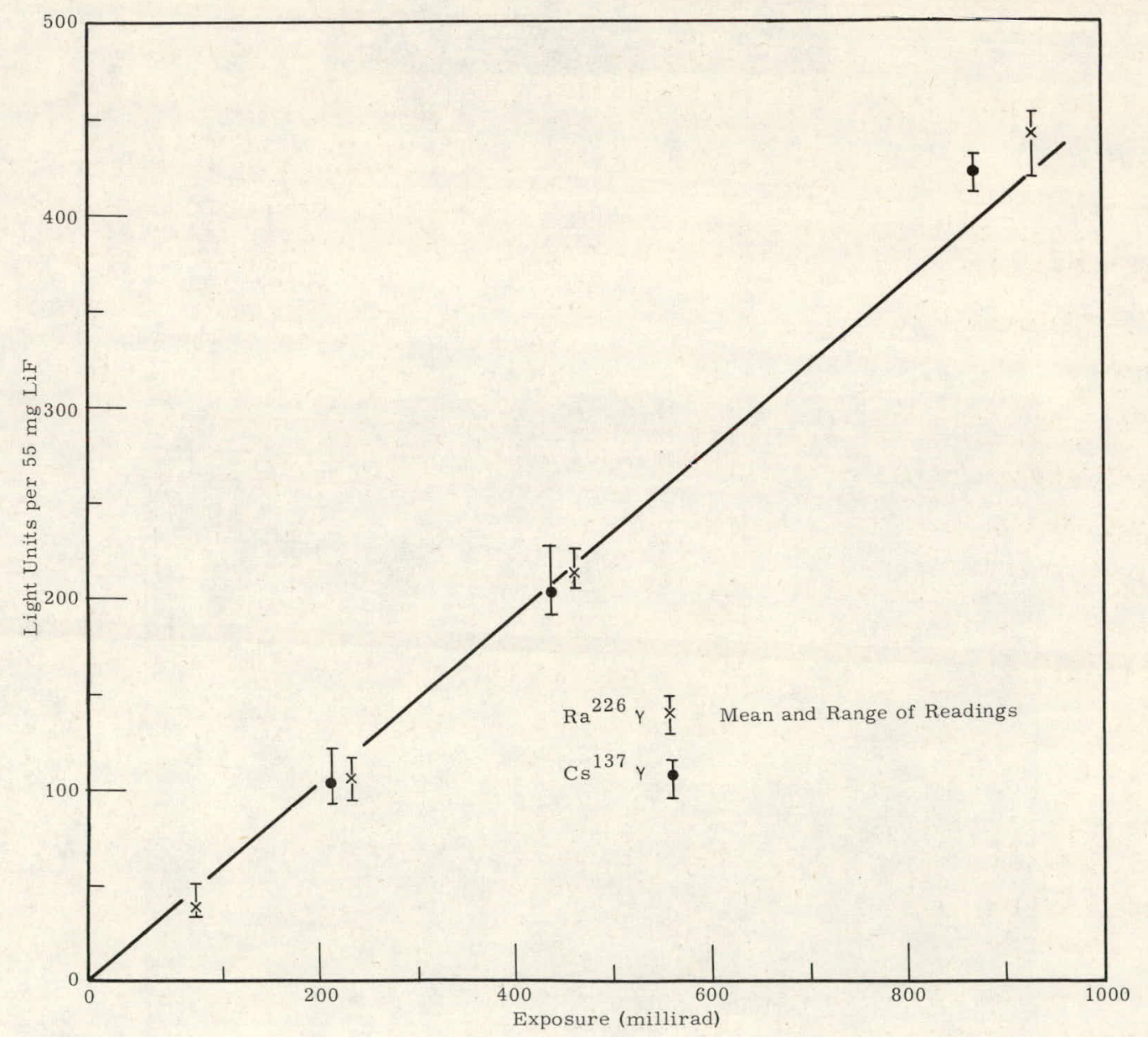

FIGURE 3. Response of LiF to Gamma Radiation from $\mathrm{Cs}^{137}$ and $\mathrm{Ra}^{266}$

The two male Suffolk sheep studied were approximately 2.25 years old, weighed $80 \mathrm{~kg}$ and had $\mathrm{Cs}^{137}$ body burdens of approximately $400 \mu \mathrm{Ci}$. Radiation dose rates for these animals are shown in Table 1. Gamma 
values were derived from LiF measurements and beta'doses were calculated using standard techniques and measured $\mathrm{Cs}^{137}$ tissue concentrations.

TABLE 1. Radiation:Dose Rates for Male Sheep Ingesting $25 \mu \mathrm{Ci} \mathrm{Cs}{ }^{137}$. Daily

(Expressed as mrad/day/mCi.Cs 137 Body Burden)

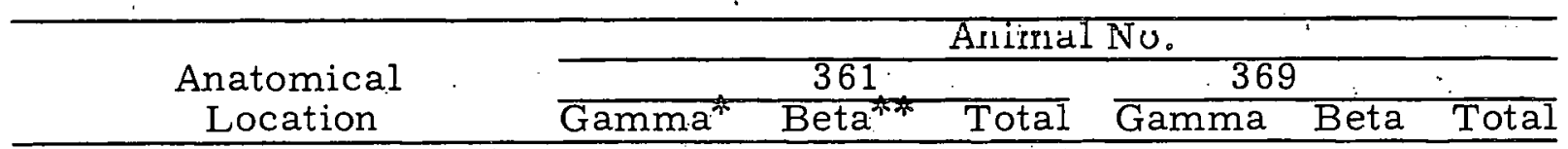

External

Mid-cervical

Anterior Lumbar

Over Sacrum

Flank

Muscle

Supraspinatus

Longisimus Dorsi

Gluteal

Viscera

Diaphragm

Rumen :Wall

Adjacent to Left Kidney

Small Intestine

Colon

Scrotum

Adjacent to

Testicle
Center of Excised
Testicle

Testicle
Center of Excised
Testicle

Testicle
Center of Excised
Testicle

Adjace
55

52

77

67

$\begin{array}{ll}85+ & --- \\ -- & 260 \\ 80^{\dagger} & 300\end{array}$

107

102

148

135

142
77

60

..-

.75

$\begin{array}{lll}140^{\dagger+} & 220 & 360 \\ 135^{+\dagger} & 260 & 395 \\ 155^{+\dagger} & .300 & 455\end{array}$

130

95

115

123

160

* Gamma doses evaluated with LiF dosimeters.

* Beta doses calculated from Cs 137 tissue concentrations.

$\dagger$ Dosimeters implanted superficially.

$\uparrow$ Dosimeters implanted deep.

Using the nomogram of Bertinchamps and Cotzias, a gamma dose rate at the center of an aqueous cylinder of $80 \mathrm{~kg}$ and containing $1 \mathrm{mCi}$ of $\mathrm{Cs}^{137}$ is estimated at $225 \mathrm{mrad} / \mathrm{day}$. The beta dose, assuming a uniform 
distribution, would be approximately $140 \mathrm{mrad} / \mathrm{day}$. The measured gamma doses are less than those calculated from the nomogram while the beta doses calculated from measured tissue concentrations are greater than those based on a uniform distribution. These differences may well be related to the nonuniform distribution of $\mathrm{Cs}^{137}$ in the body mass. The values obtained in this experiment are generally comparable to values obtained previously in short term experiments with $\mathrm{Cs}^{137}$ fed male sheep in which Victoreen ionization chambers were used (McCleilan, et al. Nature 194: 1145, 1962). The gamma dose to the gonads was less than that to some of the other body tissues, confirming the use of the whole body as the critical organ as defined by the N.C.R.P.

These preliminary studies have demonstrated the potential usefulness of LiF thermoluminescent dosimetry in determining gamma dose distributions in vivo for animals ingesting radionuclides. 


\section{METABOLISM OF $\mathrm{Cs}^{137}$ IN TROUT}

J. M. Dean; J. Eapen, and R. E。 Nakatani

Cesium-137 injected intravenously into yearling rainbow troilt was distributed uniformly through the soft tissues with the exception of the white muscle. The effective half-life of $\mathrm{Cs}^{137}$ in red muscle was $51 / 2$ days and in white muscle was 13 days.

The fact that $\mathrm{Cs}^{137}$ can be concentrated from the environment by aquatic organisms is well demonstrated. Past studies of the metabolism of $\mathrm{Cs}^{137}$ by components of the aquatic community have been largely based upon experimental introduction of $\mathrm{Cs}^{137}$ to the water or sampling of natural populations. By correlating these results with laboratory experiments, it is hoped that better conclusions may be drawn about the transfer and movement of $\mathrm{Cs}^{137}$ in the native populations.

Yearling rainbow trout (Salmo gairdneri) were injected intravenously with $10 \mu \mathrm{Ci}$ of $\mathrm{Cs}^{137}$ and sampled at $6 \mathrm{hr}$, and $1,2,3,7,10$, and 14 days postinjection. A minimum of three animals was used for each serial sacrifice. Samples were taken of the blood, opercle (bone), gill filaments, midgut, liver, kidney, and the three types of muscle, red, white, and cardiac. The activity of each sample and the remainder of the fish were determined.

Cesium-137 was evenly distributed throughout the tissue with the exception of bone which did not accumulate any measurable amount. However, there was an obvious difference in the metabolism of $\mathrm{Cs}^{137}$ by white muscle tissue. All other soft tissues showed a decrease in the isotope after $6 \mathrm{hr}$ (Figure 1). White muscle increased its $\mathrm{Cs}^{137}$ level until day 10 when it started to decline. The slopes of the regression lines computed for the interval days 3-14 for the soft tissues, with the exception of white muscle, were not significantly different from each other. The effective half-life for the soft tissues was $51 / 2$ days. White muscle had an effective half-life of 13 days. It has been reported that the more active metabolic tissues will concentrate and turn over $\mathrm{Cs}^{137}$ more rapidly than less active types. This appears to be the case for the three muscle tissues since the 
concentration in the cardiac muscle was higher than red muscle, which was correspondingly greater than white. Manometric and morphological studies support this concept as the $\mathrm{QO}_{2}(\mathrm{~N})$ for red muscle is higher than white muscle. Electron and light microscopy showed abundant mitochondria in cardiac and red muscle but few in white muscle.

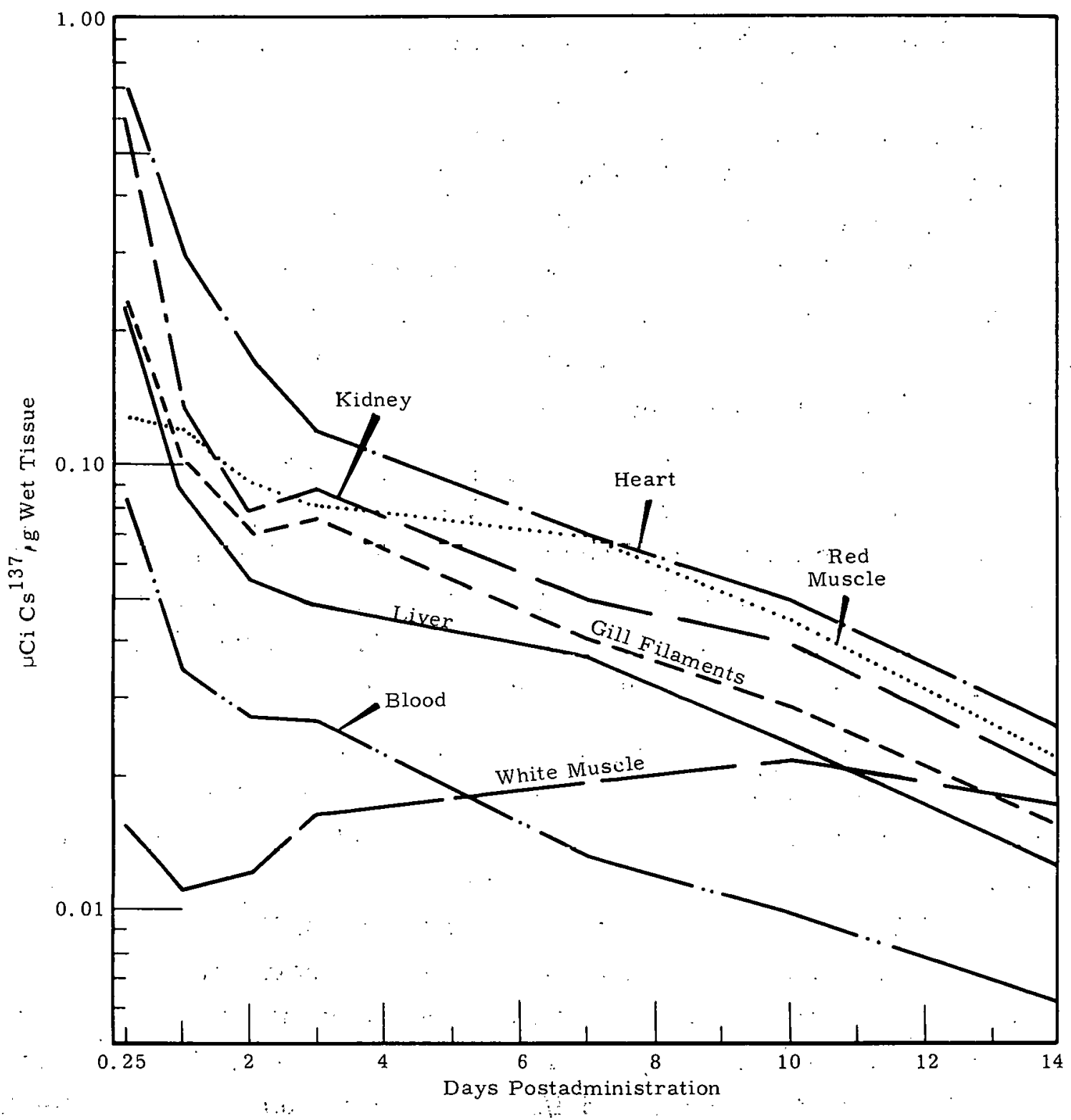

FIGURE 1. Concentration of $\mathrm{Cs}^{137}$. in Various Tissues of Rainbow Trout Injected Intravenously with $10 \mu \mathrm{Ci}$ 


\title{
LIVER DAMAGE FROM Np ${ }^{237}$ IN SHEEP
}

\author{
D. H. Wood*, J. L. Murray*, and J. L. Palotay
}

There was a close correlation between rose bengal liver function tests and the histopathologic changes found in serial liver biopsics from sheep following the intravenous administration of the hepatotoxic agent, $\mathrm{Np}^{237}$. The most severe cellular damage and the slowest blood clearance of the dye occurred the fourth day postinjection. Cellular repair was evident by the sixth day and was almost complete by the tenth day.

This study was designed to compare rose bengal dye blood clearance with cellular damage observed by histopathologic examination of serial liver biopsies from sheep. Neptunium-237 was used as a hepatotoxic agent because of its demonstrated chemical toxicity and because its alpha emission permitted determination of its cellular distribution by autoradiography.

Three groups of yearling Suffolk sheep (each group included one ram, one wether, and one ewe) were given an intravenous injection of $1.5 \mathrm{mg} / \mathrm{kg} \mathrm{Np}^{237}$ nitrate buffered to $\mathrm{pH} 4.5$ with sodium citrate. A group of three control sheep was given buffered solution without the $\mathrm{Np}^{237}$. Liver biopsies were taken from all animals in each group before $\mathrm{Np}^{237}$ administration and on the first, second, fourth, sixth, and eighth days postinjection. Rose bengal blood clearance tests were preformed before $\mathrm{Np}^{237}$ administration and on days $2,4,6,8$, and 10 as were plasma levels of isocitric dehydrogenase (ICD). The ICD levels were chosen to determine if it would be a more sensitive and reliable endpoint for cell damage than histological examination.

Comparison of rose bengal clearances was made on the basis of the dye concentration in the blood 20 min after administration. A slight increase in dye retention was usually noted on the second day after $\mathrm{Np}^{237}$ administration, with maximum levels invariably attained on the fourth day. By the tenth day, clearances were approaching control values in

* Captain, USAF, VC, assigned to Hanford Laboratories. 
most animals (Figure 1). Early cellular changes were noted after $24 \mathrm{hr}$ and included cloudy swelling, hyalinization of the cytoplasm of some of the hepatic cells, obliteration of the sinusoidal spaces, and foci of nuclear debris. On the second day after $\mathrm{Np}^{237}$ administration, single alpha tracks appeared to be scattered randomly in the autoradiographs of the

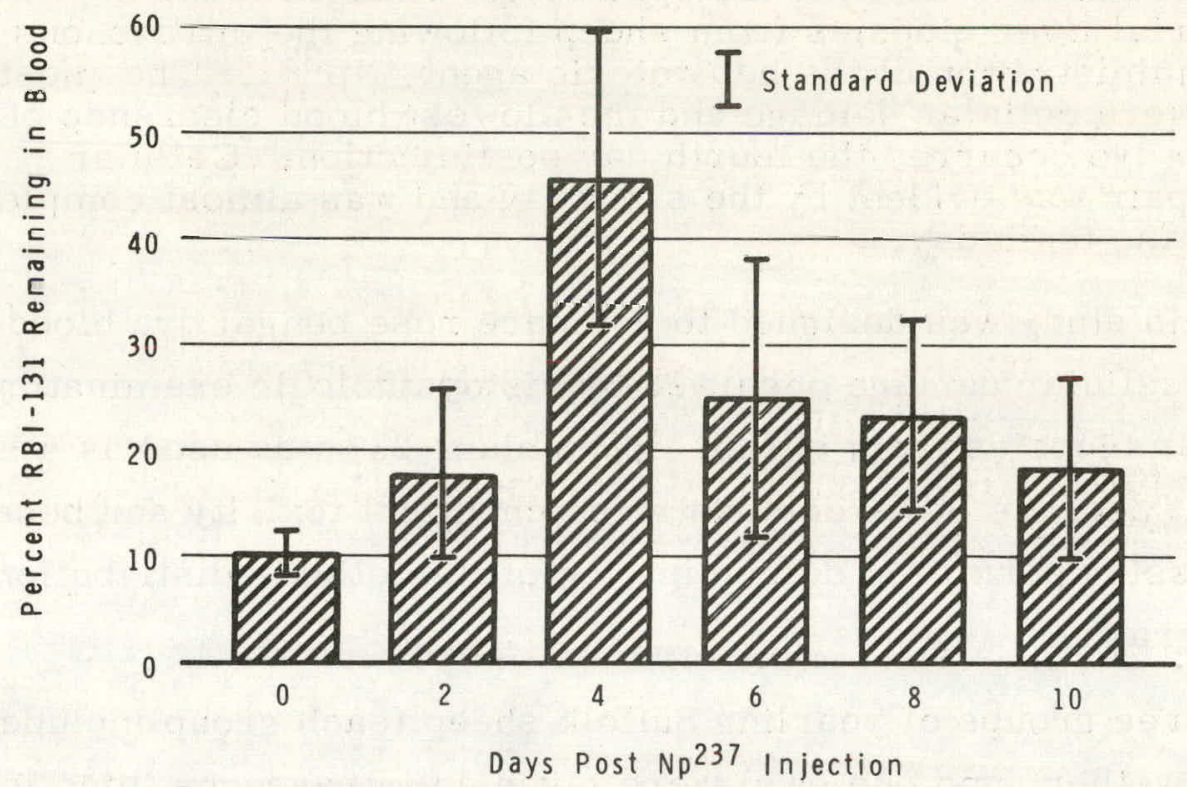

FIGURE 1. Average Rose Bengal-I ${ }^{131}$ Blood Clearance Values of Eight Sheep, Based on Percent Remaining After 20 min

liver, indicating a diffuse distribution of the isotope in ionic form. By this same time, necrosis of hepatic cells and disruption of their normal cord-like arrangement was evident (Figure 2). Degenerative changes reached a maximum on the fourth to sixth day with necrosis of $50-80 \%$ of all hepatic cells (Figure 3 ). The period of maximum vissible cellular damage corresponded closely to that of lowest rose bengal clearance. The diffuse distribution of $\mathrm{Np}^{237}$ persisted until the sixth to eighth day when a greater concentration of tracks were seen toward the periphery of the lobules. By the sixth day, regeneration and repair were clearly evident beginning with the gradual disappearance of the erythrocytes from the perilobular areas and replacement by mononuclear cells. By the eighth 


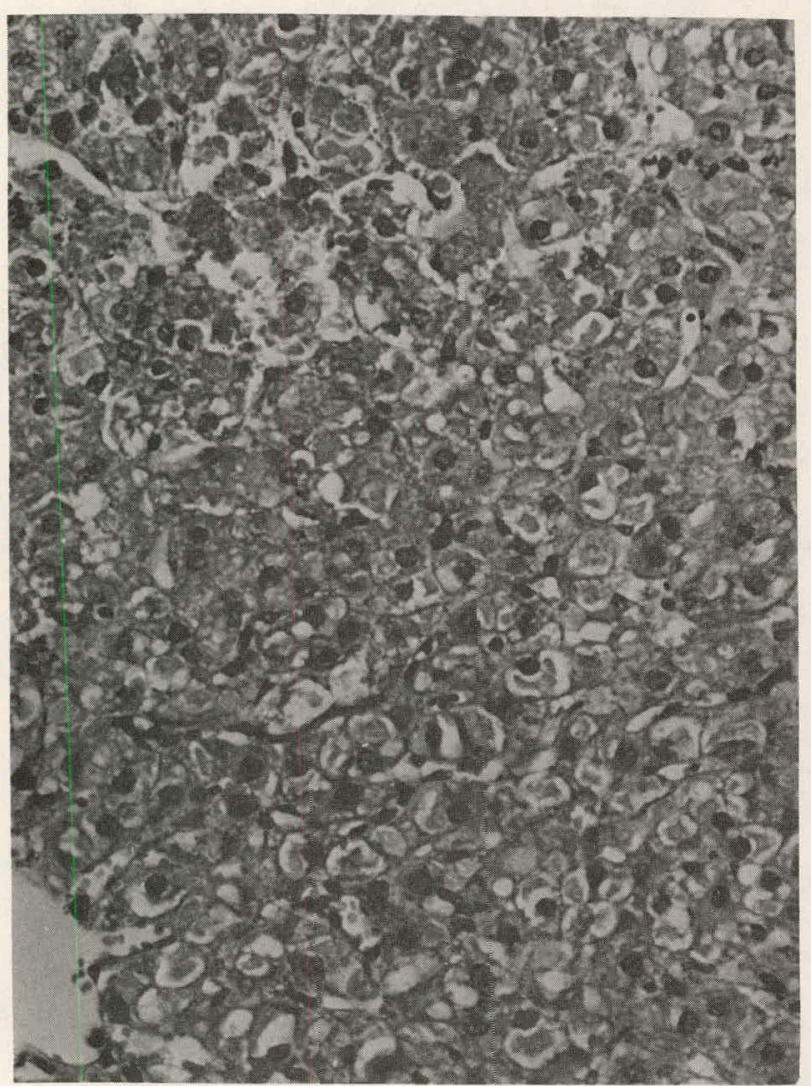

FIGURE 2. (Day 2) Necrosis of Hepatic Cells, Nuclear Debris, and Eosinophilic Globules

Can Be Seen in the Liver of Sheep $48 \mathrm{hr}$ Postinjection with NP237

(H\&E Stain 224X)

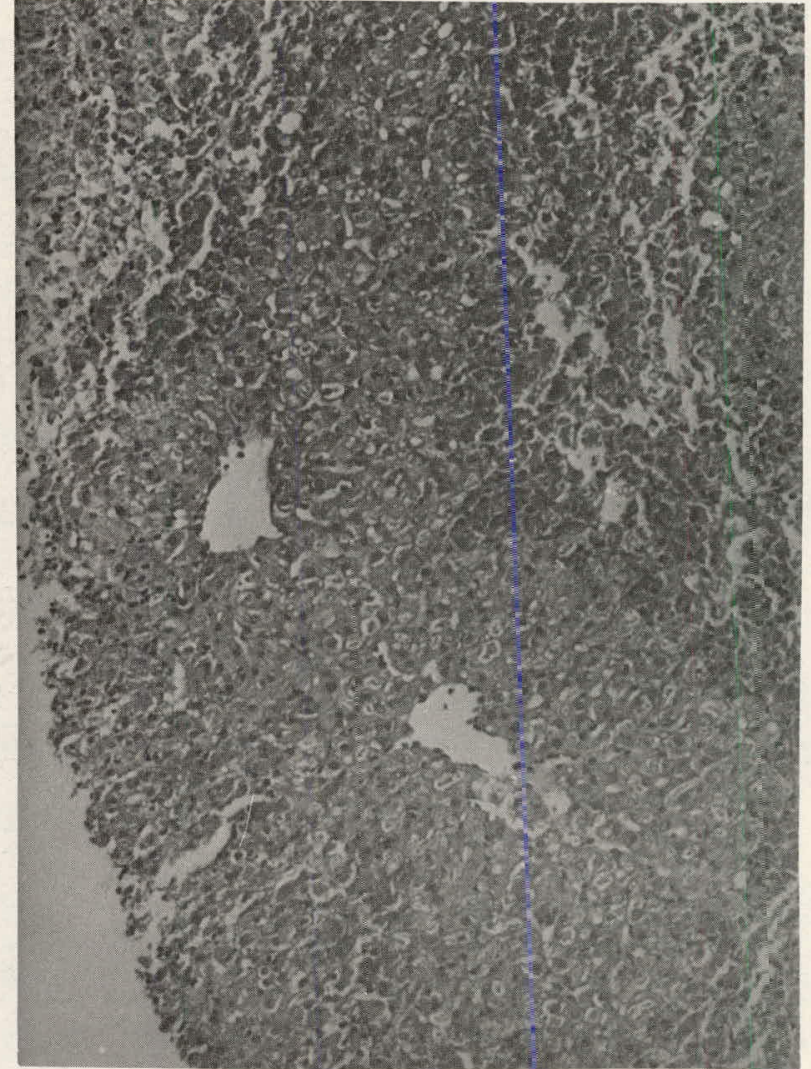

FIGURE 3. (Day 4) Necrosis and Filling In with RBC's Is Evident at the Periphery

of the Hepatic Lobules

in a Sheep Given NP
(H\&E Stain 88X) 
BNWL-122

day, alpha tracks appeared to originate from Kupffer and other reticuloendothelial-type cells. Hypertrophy and hyperplasia of hepatic cells, as evidenced by the appearance of enlarged nuclei, binucleate forms and mitotic figures were accompanied by a gradual increase in rose bengal clearance. By the tenth day postadministration, most liver sections showed extension of the restorative processes, but some neutrophils and mononuclear cells remained, and some residual damage was still noticeable. No sex difference in degree of toxicity could be seen between ewes, wethers and rams, as described by Mahlum between male and female rats (Hanford Biology Annual Report for 1963).

Clinically, most animals became moderately anorectic, were depressed and had low grade fevers $\left(104-105^{\circ} \mathrm{F}\right.$ ) from the second to eighth days after $\mathrm{Np}^{237}$ administration. Mild to moderate icterus was common from the fourth to the tenth days. Close correlation could be made in individual animals between degree of tissue damage and rose bengal clearance on corresponding days. All animals had increased ICD levels, beginning as early as $24 \mathrm{hr}$ after $\mathrm{Np}^{237}$ administration, but no consistent patterns could be seen. 


\title{
EFFECT OF DIETARY AND HORMONAL MANIPULATIONS ON Np ${ }^{237}$-INDUCED FATTY LIVERS
}

\author{
D.D. Mahlum
}

Liver fat accumulation induced hy injection of $\mathrm{N \mu} \mathrm{p}^{237}$ into female rats can be reduced by prior hypophysectomy or adrenalectomy. Oral administration of glucose or butylated hydroxytoluene also resulted in a decreased fatty response to $\mathrm{Np}^{237}$. Thyroidectomy, ovariectomy, and testosterone treatment were without effect in female rats. Castration or injection of estradiol did not render the male more susceptible to $\mathrm{Np}^{237}$-induced fatty livers.

Neptunium-237 has been shown to be a potent hepatotoxin causing fat accumulation in the liver of female rats (Hanford Biology Report for 1963). Fatty livers induced by other toxic agents have been shown to respond to certain surgical manipulations such as hypophysectomy, adrenalectomy, thyroidectomy, castration, and ovariectomy. Dietary alterations may also modify the fatty liver response produced by some hepatotoxins. Some dietary and surgical manipulations were tested on $\mathrm{Np}^{237}$-induced fatty livers to compare the action of $\mathrm{Np}^{237}$ with other hepatotoxins.

Surgically treated and normal rats were obtained from Charles River Company. Neptunium-237 was administered intravenously as the citrate complex, $\mathrm{pH} 4.0-4.5$ and livers removed 24 or $48 \mathrm{hr}$ after $\mathrm{Np}^{237}$ administration for fat determination.

Figure 1 shows the effect of the surgical and dietary treatments that decreased the fatty liver response to $\mathrm{Np}^{237}$. Adrenalectomy and hypophysectomy reduced liver fat accumulation as did glucose and butylated hydroxytoluene (BHT) administered intragastrically following $\mathrm{Np}^{237}$ treatment. Adrenalectomy, hypophysectomy, and glucose feeding have been shown by others to protect against cerium-induced fatty livers while an antioxidant mixture containing BHT reduced the liver fat response to ethanol intoxication. 


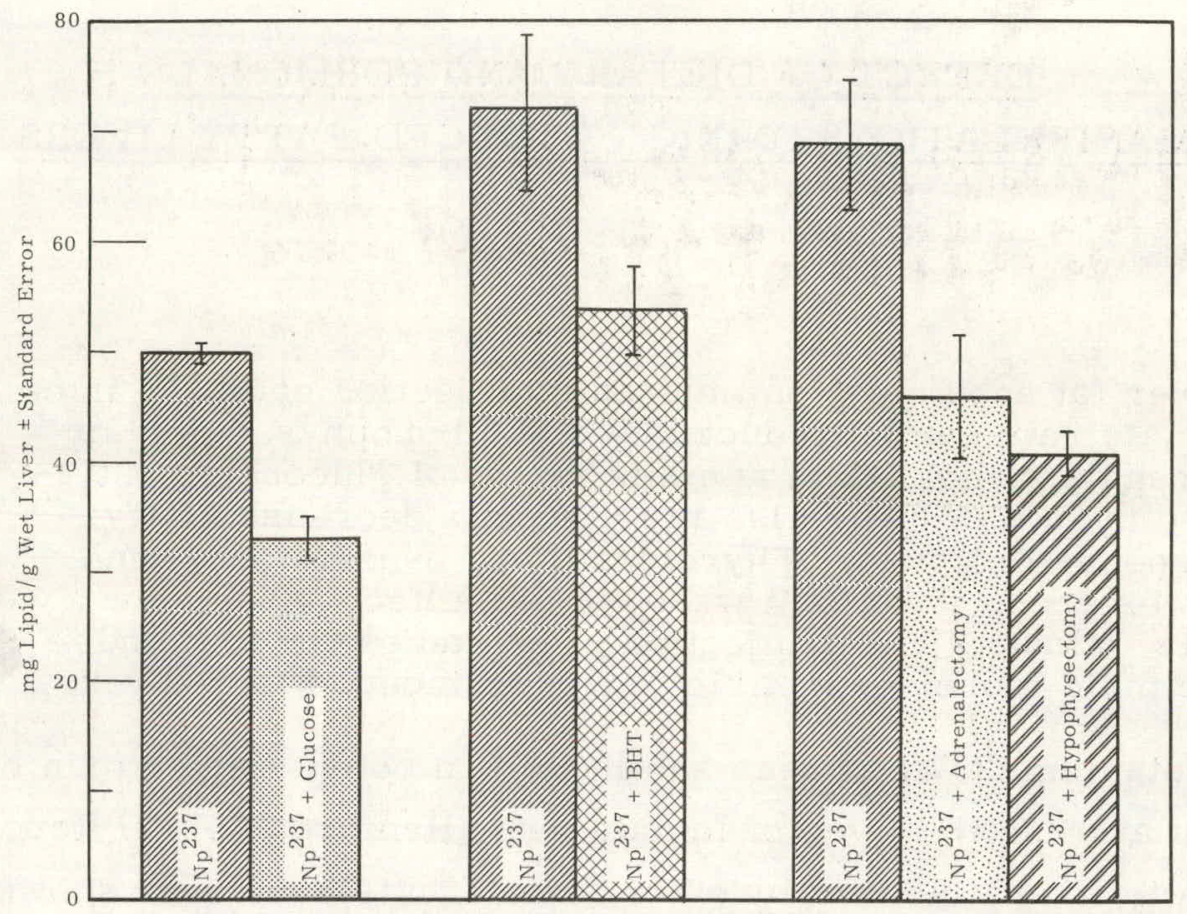

FIGURE 1. Protective Effect of Some Surgical and Nutritional Treatments on $\mathrm{Np}^{237}$-Induced Fatty Livers

Thyroidectomy and ovariectomy failed to decrease the sensitivity of female rats to $\mathrm{Np}^{237}$-induced fatty livers as did injections of testosterone given for 10 days prior to $\mathrm{Np}^{237}$ administration. Neither castration or estradiol injections increased the sensitivity of male rats to $\mathrm{Np}^{237}$-induced fatty livers.

Female rats fed large quantities of a choline-methionine mixture (known lipotropic substances) or adenine sulfate, which protects against fatty livers produced by ethionine and orotic acid, for 10 days prior to $\mathrm{Np}^{237}$ treatment had as much liver fat as those that received the control diet before $\mathrm{Np}^{237}$ administration. Injections of choline and methionine after $\mathrm{Np}^{237}$ injection were also ineffective.

The effects of nutritional and hormonal alterations indicate that the hepatotoxic action of $\mathrm{Np}^{237}$ is complex, involving effects other than just direct cellular destruction of the liver. Furthermore, $\mathrm{Np}^{237}$-induced fatty livers show some differences as well as certain similarities to fatty livers produced by other hepatoxins. 
TRANSSLOCATIÓN OF SUBCUTANEOUSLY ADIMINISTERED Pu ${ }^{239} \mathrm{O}_{2}$

B. J: McClanahan and H. A.: Ragan

The amount of plutonium deposited in soft tissues following subcutaneous injections of $\mathrm{Pu}^{239} \mathrm{O}_{2}$ was about one-hundreth of lhid deposiled when $\mathrm{Hu}^{239}$ nitrate was injected. The regional lymph nodes were an exception, accumulating up to one-half as much when $\mathrm{Pu}^{2} 39 \mathrm{O}_{2}$ was injected as when $\mathrm{Pu} 239$ nitrate was injected.

In an continuation of earlier work (Hanford Biology Research Annual Report for 1962), swine were injected subcutaneously with $\mathrm{Pu}^{239} \mathrm{O}_{2}$ to obtain preliminary data on the extent of plutonium translocation to various tissues. Blond miniature swine were injected with $3.5 \mu \mathrm{Ci}$ of $\mathrm{Pu}^{239} \mathrm{O}_{2}$ in $0.01 \mathrm{ml}$ of $0.1 \%$ polypropyleneglycolethyleneoxide polymer in each foreleg at each of two sites. The animals were sacrificed 1, 7, 30, 60, and 90 days after injection. Table 1 summarizes the data available on the $\mathrm{Pu}{ }^{239}$ content of tissues taken from the animals sacrificed one and seven days after injoction.

TABLE 1. $\mathrm{Pu}^{239}$ in Tissues of Swine (in percent of injected dose)

\begin{tabular}{|c|c|c|}
\hline & $\frac{\text { Days after }}{1 *}$ & $\frac{\text { injection }}{7 * * 2}$ \\
\hline Liver & 0.0094 & 0.015 \\
\hline Kidney & 0.00058 & 0.00056 \\
\hline Spleen & 0.00029 & 0.00054 \\
\hline Injection site & 40 & 45 \\
\hline Regional lymph nodes & 1.1 & 7.1 \\
\hline
\end{tabular}

The quantity of $\mathrm{Pu}^{239}$ translocated to the soft tissues was larger by a factor of approximately 100 when the plutonium was administered as the nitrate (Hanford Biology Research Annual. Report for 1963). A notable exception was the regional lymph nodes which accumulated a substantial 
82

BNWL- 122

quantity of the oxide. The lymphatic system is apparently the major route of translocation for $\mathrm{Pu}^{239}$ administered as the oxide. Further data to be obtained from this study should aid in the evaluation of the potential hazard of skin wounds contaminated with $\mathrm{Pu}^{239} \mathrm{O}_{2}$. 


\section{EFFECT OF SPLENECTOMY ON ACUTE PLUTONIUM TOXICITY}

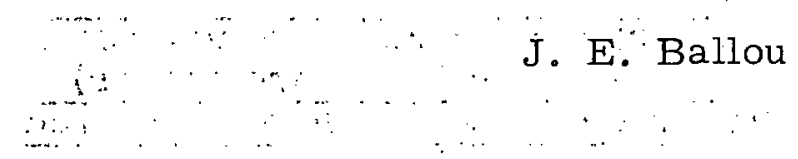

The survival time of rats injected intravenously with either $\mathrm{Pu} 238$ or $\mathrm{Pu}^{239}$ was not altered by prior splenectomy. This would seem to eliminatc spleen damidge as a critical factor in explaining the greater acute toxicity of $\mathrm{Pu} 239$.

Previous studies have demonstrated marked differences in the pattern of acute toxicity following intravenous injection of equal microcurie amounts of $\mathrm{Pu}^{238}$ and $\mathrm{Pu}^{239}$ in rats (Hanford Biology Reports for 1962 and 1963). These studies indicated that the greater toxicity of $\mathrm{Pu}^{239}$. was probably related to the greater mass of $\mathrm{Pu}^{239}$ involved $(1 \mu \mathrm{Ci}$ of $\mathrm{Pu}^{239}$ weighs about 270 times as much as $1 \mu \mathrm{Ci}$ of $\mathrm{Pu}^{238}$ ), but probably did not involve any factor of direct chemical toxicity. It seemed most likely that the different toxicities were explainable in terms of different distributions of the two isotopes among body organs, the distribution being influenced by the mass of material involved. It was observed that initial deposition of $\mathrm{Pu}^{239}$ in the spleen was several times greater than that of $\mathrm{Pu}^{238}$ (as percent of injected dose) and that histopathologic damage to the spleen was greater in the case of $\mathrm{Pu}^{239}$.

The present experiment was designed to check upon the possibility of critical involvement of the spleen in this problem. Rats were splenectomized three weeks prior to intravenous injection of $\mathrm{Pu}^{238}$ or $\mathrm{Pu}^{239}$ as citrate solutions. Details of the experiment and the results obtained are shown in Table 1.

Clearly, there was no significant effect of splenectomy on survival time in the case of either $\mathrm{Pu}^{238}$ or $\mathrm{Pu}^{239}$ injection. The spleen, and its possible role in extramedullary hematopoiesis, would therefore seem to be an unimportant factor in the acute toxicity of these radionuclides. The liver, which also accumulates a greater proportion of $\mathrm{Pu}^{239}$ than of $\mathrm{Pu}^{238}$ may offer a more likely explanation for the observed toxicity differences. 
84

BNWL- 122

: TABLE 1. Effect of Splenectomy on Acute Toxicity of $\mathrm{Pu}^{238}$ and $\mathrm{Pu}^{239}$ in Rats

\begin{tabular}{|c|c|c|}
\hline \multirow[b]{2}{*}{ Isotope administered } & \multicolumn{2}{|c|}{$\begin{array}{l}\text { Average survival time in days } \\
\text { (number of rats in parentheses) }\end{array}$} \\
\hline & Intact controls & Splenectomized \\
\hline $\mathrm{Pu}^{238}(100 \mu \mathrm{Ci} / \mathrm{kg})$ & 47 (7) & $50 \quad(9)$ \\
\hline $\mathrm{Pu}^{239}(73 \mu \mathrm{Ci} / \mathrm{kg})$ & (8) & $19(10)$ \\
\hline
\end{tabular}




\section{GASTROINTESTINAL ABSORPTION OF $\mathrm{Ce}^{144}$ AND Pm ${ }^{147}$ IN MINIATURE SWINE}

R. O. McClellan*, L.K. Bustad, and R.F. Keough

Miniature swine absorbed about $0.01 \%$ of an oral dose of $\mathrm{Ce} 144$ chloride or oxide and about $0.001 \%$ of an oral dose of $\mathrm{Pm} 147$ perchlorate. The majority of the absorbed material was found in liver and skeleton.

The potential use of $\mathrm{Ce}^{144}$ and $\mathrm{Pm}^{147}$ in terrestrial and space thermoelectric power generators has stimulated interest in their potential biological hazard. In event of the accidental release of these radionuclides, ingestion will be one of the most probable routes of entry into the body.

This report describes studies designed to determine the extent to which these radionuclides may be absorbed from the gastrointestinal tract of miniature swine, an omnivore similar to size to man. Five young adult miniature swine were given $\mathrm{Ce}^{144}$ or $\mathrm{Pm}^{147}$ orally in contaminated feed pellets.

All animals were held in metabolism cages to permit collection of excreta for analysis or disposal. For collection of urine, indwelling catheters were placed in the bladder of the animals given $\mathrm{Ce}^{144}$ chloride or Pm 147 perchlorate

Ten days after dosing, the animals were killed and representative tissues taken for radioanalysis.

Radioanalyses were performed by standard methods except in the case of low level Pm ${ }^{147}$ samples. Either dibutyl phosphate (DBP) plus tributyl phosphate (TBP) or trioctylphosphine oxide (TOPO) plus Thenoyltrifluoroacetone (TTA) were used to concentrate Pm ${ }^{147}$. The DBP-TBP method was generally preferred, but the TOPO-TTA method was found to be more satisfactory for samples that were high in calcium or iron such as feces and bone.

* Present address: Medical Research Branch, Division of Biology and Medicine, U.S. Atomic Energy. Commission, Washington, D.C. 
The body burden of $\mathrm{Ce}^{144}$ following oral administration is shown in Figure 1. The body burden, which included that present in the gastrointestinal tract, remained high for several days and then dropped sharply as the radionuclide was excreted in the feces. Thus, the early whole body count was determined by the transit time for the radionuclide through the gastrointestinal tract.

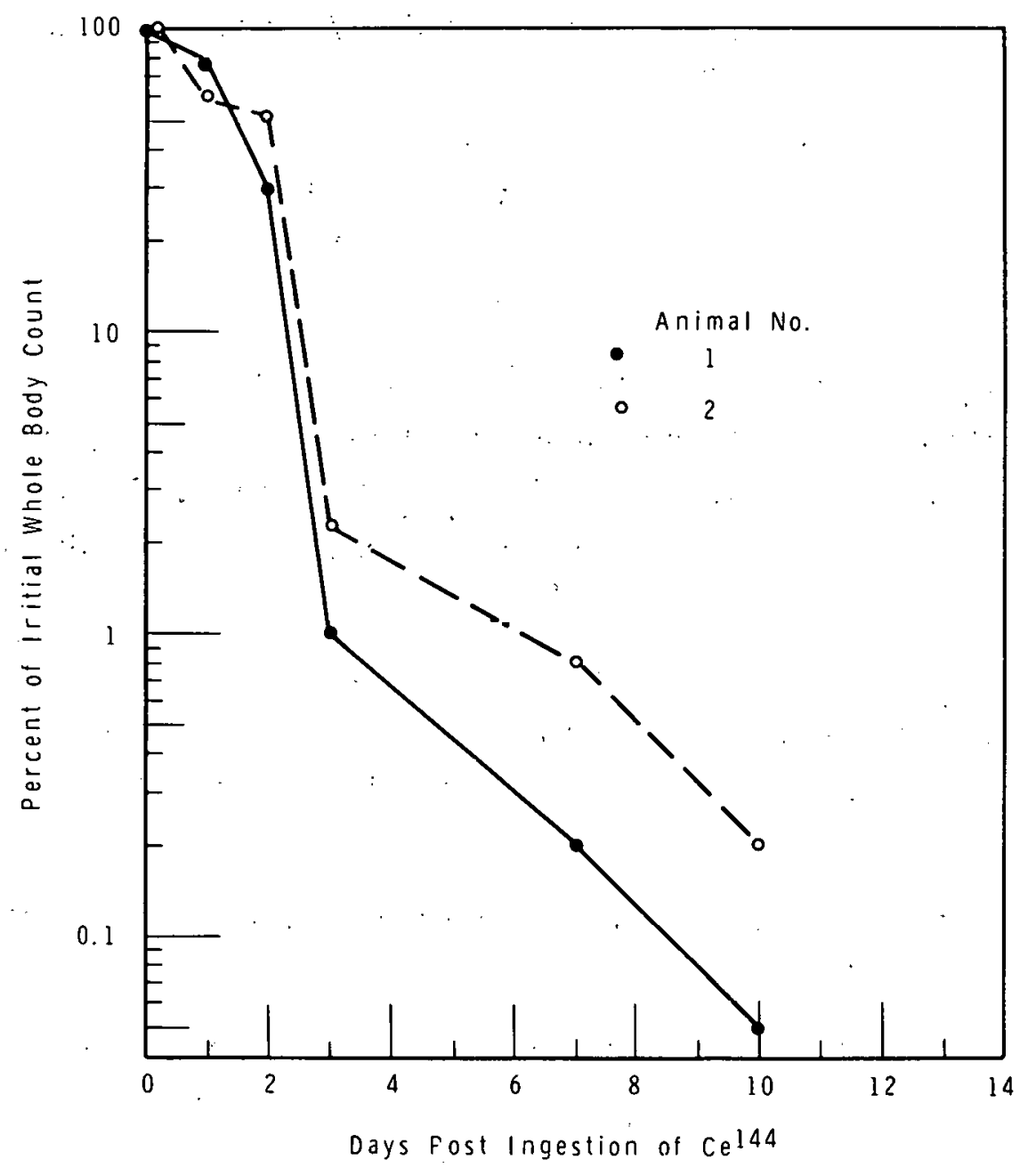

FIGURE 1. Whole Body Retention of $\mathrm{Ce}^{144}$ Following Ingestion $\therefore$ of $\mathrm{Ce}^{144}$ Chloride by Miniature Swine

Due to contamination of the exterior of the animal with small amounts of excreta, the body burdens estimated by whole body counting were higher than those estimates based on tissue radioanalysis. 
The daily urinary excretion of $\mathrm{Ce}^{144}$ is shown in Figure 2. The total urinary $\mathrm{Ce}^{144}$ excretion during the 10 day holding period was approximately $0.001 \%$ of the administered dose.

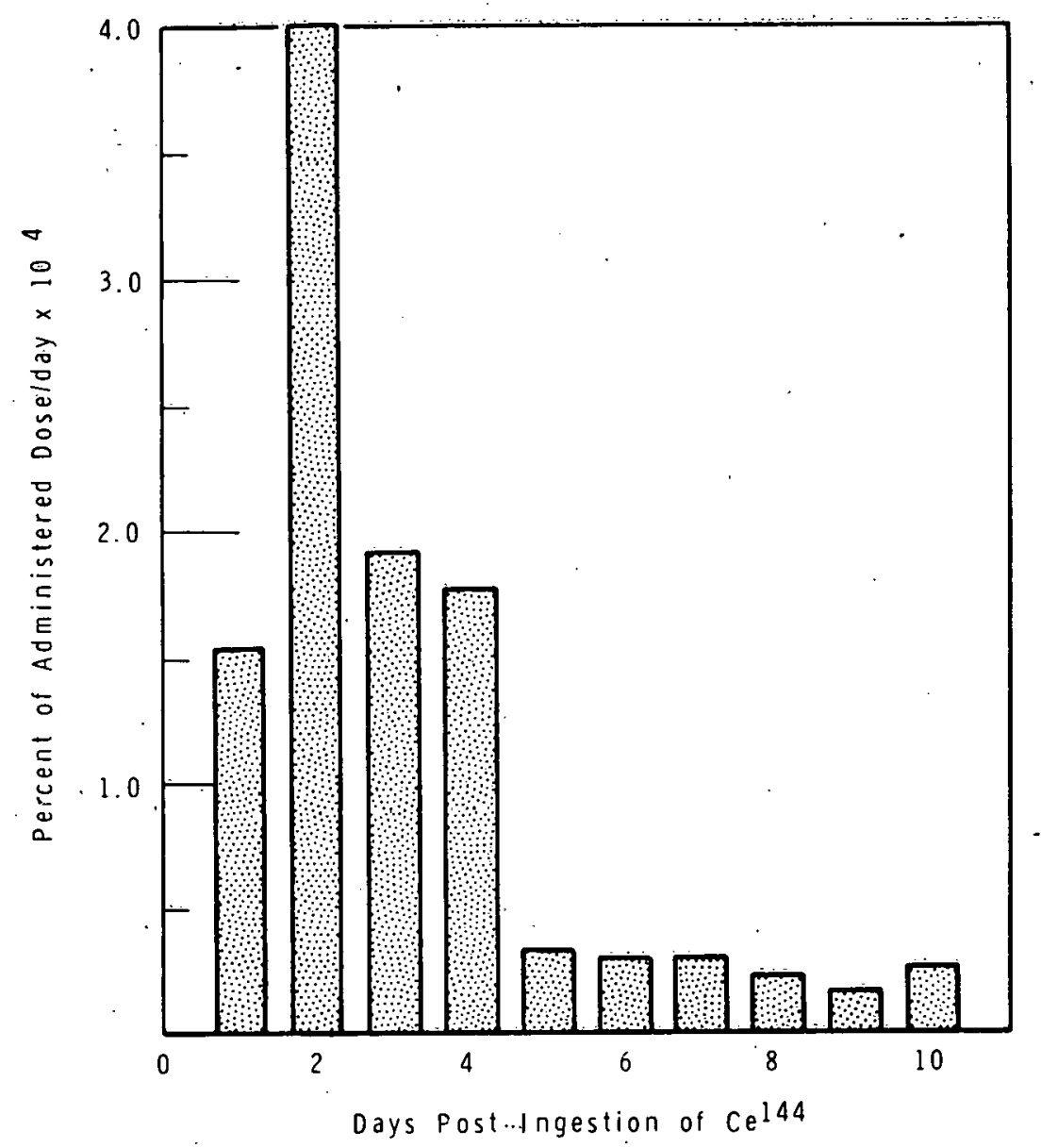

FIGURE 2. Urinary Excretion of $\mathrm{Ce}^{144}$ Following Ingestion of $\mathrm{Ce}^{144}$ Chloride by Miniature Swine

The absorbed $\mathrm{Ce}^{144}$ was found principally in liver, bone; and kidney (Table 1).

The daily fecal excretion of $\mathrm{Pm}{ }^{147}$ by one of the animals is shown in Figure 3. As with $\mathrm{Ce}^{144}$, the excretion pattern is a reflection of the transit time of the poorly absorbed material through the gastrointestinal tract. 
88:

BNWL- 122 .

TABLE 1. Experimentaî Design: and Fraction of Oral Dosë of $\mathrm{Ce}^{144}$ in Various Tissues 10 Days After Admiristration

\begin{tabular}{|c|c|c|c|c|}
\hline \multirow{2}{*}{$\begin{array}{l}\text { Chemical form of } \\
\text { radionuclide used }\end{array}$} & \multirow{2}{*}{$\begin{array}{c}\text { Amount } \\
\text { administered } \\
\text { (mCi) }\end{array}$} & \multicolumn{3}{|c|}{$\begin{array}{l}\text { Organ burden } \\
\left(\% \text { of dose/organ } \times 10^{4}\right)\end{array}$} \\
\hline & & Skeleton & Liver & Kidney \\
\hline $\mathrm{Ce}^{144}$ chloride & 31 & 26 & 4 & 1 \\
\hline $\mathrm{Ce}^{144}$ chloride & 31 & 21 & 3 & 1 \\
\hline $\mathrm{Ce}^{144}$ oxide & 100 & 44 & 31 & 2 \\
\hline Pm 147 perchlorate & 92 & 3.9 & 4.5 & 0.1 \\
\hline $\mathrm{Pm}^{147}$ perchlorate & 92 & 3.4 & 4.8 & 0.1 \\
\hline
\end{tabular}

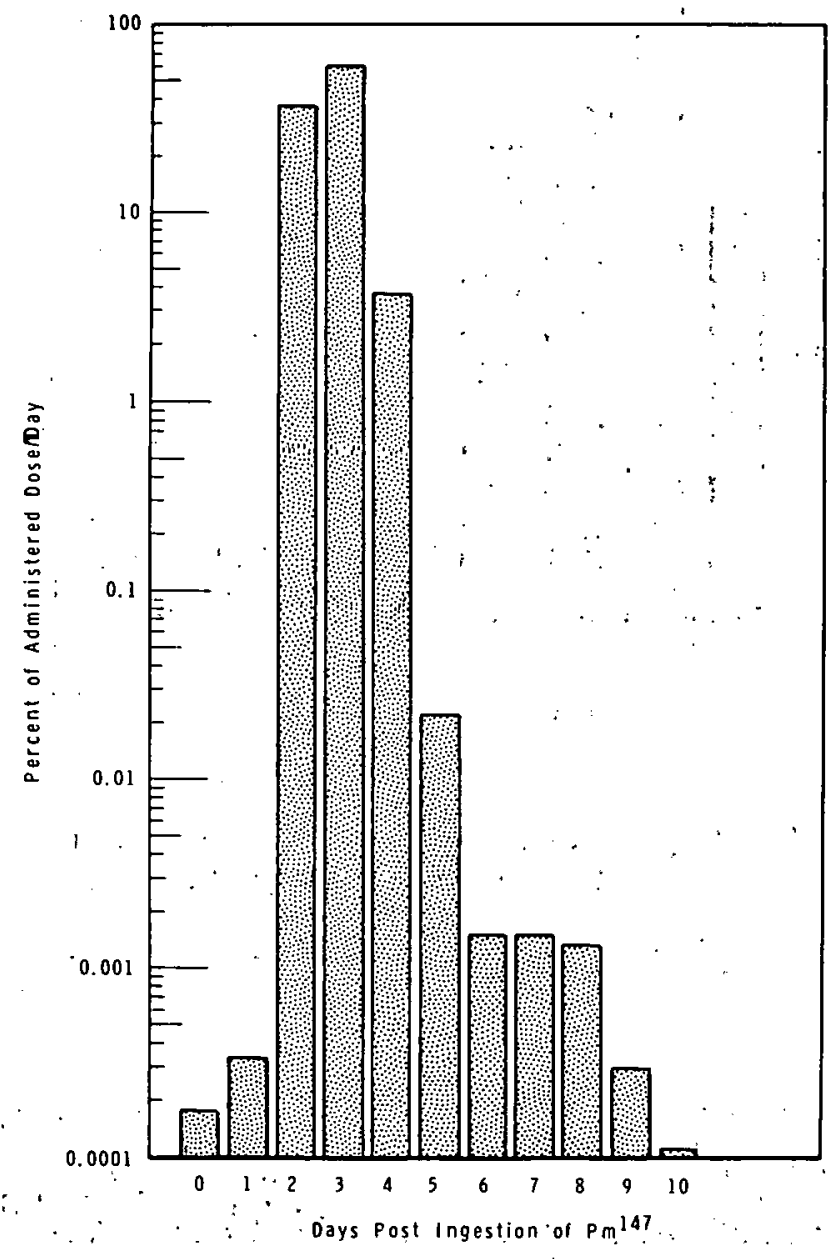

FIGURE 3. Daily Fecal Excretion of $\mathrm{Pm}^{147}$

Following a Single Oral Dose of $\mathrm{Pm}^{147}$ by Miniature Swine 
The urinary excretion of $\mathrm{Pm}^{147}$ is shown in Figure 4. The total urinary excretion during the 10 day holding period was less than $0 . .0004 \%$ of the orally administered dose.

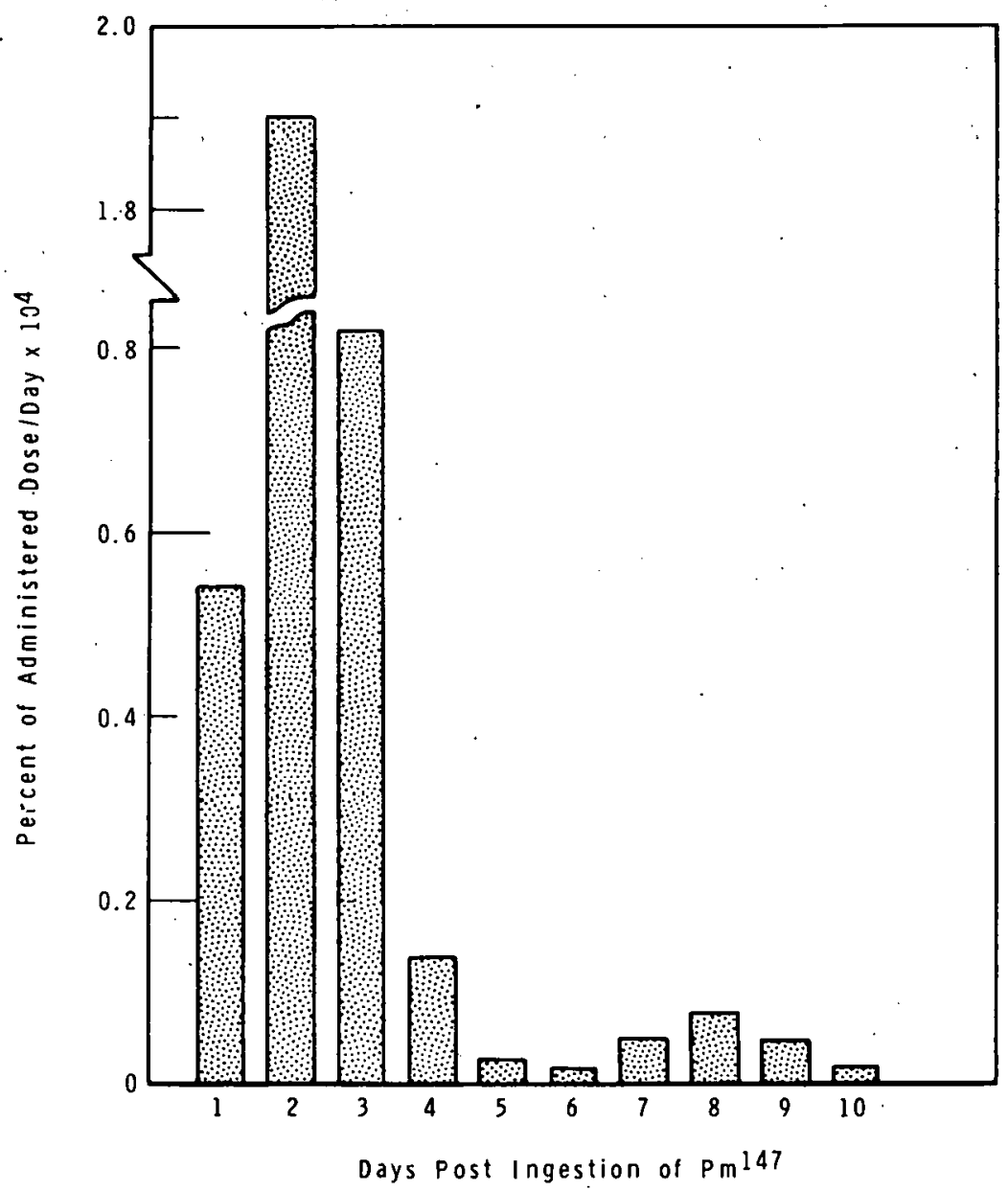

FIGURE 4. Daily Urinary Excretion of $\mathrm{Pm}^{144}$ Following Ingestion of Pm 147 by Miniature Swine As with $\mathrm{Ce}^{144}$, the absorbed $\mathrm{Pm}^{147}$ was found principally in skeleton, liver and kidney (Table 1).

On the basis of skeleton, liver, and kidney concentrations (other tissues analyzed had negligible quantities of $\mathrm{Ce}^{144}$ ), 0.0025-0.0077\% of the oral administered dose of $\mathrm{Ce}^{144}$ was found in the body 10 days after administration. From the limited number of animals studied, it is 
uncertain as to how much significance should be placed on the differences seen in tissue retention of $\mathrm{Ce}^{144}$ oxide as compared to $\mathrm{Ce}^{144}$ chloride. The relative body burden of $\mathrm{Pm}^{147}$ was lower than that for the $\mathrm{Ce}^{144}$, approximately $0.001 \%$ of the orally administered dose.

Considering the very low gastrointestinal absorption of these radionuclides, there would appear to be minimal hazard associated with the ingestion and absorption of these radionuclides. If sufficiently large quantities of these radionuclides were ingested to result in a significant absorbed body burden, acute gastrointestinal radiation effects would almost certainly occur.

The radiation dose to the gastrointestinal tract from the passage of the poorly absorbed $\mathrm{Ce}^{144}$ and $\mathrm{Pm}^{147}$ would, therefore, appear to be the overriding consideration in any evaluation of the potential hazard. 


\title{
CHEMICAL CARCINOGENS AND RADIONUCLIDE METABOLISM
}

\author{
D. D. Mahlum
}

The liver carcinogens, dimethylaminoazobenzene and diacetylaminofluorene, have been shown to inr.rease the retention of $\mathrm{Ce}^{144}-\mathrm{Pr}^{144}$ and $\mathrm{Pu} 238$ by the liver. These carcinogens appear to act by decreasing biliary excretion of the radionuclides.

A study of possible interrelationships between some internal emitters and chemical carcinogens was undertaken. One aspect of this study is the effect of carcinogens on radionuclide metabolism.

Female rats were injected intravenously with $\mathrm{Ce}^{144}-\mathrm{Pr}^{144}$ or $\mathrm{Pu}^{238}$. They were then fed a diet containing a hepatocarcinogen, dimethylaminoazobenzene (DMAB), or a control diet. At the end of the experimental period ( 11 months), the animals were killed and livers and femurs analyzed. Table 1 shows that DMAB-fed rats retained greater quantities of $\mathrm{Ce}^{144}-\mathrm{Pr}^{144}$ or $\mathrm{Pu}^{238}$ in their livers than did the controls. Differences in femur values were not significant.

TABLE 1. The Effect of DMAB Feeding on the Distribution of $\mathrm{Ce}^{144}-\mathrm{Pr}^{144}$ in $\mathrm{Rat}$ Liver and Femur

\begin{tabular}{cccc}
\hline Isotope & DMAB & $\begin{array}{c}\text { Dose/liver } \\
(\%)\end{array}$ & $\begin{array}{c}\text { Dose/femur } \\
(\%)\end{array}$ \\
\hline $\mathrm{Ce}^{144}$ & - & 0.16 & 1.02 \\
\multirow{2}{*}{$\mathrm{Pu}^{238}$} & + & 1.24 & 1.25 \\
& - & 0.78 & 2.62 \\
& + & 1.20 & 2.92 \\
\hline
\end{tabular}

Figure 1 shows the results of a second experiment in which the liver retention of $\mathrm{Ce}^{144}-\mathrm{Pr}^{144}$ was studied as a function of time and as influenced by DMAB feeding. Greater liver retention of the radionuclide by carcinogen-fed rats was apparent as early as 21 days after initiation of DMAB feeding. Analysis revealed that DMAB-fed animals excreted $67 \%$ of the dose of $\mathrm{Ce}^{144}-\mathrm{Pr}^{144}$ in 30 days compared to $76 \%$ for the 
92

BNWL- 122

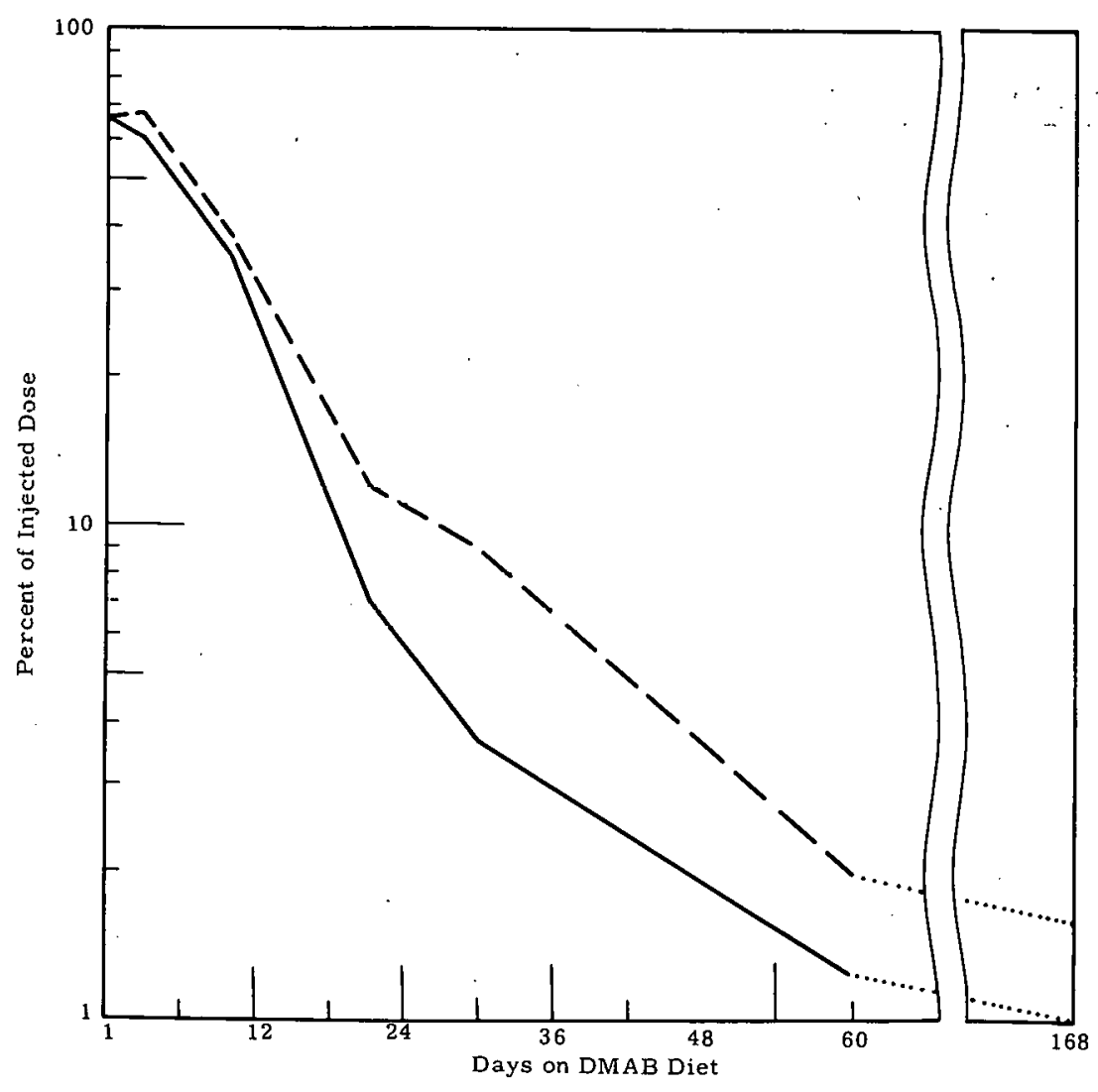

FIGURE 1. Incrcacod Liver Retention of Ce ${ }^{144}-\mathrm{Pr}^{144}$ Caused by DMAB Feeding

controls. The difference in excretion of $\mathrm{Ce}^{144}-\mathrm{Pr}_{. .}^{144}$ was great enough to account for the difference in liver retention.

It was observed during the course of another experiment that the potent hepatocarcinogen, diacetylaminofluorene (DAF), affected the liver retention of $\mathrm{Ce}^{144}-\mathrm{Pr}^{144}$ to a greater extent than had DMAB. Use was therefore, made of DAF in subsequent experiments on the mechanism of of altered radionuclide retention by the liver.

The effect of DAF on the fecal excretion of $\mathrm{Ce}^{144}-\mathrm{Pr}^{144}$ is shown in Table 2. The feeding of a diet containing $0.025 \%$ DAF resulted in a $28 \%$ reduction in the amount of $\mathrm{Ce}^{144}-\mathrm{Pr}^{144}$ excreted and doubling in the quantity of radionuclide retained in the liver. The distribution of $\mathrm{Ce}^{144}$ $\mathrm{Pr}^{144}$ in other tissues appeared little affected by the DAF feeding. 
TABLE 2。 Decreased Fecal Excretion and Increased Liver Retention of $\mathrm{Ce}^{144}-\mathrm{Pr}^{144}$ Causcd by Feeding DAF for 18 Days

\begin{tabular}{ccc}
\hline Treatment & $\begin{array}{c}\text { Percent dose } \\
\text { excreted }\end{array}$ & $\begin{array}{c}\text { Dose/liver } \\
(\%)\end{array}$ \\
\hline Control & 59.3 & 13.7 \\
DAF & 42.5 & 27.9 \\
\hline
\end{tabular}

Most of the Ce $\mathrm{e}^{144}-\mathrm{Pr}^{144}$ was excreted by way of the feces, which suggested the bile as an important route of $\mathrm{Ce}^{144}-\mathrm{Pr}^{144}$ removal. Ligation of the common bile duct resulted in practically no $\mathrm{Ce}^{144}-\mathrm{Pr}^{144}$ excretion, confirming the importance of this pathway.

Cannulation of the common bile duct was performed on rats that had been injected with $\mathrm{Ce}^{144}-\mathrm{Pr}^{144}$ and fed either control or DAF diet. The control bile contained $607 \mathrm{cpm} / \mathrm{ml}$, while DAF bile contained $184 \mathrm{cpm} / \mathrm{ml}$. No great differences were noted in rate of bile flow, although longer collection periods might have revealcd significant differences.

The effect of DMAB and DAF in increasing liver retention of $\mathrm{Ce}^{144}$ $\mathrm{Pr}^{144}$ appears to involve the biliary excretion mechanism. It is not known at this time whether the increased liver retention of certain radionuclides is associated only with hepatocarcinogenic chemicals, or if other hepatotoxins might have a similar action. 


\title{
MILK SECRETION OF $\mathrm{Zn}^{65}$ AND Cd ${ }^{115 m}$ IN SHEEP
}

\author{
B. J. McClanahan and H. A. Ragan
}

The concentration of intravenously administered $\mathrm{Zn}^{65}$ in the milk of lactating ewes was approximately 8 times that in plasmá, while the concentration of $\mathrm{Cd}^{115 \mathrm{~m}}$ in milk was 15 times its plasma concentration. Elevating the quantity of stable zinc simultaneously injected reduced the plasma clearance rate of $\mathrm{Zn} 65$ and $\mathrm{Cd} 115 \mathrm{~m}$, while their milk concentration was unchanged. Intramammary infusion of $\mathrm{Zn} 65$, Cd115m and stable zinc via the teat canal demonstrated that both radionuclides were rapidly transferred from milk, but neither transfer rate was influenced by the presence of additional stable zinc in the milk.

Recent studies by Cotzias, et al (Am. J. Physiol. 201, 63, 1961) in rodents indicate that stable cadmium causes marked disturbances in blood and tissue concentrations of $\mathrm{Zn}^{65}$. To examine the zinc-cadmium relationship the effect of stable zinc on the behavior of $\mathrm{Zn}^{65}$, and $\mathrm{Cd} 115 \mathrm{~m}$ was investigated. The mammary gland was selected for study since it consists of a cellular system separating two fluids, plasma and milk, both easily obtained for radioanalysis.

In the experiments concerned with the transfer of $\mathrm{Zn}^{65}$ and $\mathrm{Cd}^{115 \mathrm{~m}}$ from plasma to milk, a single intravenous injection into the external jugular vein of different amounts of zinc as $\mathrm{ZnCl}_{2}$ containing $\mathrm{Zn} 65$ and $\mathrm{Cd} 115 \mathrm{~m}$ was administered to each ewe. Samples of blood and milk were taken at intervals for radiochemical determination of $\mathrm{Zn}^{65}$ and $\mathrm{Cd} 115 \mathrm{~m}$.

To measure the transfer of $\mathrm{Zn}^{65}$ and $\mathrm{Cd} 115 \mathrm{~m}$ from milk to plasma, one-half of each ewe's udder of one group was infused through the teat canal with the radionuclides. The other group received $\mathrm{ZnCl}_{2}$ in addition to the radionuclides.

The experimental design is presented in Table 1.

The effect of intravenously injected zinc on the transfer of simultaneously administered $\mathrm{Zn}^{65}$ and $\mathrm{Cd}^{115 \mathrm{~m}}$ from plasma to milk when a "normal" milking régimen was followed is shown in Figure 1. Significantly larger fractions of the administered dose of $\mathrm{Zn}^{65}$ were transferred to the 
95

BNWL-122.

TABLE 1. Number of Animals and Treatment ?.

\begin{tabular}{|c|c|c|c|}
\hline $\begin{array}{l}\text { Experiment } \\
\text { number }\end{array}$ & $\begin{array}{c}\text { Number } \\
\text { of } \\
\text { ewes }\end{array}$ & $\begin{array}{l}\text { Frequency and } \\
\text { route of } \\
\text { administration }\end{array}$ & Treatment \\
\hline 1 & $\begin{array}{l}4 \\
4 \\
4 \\
4\end{array}$ & $\begin{array}{l}\text { Single. IV } \\
\text { Single IV } \\
\text { Single IV } \\
\text { Single IV }\end{array}$ & 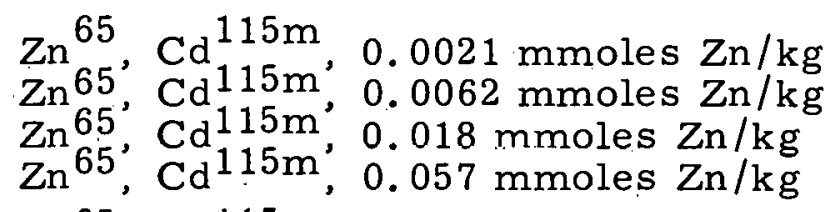 \\
\hline 2 & $\begin{array}{l}4 \\
4\end{array}$ & $\begin{array}{l}\text { Single IV } \\
\text { Single IV }\end{array}$ & $\begin{array}{l}\mathrm{Zn} 65, \text { Cd } 115 \mathrm{~m}, 0.0021 \text { mmoles } \mathrm{Zn} / \mathrm{kg} \\
\mathrm{Zn} 65, \mathrm{Cd}^{115 \mathrm{~m}}, 0.057 \mathrm{mmoles} \mathrm{Zn} / \mathrm{kg}\end{array}$ \\
\hline 3 & 4 & $\begin{array}{l}\text { Uddder } \\
\text { injection } \\
\text { Udder } \\
\text { injection }\end{array}$ & $\begin{array}{l}\mathrm{Zn}^{65}, \mathrm{Cd}^{115 \mathrm{~m}} \\
\mathrm{Zn}^{65}, \mathrm{Cd}^{115 \mathrm{~m}}, 0.63 \text { mmoles } \mathrm{Zn} / \text { liter }\end{array}$ \\
\hline
\end{tabular}

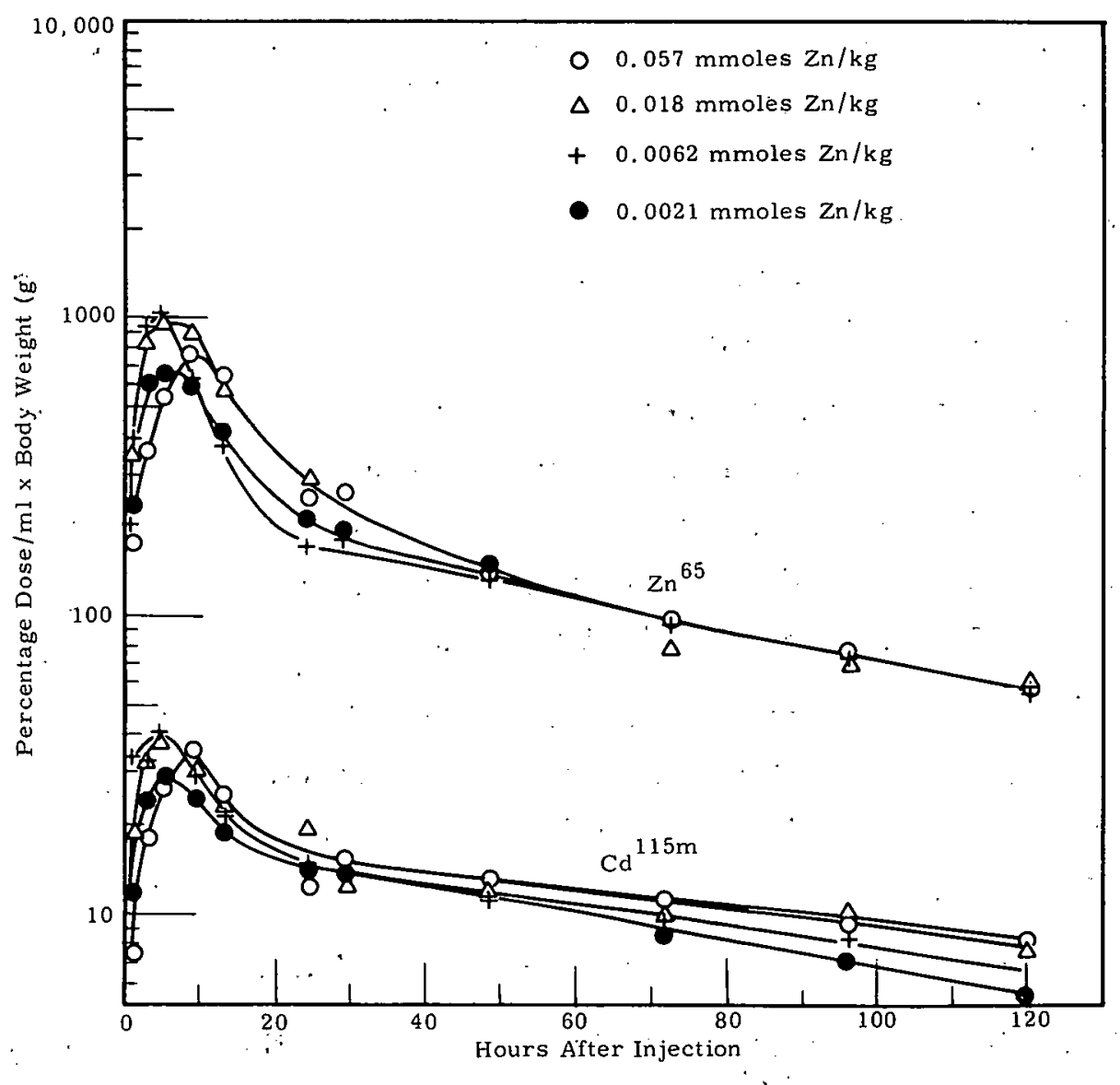

FIGURE 1. $\mathrm{Zn}^{65}$ and $\mathrm{Cd}^{115 \mathrm{~m}}$ Concentrations in Milk 'Following Intravenous Administration of $\mathrm{Zinc}, \mathrm{Zn}^{65}$, and $\mathrm{Cd}^{115 \mathrm{~m}}$ 
BNWL- 122

milk compared to $\mathrm{Cd}^{115 \mathrm{~m}}$. Except for a slight reduction in the percentage of the administered $\mathrm{Zn}^{65}$ and $\mathrm{Cd} 115 \mathrm{~m}$ present in the milk 3 and $5 \mathrm{hr}$ after injection at the highest level of zinc $(0.057 \mathrm{mmoles} / \mathrm{kg}$ body weight), there were no differences in the milk concentrations of either radioisotope related to zinc treatment.

The plasma clearance for each element was. reduced when the quantity of injected zinc was increased, so that for 24-48 hr after injection, at any given time the plasma concentration of $\mathrm{Zn}^{65}$ and $\mathrm{Cd} 115 \mathrm{~m}$ increased as the concentration of injected zinc was increased (Figure 2). Ultimately, the plasma concentrations of $\mathrm{Zn}^{65}$ reached the same values for each treatment. However, at the end of the 7 day sampling period the plasma concentration of $\mathrm{Cd}^{115 \mathrm{~m}}$ in the presence of 0.057 mmoles administered zinc.

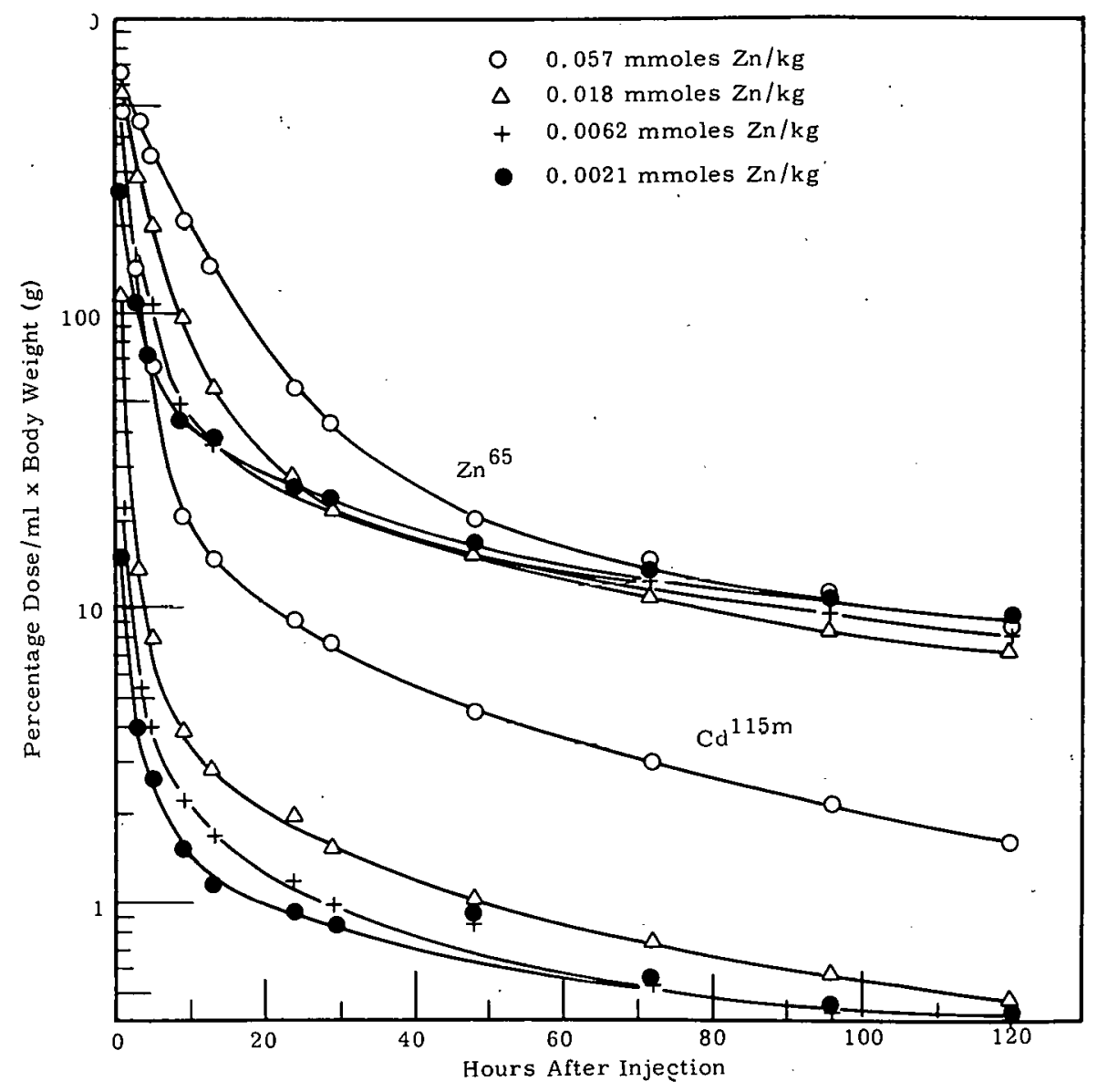

FIGURE 2. Plasma Clearance of $\mathrm{Zn}^{65}$ and $\mathrm{Cd}^{115 \mathrm{~m}}$ Following, Intravenous Administration of $\mathrm{Zinc}, \mathrm{Zn} 65$, and $\mathrm{Cd}^{115 m}$ 
per kilogram body weight was still significantly higher than at the three lower levels of zinc. As a result of the higher plasma concentrations of $\mathrm{Zn}^{65}$ and $\mathrm{Cd}^{115 \mathrm{~m}}$, the milk-to-plasma ratios for each element were diminished as the administered zinc level was elevated.

When the transfer of $\mathrm{Zn}^{65}$ and $\mathrm{Cd}^{115 \mathrm{~m}}$ from the plasma to milk was measured at a reduced level of milk secretion, achieved by allowing the udder to fill. with milk and thereby increase the intramammary pressure, approximately one-tenth of the concentration obtained during a "normal" milking regimen was found in the milk. The milk concentration of the injected $\mathrm{Cd}^{115 \mathrm{~m}}$ was one-tenth that of the $\mathrm{Zn}^{65}$. The amount of zinc injected had little effect on the transfer of either element; there was only a slight reduction in the initial rate of appearance of both $\mathrm{Zn}^{65}$ and $\mathrm{Cd}^{115 \mathrm{~m}}$ in the milk at the higher level of administered zinc.

When $\mathrm{Zn}^{65}$ and $\mathrm{Cd}^{115 \mathrm{~m}}$ were injected into the mammary gland via the teat canal, they rapidly, disappeared from the milk. Cadmium-115m disappeared from the milk more rapidly than $\mathrm{Zn}^{65}$. The increase in total concentration of zinc had no effect on the rate of disappearance of either $\mathrm{Zn}^{65}$ or $\mathrm{Cd}^{115 \mathrm{~m}}$. The rate diminished approximately $24 \mathrm{hr}$ after injection ( $36 \mathrm{hr}$ after the lambs were separated from the ewes): The disappearance of $\mathrm{Cd}^{115 \mathrm{~m}}$ and $\mathrm{Zn}^{65}$ from the milk was accompanied by an increase in the plasma concentration of each radioisotope. The plasma concentrations of $\mathrm{Cd}^{115 \mathrm{~m}}$ and $\mathrm{Zn}^{65} 29 \mathrm{hr}$ after udder infusion and intravenous injection were nearly equivalent. When plasma concentrations of this magnitude are attained, transfer back into the milk may effect an apparent reduction in their disappearance rate.

Comparison of the concentrations of $\mathrm{Zn}^{65}$ and $\mathrm{Cd}^{115 \mathrm{~m}}$ obtained in milk during "normal" milk secretion with those obtained during reduced milk secretion indicates that the rate of milk secretion determined the concentrations of both elements that occurred in milk. Although the milkto-plasma ratios obtained during milk production decreased when the amount of zinc injected was increased, this may not represent a saturation effect on the transfer of $\mathrm{Zn}^{65}$ and $\mathrm{Cd}^{115 \mathrm{~m}}$ from plasma to milk. A disturbance in the plasma binding may have occurred when the stable zinc was 
administered. If the zinc bound to the different plasma proteins were not equally available for transfer to the milk, a change in the plasma binding could account for the fact that a constant fraction of the administered $\mathrm{Zn} 65$ and $\mathrm{Cd}^{115 \mathrm{~m}}$ appeared in the milk while the plasma clearances of the two radioisotopes were reduced when increasing amounts of zinc were administered. To adequately evaluate the effect of stable zinn on the transfer of $\mathrm{Zn}^{65}$ and $\mathrm{Cd}{ }^{115 \mathrm{~m}}$ from plasma to milk, the plasma binding of both elements should be examined. 
Twenty-five percent mortality occurred when sheep received a single intravenous injection of either $0.0080 \mathrm{mmoles}$ cadmium $/ \mathrm{kg}$ or 0.069 mmoles zinc/kg: Sever'e liver and kidney daindge $w$ as observed in the animals that died. Liver, kidney, and testicular injury were evident among the survivors 14 days after injection. Only slight histological changes were observed in the spleen and epididymis.

The acute toxicity of a single intravenous injection of zinc or cadmium was determined in sheep six to eight months old to establish maximum levels that could be tolerated in a subsequent study employing lactating ewes. The animals were injected in the external jugular vein with either zinc or cadmium, as the chloride salt, in isotonic saline, pH 5. Fourteen days later the survivors were anesthetized with nembutal and sacrificed by exsanguination. Samples of tissues were examined histologically for damage. The cxperimental design and mortality is presented in 'l'able 1.

TABLE 1. Amount of Zinc or Cadmium Injected and Mortality

\begin{tabular}{ccccc}
\hline Group & $\begin{array}{c}\text { Number } \\
\text { of animals }\end{array}$ & \multicolumn{2}{c}{ Cadmoles/kg injected } & Co \\
1 & 4 & 0.0080 & Zinc & -- \\
2 & 4 & 0.0097 & -- & 25 \\
3 & 4 & 0.012 & -- & 50 \\
4 & 4 & -- & 0.054 & 75 \\
5 & 4 & -- & -0.061 & 0 \\
6 & 4 & -- & 0.069 & 0 \\
& & & & 25 \\
\hline
\end{tabular}

Cadmium was more toxic than zinc; approximately eight times as much zinc was required to cause the same mortality as cadmium. However, the toxicity syndrome was similar for the two elements. Diarrhea, inappetence, listlessness, and difficulty in standing were observed in many of the cadmium-treated animals, including those that survived at the two highest doses. 
100

BNWL- 122

Microscopic examination of kidney sections obtained from both zincand cadmium-treated lambs demonstrated tubule degeneration and necrosis. The glomeruli evidenced a loss of cellularity. Liver specimens from cadmium-treated lambs showed more severe damage than those taken from zinc-treated animals. There was moderate to severe degeneration and fatty change throughout the hepatic cells and the liver cord architecture was distorted. Zinc produced only a moderate to severe edema in testicular tissue, , while cadmium caused marked interstitial edema as well as a collapse and degeneration of the seminiferous tubules: Mature sperm were not evident in the tubules of any of the cadmium-treated animals. In general, all other tissue sections obtained from the zinc- and cadmiumtreated animals appeared relatively normal. 


\title{
EFFECT OF CHRONIC INGESTION OF ZN ${ }^{65}$ IN TROUT
}

\author{
R. E. Nakatani, D. H. W. Liu, and W. J. Clarke
}

Three groups of rainbow trout fed $\mathrm{Zn}^{65}$ at a daily rate of $0.01,0.1$, and $1.0 \mu \mathrm{Ci} / \mathrm{g}$ fish for 17 weeks differed insignificantly from control flsh in mortality, clinical hematology, and histology. However, damage was indicated when fish were fed at a rate of $10 \mathrm{\mu Ci} / \mathrm{g}$ fish. The effective half-life for long term retention was 135 days. Trout with a body burden of $1600 \mu \mathrm{Ci}$ suffered no swimming performance decrement. Fish with more than 10,000 times the burden observed in river fish showed no effect.

The concentrations of $\mathrm{Zn}^{65}$ observed in Columbia River fishes are at acceptable levels for the health of fish populations. Muscle tissue of Columbia River whitefish, Prosopium williamsoni, averaged about $38 \mathrm{pCi} / \mathrm{g}$, with a maximum of $120 \mathrm{pCi} / \mathrm{g}$, during 1963. Because of this low concentration, biological effects in river fish are neither identified nor expected. Hence, in the laboratory, relatively large amounts of $\mathrm{Zn}^{65}$ were chronically: force-fed to yearling rainbuw trout, Salmo gairdneri. Gelatin capsules containing $0,0.01,0.1$, and $1.0 \overline{\mu \mathrm{Ci} . \mathrm{Zn}}{ }^{65} / \mathrm{g}$ fish were fed daily, Monday through Friday, for 17 weeks to four treatment groups (control, low, medium, and high level) with $50 \mathrm{fish}$ each. The total amounts of $\mathrm{Zn} 65$ ingested by each fish in the low; medium, and high level groups were 130, 1300 , and $13,000 \mu \mathrm{Ci}$, respectively.

Growth, mortality, hematology, and swimming performance were studied as related to ingestion levels. Analysis of variance showed significant difference in body weights between controls, low and high groups, at weck 23. The controls were significantly smaller, but no difference was indicated between the two $\mathrm{Zn}^{65}$ groups. The greater growth of the $\mathrm{Zn}^{65}$ fish was unexpected and unexplained.

Figure 1 shows the $\mathrm{Zn}^{65}$ body burden of fish killed serially from the medium level group. By week 10 the body burden appeared to approach equilbrium at about $260 \mathrm{\mu Ci}$. The effective half-life of 135 days for long term retention was computed from the regression line fitted for the interval week 22 through 44. The computed biological half-life was 300 days. 


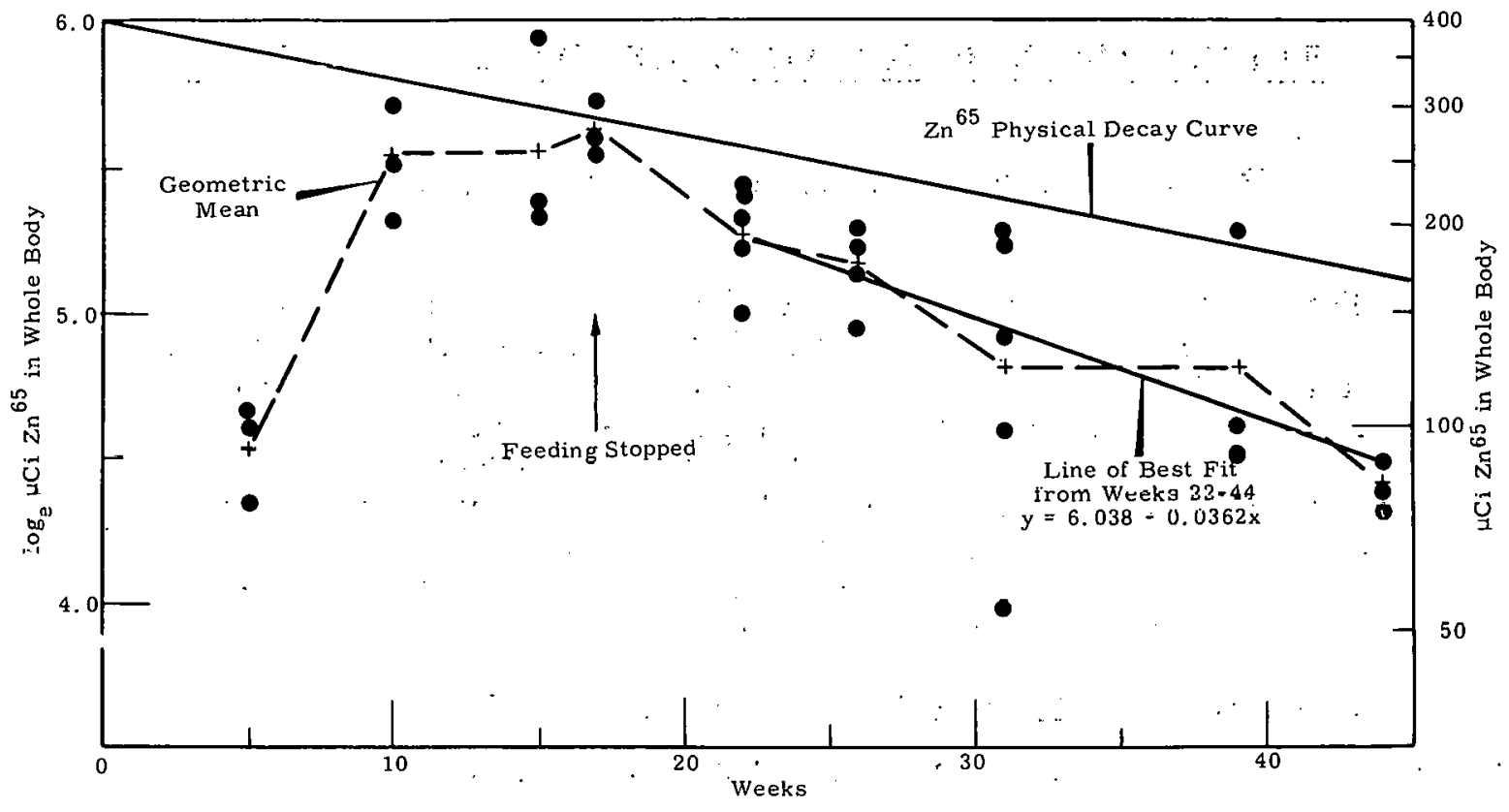

FIGURE 1. $\mathrm{Zn}^{65}$ Body Burden in Rainbow Trout Fed $0.1 \mu \mathrm{Ci} / \mathrm{g}$ Fish Daily for 17 Weeks

The concentration of $\mathrm{Zn}^{65}$ in the gill filaments, GI tract, bone, and muscle tissue sampled from the medium level group is illustrated in Figure 2. The relatively high activity observed in the GI tract, bone, and gill filaments is in contrast to the low activity of muscle tissue. The high activity observed in the gill filaments is associated with excretion of $\mathrm{Zn} 65$ by the gills. During feeding, highest concentrations of $\mathrm{Zn}^{65}$ were in the gill filaments; but when feeding was stopped, the concentration in the gill filaments decreased rapidly.

No anomalies were observed in hematocrit, hemoglobin, erythrocytes, or leukocytes. No mortality occurred during the ingestion period of 17 weeks, and subsequent mortality was unrelated to treatments.

Because no damage was observed at the initial treatment levels, 10 fish were fed $105 \mathrm{mCi}$ each over a 10 week period at a daily rate of $10 \mu \mathrm{Ci} / \mathrm{g}$ fish. The body burden averaged about $4.7 \mathrm{mCi}$ at week 10 . Blood samples showed no anomalies in hematocrit, hemoglobin, or I erythrocytes, but leukopenia was indicated by the pronounced drop in 


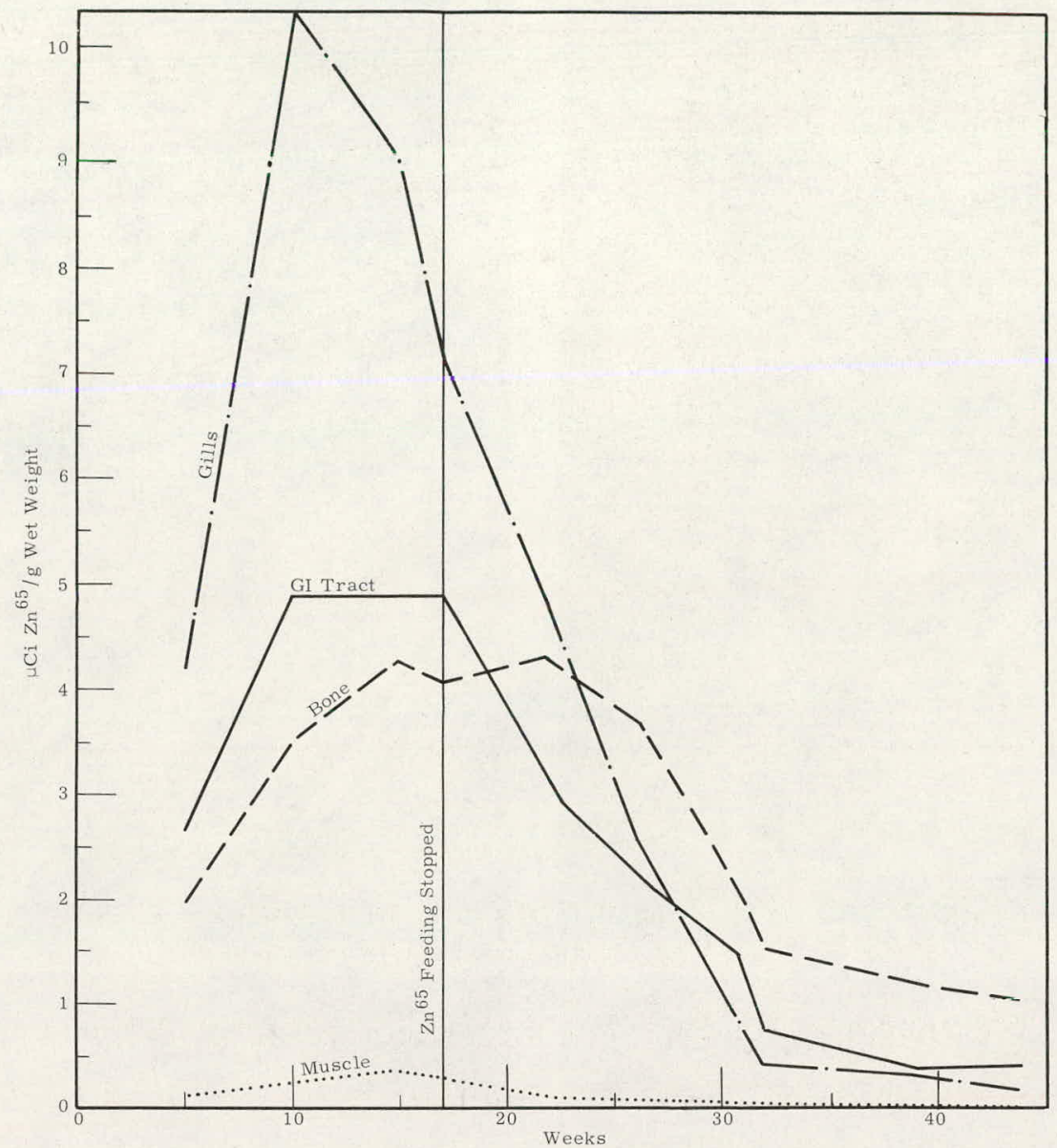

FIGURE 2. Concentration of $\mathrm{Zn}^{65}$ in Tissues of Rainbow Trout Fed $0.1 \mathrm{\mu Ci} / \mathrm{g}$ Fish Daily for 17 Weeks

leukocytes from 87,000 to 11,000 cells $/ \mathrm{mm}^{3}$. Histopathologic examinations of the liver, kidney, spleen, bone, GI tract, and gills revealed no evidence of tissue damage with the possible exception of the gill filaments. Crisp outlines of the gill filaments were not apparent in the $\mathrm{Zn}^{65}$ fish as in the control fish, and the blood sinusoids (or lacunae) in the gill filaments appeared collapsed. Some of the epithelial cells also showed early coagulation necrosis.

To localize the deposition of $\mathrm{Zn}^{65}$ in the GI tract, autoradiographs were prepared from tissue samples from the $10 \mu \mathrm{Ci}$ group (Figure 3 ). Activity was greatest in the basilar portion of the epithelial cells in all parts of the GI tract. Very heavy activity was seen in the fundic glands 

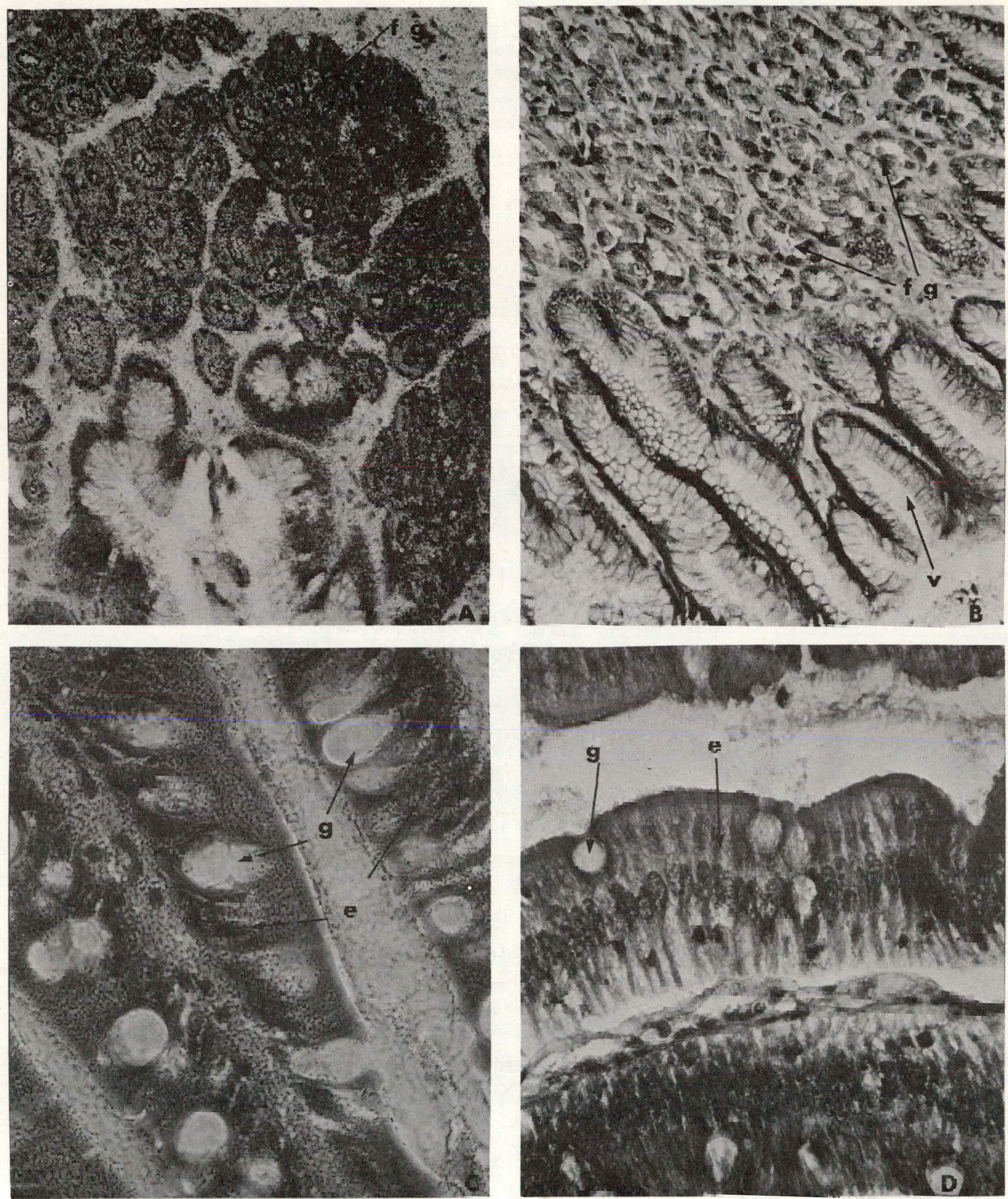

FIGURE 3. Autoradiographic and Control Photographs of the Stomach

(A and B 160X) and the Villi of the Pyloric Caeca (C and D 400X) (Epithelial cells-e, villi-v, fundic glands-fg, goblet cell-g) (Autoradiographic sections are shown in $\mathrm{A}$ and $\mathrm{C}$. ) 
of the stomach and lamina propia of the hind-gut, while the smooth muscle of the submucosa contained moderate amounts of activity. Activity in the goblet cells and their lumens was very light or absent.

Two series of swimming tests compared the performance of controls and the group fed $1.0 \mu \mathrm{Ci} \mathrm{Zn}^{65} / \mathrm{g}$ fish daily. The hydraulic test flume designed fur the swim tests has been described elsewhere (Hanford Biology Annual Report, 1961). Briefly, the test procedure was to introduce a single fish, at the upstream part of the test channel, into water of known velocity. The performance time was scored when the fish became impinged on a downstream inclined plane trap. All fish tested experienced one pretest trial and no fish was given more than one trial per day. To minimize disturbance between trials, each fish was held separately in a covered compartment. The body burden averaged about $1600 \mu \mathrm{Ci}$ at termination of swim tests. In the first test series, nine controls and nine $\mathrm{Zn}^{6,5}$ fish selected from the $29-31 \mathrm{~cm}$ size interval were tested in average water velocity of $5.1 \mathrm{fps}$. The experimental design considered three main effects, i.c., treatment levels of $\mathrm{Zn}^{65}$, trials, and order of testing. The overall mean performance time was 77 and 73 sec for controls and $\mathrm{Zn}^{65}$ fish, respectively. Analysis of variance showed that none of the main effects or the interaction effects were statistically significant.

In the second series of swim tests, 10 controls and $10 \mathrm{Zn}^{65}$ fish were each tested at three different velocities of $5.1,4.1$, and $3.5 \mathrm{fps}$. The data are presented in Figure 4. Because the size of the fish in the second series of tests ranged from 27-34 cm, adjustment for length differences was made by analysis of covariance. The treatments were significantly different for $4.1 \mathrm{fps}$ at the 0.05 level of significance. The mean performance time was $621 \mathrm{sec}$ for $\mathrm{Zn}^{65} \mathrm{fish}$ and $477 \mathrm{sec}$ for the controls. No difference in performance was found at 5.1 or 3.5 fps. Clearly, trout with body burden as much as $1800 \mu \mathrm{Ci} \mathrm{Zn}^{65}$ suffered no decrement in swimming performance.

The $\mathrm{Zn}^{65}$ experiment provided information on uptake, retention, and distribution which cannot be readily obtained from river fish with unknown and uncontrolled intake of $\mathrm{Zn}^{65}$. There was no indication that trout fed $13,000 \mu \mathrm{Ci}$ at a daily rate of $1.0 \mu \mathrm{Ci} / \mathrm{g}$ fish will show anomalies 
BNWL-122

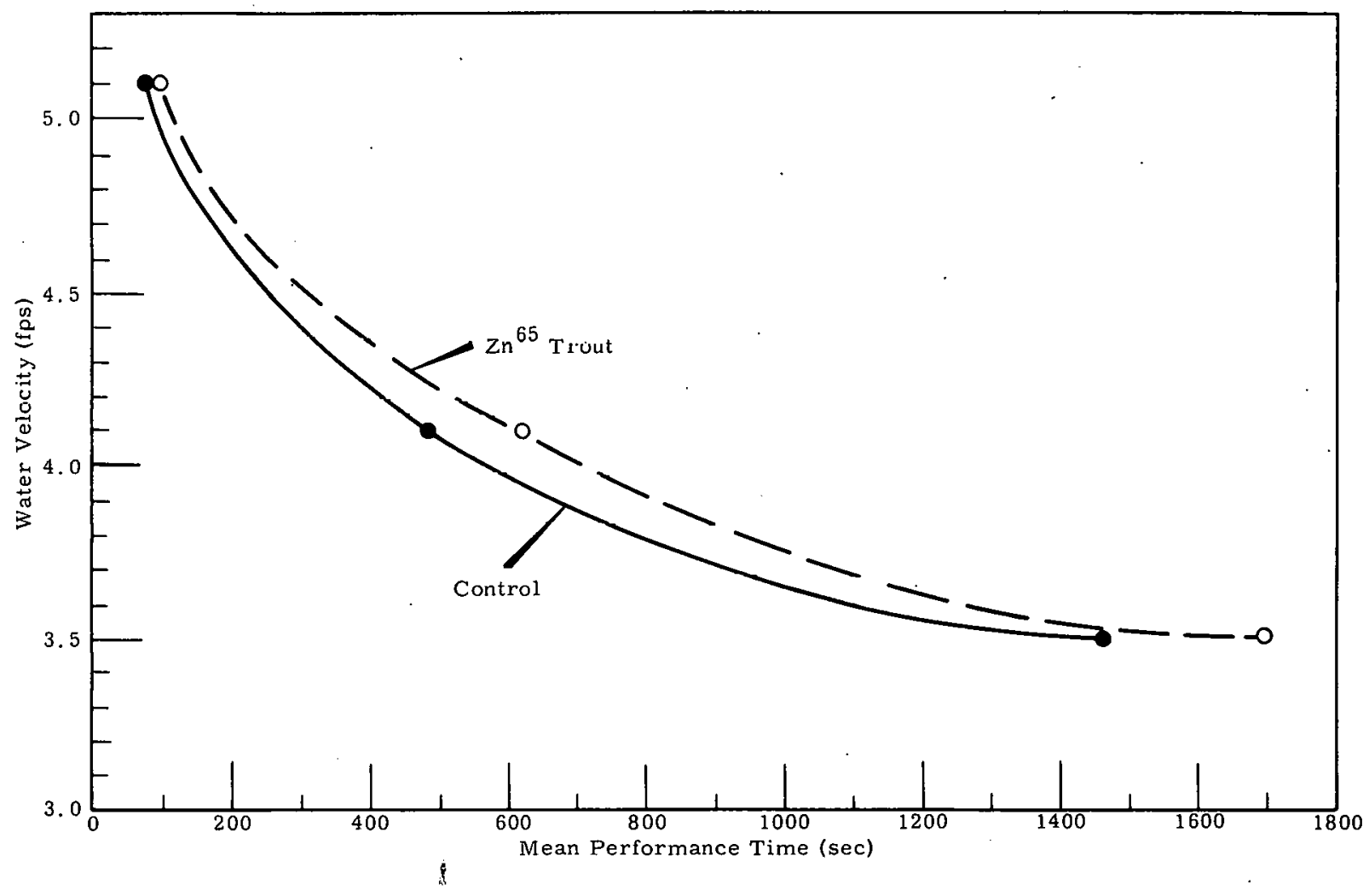

FIGURE 4. Swimming Performance of Yearling Trout (Salmo gairdneri) Fed 1.0 $\mu \mathrm{Ci} \mathrm{Zn}{ }^{65} / \mathrm{g}$ Fish Daily for 17 Weeks

in the blood, histological damage, or mortality. However, when trout were fed $105 \mathrm{mCi}$ at a rate of $10 \mathrm{\mu Ci} / \mathrm{g}$ fish, leukopenia and apparent damage to the gill filaments occurred. Because trout with a 10,000 times greater burden of $\mathrm{Zn}^{65}$ than river fish showed no detrimental effect, there is considerable assurance that Columbia River fish populations are not adversely affected by present river $\mathrm{Zn}^{65}$ concentrations. 


\title{
TOXICITY OF COPPER AND X RAYS IN RATS
}

\author{
P. L. Hackett, W. J. Clarke, and J. L. Palotay
}

The administration of toxic levels of copper or X ray caused a depression of erythrocyte and lymphocyte values. Coppcr adminislratioñ produced a neutrophilic leukocytosis. Degenerative changes of the spleen, liver, and kidney were observed following treatment by either agent. High levels of copper increased $\mathrm{Fe} 59$ levels in erythrocytes in contrast to the depression of these values following $\mathrm{X}$ irradiation.

This report summarizes hematological, histopathological, and $\mathrm{Fe}^{59}$ distribution data obtained from studies of the toxicity of copper and $\mathrm{X}$ rays in rats (Hanford Biology Report for 1963).

Effects caused by $850 \mathrm{R}$ of whole-body X irradiation, subcutaneous injection of toxic levels of copper (20 or $30 \mathrm{mg} \mathrm{Cu} / \mathrm{kg}$ ), or a combination of one-half of the above levels of the two agents $(425 \mathrm{R}+10 \mathrm{mg} \mathrm{Cu} / \mathrm{kg}$ or $425 \mathrm{R}+15 \mathrm{mg} \mathrm{Cu} / \mathrm{kg}$ ) were compared。

Mortality values were $48 \%$ for animals receiving $30 \mathrm{mg} \mathrm{Cu} / \mathrm{kg}$ and $62 \%$ for rats given $850 \mathrm{R}$ of $\mathrm{X}$ irradiation. Hemoglobinuria appeared to be a good indicator of lethality in copper poisoning. Significant results from hematological studies are shown in Figure 1. Organ distribution of $\mathrm{Fe}^{59}$, which was administered immediately following treatment with the toxic agents," is summarized in Table 1 .

Erythrocyte values were depressed in animals given toxic levels of copper or $\mathrm{X}$ irradiation but minima were observed at different postt.reatment times. Differences in response to the two agents were evident. In copper treated animals, immature erythrocytes were present in the peripheral blood, the bone marrow had a normal appearance, and $\mathrm{Fe}^{59}$ values for erythrocytes were higher. In the $\mathrm{X}$-irradiated rats, marrow was hypoplastic and $\mathrm{Fe}^{59}$ uptake in the erythrocytes was decreased.

Alterations in leukocyte levels were also observed in rats that received copper or X irradiation. Lymphocytes were decreased in animals that received either treatment. The neutrophilic leukocytosis that followed 
ERYTHROCYTES

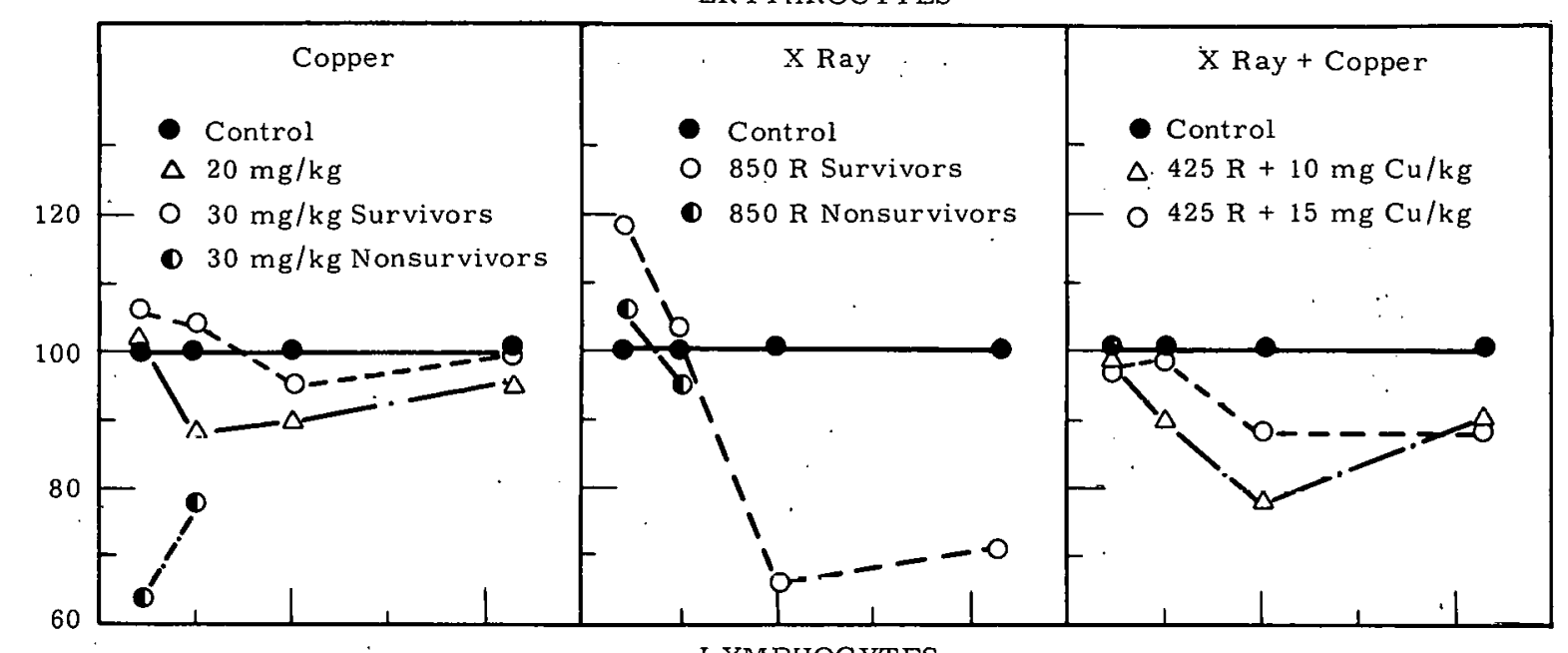

LYMPHOCYTES
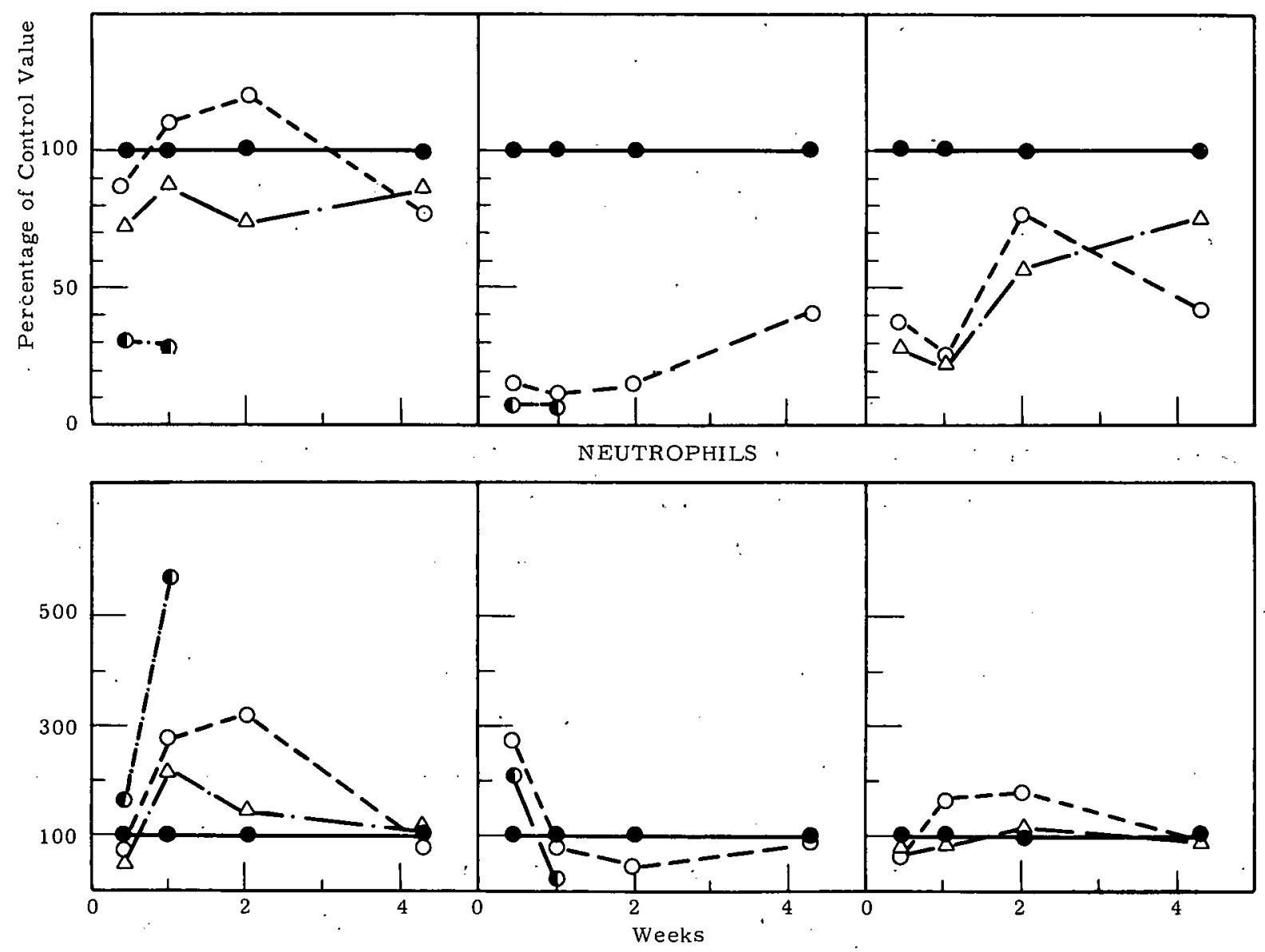

FIGURE 1... Effect of Copper, X Ray, or a Combination of the Two Agents

- on Erythrocyte, Lymphocyte, and Neutrophil Levels of Rats 


\begin{tabular}{|c|c|c|c|c|c|c|c|c|c|c|c|c|c|}
\hline \multirow{2}{*}{$\begin{array}{c}\text { Organ } \\
\begin{array}{c}\text { Erythrocytes } \\
\text { (per mi) }\end{array}\end{array}$} & \multirow{2}{*}{$\begin{array}{c}\text { Time after } \\
\text { treatment } \\
\text { (days) }\end{array}$} & \multicolumn{2}{|c|}{ Control } & \multicolumn{2}{|c|}{$20 \mathrm{mg} \mathrm{Cu} / \mathrm{kg}$} & \multicolumn{2}{|c|}{$30 \mathrm{mg} \mathrm{Cu} / \mathrm{kg}$} & \multicolumn{2}{|c|}{$850 \Omega$} & \multicolumn{2}{|c|}{$\begin{array}{r}425 \mathrm{R}+ \\
10 \mathrm{mg} \mathrm{Cu} / \mathrm{kg}\end{array}$} & \multicolumn{2}{|c|}{$\begin{array}{r}425 \mathrm{R}+ \\
15 \mathrm{mg} \mathrm{Cu} / \mathrm{kg} \\
\end{array}$} \\
\hline & & $\begin{array}{l}7.2 \\
7.5\end{array}$ & $\begin{array}{l} \pm 0.90^{b^{*}} \\
\pm 0.60^{\mathrm{a}}\end{array}$ & $\begin{array}{l}6.3 \\
6.5\end{array}$ & $\begin{array}{l} \pm 1.1^{\mathrm{bc}} \\
\pm 1.0^{\mathrm{ab}}\end{array}$ & $\begin{array}{l}8.7 \\
6.7\end{array}$ & $\begin{array}{l} \pm 1.5^{\mathrm{a}} \\
\pm 1.6^{\mathrm{ab}}\end{array}$ & $\begin{array}{l}4.1 \\
4.9\end{array}$ & $\begin{array}{l} \pm 0.90^{\mathrm{d}} \\
\pm 1.2^{\mathrm{c}}\end{array}$ & $\begin{array}{l}4.6 \\
6.5\end{array}$ & $\begin{array}{l} \pm 0.90^{\mathrm{d}} \\
\pm 0.80^{\mathrm{ab}}\end{array}$ & $\begin{array}{l}5.4 \\
5.8\end{array}$ & $\begin{array}{l} \pm 1.2^{\mathrm{cd}} \\
\pm 1.0^{\mathrm{bc}}\end{array}$ \\
\hline $\begin{array}{c}\text { Femurs + marrow } \\
\text { (per organ) }\end{array}$ & $\begin{array}{r}6 \\
14 \\
30\end{array}$ & $\begin{array}{l}0.67 \\
0.51 \\
0.39\end{array}$ & $\begin{array}{l} \pm 0.05 \\
\pm 0.10^{\mathrm{b}} \\
\pm 0.05\end{array}$ & 0.41 & $\begin{array}{l}- \\
- \\
\dot{ \pm} 0.04\end{array}$ & $\begin{array}{l}0.72 \\
0.39\end{array}$ & $\begin{array}{l} \pm 0.19 \\
\pm 0.07\end{array}$ & $\begin{array}{l}1.8 \\
0.69\end{array}$ & $\begin{array}{l} \pm 0.20^{\mathrm{a}} \\
\pm 0.19\end{array}$ & 0.53 & $\begin{array}{l}- \\
\pm 0.13\end{array}$ & & $\begin{array}{l}- \\
\pm 0.05\end{array}$ \\
\hline $\begin{array}{l}\text { Spleen } \\
\text { (per g dry weight) }\end{array}$ & $\begin{array}{r}6 \\
14 \\
30\end{array}$ & $\begin{array}{l}6.7 \\
8.7 \\
9.5\end{array}$ & $\begin{array}{l} \pm 1.5 \\
\pm 2.8^{b} \\
\pm 1.5\end{array}$ & 14 & $\begin{array}{l}- \\
\pm 3.3 .\end{array}$ & $\begin{array}{l}11 \\
14\end{array}$ & $\begin{array}{l} \pm 4.9 \\
\pm 4.3\end{array}$ & $\begin{array}{l}40 \\
13\end{array}$ & $\begin{array}{l}- \\
\pm 3.4^{\mathrm{a}} \\
\pm 4.3\end{array}$ & 11 & $\begin{array}{l}- \\
\pm 2.5\end{array}$ & $2 . n$ & $\bar{z}$ \\
\hline $\begin{array}{l}\text { Liver } \\
\text { (per organ) }\end{array}$ & $\begin{array}{r}6 \\
14 \\
30\end{array}$ & $\begin{array}{l}18 \\
19 \\
18\end{array}$ & $\begin{array}{l} \pm 1.0^{\mathrm{h}} \\
\pm 3.0^{\mathrm{b}} \\
\pm 2.1^{\mathrm{bc}}\end{array}$ & 16 & $\begin{array}{l}\because \\
\pm 1.2^{c}\end{array}$ & $\begin{array}{l}27 \\
16\end{array}$ & $\begin{array}{l} \pm 4.3 \\
\pm \\
\pm 3.1^{c}\end{array}$ & $\begin{array}{l}30 \\
24\end{array}$ & $\begin{array}{l}- \\
\pm 3.0^{\mathrm{a}} \\
\pm 5.4^{\mathrm{a}}\end{array}$ & 20 & $\begin{array}{l}- \\
\pm 2.2^{b}\end{array}$ & 19 & $\begin{array}{l}- \\
\pm 2.1^{b}\end{array}$ \\
\hline $\begin{array}{l}\text { Kidney } \\
\text { (per organ) }\end{array}$ & $\begin{array}{r}6 \\
14 \\
30\end{array}$ & $\begin{array}{l}1.2 \\
1.3 \\
1.0\end{array}$ & $\begin{array}{l} \pm 0.20^{\mathrm{b}} \\
\pm 0.20 \\
\pm 0.10^{\mathrm{ab}}\end{array}$ & 0.85 & $\begin{array}{l}- \\
\pm 0.08^{c}\end{array}$ & $\begin{array}{l}2.3 \\
0.92\end{array}$ & $\begin{array}{l} \pm 0.30^{\mathrm{a}} \\
\pm 0.08^{\mathrm{bc}}\end{array}$ & $\begin{array}{l}1.5 \\
1.1\end{array}$ & $\begin{array}{l}- \\
\pm 0.20 \\
\pm 0.30^{\mathrm{a}}\end{array}$ & 0.97 & $\begin{array}{l}- \\
\pm 0.08^{a b c}\end{array}$ & 0.94 & $\begin{array}{l}- \\
\pm 0.11^{b c}\end{array}$ \\
\hline
\end{tabular}

* Mean \pm yb\% confidence limits about the mean. Values with different letters are significantly different $(P<0.05)$ within the same time interval.

subcutaneous injection of copper appeared to be dose dependent. Both agents depleted lymphocyte reserves in the spleen, but lymphoblasts were also damaged by $\mathrm{X}$ irradiation.

Degenerative changes of the liver and kidney, as well as elevated concentrations of $\mathrm{Fe}^{59}$ in these organs were noted in rats treated with copper or X ray. Iron-59 levels of the spleen were also increased in animals that succumbed to treatment with $850 \mathrm{R}$ of $\mathrm{X}$ ray.

The cumulative fecal excretion of $\mathrm{Fe}^{59}$ tended to be increased in irradiated rats although no specific lesions of the gastrointestinal tract were evident 10 days after exposure. Generalized necrosis and loss of villar tips were observed in the small intestine of rats dying from copper treatment. Fecal $\mathrm{Fe}^{59}$ excretion was not elevated in these animals but urinary $\mathrm{Fe}^{50}$ tended to be higher.

Observations on the effect of a combined assault of one-half the lethal level of the two agents would not indicate that the actions of copper and $\mathrm{X}$ ray were additive since no deaths occurred and hematological. response was similar to but never greater than with one or the other toxic agent alone.

Copper appeared to act rapidly and directly on cellular structure and function, and, if the animal survived, repair was initiated very early. In contrast, $\mathrm{X}$ irradiation caused immediate as well as prolonged effects by impairing cèll production. 
BNWL-122

\title{
ULTRAHIGH-SPEED GROSS ALPHA AUTORADIOGRAPHY
}

\author{
J. J. C. Hsieh, F. P. Hungate, and S. A. Wilson
}

High-speed gross alpha autoradiograms can be obtained using $\mathrm{ZnS}: \mathrm{Ag}$ as an intensifier in conjunction with high-speed film. This tcchnique requires approximately $1 / 1000$ of the exposure time needed by conventional methods of using Kodak's NTB plates (nuclear track emulsion for beta particles).

High-speed autoradiographic technique is sought when exposure time is the prime consideration or the radiation level is too low for the conventional autoradiographic method to be practical. This report describes a technique using $\mathrm{ZnS}: \mathrm{Ag}$ as an intensifier to drastically reduce exposure time for gross alpha autoradiography.

When an alpha particle strikes a nuclear film, it is estimated that only about $0.1 \%$ of the radiation energy is utilized by the emulsion to produce the developable latent images. The phosphorescent ZnS crystals efficiently capture the alpha energy and then reradiate photons. Thus, $\mathrm{ZnS}$ phosphor helps the emulsion to use a significant quantity of the radiation energy which otherwise would have been lost. In other words, when a film is exposed for alpha radiation, it receives not only alpha radiation directly, but also a quantity of photons from the induced phosphorescence of $\mathrm{ZnS}$ crystals. Thus the film exposure time required to obtain the same photo density is greatly reduced.

The ZnS intensifier P7-920B (U.S. Radium Corporation) was chosen because of its efficiency and manipulation qualities, such as wettability and uniform grain size.

The technique is described as follows: The ZnS intensifier, bound in a $2 \%$ gelatin mixture, was coated directly on the mounted specimen or deposited by sedimentation on double aluminum coated plastic film. In the latter case, the dried ZnS:Ag film (12-14 $\left.\mathrm{mg} / \mathrm{cm}^{2}\right)$ was sandwiched between a photo emulsion and a specimen for autoradiographic exposure.

High-speed Polaroid Polascope 410 or Polaroid Land type 57 film was used because of its sensitivity and speed of film development. Also, it is convenient since no dark room is required for film development 
111

BNWL- 122

A few experiments have been conducted to determine the potential usefulness of the technique:

1. Gross autoradiography for detection of alpha emitters in biological samples: rat femur sections with plutonium deposition were used for the experiment as shown in Figure 1.

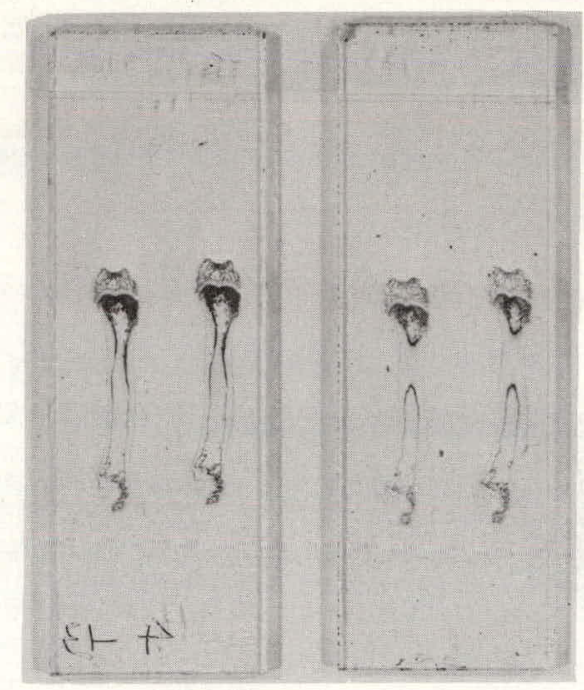

Film: $\quad$ NTB

Exposure

Time: $265 \mathrm{hr}$

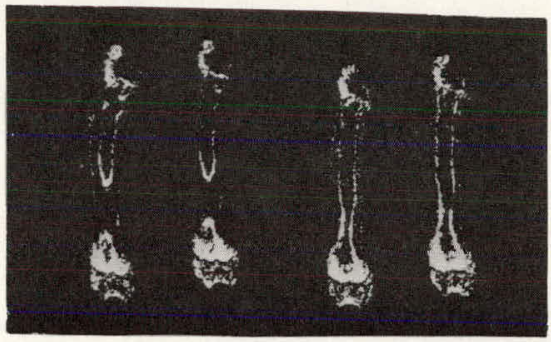

Film: Polaroid Polascope 410 Exposure

Time: $0.16 \mathrm{hr}$

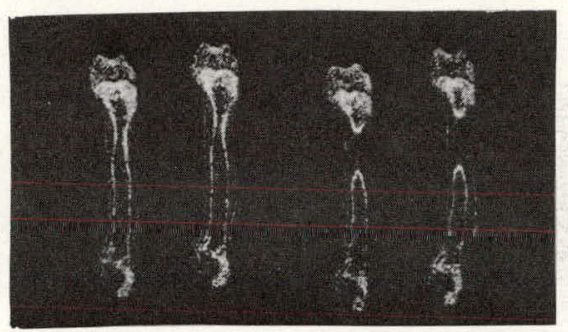

Film: Polaroid Land 57

(positive)

Exposure $0.25 \mathrm{hr}$ Time:

FIGURE 1. Gross Alpha Autoradiography of Rat Femur Sections A rat was intravenously injected with $\mathrm{Pu}^{239}$ solution. Ten micron femur sections were autoradiographed with NTB and NTA plates by conventional apposition techniques. Then the same femur sections were used in the high-speed autoradiographic techniques.

2. Detection of critical level of plutonium in urine samples: autoradiographs were made with electrolytically deposited samples from human urine. Samples with 0.06 disintegrations/min or above could be separated from the 0.03 disintegrations $/ \mathrm{min}$ samples 
with good precision. A sample with 0.03 disintegrations $/ \mathrm{min}$ is considered as normal background for bioassay purposes. The technique needs no microscopic examination and this permits substantial saving in time as compared with currently used microscopic counting of grains.

3. Detection of plutonium sliver in or on skin: Providing the sliver is not buried deeply inside the skin beyond the effective penetration range of alpha particles, an exposure time of $40 \mathrm{sec}$ or less was needed to locate the sliver in or on skin using this high-speed autoradiographic technique.

Future work is planned to improve the resolution of this technique for potential applications at the cellular level. 


\section{EFFECT OF I ${ }^{127}$ ON PASSAGE OF I ${ }^{131}$ FROM COWS TO MAN VIA MILK}

E. C. Watson, * I. C. Nelson, * D. H. Wood, *** R. O. McClellan, ${ }^{\dagger}$ and L. K. Bustad

Mill from dairy cows fed $\mathrm{I}^{131}$ and $0.002-2 \mathrm{~g}$ stable iodine was consumed by adult male volunteers. The resulting fractional thyroid uptake by eight men involved in both single and multiple intakes of $\mathrm{I}^{131}$ was 0.1-0.3. Based on single intake data, the peak thyroid burden occurred at about $24 \mathrm{hr}$ and decreased with an effective half-life of about 7 days. Increasing the iodine content of the cows' diet resulted in decreased amounts of $\mathrm{I}^{131}$ appearing in both the cows' thyroids and milk and in the thyroids of volunteers consuming the milk daily from cows fed $2 \mathrm{~g} / \mathrm{day}$ of stable iodine.

Milk from dairy cows fed $I^{131}$ either in a simulated single contamination event or in their daily ration for a prolonged period of time was ingested by volunteer, adult, male employees. During the prolonged administration of iodine, the stable iodine content of the diet was increased from about 2-5 $\mathrm{mg} /$ day to $2 \mathrm{~g} /$ day in order to test the effects on $\mathrm{I}^{131} \mathrm{con}$ centration in the cows ${ }^{1}$ milk and also in the thyroid of the cow and in man drinking the milk. The concentrations in the milk and in the cows'thyroids were previously reported (Hanford Biology Report for 1963).

At each dietary level of stable iodine, human participants ingested a single intake of the milk. Daily ingestion of milk by participants was conducted only at the lowest and highest dietary levels of stable iodine. None of the volunteers were working with radioactive sources, and none of them had any known or suspected thyroid problems.

Measurements of the thyroid burdens were made using a $3 \times 3$ in. thorium-activated NaI crystal which was calibrated using a source

* Radiation Protection Department, Battelle-Northwest.

*** Captain, USAF, VC, previously assigned to Hanford Laboratories. Present address: Brooks Air Force Base, Texas.

† Present address: Medical Research Branch, Division of Biology and Medicine, U.S. Atomic Energy Commission, Washington, D.C. 
consisting of $70 \mathrm{nCi}$ of $\mathrm{I}^{131}$ contained in a simulated thyroid of a plastic phantom (Figure 1). Gamma energy analysis was provided by a 400 channel, transistorized analyser. The subjects were monitored in a position similar to that of the phantom in Figure 1. Counting times of either 15 or 30 min were used depending upon the estimated level of activity in the thyroid. During the course of this study, two of the participants were monitored at Brookhaven National Laboratory's Medical Department and the New York University Institute of Industrial Medicine and the results were identical to ours.

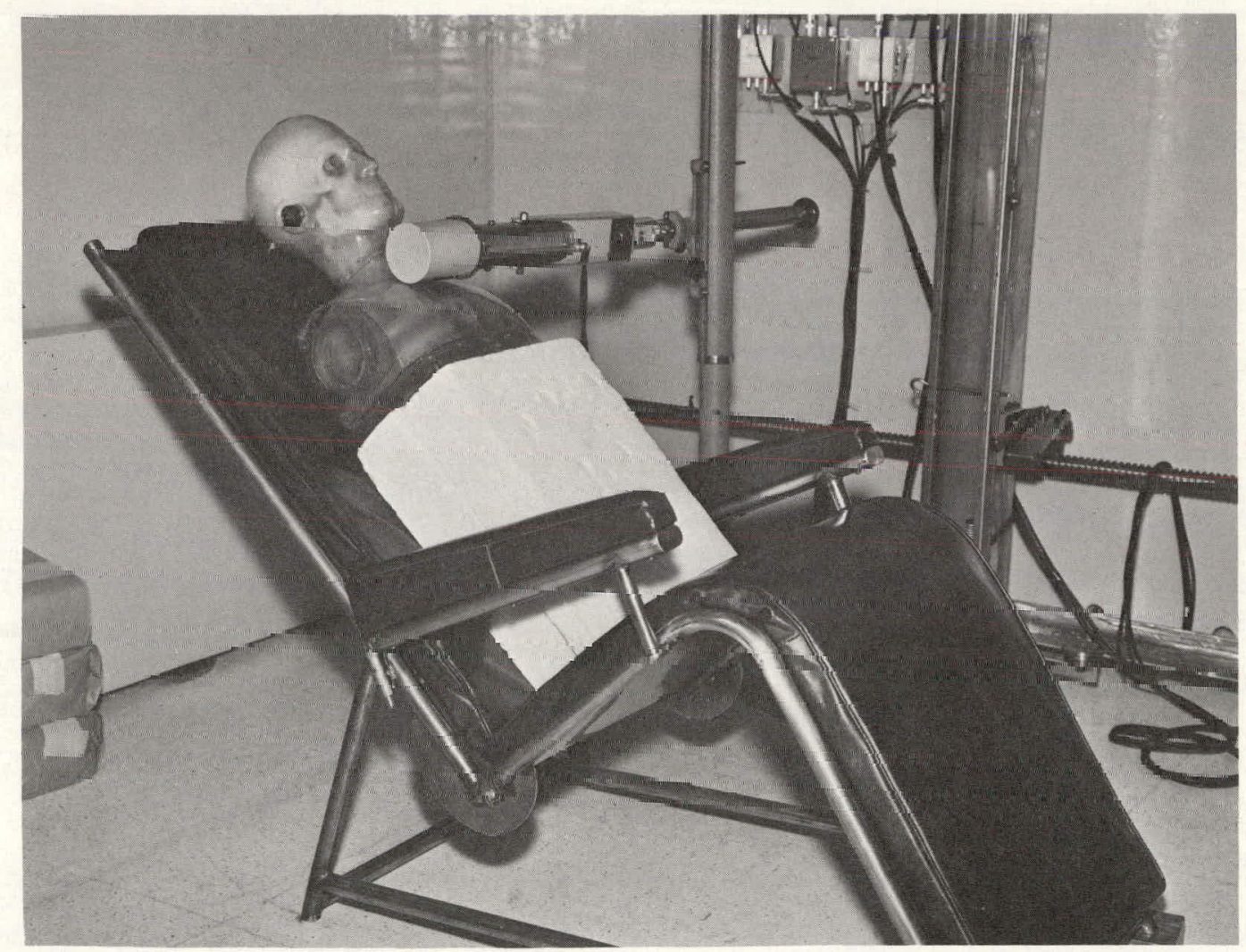

FIGURE 1. Calibrating Position of NaI Crystal and Phantom

Figure 2 shows the $I^{131}$ concentration in milk from cows on the low stable iodine diet in a simulated single contamination event as well as average thyroid burden of five subjects who consumed milk produced by these cows each day. A delay of about $72 \mathrm{hr}$ from production to consumption was utilized to simulate common marketing practices. From this plot, 
it appears that the peak in the cows' milk occurred at about 3-4 days following the initial ingestion. The peak thyroid burden of the humans occurred about 14 days later or about 15 days following their first intake. The activity of the milk dropped precipitously following the discontinuance of $\mathrm{I}^{131}$ intake by the cows.

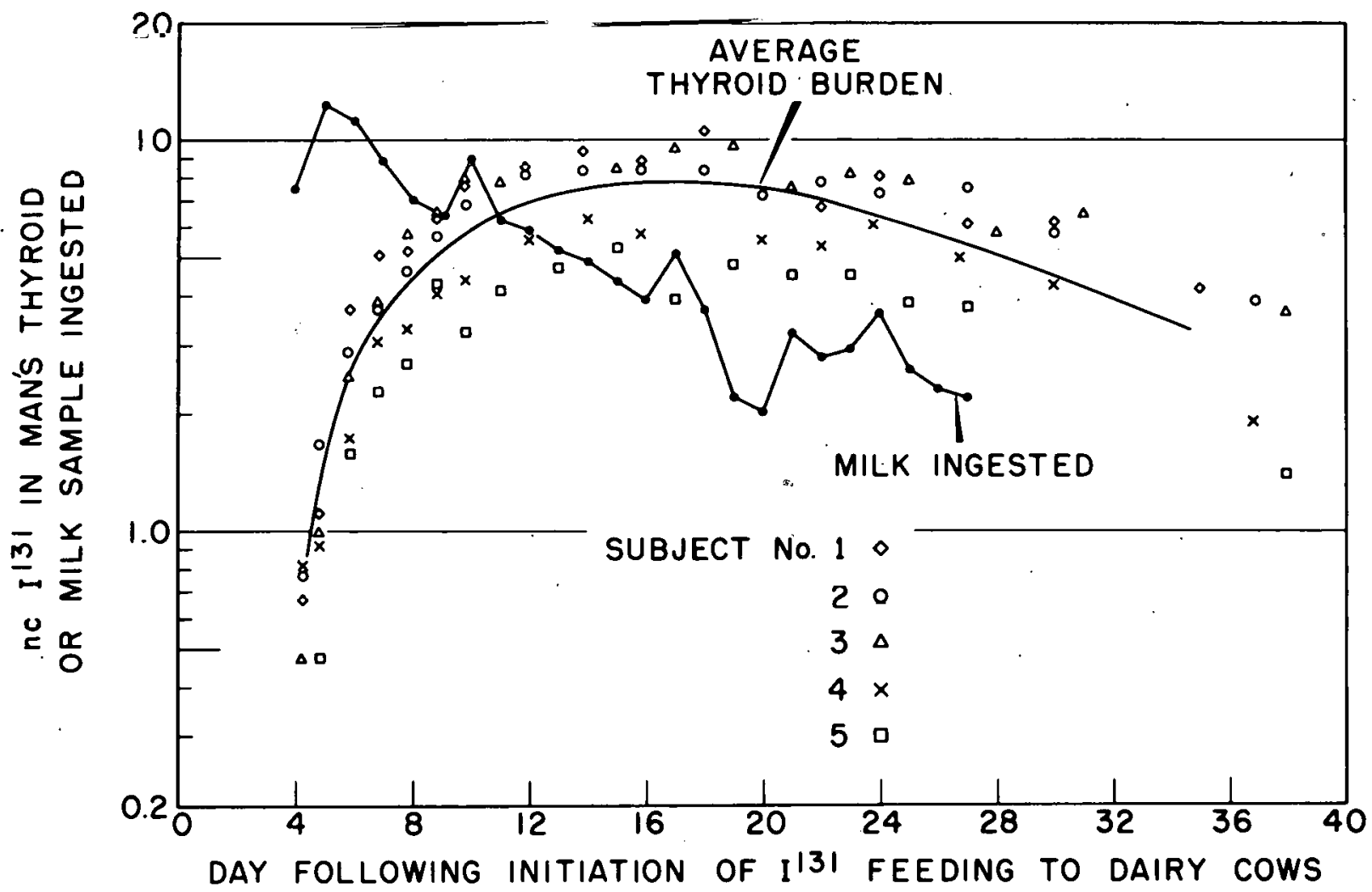

FIGURE 2. Thyroid Burden of Men Drinking I ${ }^{131}$ Contaminated Milk

The second phase of the study involved increasing the dietary level of stable iodine in animals on daily feedings. During the intermediate dietary levels of stable iodine, no detectable decrease in thyroid uptake was noted in any of the human participants. The highest dietary level of stable iodine ( $2 \mathrm{~g} /$ day in the cows' diet) resulted in a milk content of about $8 \mathrm{mg} \mathrm{I}^{127} /$ iter. The daily consumption of $700 \mathrm{ml}$ of this milk by two volunteers resulted in reducing their fractional uptake of $\mathrm{I}^{131}$ from about $25 \%$ to about $5 \%$. Figure 3 compares the data for one of these 
subjects. The graph compares this individual's uptake of $I^{131}$ from milk containing the high stable iodine level with his uptake from milk at the low stable iodine level.

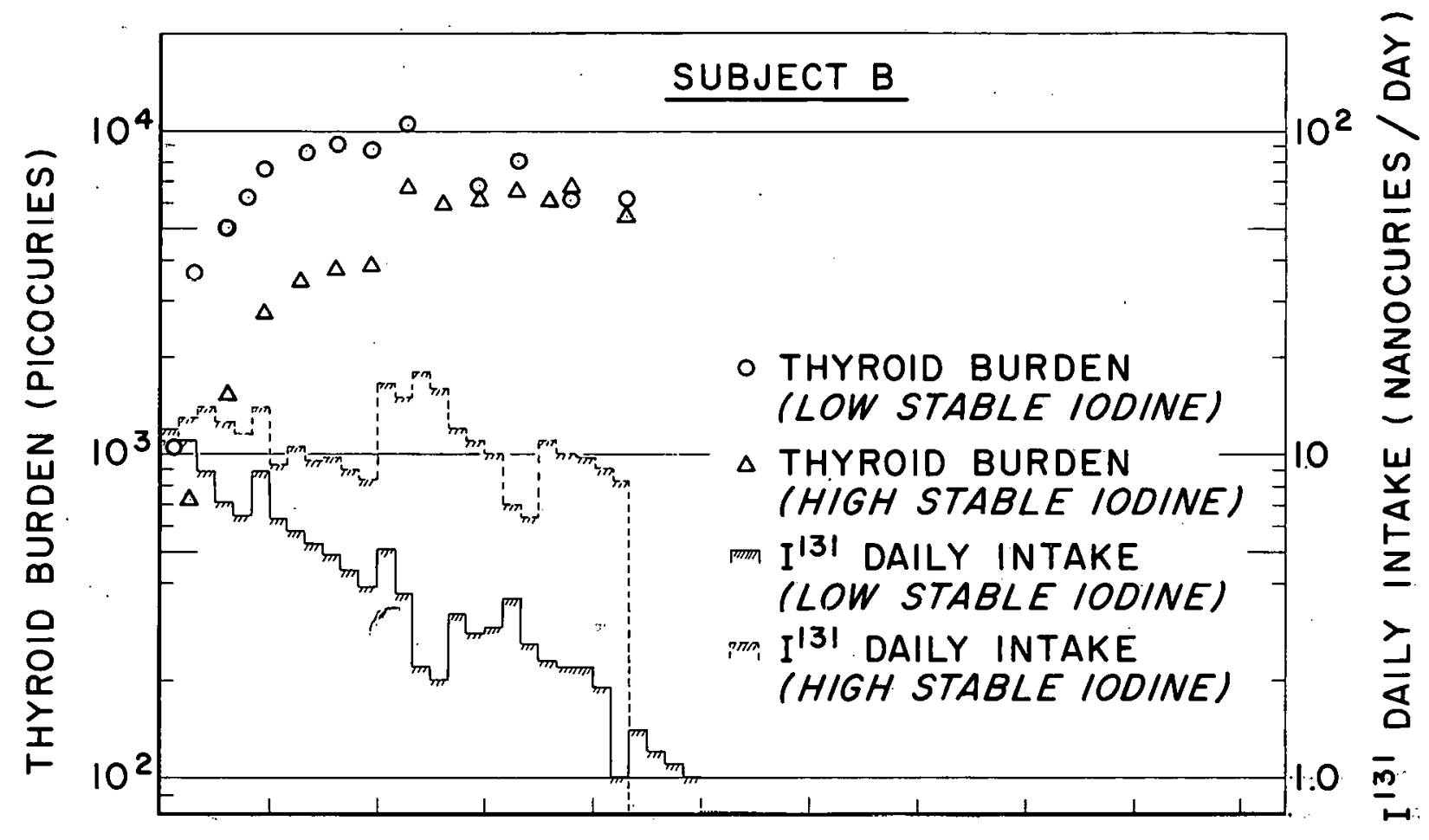

FIGURE 3. Effect of Stable Iodine on Thyroid Uptake by Adult Male Volunteers

The effective half-lives and fractional uptakes were evaluated from single intake studies conducted at the three lowest concentrations of stable iodine. These results with $95 \%$ confidence intervals are summarized in Table 1. The fractional uptakes at the highest stable iodine level were evaluated from the chronic intake data.

On the basis of this very limited study, it appears that the ICRP values for the effective half-life may be conservative for the average individual of large adult populations. The ICRP recommended value of 0.3 for $\mathrm{f}_{\mathrm{w}}$, however, may be appropriate for some individuals. From our data, a value of 7.0 days for the effective half-life appears to be more appropriate than 7.6 days utilized by ICRP. 
BNWL- 122

TABLE 1. Effective Half-Life and Apparent Fractional Thyroidal of $\mathrm{I}^{131}$ in Eight Male Adults

\begin{tabular}{|c|c|c|c|c|c|c|c|}
\hline \multirow[b]{2}{*}{ Subject } & \multirow[b]{2}{*}{$\begin{array}{l}\text { Age } \\
(\mathrm{yr})\end{array}$} & \multirow[b]{2}{*}{$\begin{array}{l}\text { Height } \\
\text { (in.) }\end{array}$} & \multirow{2}{*}{$\begin{array}{l}\text { Weight } \\
\text { (lb) }\end{array}$} & \multirow{2}{*}{$\begin{array}{c}\text { Milk } \\
\text { consumption } \\
(\mathrm{ml} / \text { day })(1)\end{array}$} & \multirow{2}{*}{$\begin{array}{c}\text { Effective } \\
\text { half-life } \\
\text { (days) }\end{array}$} & \multicolumn{2}{|c|}{$\begin{array}{c}\text { Apparent fractional uptake } \\
\text { by thyroid }\end{array}$} \\
\hline & & & & & & $\begin{array}{l}\text { Low } \\
\text { stable iodine } \\
\text { s }\end{array}$ & $\begin{array}{c}\text { High } \\
\text { stable iodine } \\
\text { s }\end{array}$ \\
\hline A & 35 & 72 & 170 & 1300 & $6.9 \pm 0.4^{(4)}$ & $0.26-0.32$ & $\begin{array}{c}0.06 \\
\text { (After } 8 \text { days) }\end{array}$ \\
\hline$B$ & 41 & 6.5 & 135 & $5 * 10$ & $6.9 \pm 0.6$ & $0.20-0.26$ & $\begin{array}{c}0.05 \\
\text { (After } 8 \text { days) }\end{array}$ \\
\hline $\mathrm{C}$ & 46 & 71 & 217 & 300 & $7.3 \pm 0.3$ & $0.11-0.12$ & \\
\hline $\mathrm{D}$ & 38 & 70 & 134 & 300 & $7.0 \pm 0.5$ & $0.18-0.22$ & \\
\hline$E$ & 26 & 69 & 170 & 300 & $7.1 \pm 0.6$ & $0.18-0.26$ & \\
\hline$F$ & 37 & 68 & 150 & 300 & $7.2 \pm 0.6$ & $0.14-0.16$ & \\
\hline G & 23 & 72 & 145 & 2300 & $6.2 \pm 1.2$ & $0.14-0.22$ & \\
\hline $\mathrm{H}$ & 39 & 68 & 170 & 760 & $7.2 \pm 0.5$ & $0.18-0.21$ & \\
\hline$B, D, G, H$ & $\mathrm{POC}$ & led data & & & $7.0 \pm 0.5$ & $0.18-0.22$ & \\
\hline
\end{tabular}

(1) Includes $300 \mathrm{~g}$ of $\mathrm{I}^{131}$-labeled milk.

(2) Measured from single intake of $\mathrm{I}^{131}$ in milk.

(3) Calculated from thyroid burden measurement following chronic intake of $\mathrm{I}^{131}$ in $\mathrm{milk}$.

(4) $\pm 95 \%$ confidence limits. 


\title{
REMOVAL OF INTERNALLY DEPOSITED PLUTONIUM FROM RATS
}

\author{
V. H. Smith
}

Deferoxamine (DFA) and diethylenetriaminepentaacetic acid (DTPA) when administered to the same rat showed a rooperative action wherein the plutonium deposition in bone reflected the DFA effect and the soft tissue response was that of DTPA. A similar response was not shown for the removal of wellfixed plutonium.

Considerations of the chelating properties and toxicology of deferoxamine* [Tripod, J. in Iron Metabolism, F. Gross (ed.) 1964. SpringerVerlag, Berlin. p. 503-17] made desirable a test of its possible efficacy in preventing the deposition or promoting the removal of plutonium.

Female, Sprague-Dawley rats were intravenously injected with $2 \mu \mathrm{Ci} \mathrm{Pu}^{239}$ (IV) in $0.2 \mathrm{ml}$ of $\mathrm{pH} 5$ citrate buffer. One, 5 , and $24 \mathrm{hr}$ later they were treated with $0.1 \mathrm{mmol}$ of the agents (total treatment dose, 0.3 mmol). To prevent tetany, slightly less than an equivalent amount of calcium was given with all DTPA doses. Urine and feces were collected daily from each treatment group of 10 rats. Five days after injection of plutonium the animals were killed and tissues analyzed by conventional methods.

Two results of practical importance are apparent from the results presented in Table 1: (1) treatment with DFA. decreased bone deposition of plutonium to about one-half the value obtained with DTPA, and (2) the two agents given together produced a partially additive effect. This latter observation was not expected since usually two chelating agents merely compete with one another for the available metal, the sum of their actions being the same as the effect of the stronger agent by itself. The enhanced effect of DFA is probably due to its different in vivo distribution and the consequent tapping of plutonium pools not available to DTPA. The greater fecal output and lower bone concentration when DFA is used also suggest a plutonium source and route of elimination different to that used by DTPA.

* Supplied through the courtesy of CIBA, Ltd., Basel, Switzerland 
119

BNWL- 122

TABLE*1. Effects of Treatments on Plutonium Content of Tissues and Excreta Five Days After Administration

\begin{tabular}{|c|c|c|c|c|c|}
\hline \multirow{3}{*}{$\begin{array}{c}\text { Treatment } \\
\text { and route of } \\
\text { administration }\end{array}$} & \multicolumn{5}{|c|}{ Percent of $\mathrm{Pu} 239$ Dose } \\
\hline & \multirow[b]{2}{*}{ Liver. } & \multirow[b]{2}{*}{ Kidneys } & \multirow[b]{2}{*}{ Femur } & \multicolumn{2}{|c|}{$\begin{array}{l}\text { Accumulated } \\
\text { excreta* }\end{array}$} \\
\hline & & & & Urine & Feces \\
\hline DFAB, i.p. $†$ & $1.3 \neq 0.1$ & $2.1 \pm 0.2$ & $0.14 \pm 0.01$ & 62. & 20 \\
\hline DTPA, i.p. & $0.58 \pm 0.07$ & $0.24 \pm 0.01$ & $0.28 \pm 0.02$ & 67 & 17 \\
\hline DFAB, i.m. ${ }^{\dagger}$ & $1.3 \pm 0.1$ & $1.5 \pm 0.1$ & $0.16 \pm 0.01$ & 66 & 23 \\
\hline $\begin{array}{l}\text { DFAB, i.m. + } \\
\text { DTPA, i.p. }\end{array}$ & $0.39 \pm 0.04$ & $0.54 \pm 0.04$ & $0.1 .3 \pm 0.01$ & 73 & 21 \\
\hline No treatment & \pm 1 & $1.4 \pm 0.2$ & \pm 0.2 & 2.5 & $6: 5$ \\
\hline
\end{tabular}

* Mean \pm standard error of the mean.

*** Being pooled results, these data were not statistically analyzed.

$\dagger$ i.p., intraperitoneally; i.m., intramuscularly.

Note: All treatments lowered the spleen content 5 - to 7 -fold below the control value of $0.35 \%$.

The poor removal. of plutonium from the liver and the buildup in the kidneys when DFA is used alone may be due to lability of the chelating agent. The organic moiety of the plutonium-DFA complex may be destroyed, surrendering its plutonium to the tissue where DTPA, in the combined treatment, can pick it up and complete the removal.

Since DFA was successful in preventing the deposition of plutonium in bone, it was tested for its ability to remove well-fixed plutonium, i.e., treatments were delayed until several days after the isotope injection. The answers sought were whether DFA would be better than DTPA in removing plutonium from bone, and whether it would act cooperatively with DTPA in overall removal. Eight days after the intravenous administration of $17.9 \mu \mathrm{Ci}$ of $\mathrm{Pu}^{238}$ as the $\mathrm{pH} 5$ citrate, $0.3 \mathrm{mmol}$ of DTPA was given to all animals (including controls) to flush out the "loose" plutonium. The various subsequent treatments should, then, reflect their; ability to improve on DTPA treatment. Phenylbutazone* (PBZ) was included among the agents tested since its pharmacology. (v. Rechenberg, H.:K., Phenylbutazone. 1962. Edward Arnold Publishers, Ltd., London) suggested that it might influence

: Supplied through the courtesy of Geigy Pharmaceutical Co. , Rahway, New Jersey 
isotopes in bone. Treatments were initiated two weeks after the isotope injection and were maintained according to the treatiment schedule shown in Table 2 for two weeks, followed. by alternate weeks of rest and treatment until the experiment was terminated at the end of the eighth week. Pooled excreta from each treatment group were collected three times weekly, dried, sealed in plastic bags, and sounted by gainnd analysis. The livers were minced into a plastic bag, spread evenly, dried in vacuo and counted in the same gamma analyzer used for the excreta. Other tissues were digested with nitric acid, plated and alpha counted in gas-flow, proportional counters.

TABLE 2. Concentration of $\mathrm{Pu}^{238}$ in Tissues and Cumulative Excreta for Treated and Control Rats Eight Weeks After Isotope Administration

\begin{tabular}{|c|c|c|c|c|c|c|c|c|c|c|c|c|}
\hline & & $\begin{array}{l}\mathrm{re} \\
\mathrm{Sc}\end{array}$ & tedv & & & & Percent I & ose per gran & dry weight & S. E. & Cumu & lative \\
\hline Agent (1) & $\overline{\mathrm{M}}$ & $\mathrm{T}$ & W & Th & F S & Survivors & Liver & Kidneys & Spleen & Femur & Urine & Feces \\
\hline $\begin{array}{l}\text { DFA } \\
\text { DTPA }\end{array}$ & $\mathrm{x}$ & $\mathrm{x}$ & $\mathrm{x}$ & $x$ & $\begin{array}{l}x \\
x^{(4)}\end{array}$ & $6 / 8$ & $0.11 \pm 0.02$ & $0.68 \pm 0.06$ & $0.18 \pm 0.01$ & $2.5 \pm 0.3$ & 4.2 & 2.6 \\
\hline $\begin{array}{l}\text { DFA } \\
\text { DTPA }\end{array}$ & $\begin{array}{l}x \\
x\end{array}$ & & $\begin{array}{l}x \\
x\end{array}$ & & $\begin{array}{l}\mathrm{x} \\
\mathrm{x}\end{array}$ & $7 / 8$ & $0.15 \pm 0.02$ & $0.38 \pm 0.03$ & $0.15 \pm 0.01$ & $3.4 \pm 0.1$ & 4.0 & 2.6 \\
\hline DFA & $\mathrm{x}$ & & $\mathrm{x}$ & & $\mathrm{x}$ & $4 / 8$ & $0.50 \pm 0.07$ & $0.86 \pm 0.05$ & $0.29 \pm 0.02$ & $3.6 \pm 0.2$ & 1.8 & 3.1 \\
\hline DTPA & $\mathrm{x}$ & & $x$ & & $x$ & $5 / 0$ & $0.23 \pm 0.04$ & $0.54 \pm 0.04$ & $0.24 \pm 0.03$ & $3.4 \pm 0.4$ & 3.5 & 2.6 \\
\hline Control ${ }^{(5)}$ & $\mathrm{x}$ & & $\mathrm{x}$ & & $\mathrm{x}$ & $7 / 9$ & $0.70 \pm 0.08$ & $0.86 \pm 0.09$ & $0.29 \pm 0.01$ & $3.8 \neq 0.2$ & 1.1 & 3.2 \\
\hline $\begin{array}{l}\mathrm{PBZ}^{(6)} \\
\mathrm{DFA}\end{array}$ & $\mathrm{x}$ & $\mathbf{x}$ & $\mathrm{x}$ & $\begin{array}{l}\mathrm{x} \\
\mathrm{x}\end{array}$ & $\mathrm{xx}^{(4)}$ & $5 / 8$ & $0.54 \pm 0.04$ & $1.0 \pm 0.1$ & $0.35 \pm 0.04$ & $3.8 \pm 0.2$ & 1.9 & 1.7 \\
\hline $\begin{array}{l}\text { PBZ } \\
\text { DTPA }\end{array}$ & $\mathrm{x}$ & $\mathrm{x}$ & $x$ & $\begin{array}{l}x \\
x\end{array}$ & $x x^{(4)}$ & $5 / 8$ & $0.19 \pm 0.05$ & $0.43 \pm 0.08$ & $0.19 \pm 0.01$ & $3.5 \pm 0.2$ & 3.7 & 2.4 \\
\hline $\begin{array}{l}\text { PBZ } \\
\text { Saline }\end{array}$ & $\mathrm{x}$ & $\mathrm{x}$ & $\mathrm{x}$ & $\begin{array}{l}x \\
x\end{array}$ & $x x^{(4)}$ & $5 / 8$ & $0.44 \pm 0.02$ & $0.70 \pm 0.09$ & $0.29 \pm 0.04$ & $4.4 \pm 0.3$ & 1.3 & 1.9 \\
\hline
\end{tabular}

(1) Unless noted otherwise, DFA given intramuscularly at $0.1 \mathrm{mmol} /$ dose; DTPA given intraperitoneally at same level.

(2) Being ponled results, these data were not statistically analyzed.

(3) Percent dose per organ.

(4) This dose given in p.m. and other in a.m.

(5) $2 \mathrm{cc}$ of physiological saline given intraperitoneally.

(6) $100 \mathrm{mg} / \mathrm{kg}$ given subcutaneously.

As shown in Table 2 , the $\mathrm{Pu}^{238}$ dose was marginally lethal, animals dying in each group despite the preliminary DTPA treatment. In animals receiving treatments, deaths occurred during the first or second treatment week; the control animals suffered one early death, one late death, and were all becoming moribund and showing symptoms resembling radiation bone-marrow death when the experiment was terminated. The rats which received DFA or DTPA treatments were all in good condition when the experiment was terminated. The PBZ-treated animals exhibited inappetance and diarrhea from the second treatment week. 
There was no clear evidence that DFA, alone or in combination with DTPA, was more effective than DTPA alone. Administration of DFA and DTPA on alternate days resulted in a significantly lower femur concentration than with any other treatment, but since this did not occur with any of the other DFA treatments it is not convincing. The DFA treatments were definitely inferior to DTPA in removal of plutonium from soft tissues. The PRZ was without beneficial effect.

Histology from this experiment is not completed, but the livers and kidneys of the treated animals show damage not present in the controls. Until this experiment can be repeated using less toxic levels of plutonium and a longer treatment series on a greater number of animals, one cannot recommend DFA as an adjunct to DTPA in the removal of well-fixed plutonium. 


\title{
REMOVAL OF INTERN ALLY DEPOSITED RUTHENIUM
}

\section{FROM RATS}

\author{
V. H. Smith
}

Several treatments were teatcd for the resuvval of Ru 106 from rats. None were successful on a practical basis. Results indicate that further study of reducing agents or sulfhydryl compounds in combination with chelons might lead to more effective treatments.

According to Catsch (Seidel, D., A. Catsch, and K. H. Schweer. Strahlentherapie 122: 595, 1963), ruthenium reacts so rapidly with blood. proteins and is so firmly bound that a chelon to be of use in removing it must have a very high affinity for the metal. Deferoxamine*(DFA) reacts rapidly and forms a highly stable chelate with Fe(III), and is capable of removing iron from most body ligands and hastening its excretion. Since ruthenium and iron are both transition elements, DFA might be expected to form a strong enough chelate with ruthenium to compete with the body ligands for the metal and thus hasten its excretion. Test tube experiments confirmed that Ru(III) did form a stable chelate with DFA, and one that was soluble at $\mathrm{pH} 7$ so that kidney excretion of the chelate could be expected. On the other hand, the formation rate of the chelate was fairly slow so that the DFA would have to be in contact with the ruthenium for several minutes to effect chelation. Ruthenium prefers to complex with sulfur rather than oxygen or nitrogen so several agents with available -SH groups were tested. Reduced glutathion (GSH) was tested, not only because it has an -SH group, but because its reducing properties might stabilize ruthenium in the +4 or +3 states which are more favorable for chelate formation with DFA or diethylenetriaminepentaacetic acid (DTPA).

Female, Sprague-Dawley rats were injected intravenously with about $5 \mu \mathrm{Ci}$ of tracer-free $\mathrm{Ru}{ }^{106}-\mathrm{Rh}^{106}$ contained in $0.2 \mathrm{~cm}^{3}$ of $0.5 \mathrm{~N} \mathrm{HC1}$. Pooled urine and feces were collected daily from each group of 10 rats and counted by gamma analysis in plastic containers set in a large,

* Supplied through the courtesy of CIBA, Ltd. , Basel, Switzerland 
well-type crystal. Animals were sacrificed five days after the isotope administration. All soft tissues.were solubilized with $4 \mathrm{~N} \mathrm{HCl}$ and counted in the liquid state.

As shown in Table 1 , the only treatment resulting in an overall lowering of the body content of ruthenium was the $500 \mathrm{mg}$ dose of $\mathrm{pH} 4$ GSH with DFA and DTPA. This dose of GSH was near the toxic limit; three rats from this group died and all were sick for 1-2 days after the treatment. When GSH was given at a more neutral $\mathrm{pH}$ in a dose of only $200 \mathrm{mg}$ the toxic effects were banished along with the beneficial ones. However, the data would indicate that the use of organic sulfhydryl compounds and reducing agents in combination with chelating agents should be explored further.

\begin{tabular}{|c|c|c|c|c|c|c|c|}
\hline Treatment $(1)$ & Liver & Kidneys & Spleen & Muscle. & Femur & Blood & Excreta \\
\hline & \multicolumn{7}{|c|}{ (percent of dose \pm standard error) } \\
\hline \multirow[t]{2}{*}{ None } & $5.5+0.3$ & $3.3+0.2$ & $0.78+0.10$ & $0.097+0.020^{(2)}$ & $0.18+0.02$ & $0.17+0.03^{(3)}$ & $30^{(4)}$ \\
\hline & & & \multicolumn{3}{|c|}{ (Fraction of Control Values ${ }^{(5)}$ ) } & & \\
\hline DFA & $-\cdot$ & -- & -- & --- & 0.82 & 0.76 & $\cdots$ \\
\hline DTPA & -- & $+\cdot$ & $\cdots$ & $\cdots$ & -- & $\cdots$ & $\cdots$ \\
\hline $\begin{array}{l}\mathrm{DFA}+\mathrm{DTPA} \\
\mathrm{DFA}+\mathrm{DTPA}+\mathrm{GSH}\end{array}$ & $0.42^{\mathrm{a}}$ & $\begin{array}{ll}\cdots \\
\cdots\end{array}$ & $0.36^{\mathrm{a}}$ & $0-\overline{b c}$ & $0-\overline{64^{a}}$ & $0^{--} 3^{\mathrm{a}}$ & $\because \%$ \\
\hline $\mathrm{DFA}_{*}$ at $10 \mathrm{~min}$ & $\begin{array}{ll}-4 \\
-2 .\end{array}$ & $\ldots$ & -- & 0.12 & 0.85 & 0.43 & $\begin{array}{l}1.5 \\
-. .\end{array}$ \\
\hline $\mathrm{GSH}^{*} \quad \ldots$ & -- & $\cdots$ & -. & $0.68^{b c}$ & -- & $\cdots$ & -- \\
\hline $\mathrm{GSH}^{*}+\mathrm{DTPA}$ & $\cdots$ & $\cdots$ & 0.81 & $0.76^{\mathrm{c}}$ & -- & $\cdots$ & -- \\
\hline DMSO + DTPA & $\cdots$ & $\cdots$ & $-\cdot$ & $0.63^{\mathrm{ab}}$ & -- & $\cdots$ & -- \\
\hline SPCA : $: \cdot$ & $\cdots$ & $\ldots$ & $\therefore$ & $0.86^{\mathrm{c}}$ & -- & $\cdots$ & $-\cdots$ \\
\hline $\begin{array}{l}\text { DMSO } \\
\text { MPTT }\end{array}$ & $\ldots$ & $\cdots$ & 0.78 & $\begin{array}{l}0.63^{\mathrm{ab}} \\
0.57^{\mathrm{a}}\end{array}$ & -- & -- & -- \\
\hline $\mathrm{GSH}^{*}+\mathrm{DMSO}+\mathrm{DTPA}$ & 0.83 & $\cdots$ & 0.71 & $0.72^{b c}$ & $\cdots$ & $\cdots$ & -- \\
\hline
\end{tabular}

(1) Unless otherwise noted, treatments were given $1 \mathrm{hr}$ after isotope injection at a dose of $0.1 \mathrm{mmol}$. GSH refers to a dose of $500 \mathrm{mg}$ as a $\mathrm{pH} 4$ slurry; GSH" refers to a dose of $200 \mathrm{mg}$ as a $\mathrm{pH}^{\circ} 6.8$ solution. All treatments were given intraperitoneally except DFA was given intramuscularly. Abbreviations are defined in the text except:

DMSO = dimethylsulfoxide, dose $500 \mathrm{mg}$ as an aqueous $\mathrm{pH} 7$ solution

MPTT $=5$-mercapto-3-phenyl-1,3,4-thiadiazole-2-thione, as $\mu \mathrm{H} 7$ solution

(2) Percent of dose $/ \dot{g}$.

(3) Percent of dose $/ \mathrm{ml}$.

(4) Percent of dose/rat.

(5) All listed values are significantly different from the control values at the $5 \%$ level. Any values in the same column with different superscripts are significantly different from each other. No listing indicates a value not significantly different from controls.

DFA was no more effective. when given 10 min after the ruthenium than when given after $1 \mathrm{hr}$. indicating that the slowness of chelate formation is probably one factor in this chelon's inability to promote ruthenium 
excretion. Although DFA did lower the femur $\mathrm{Ru}^{106}$ content, the combination of DFA and DTPA did not enhance this effect. Several of the treatments depressed the muscle. Ru ${ }^{106}$ content leading one to suspect that the se agents could compete with the muscle ligands for the metal ions but not with the ligands of other tissues. 
THE EFFECT OF DTPA ON TRANSLOCATION AND EXCRETION OF INHAI,EN $\mathrm{Ce}^{14.4}-\mathrm{Pr}^{144}$ OXIDE IN DOGS:

E. G. Tombropoulos; W. J. Bair, and K. E. McDonald

DTPA treatments increaser the clearance of $\mathrm{Ce}{ }^{144-} \mathrm{Pr}^{144}$ from all tissues after inhalation of $\mathrm{Ce}^{144} \mathrm{O}_{2}$ which was prepared by precipitation with peroxide. However, after inhalation of calcined $\mathrm{Ce}^{144} \mathrm{O}_{2}$, DTPA treatments caused the removal of only Ce $\mathrm{C}^{144}-\mathrm{Pr}^{144}$ translocated to other tissues and did not appreciably reduce the lung burden.

The effectiveness of diethylenetriaminepentaacetate (DTPA) in decreasing the total body burden of inhaled. $\mathrm{Ce}^{144}-\mathrm{Pr}^{144}$ oxide in dogs was found to be appreciably less for cerium oxide prepared by calcination than by peroxide precipitation (Hanford Biology Research Annual Report for 1963). Further data from these experiments describing the tissue distribution and excretion of $\mathrm{Ce}^{144}-\mathrm{Pr}^{144}$ are reported here.

Seven beagle dogs were exposed to cerium oxide aerosols prepared by peroxide precipitation and three dogs were exposed to cerium oxide prepared by.calcination. The experimental procedures and the treatment regimes are described elsewhere (Hanford Biology Research Annual Report for 1963). At the end of the experiments the animals were killed by exsanguination under anaesthesia.

Table 1 shows that the effect of DTPA on the tissue distribution of $\mathrm{Ce}^{144}-\mathrm{Pr}^{144}$ depended on the method by which the oxide was prepared and on the time at which the DTPA was administered after exposure to the $\mathrm{Ce}^{144}-\mathrm{Pr}^{144}$ oxide. DTPA treatment reduced the amount of $\mathrm{Ce}^{144}-\mathrm{Pr}^{144}$ found in tissues of dogs that inhaled $\mathrm{Ce}^{144}-\mathrm{Pr}^{144}$ oxide prepared by peroxide precipitation. The magnitude of reduction was greatest when the DTPA treatment was given immediately after exposure and varied among the tissues. The smallest reduction was observed in the amount of $\mathrm{Ce}^{144}-$, $\mathrm{Pr}^{144}$ found in lung tissue and bronchial lymph nodes. It is possible that immediate DTPA treatment caused early transport of $\mathrm{Ce}^{144}-\mathrm{Pr}^{144}$ from the lung by the blood and excretion in the urine without appreciable deposition in other tissues. 
TABLE 1. Distribution of $\mathrm{Ce}{ }^{144}-\mathrm{Pr}^{144}$ in Different Tissues Four Months After Inhalation of $\mathrm{Ce}^{144} \cdot \mathrm{Pr}^{144} \mathrm{Oxide}^{14}$

\begin{tabular}{|c|c|c|c|c|c|c|c|c|c|c|c|c|}
\hline \multirow[b]{2}{*}{$\begin{array}{c}\text { Method } \\
\text { of } \mathrm{CeO} 2 \text { preparation }\end{array}$} & \multirow{2}{*}{$\begin{array}{c}\text { Day } \\
\text { treatment } \\
\text { began } \\
\text { (DTPA) } \\
\end{array}$} & \multirow{2}{*}{$\begin{array}{c}\text { Percent } \\
\text { of initial } \\
\text { body burden } \\
\text { found in tissues }\end{array}$} & \multirow{2}{*}{ Lung } & \multicolumn{8}{|c|}{ - Percent of lulal mCi in tissue } & \multirow[b]{2}{*}{ Remaining } \\
\hline & & & & $\begin{array}{c}\text { Bronchial } \\
\text { lymph } \\
\text { nodes } \\
\end{array}$ & Liver & Kidney & Skeleton & $\begin{array}{c}\text { Large } \\
\text { intestine }\end{array}$ & $\begin{array}{c}\text { Small: } \\
\text { intestine }\end{array}$ & $\begin{array}{c}\vdots \\
\text { Muscle }\end{array}$ & Spleen & \\
\hline Peroxide precipitation & None & 62 & 27 & 0.32 & 41 & 0.86 & 25 & 0.11 & 0.26 & 4.0 & 0.07 & 1.4 \\
\hline Peroxide precipitation & None & 72 & 69 & 0.06 & 13 & 3.6 & 9.2 & 0.03 & 0.22 & 3.0 & 0.04 & 1.5 \\
\hline Peroxide precipitation & 0 & 2.3 & 86 & 0.40 & 1.9 & 0.65 & 6.9 & 0.20 & 0.42 & 0.57 & 0.06 & 3.4 \\
\hline Peroxide precipitation & 0 & 4.5 & 95 & 0.99 & 1.6 & 0.41 & 1.1 & 0.04 & 0.05 & 0.07 & 0.02 & 1.1 \\
\hline Peroxide precipitation & 5 & 15 & 56 & 0.49 & 3.3 & 0.99 & 35 & 0.03 & 0.11 & 2.2 & 0.05 & 1.5 \\
\hline Peroxide precipitation & 27 & 32 & 4.4 & 0.46 & .3 .8 & 1.1 & 41 & 0.05 & 0.42 & 6.2 & 0.04 & 3.1 \\
\hline Peroxide precipitation & 98 & 60 & 33 & 0.33 & 30 & 0.76 & 28 & 0.10 & 0.26 & 4.5 & 0.08 & 2.9 \\
\hline Calcination & None & 11 & .74 & 0.85 & $0.46^{\circ}$ & 1.2 & 14 & 0.72 & 0.11 & 6.1 & 0.06 & 2.1 \\
\hline Calcination & 0 & 17 & 93 & 1.4 & 0.64 & 0.20 & 2.8 & 0.09 & 0.04 & 0.88 & 0.01 & 0.8 \\
\hline Calcination & 15 & 12 & 91 & 3.3 & 0.37 & 0.70 & 3.2 & 0.03 & 0.03 & 0.24 & 0.01 & 0.78 \\
\hline
\end{tabular}

DTPA treatment reduced the amount of $\mathrm{Ce}^{144}-\mathrm{Pr}^{144}$ in all tissues except lung, liver, and bronchial lymph nodes in dogs which inhaled calcined cerium oxide. This reduction was more pronounced in the skeleton. However, since translocation of $\mathrm{Ce}^{144}-\mathrm{Pr}^{144}$ from the respiratory tract to other tissues was minimal as indicated by the data from the untreated dog, the removal of $\mathrm{Ce}^{144}-\mathrm{Pr}^{144}$ from the tissues did not cause a significant decrease in total body burden.

These results in connection with the excreta data (Table 2). suggest that DTPA may prevent the mobilization of calcined $\mathrm{Ce}^{144}-\mathrm{Pr}^{144}$ oxide from the lung. DTPA may: also facilitate urinary excretion of the small. amount of $\mathrm{Ce}^{144}-\mathrm{Pr}^{144}$ which passes into the circulation, and thus prevent deposition in other tissues.

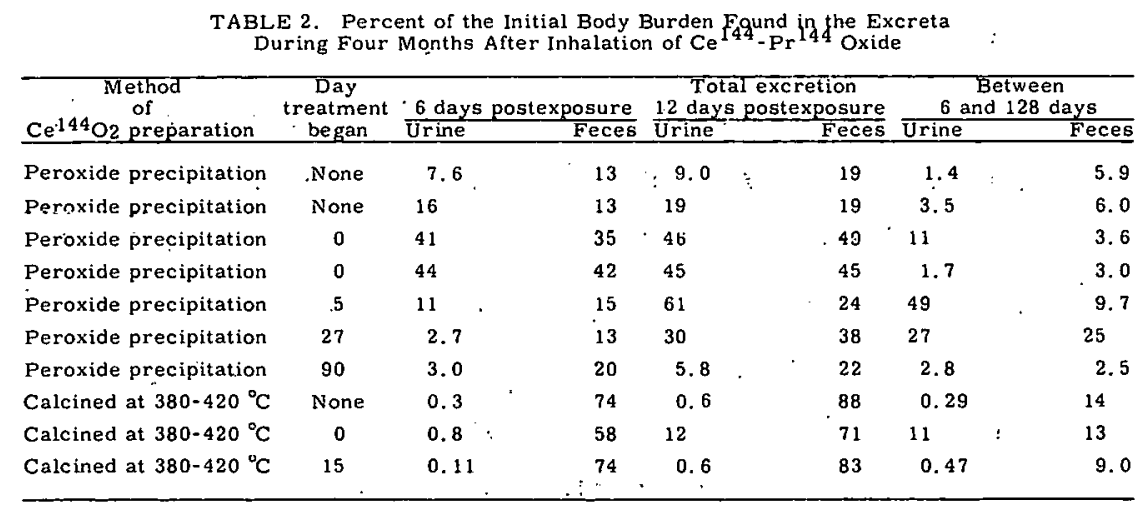

Table 2 shows the percent of initial body burden found in the excreta 0 to 6 days postexposure and 6 to 128 days postexposure. For both methods of preparation of cerium oxide, DTPA treatment increased the percent of 
$\mathrm{Ce}^{144}-\mathrm{Pr}^{144}$ found in the urine as compared with untreated animals. The fecal excretion of $\mathrm{Ce}^{144}-\mathrm{Pr}^{144}$ was also accelerated by treatment with DTPA when the $\mathrm{Ce}^{144}-\mathrm{Pr}^{144}$ oxide was prepared by peroxide precipitation, but decreased in the case of calcined $\mathrm{Ce}^{144}-\mathrm{Pr}^{144}$ oxide. The suppression of $\mathrm{Ce}^{144}-\mathrm{Pr}^{144}$ excretion in feces by DTPA after inhalation of calcined $\mathrm{Ce}^{144}-\mathrm{Pr}^{144}$ occurred during the first six days and was not compcnsated for by even the accelerated urinary excretion occurring during the entire 128 days of the experiment. Thus, DTPA actually failed to reduce the net total body burden of $\mathrm{Ce}^{144}-\mathrm{Pr}^{144}$ although considering urinary excretion alone it would appear otherwise.

These data indicate that the method of preparation determines the biochemical reactivity of cerium oxide in the body, the nature of possible complexes, and specifically whether it can be removed from the body by DTPA. 


\title{
BILE SALT ABSORPTION
}

\section{FROM THE IRRADIATED RAT INTESTINE}

\author{
M. F. Sullivan
}

Exposure of the abdomen to $1500 \mathrm{R}$ resulted in a $50 \%$ decrease in bile salt ahsorption at three days after exposure. This decreased function in the small intestine was shown to result in an increased excretion of bile salts.

The bile salts have bcen shown to be of significance in the intestinal radiation syndrome by influencing mucus removal and promoting radiation diarrhea. Such effects may be caused by an increased sensitivity of the intestine to the action of bile constituents in the lumen of the irradiated intestine. This sensitivity may result from, or be intensified by, a loss of absorptive function. This report describes studies of bile salt absorption as influenced by irradiation.

Rats were exposed to abdominal X irradiation with a $250 \mathrm{kV}$ potential $X$-ray therapy machine. At variuus intervals after exposure to $1500 . R$ their bile ducts were cannulated, and a $15 \mathrm{~cm}$ segment of the ileum was isolated with ligatures and injected with $0.3 \mathrm{ml}$ of labeled bile. The labeled bile was obtained by injecting $\mathrm{C}^{14}$-labeled cholic acid into normal rats and collecting labeled bile secreted by these animals.

The data shown in Figure 1 demonstrate that $80 \%$ of the labeled rat bile was absorbed and resecreted in the bile of unirradiated, bile duct cannulated rats, within one hour after injection. Absorption was not appreciably depressed during the first or second day after irradiation but at three days a $50 \%$ decrease occurred. At five days, bile salt absorption was decreased $70 \%$ from control values in spite of marked mucosal regeneration.

From this observation of decreased absorption, an increased accumulation of bile salt in the lumen of the irradiated intestine might be anticipated. To test this, rats were injected intravenously with $\mathrm{C}^{14}$-labeled cholic acid. After $24 \mathrm{hr}$, during which time the injected bile should have thoroughly mixed with the bile salt pool, their bile ducts were cannulated. 
BNWL- 122

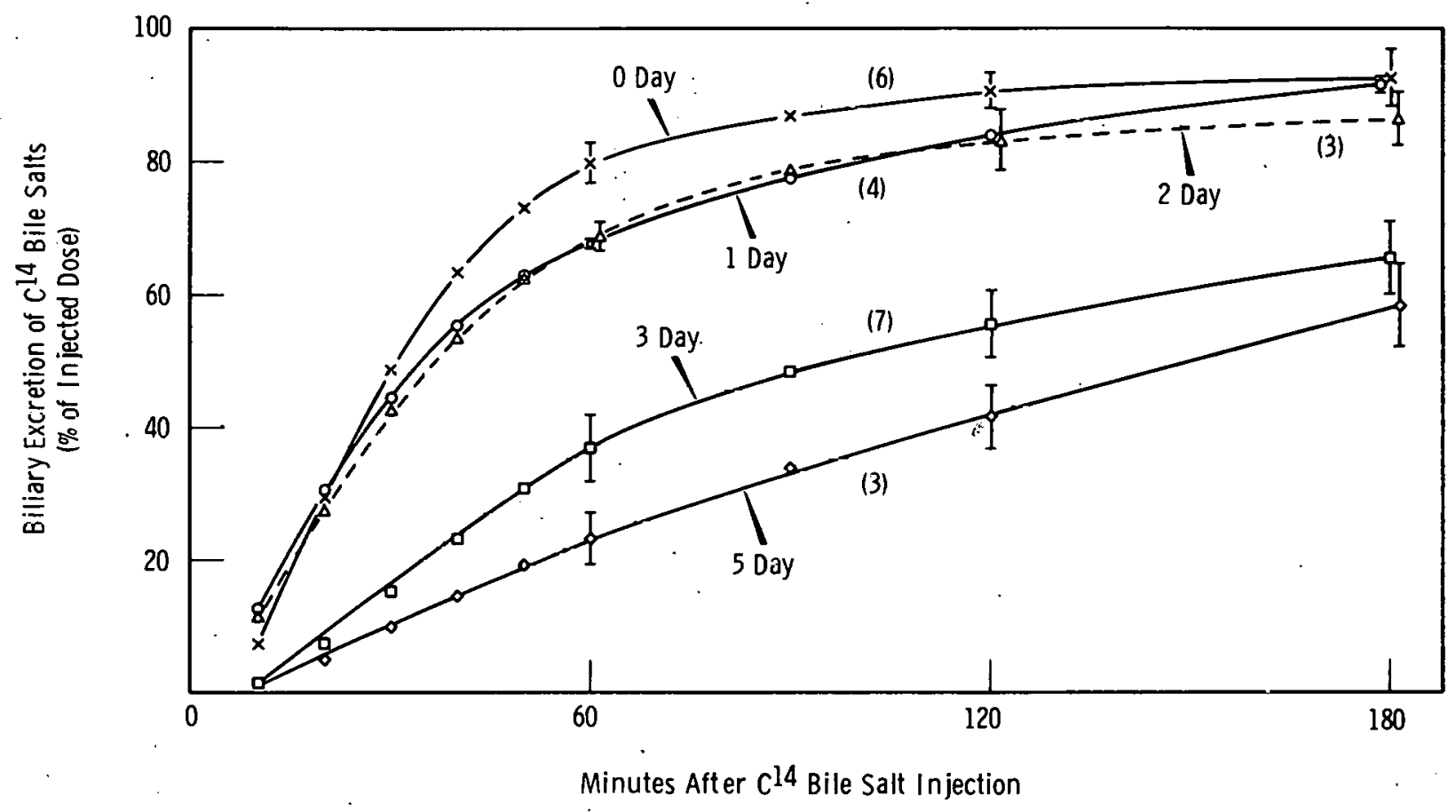

FIGURE 1. Biliary Secretion of $C^{14}$-Labeled Bile Salts After Injection of Radioactive Rat Bile into the Ileum of Rats at Various Intervals After Exposure of the Abdomen to $1500 \mathrm{R}$ of X Rays

Six unirradiated rats secreted $12.9 \pm 0.4 \%$ (S. E.) of the label hourly in the bile while irradiated rats secreted only half $(6.3 \pm 2.1 \%)$ that quantity at three days after $1500 \mathrm{R}$. An analysis of the distribution of label in intravenously injected rats that were not bile duct cannulated showed (Table 1) almost twice as much in the lower bowel and fecal excreta after irradiation. Only one-fifth as much label was found in the small intestine of irradiated rats as compared to nonexposed controls, a consequence which might be predicted from the decreased secretion of radioactivity in the bile at that time, due to prior excretion into the colon.

The colon has a low capacity for bile salt absorption and is apparently unable to compensate for the loss of function of the ileum. It is, therefore, exposed to an increased concentration of bile salts after irradiation. Since bile salts are changed by bacterial action in the large bowel to free acids that are even more potent surfactants, permeability may be 
altered or the reabsorptive capacity of the large bowel reduced, which could lead to the increased fluid and electrolyte losses that follow irradiation. Such an action may explain the effect of bile duct cannulation in preventing radiation diarrhea. Studies on the effect of bile salts on fluid and electrolyte transport are presently in progress:

TABLE 1. Distribution of Radiuactivity $24 \mathrm{hr}$ $\Lambda$ fter Irtravenous Administration of $\mathrm{C}^{14}$ Cholic A.cid $\left(1 \times 10^{5} \mathrm{cpm} / 0.02 \mathrm{mg}\right)^{*}$

\begin{tabular}{lcc}
\hline & Control & $\begin{array}{c}\text { X Ray } \\
\text { (4 days after 1500 R) }\end{array}$ \\
$\begin{array}{l}\text { Percent. Recovered in: } \\
\text { Liver }\end{array}$ & & $0.3(3)$ \\
Stomach & & $1.5(3)$ \\
Small Intestine & & \\
$\quad$ Contents & 40.2 & 7.7 \\
Wall & 18.5 & 3.8 \\
$\quad$ Total & $58.7(6) \pm 3.9$ & $11.5(7) \pm 2.4$ \\
Large Intestine & & \\
Contents & 23.8 & $42.9 \pm 2.0$ \\
$\quad$ Wall & 0.5 & 0.6 \\
$\quad$ Total & $24.3(6) \pm 3.5$ & $43.5(7) \pm 2.0$ \\
Total Recovery & 83.0 & 56.8 \\
\hline
\end{tabular}

* Average values \pm standard error of the mean

Note: number of rats in parentheses 


\section{THE EFFECT OF BILE ON S ${ }^{35}$ INCORPORATION INTO INTESTINAL MUCOPOLYSACCHARIDES}

M. F. Sullivan

Sulphur-35 uptake was 11 sed as a mcasure of mucus synthesis in the intestine. Exposure to $1000 \mathrm{R}$ decreased $\mathrm{S}^{35}$ uptake in the stomach, duodenum, ileum, cecum, and colon at three and four days after exposure. Draining the bile outside the lumen had the effect of preserving the mucus. This sparing effect was especially notable in the large intestine, where the quantity of mucus was greater than in the small bowel.

The elimination of bile from the lumen of the irradiated intestine of rats after exposure results in a preservation of goblet cells in the damaged mucosa. Since the goblet cells contain a large component of neutral sulfomucopolysaccharides, the uptake of $\mathrm{S}^{35}$ may be used as an index of mucus content and mucus synthesis in the irradiated gut.

Rats were exposed to $1000 \mathrm{R}$ of abdominal irradiation $(250 \mathrm{kV}$ potential $\mathrm{X}$ rays) and killed at three or four days after $\mathrm{X}$ ray. This was the time when the influence of bile on changes in mucus content was most obvious by microscopic observation. Six hours prior to sacrifice $2 \mu \mathrm{Ci} / \mathrm{g}$ body weight of $\mathrm{S}^{35}$ as $\mathrm{Na}_{2} \mathrm{SO}_{4}$ were administered intraperitoneally. The mucus was extracted in alkali and dialyzed. Sections adjacent to those used for radiochemical analysis were fixed in $10 \%$ formalin and stained with alcian bluc. Autoradiograms were also prepared to show localization of the $\mathrm{S}^{35}$ in mucus glands.

Results from scintillation counting of the extracted and dialyzed mucus are shown in Figure 1. The uptake of $\mathrm{S}^{35}$ increases as one proceeds distally in the gastrointestinal tract. Irradiation of the abdomen with $1000 \mathrm{R}$ caused a depression in all regions of the GI tract that was apparent at three days but which was more obvious at four days. The greatest change occurred in the $S^{35}$ uptake by the large bowel where incorporation was about one-third the preirradiation value. 
BNWL- 122

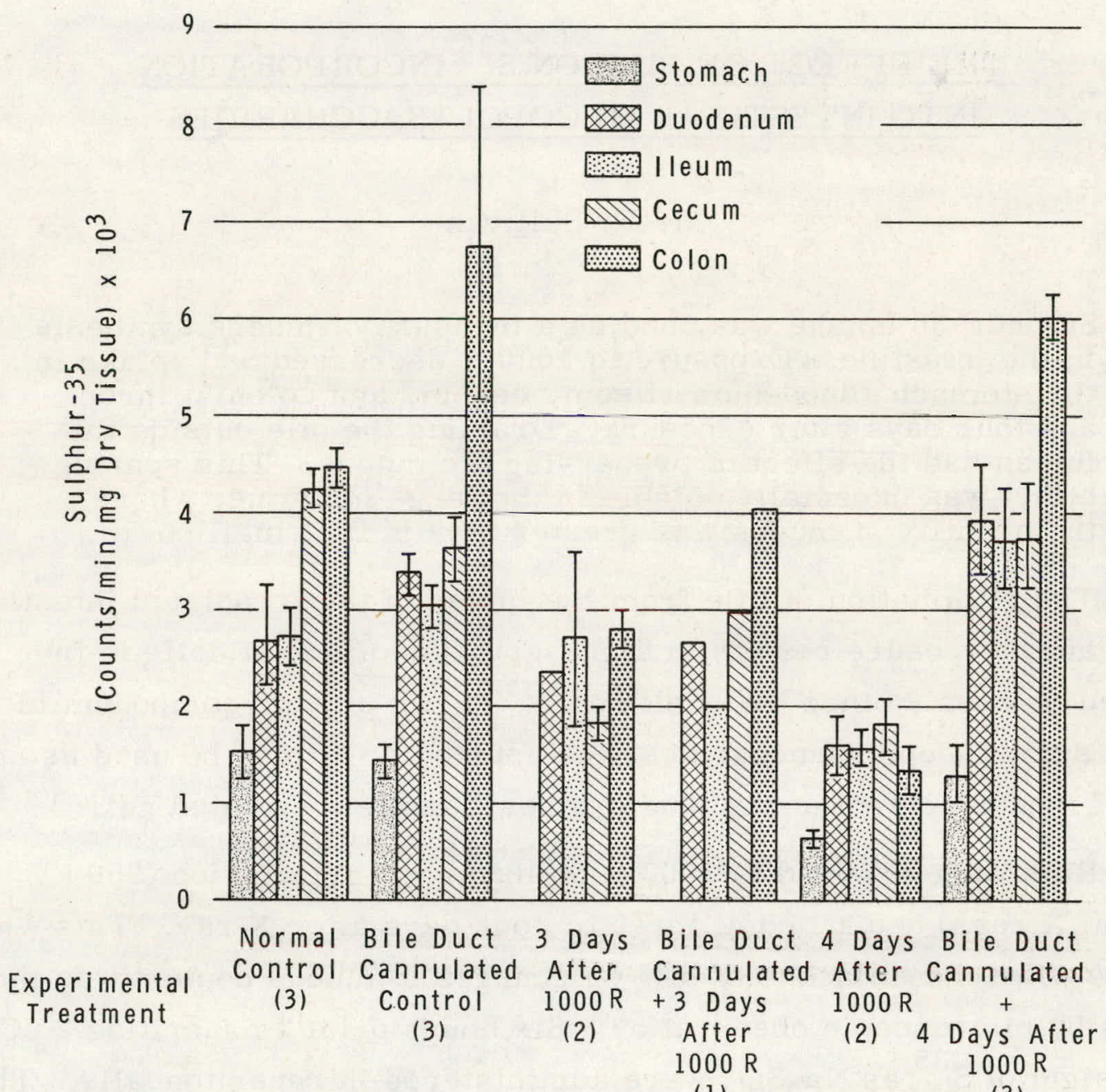

FIGURE 1. Sulphur-35 Incorporation into the Mucus of Various Portions of the Gastrointestinal Tract After Abdominal X-Irradiation of Rats

If the animals were not irradiated following bile duct cannulation, the goblet cells often appeared enlarged under microscopic examination. The incorporation of $\mathrm{S}^{35}$ was increased, especially in the colon. This influence of bile on mucus was noted at three days after $\mathrm{X}$ ray but was more obvious at four days. The effect of radiation on $\mathrm{S}^{35}$ incorporation in the colon of rats with or without bile present is shown in Figure 2. Damage to cells other than the mucus cells was not appreciably less in the absence of bile. A change in the rate of mucus production may be responsible for the near normal uptake of $\mathrm{S}^{35}$ per gram of tissue in spite 

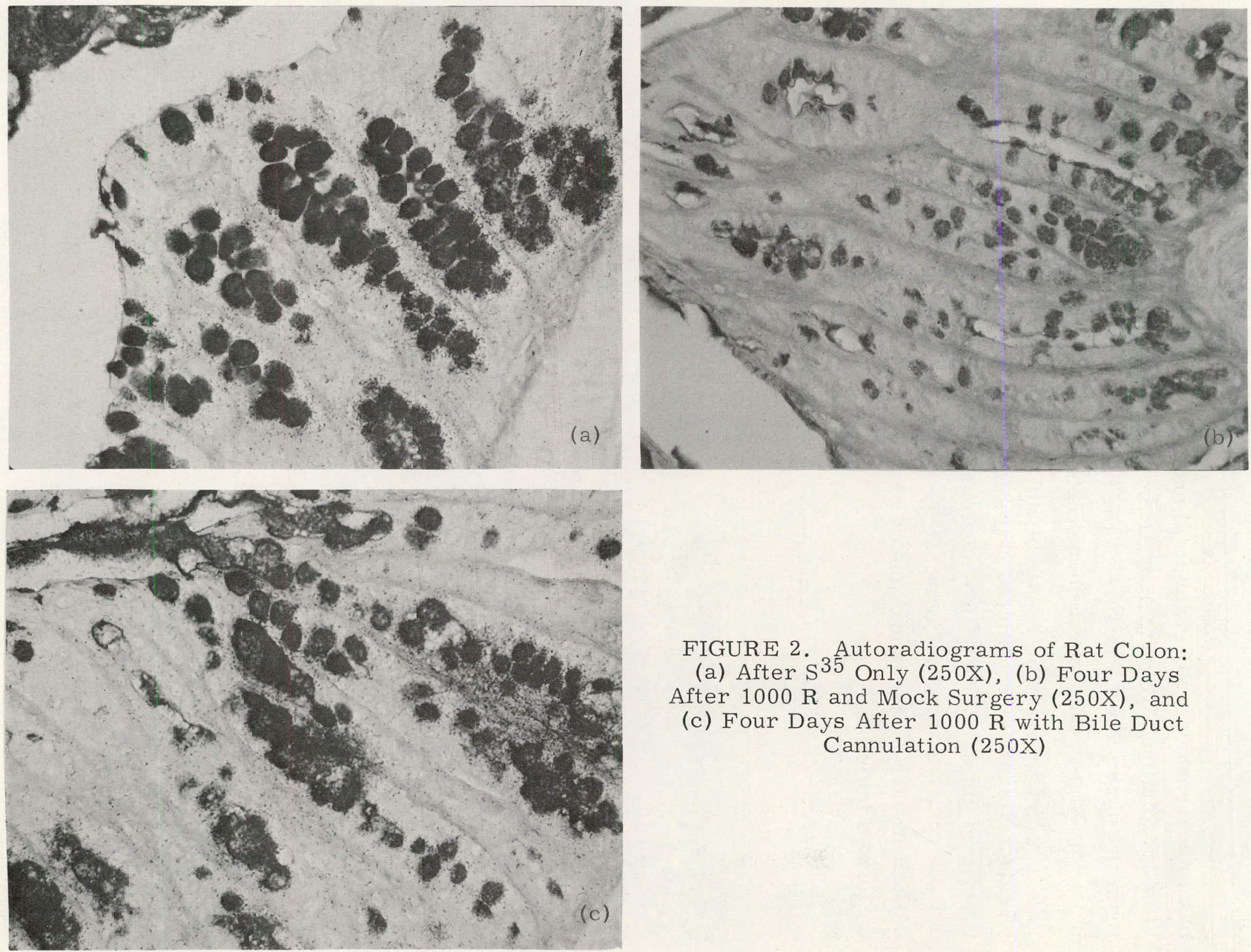

FIGURE 2. Autoradiograms of Rat Colon: (a) After $\mathrm{S}^{35}$ Only (250X), (b) Four Days After $1000 \mathrm{R}$ and Mock Surgery (250X), and (c) Four Days After $1000 \mathrm{R}$ with Bile Duct Cannulation (250X) 
134

BNWL-122

of an apparent decrease in the total number of goblet cells at four days after irradiation. Nevertheless, it is apparent that the absence of bile from the lumen after exposure of the intestine to radiation resulted in a markedly higher incorporation and retention of $\mathrm{S}^{35}$ than when the biliary flow was uninterrupted. This indicates that the quantity of mucus in the bile duct cannulated irradiated rat is much in excess of the noncannulated irradiated animals. This provides quantitative information that supports our microscopic observations that the bile salts exert an action resulting in the removal of mucus and mucus producing goblet cells from the irradiated intestine. 


\title{
INFLUENCE OF FISSION NEUTRONS ON RAT REPRODUCTION
}

\author{
M. F. Sullivan
}

Survivors of a neutron study were mated three successive times to determine the effect of fission neutrons on rat reprodurtivity. Males were temporarily sterile, but 2 of 11 recovered fertility. Doses of 145-265 rad did not render females infertile but litter size and the length of reproductive capacity was reduced.

In a previous report (Hanford Biology Report for 1963) data were presented on the use of $I^{131}$ labeled PVP as an index of damage to the intestine of rats exposed to fission neutrons in the Hanford Physical Constants Test Reactor. The animals that survived that study were mated to determine the influence of fission neutrons on their reproductive capability. Eleven male rats that survived neutron exposures of 130 and 160 rad were each mated with two normal females and two neutron exposed females on the first mating, and to four normal females thereafter. Four males exposed to 210 rads were mated to only normal females at all. matings. Exposed females were paired with nonirradiated females and mated with nonirradiated males. Six month old males were mated at two and -one-half months postexposure and six month old females were mated one month postexposure. For all matings rats were caged together for 10 days. At two weeks after birth the young were removed from their mothers and remating attempted a week later. Three successive matings were made in this study.

None of the neutron irradiated males were fertile in their first mating but two of three after 130 rad regained fecundity on the succeeding matings. Of the eight rats exposed to either 160 or 210 rads, none regained fecundity during the course of the experiment. At the conclusion, their testes were sectioned for histologic analyses. Spermatogenesis ranged from absent at 160 and 210 rad to near normal after $130: \mathrm{rad}$.

Results of mating the neutron irradiated and control females with nonirradiated males are listed in Table 1. The average control litter size 
for all threc matings was 10.5. Neutron exposure did not render the irradiated females infertile on the first mating, but the average litter size was reduced. The effect of neutron radiation dose on fertility became evident in the second and third matings when only 8 of 58 mated females bore young. Some of the animals had been pretreated with $1 \mathrm{~g} / \mathrm{kg}$ of cysteine but it had no apparent effect on productivity.

TABLE 1。 Female Rat Fertility After Neutron Irradiation

\begin{tabular}{|c|c|c|c|c|c|}
\hline $\begin{array}{c}\text { Number } \\
\text { of } \\
\text { rats }\end{array}$ & $\begin{array}{l}\text { Dose } \\
\text { (rad) }\end{array}$ & $\begin{array}{c}\text { Mortality } \\
(\%)\end{array}$ & $\begin{array}{c}\text { No. } \\
\text { First } \\
\text { mating }\end{array}$ & $\begin{array}{l}\text { rtile/No. } \\
\text { Second } \\
\text { mating. }\end{array}$ & $\begin{array}{l}\text { ested } \\
\text { Third } \\
\text { mating }\end{array}$ \\
\hline 11 & 0 & 0 & $\begin{array}{l}10 / 1.1 \\
(10.8)^{3 *}\end{array}$ & & \\
\hline 16 & 0 & $\begin{array}{r}0 \\
-\end{array}$ & & $\begin{array}{r}13 / 16 \\
.(9.4)\end{array}$ & \\
\hline 16 & 0 & . 0 & & & $\begin{array}{l}13 / 16 \\
(11.5)\end{array}$ \\
\hline 5 & 145 & 0 & $\begin{array}{l}1 / 3 \\
(6)\end{array}$ & $\begin{array}{l}3 / 6 \\
(6.3)\end{array}$ & $\begin{array}{r}2 / 6 \\
\quad(7)\end{array}$ \\
\hline 6 & 180 & 17 & $\begin{array}{l}2 / 3 \\
(6) .\end{array}$ & $\begin{array}{l}1 / 6 \\
(1)\end{array}$ & $0 / 5$ \\
\hline 6 & $215+$ cysteine & 17 & $\begin{array}{c}2 / 3 \\
(8.5)\end{array}$ & $\begin{array}{l}1 / 6 \\
(1)\end{array}$ & $0 / 5$ \\
\hline 6 & 215 & 33 & $\begin{array}{l}1 / 3 \\
(10)\end{array}$ & $0 / 4$ & $\begin{array}{l}1 / 4 \\
(2)\end{array}$ \\
\hline 3 & 240 & 66 & $0 / 1$ & $0 / 1$ & $0 / 1$ \\
\hline 6 & $265+$ cysteine & 50 & $\begin{array}{c}2 / 2 \\
(5.5)\end{array}$ & $0 / 3$ & $0 / 3$ \\
\hline 6 & 265 & 50 & $\begin{array}{l}1 / 3 \\
(4)\end{array}$ & $0 / 3$ & $0 / 3$ \\
\hline \multicolumn{3}{|c|}{ Total (neutron exposed) } & $9 / 18$ & $5 / 29$ & $3 / 27$ \\
\hline
\end{tabular}

* Average litter size.

These results, while meager, suggest that the male rat gonads are quite sensitive to neutron irradiation. They also show an effect of fission neutron dose on rat litter size and on the duration of female productivity due to the radiosensitivity of the developing oocytes. 
H. E. Erdman .

Effects of temperature, X ray; and the sex irradlated were studied for the day-old flour beetle, Tribolium castaneum (Herbst)。 Onset of reproduction.was earlier and productivity greater as temperature increased. A $4 \mathrm{kR}$ exposure of females delayed reproductive onset by two to three days. Productivity was reduced by 2 and $4 \mathrm{kR}$. Radiation effect on productivity was additive when both sexes were $\mathrm{X}$ rayed.

The ratio of doses required to produce $50 \%$ dominant lethals was $2.4: 1$ relative to $250 \mathrm{kV}$ potential $\mathrm{X}$ rays and $4.6 \mathrm{MeV}$ fast neutrons.

Differential sensitivities of cells in various stages of division were among the first observations of biological effects of radiation. Gametic cells in different stages of maturation exhibit different radiation sensitivities which are altered by environmental conditions especially in polkl.lothermic organisms such as insects. This report concerns.X-ray effects on productivity of flour beetles and modifications due to culture temperature and to the sex irradiated. The experiment described is similar to the neutron exposure study reported last year (Hanford Biology Report for 1963)。 Dose rates of $1 \mathrm{kR} / \mathrm{min}$ were obtained from a $250 \mathrm{kV}$ potential beam with $0.25 \mathrm{~mm}$ copper and $1.0 \mathrm{~mm}$ aluminum filtration.

The mean day of reproductive onset (Table 1) was delayed at all temperatures following exposure of females to $4 \mathrm{kR}$. Slight delay at the two lower. temperatures occurred after exposure to $2 \mathrm{kR}$. Radiation effects were relatively greater as temperature decreased. By comparing the data when both sexes were exposed with the data when females only were exposed, there is an indication of significant reproductive delay resulting from male exposure to $\mathrm{X}$ rays.

Productivity increased with higher temperature (Table 2)。 Decreased productivity followed exposure of either males or females to 2 and $4 \mathrm{kR}$ dośes. When plotted semi-logarithmically the shape of the $\mathrm{F}_{1}$ survival curve suggests that lack of productivity, or lower survival, was 
BNWL $\div 122$

due to "multihit" type damage. When both sexes were irradiated, the decreased productivity was roughly the product of male-exposed and femaleexposed effects indicating that lethality behaved like genetic dominants.

TABLE 1. Mean Day of Reproductive Onset

for Various Mating Combinations of Day-Old Adult Flour Beetles*

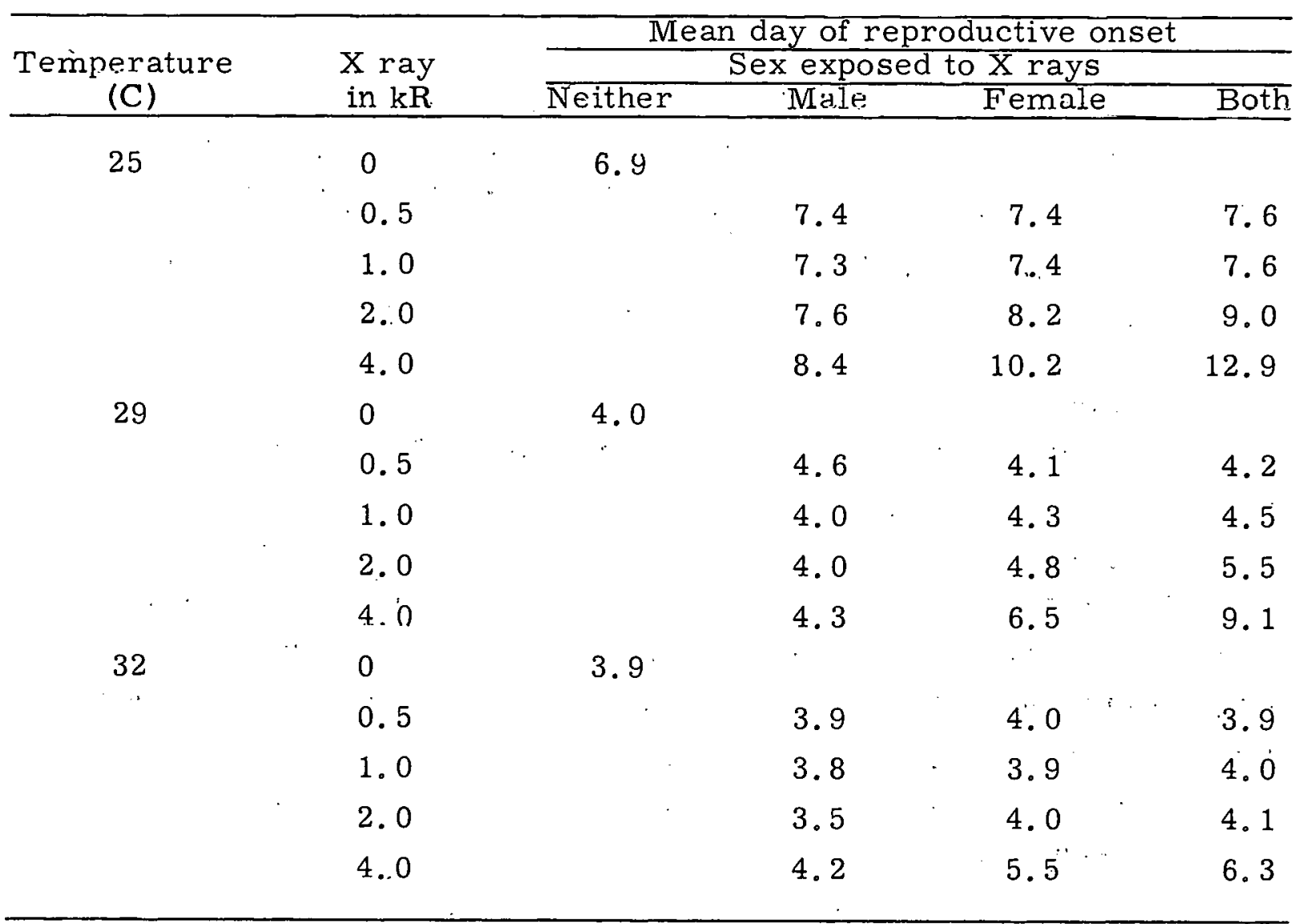

* Beetles were exposed to $250 \mathrm{kV}$ potential. $\mathrm{X}$ rays and maintained at different temperatures in 65-70\% relative humidity. A difference of 1.27. between any two values indicates a significant difference at the $95 \%$ confidence limits.

By comparing productivity of nonirradiated beetles at the different temperatures with comparable values for the irradiated beetles, it appears that higher temperature increased the number of gametes but did not affect recovery from radiation damage. It is possible that the higher lethality in females is due to oocytes being in a particular, radiosensitive stage of development, as has been shown to be the case in mice. 
TABLE 2. Total Mean Number F Progeny per Pair for Two Weeks Reproduction of X-Rayed Day-Old Flour Beetles, Tribolium castaneum. Kept at Different Temperatures and 65-70\% Relative Humidity

\begin{tabular}{|c|c|c|c|c|c|c|c|c|c|c|c|c|c|}
\hline \multicolumn{7}{|c|}{$\mathrm{X}$ Ray in $\mathbf{R}$} & \multicolumn{7}{|c|}{$\mathrm{X}$ Ray in $\mathrm{R}$} \\
\hline & q & 0 & 500 & 1000 & 2000 & 4000 & \multirow{4}{*}{$\cdot$} & 01 & 0 & 500 & 1000 & 2000 & 4000 \\
\hline \multirow{3}{*}{ 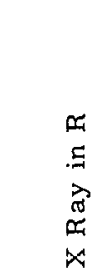 } & 0 & 62 & 60 & 58 & 36 & 11. & & 0 & 231 & 1.95 & 199 & 143 & 52 \\
\hline & 500 & 70 & 50 & -- & -- & -- & & 500 & 213 & 209 & -- & -- & -- \\
\hline & 1000 & 66 & -- & 50 & -- & $\cdots$ & & 1000 & 189 & -- & 166 & -- & -- \\
\hline & 2000 & 48 & -- & -- & 21 & -- & & 2000 & 126 & -- & -- & 75 & -- \\
\hline & 4000 & 7 & -- & -- & -- & 0.9 & & 4000 & 13 & -- & -- & -- & 4 \\
\hline
\end{tabular}

\begin{tabular}{|c|c|c|c|c|c|c|}
\hline Temp & & & X R & in $\mathrm{R}$ & & \\
\hline & 1 & 0 & 500 & 1000 & 2000 & 4000 \\
\hline & 0 & 260 & 258 & 247 & 188 & 12 \\
\hline $\begin{array}{l}\text { 口4 } \\
\Xi\end{array}$ & 500 & 253 & 253 & $\cdots$ & -- & -- \\
\hline$x$ & 1000 & 251 & -- & 232 & -- & .-- \\
\hline & 2000 & 150 & -- & -- & 102 & $\cdots$ \\
\hline & 4000 & 14 & -- & -. & -- & 4 \\
\hline
\end{tabular}

These data were compared with those earlier reported for $4.6 \mathrm{MeV}$ fast neutrons. Because the shapes of the dose response curves differ, it is more appropriate to speak of dose-ratio than RBE. Fast neutrons were two to three times more effective than $X$ rays in producing $50 \%$ lethality in the $F_{1}$ regardless of sex exposed or temperature. The mean dose ratio of 2.4 represents the response of all meiotic stages at the time of irradiation and is similar to that observed for mice, Drosophila and Tradescantia. 
Adult survival and propagation of flour beetles, Tribolium confusum (Chicago Standard) and T. castaneum (Brazil CI and sooty), are possible at $0.002 \%$ DDT. Sooty was more DDT sensitive than the other two strains. No effect of DDT on sex ratio was noted.

The use of chlorinated hydrocarbons as insecticides has stimulated continued research because of their toxicity to other organisms and.persistence in food chains. This preliminary study determined concentrations of DDT in which populations of flour beetles could be established. Subsequently. such populations will be irradiated to determine the effects of insecticide in combination with irradiation.

Experiment 1

Triplicate samples of $25 \mathrm{~T}$. castaneum (sooty) adults each were placed on flour containing $0-50 \%$ DDT. Beetles in 50 and $10 \%$ DDT were dead after one day; those in $1 \%$ were dead by six days; those in $0.1 \%$ were dead by 11 days. In 0.005 and $0.0005 \%$ DDT, adults survived and produced an. $F_{1}$ generation, as did the controls. Rate of development was retarded in $0.005 \%$ DDT.

\section{Experiment 2}

Twenty.sooty larvae of age groups $10,12,14,17$, and 19 days were placed in flour containing $0.0,0.05,0.01,0.0066,0.0050,0.0020,0.0010$, 0.00065 , and $0.00050 \%$ DDT. Data (Table 1) showed that when placed on DDT-food, older larváe had a better chance for survival. Growth to adulthood without reproduction to form an $\mathrm{F}_{1}$ may have been due to the adults all being of one sex or to DDT effects on the very early stages of the $F_{1}$. No attempt was made to quantitate numbers of $\mathrm{F}_{1}$ produced. Adult $\mathrm{F}_{1}$ showed an expected sex-ratio of $1: 1$. 
141

BNWL-122

TABLE 1. Observations of T. castaneum (sooty) Set as Larvae of Different Ages on Various Concentrations of DDT in Food

\begin{tabular}{|c|c|c|c|c|}
\hline \multirow{2}{*}{$\begin{array}{c}\text { Larval age } \\
\text { (days) }\end{array}$} & \multicolumn{4}{|c|}{ Percent DDT in food } \\
\hline & 0.05 & 0.01 & 0.0066 & 0.0020 \\
\hline 10 & Died as larvae.. & Died as larvae & $F_{1}$ & $\mathrm{~F}_{1}$ \\
\hline 12 & Died as larvae & 2 adults* & 1 adult ${ }^{*}$ & $\mathrm{~F}_{1}$ \\
\hline 14 & Died as larvae & 8 adults $^{*}$ & 9 adults $^{*}$ & $\mathrm{~F}_{1}$ \\
\hline 17 & 1 adult* & $F_{1}$ & $\mathrm{~F}_{1}$ & $\mathrm{~F}_{1}$ \\
\hline 19 & 6 adults $^{*}$ & $\mathrm{~F}_{1}$ & $F_{1}$ & $\mathrm{~F}_{1}$ \\
\hline
\end{tabular}

* Adults-number of adults developing from 20 larvae but no $F_{1}$ progeny. $F_{1}$-progeny produced from adults originally set as larvae. 


\title{
EFFECTS OF A SULFOXIDE COMPOUND
}

\section{ON FLOUR BEETLES EXPOSED TO X RAYS}

\author{
H. E。 Erdman
}

\begin{abstract}
Limethylsulfoxidc (DMSO) was toxic lu fluur beetles when ingested or topically applied under several experimental conditions. No protective effect was evidenced by DMSO when administered prior to $\mathrm{X}$ irradiation of female flour beetles.
\end{abstract}

The degree and extent of injury to biological systems subjected to irradiation depends on the chemical as well as the physical environment.. Dimethylsulfoxide has been reported to increase survival in acutely irradiated mice (Intern. J. Radiation Biol. , 3, 1961) but gave no protection to spermatogenesis. This report gives results of preliminary.studies with DMSO in.X-rayed germ cells of female flour beetles, Tribolium castaneum (Herbst), mutant: sooty。

Beetles were exposed to DMSO under defined conditiuns (dipping or placement of beetles on solutions of DMSO in water); however, the exact concentrations to which they were exposed and amounts absorbed were not evaluated. Exposure of pupae to $100 \%$ DMSO for 1 min resulted in the same mortality as exposure of adult beetles for $30 \mathrm{sec}$. The pupal case may have interfered with the absorption of the DMSO. Adults died within $2 \mathrm{hr}$ when placed in DMSO saturated atmosphere. Death was probably not due to lack of $\mathrm{O}_{2}$ since control beetles survived over $24 \mathrm{hr}$ in a similar closed container not containing.DMSO。Adults survived exposure to $67 \%$ DMSO for $10 \mathrm{~min}$.

Virgin sexually mature beetles were exposed on filter paper saturated with $0,1,10$, and $67 \%$ solutions of DMSO in water, and then irradiated with $0,1,2$, and $4 \mathrm{kR}$ of $\mathrm{X}$ rays, given 15 min to $20 \mathrm{hr}$ after DMSO treatment. The effect of $\mathrm{X}$ irradiation on fecundity and fertility was not modified by any of the prior DMSO treatments. 
Parenchymal cells constituted $60-70 \%$ of the trital cells of LAF strain molise liver tissue. 'I'he parenchymal cell population consisted of about 30\% diploid and 65\% tetraploid classes. Rat bone marrow or spleen cell injections into irradiated or nonirradiated mice resulted in a shift to a lower DNA content population; the relative proportion and size of parenchymal cells was unchanged.

Hepatomegaly is an early manifestation of bone marrow injection into lethally irradiated or normal mice. To further describe this phenomenon, the proportion, and nuclear DNA content of liver parenchymal cells was studied during the two week period following treatment of mice with rat bone marrow or spleen cells.

Twelve-week-old, male, LAF strain mice were injected intravenously with $1.6 \times 10^{7}$ viable hone marruw or spleen cells. Irradiated animals received $950 \mathrm{R}$ of $250 \mathrm{kV}$ potential $\mathrm{X}$ ray a few hours prior to injection of the cells. A group of nonirradiated mice were injected with polyvinylpyrrolidone $(0.3 \mathrm{ml}$ of $6 \% \mathrm{PVP}$, intravenously) since this macromolecule is also known to produce a prompt hepatomegaly. Animals were sacrificed at $1,3,7$, and 14 days posttreatment. Liver sections (Feulgenfast green staining) were evaluated for cell-typc frequency, and photometric measurement of Feulgen staining was accomplished w th a Canalco microspectrophotometer.

Nuclear DNA content, as measured in arbitrary units, was interpreted as representative of diploid or tetraploid cell classes, by reference to results obtained on kidney cells, which were assumed to be diploid. Typical histograms of nuclear DNA content of control liver, control kidney, and liver from irradiated, bone-marrow injected mice are shown in Figure 1. 


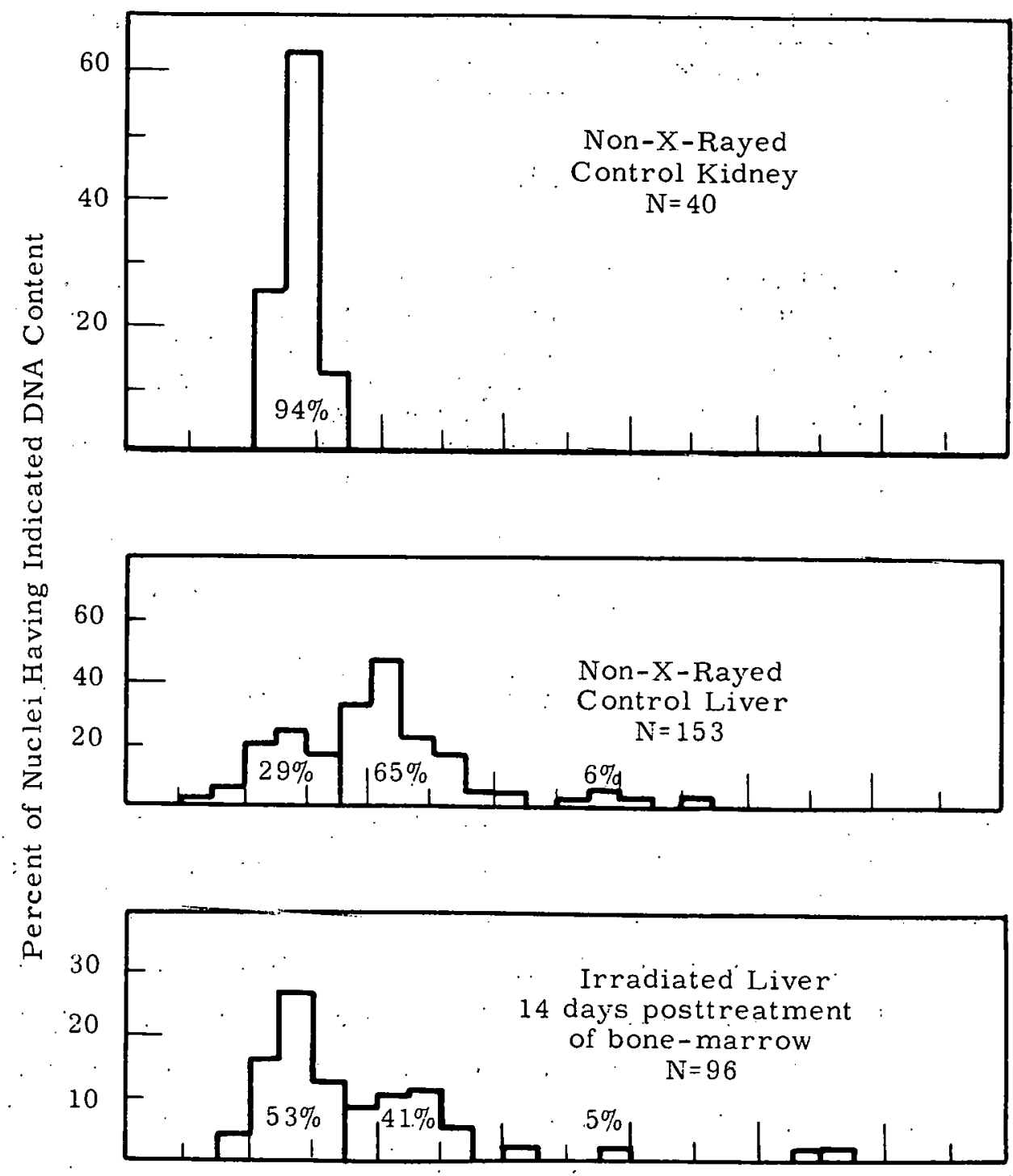

DNA Content (in Arbitrary Units)

FIGURE 1. Distribution of Cells in Nuclear DNA Content Classes

Results are summarized in Table 1. Foreign bone-marrow or spleen cell injections into irradiated or nonirradiated mice clearly did not raise the parenchymal cell distribution to one of higher ploidy.during the two week period studied. There was, instead, a shift to a lower.DNA content population. Analysis of the cellular composition of liver lobules. indicated that parenchymal cells constituted $60-70 \%$ of the total cells with 
no significant changes in binucleated cells during the two week period following treatment. These findings suggest that the hepatomegaly observed with the injection of hemopoietic cells and PVP results from an increase in all functional cells rather than from enlargement of individual parenchymal cells.

TABLE 1. Distribution of Nuclear. DNA in Liver Parenchymal Cells of LAF Mice

\begin{tabular}{|c|c|c|c|}
\hline \multirow{2}{*}{$\begin{array}{l}\text { Treatment and time interval } \\
\text { following treatment }\end{array}$} & \multirow{2}{*}{$\begin{array}{c}\text { No. of } \\
\text { nuclei } \\
\text { measured }\end{array}$} & \multicolumn{2}{|c|}{$\begin{array}{c}\text { Percent of nuclei } \\
\text { in DNA class }\end{array}$} \\
\hline & & Diploid & Tetraploid \\
\hline Control & 153 & 29 & 65 \\
\hline \multicolumn{4}{|l|}{ Irradiated (950 R) } \\
\hline $\begin{array}{l}\text { Bone Marrow Cells Injected } \\
1 \text { day } \\
3 \text { days } \\
7 \text { days } \\
14 \text { days }\end{array}$ & $\begin{array}{l}78 \\
48 \\
84 \\
9.6\end{array}$ & $\begin{array}{l}25 \\
40 \\
32 \\
53\end{array}$ & $\begin{array}{l}68 \\
54 \\
54 \\
41\end{array}$ \\
\hline $\begin{array}{l}\text { Spleen } \text {. Cells Injected } \\
1 \text { day } \\
3 \text { days } \\
7 \text { days } \\
14 \text { days }\end{array}$ & $\begin{array}{r}88 \\
132 \\
112 \\
44\end{array}$ & $\begin{array}{l}19 \\
47 \\
38 \\
32\end{array}$ & $\begin{array}{l}64 \\
50 \\
61 \\
64\end{array}$ \\
\hline \multicolumn{4}{|l|}{ Nonirradiated } \\
\hline $\begin{array}{l}\text { Bone Marrow Cells Injected } \\
1 \text { day } \\
3 \text { days } \\
10 \text { days }\end{array}$ & $\begin{array}{r}64 \\
104 \\
78\end{array}$ & $\begin{array}{l}27 \\
32 \\
37\end{array}$ & $\begin{array}{l}62 \\
58 \\
58\end{array}$ \\
\hline $\begin{array}{c}\text { Spleen Cells Injected } \\
1 \text { day } \\
3 \text { days }\end{array}$ & $\begin{array}{l}90 \\
66\end{array}$ & $\begin{array}{l}24 \\
33\end{array}$ & $\begin{array}{l}59 \\
58\end{array}$ \\
\hline $\begin{array}{l}\text { PVP Injected } \\
1 \text { day } \\
3 \text { days } \\
7 \text { days } \\
14 \text { days }\end{array}$ & $\begin{array}{l}48 \\
44 \\
48 \\
48\end{array}$ & $\begin{array}{l}38 \\
25 \\
33 \\
34\end{array}$ & $\begin{array}{l}62 \\
64 \\
54 \\
57\end{array}$ \\
\hline
\end{tabular}




\title{
LIVER INFILTRATES IN RADIATION CHIMERAS
}

\author{
E. M. Uyeki and J. L. Palotay
}

\begin{abstract}
A numerical tally of microscopic foci of leukocytic infiltrates in the liver was shown to provide a sensitive means of detecting early graft-host interaction in radiation chimeras. The results suggest that the hepatomegaly of radiation chimeras arises from an increase in all functional elements of the liver and that the infiltrates are a host response to graft versus host activity of donor cells.
\end{abstract}

This report deals with the early response of host liver tissue to the injection of syngeneic bone marrow, xenogeneic bone marrow or spleen cells, xenogeneic serum protein, and "lysed" xenogeneic bone marrow. Observations were made of the distribution of cell types and microscopic foci of cellular infiltrates in host liver tissue during the first two weeks following treatment.

Radiation chimeras were prepared by exposing male LAF mice to ybu R X ray followed within $2 \mathrm{hr}$ by an intravenous injection of $2 \times 10^{7}$ viable bone marrow or spleen cells from Sprague-Dawley or Fisher rats. In other studies, LAF mouse bone marrow was injected, and lower radiation doses of 400,600 , and $800 \mathrm{R}$ were employed. Animals were sacrificed at intervals up to 10 days following treatment. Liver sections were examined for areas of leukocytic infiltration and an estimate was made of the relative proportion of parenchymal, littoral, and leukocytic cells.

The percentage of cellular components in the liver sections examined remained quite constant in control and experimental groups. Parenchymal cells represented between 60 and $70 \%$ of the cellular elements; littoral and leukocytic cells represented between 10 and $20 \%$.

Table 1 summarizes some preliminary data on leukocytic infiltrations. Unirradiated animals injected with foreign bone marrow or spleen cells showed a marked and prompt increase in the number of infiltrates. This effect was eliminated or delayed in the irradiated animals. A typical infiltrate showing both mononuclear and developmental forms is shown in Figure 1. 
147

BNWL-122

TABLE 1. Leukocytic Infiltrations in Livers of Irradiated and Unirradiated LAF Mice Injected with Rat Bone Marrow or Spleen Cells

\begin{tabular}{ccccc}
\hline Treatment & $\begin{array}{c}\text { Days } \\
\text { posttreatment }\end{array}$ & $\begin{array}{c}\text { No. of } \\
\text { animals }\end{array}$ & $\begin{array}{c}\text { No. of low } \\
\text { power fields } \\
\text { examined }\end{array}$ & $\begin{array}{c}\text { No. of } \\
\text { leukocytic } \\
\text { infiltrations }\end{array}$ \\
\hline Controls & & 3 & 97 & 17 \\
Unirradiated & 1 & 1 & 8 & 50 \\
$\quad \begin{array}{c}\text { Bone marrow } \\
\text { injected }\end{array}$ & 3 & 1 & 11 & 100 \\
Spleen ccll & 10 & 1 & 19 & 37 \\
injected & 1 & 1 & 11 & 375 \\
Irradiated (950 R) & 3 & 1 & 24 & 81 \\
$\quad$ Bone marrow & & & & \\
injected & 1 & 2 & 14 & 32 \\
Spleen cell & 3 & 2 & 10 & 10 \\
injected & 7 & 1 & 9 & 3 \\
& 1 & 2 & 12 & 1 \\
& 3 & 2 & 16 & 2 \\
\hline
\end{tabular}

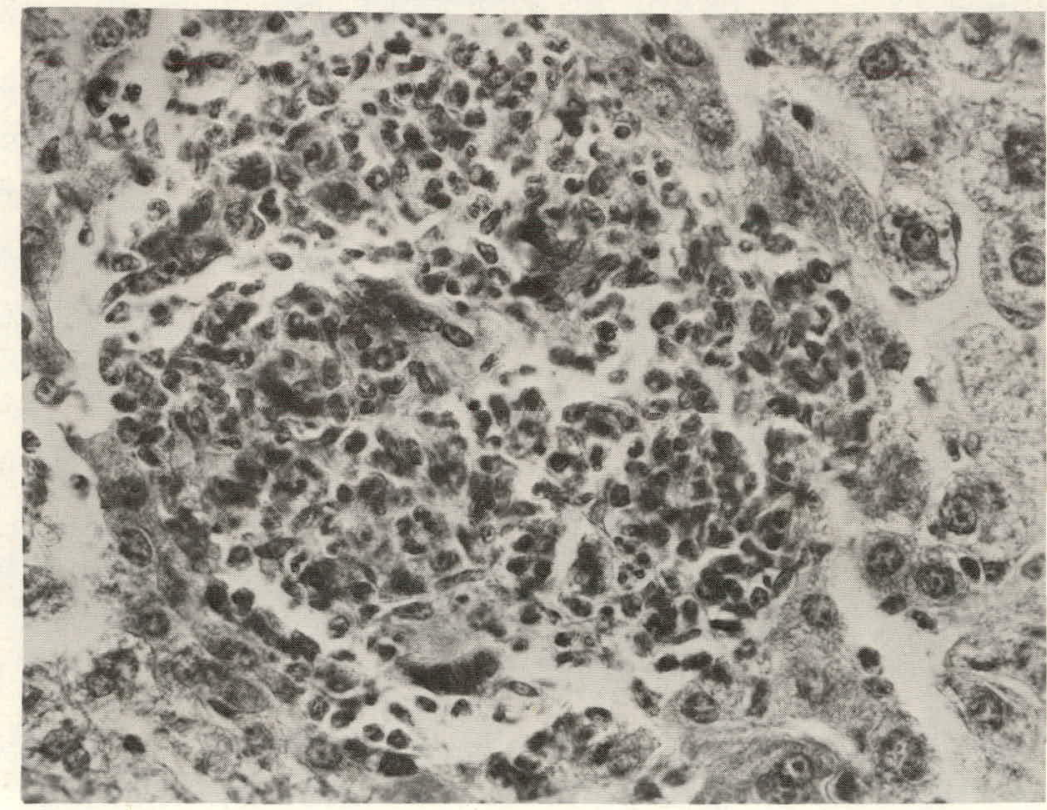

FIGURE 1. Large Accumulation of Cells Containing Both Mononuclear and Developmental Granulocytic Forms-from Liver of LAF Mouse Injected 3 Days Previously with 2 x $10^{7}$ Viable Rat Bone Marrow Cells (H\&E 530X) 
More extensive data at short time periods is summarized in Table 2. Again irradiation was shown to abolish the early infiltrative response. A dose of $400 \mathrm{R}$ was as effective in this regard as higher doses. A degree of nonspecificity of the infiltrative response is indicated. Thus syngeneic bone marrow provoked some response, as did lysed rat bone marrow (5-10\% of these calls were viable as indicated by dye exclusion analysis). These nonspecific responses, as well as the normal control incidence of infiltrates were reduced by irradiation.

TABLE 2. Leukocytic Infiltrations in Livers of LAF Mice Subjected to Various Treatments

\begin{tabular}{|c|c|c|c|c|}
\hline Treatment & $\begin{array}{c}\text { Days } \\
\text { posttreatment } \\
\end{array}$ & $\begin{array}{c}\text { No. of } \\
\text { animals }\end{array}$ & $\begin{array}{l}\text { No. of low } \\
\text { power fields } \\
\text { examined }\end{array}$ & $\begin{array}{c}\text { No. of } \\
\text { leukocytic } \\
\text { infiltrations }\end{array}$ \\
\hline Controls & & 3 & 97 & 17 \\
\hline \multicolumn{5}{|c|}{ Rat bone marrow injected } \\
\hline $\begin{array}{l}\text { No irradiation } \\
400 \mathrm{R} \\
600 \mathrm{R} \\
800 \mathrm{R}\end{array}$ & $\begin{array}{l}3 \\
3 \\
3 \\
3\end{array}$ & $\begin{array}{l}5 \\
2 \\
2 \\
2\end{array}$ & $\begin{array}{r}152 \\
52 \\
62 \\
65\end{array}$ & $\begin{array}{r}102 \\
8 \\
0 \\
4\end{array}$ \\
\hline \multicolumn{5}{|c|}{ LAF mouse bone marrow injected } \\
\hline No irradiation & $\begin{array}{l}1 \\
3\end{array}$ & $\begin{array}{l}3 \\
3\end{array}$ & $\begin{array}{l}83 \\
86\end{array}$ & $\begin{array}{l}30 \\
42\end{array}$ \\
\hline $950 \mathrm{R}$ & 1. & $\begin{array}{l}3 \\
3\end{array}$ & $\begin{array}{l}85 \\
85\end{array}$ & $\begin{array}{l}7 \\
0\end{array}$ \\
\hline \multicolumn{5}{|c|}{ Lysed rat bone marrow injected } \\
\hline No irradiation & 3 & 3 & 86 & 55 \\
\hline \multicolumn{5}{|c|}{ Rat serum $(0.1 \mathrm{ml})$ injected } \\
\hline No irradiation & 3 & 3 & 82 & 16 \\
\hline \multicolumn{5}{|c|}{ No bone marrow injected } \\
\hline $\begin{array}{l}400 \mathrm{R} \\
800 \mathrm{R}\end{array}$ & $\begin{array}{l}3 \\
3\end{array}$ & $\begin{array}{l}3 \\
3\end{array}$ & $\begin{array}{l}96 \\
90\end{array}$ & $\begin{array}{l}7 \\
1\end{array}$ \\
\hline
\end{tabular}

The mechanism by which irradiation suppresses the formation of leukocytic infiltrations is not clear. One may conjecture that irradiation drastically reduces the number of immunologically competent host cells which 
BNW.L- 122

normally participate in this graft-host interaction. The fact that our studies indicated no significant change in the relative percentage composition of fixed phagocytic cells of the liver would seem to implicate the mobile immunologically competent cells of the host. 


\title{
THE SYNTHESIS OF RNA. IN ESCHERICHIA. COLI
}

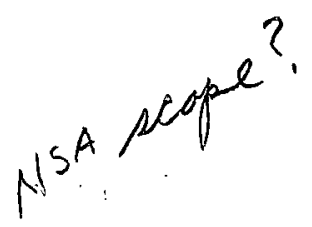

\author{
W. H. Matchett and R. T: O'Brien*
}

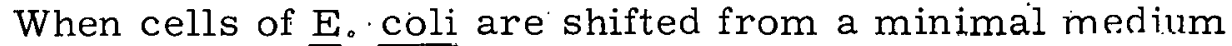
to one containing cacamino acids, an incredse is observed in the rate of growth of the cells and also in the relative rate of RNA synthesis.' When cells are shifted from a minimal medium to one containing the single amino acid methionine, a similar increase in the relative rate of RNA synthesis is observed with only a trivial increase in the rate of growth. These results indicate a specific role for methionine in the regulation of RNA synthesis.
\end{abstract}

The ratio of ribonucleic acid (RNA) to protein in bacterial cells is known to vary directly with the rate of growth at growth rates greater than 0.5 generations per hour. It is generally believed that the relative rate of synthesis of RNA is controlled by the proportion of transfer RNA molecules which are uncharged (i。e., free of amino acids). This belief is based on the following nhservations:

1. Cells in conditions causing a deficiency of amino acids show a marked reduction in the rate of RNA synthesis.

2. Cells provided with a plentiful supply of amino acids show a marked increase in the relative rate of RNA synthesis.

In general, cultural conditions which would be expected to increase the proportion of soluble ribonucleic acid charged with amino acids also increase the relative rate of RNA synthesis. Conversely, conditions which would be expected to reduce the proportion of S-RNA charged with amino acids also reduce the relative rate of synthesis of RNA.

We have recently studied the effects of various combinations of amino acids on the relative rate of RNA synthesis by cultures of strain K-12 of Escherichia coli. Growth rates and RNA/protein ratios are shown in Table 1 for cultures in balanced growth in several media. Cultures with casamino acids show a marked increase in growth rate and in

* Present address: Defense Electronics Division, General Electric Company, Advance Electronics Center, Cornell University Industry Research Park, Ithaca, New York 
the ratio of RNA/protein. Cultures receiving the four amino acids methionine, leucine, valine, and isoleucine showed a marked increase in the ratio of RNA/protein but only a modest increase in the rate of growth. Cultures receiving only methionine gave essentially the same results. That the addition of a single amino acid would cause such an increase in the RNA to protein ratio without a concomitant increase in the rate of growth was not expected on the basis of presently accepted theory. This result suggested to us that methionine is in some way implicated in the control of the rate of synthesis of RNA and prompted the experiments described below.

TABLE 1. Growth Rates and RNA/Protein Ratios in Several Media

\begin{tabular}{|c|c|c|c|c|c|c|c|}
\hline & \multicolumn{3}{|c|}{ High RNA./P ratio } & \multicolumn{4}{|c|}{ Low RNA/P ratio } \\
\hline & $\begin{array}{c}0.5 \% \\
\text { Casamino } \\
\text { Acids }\end{array}$ & $\begin{array}{c}\text { Methionine } \\
\text { Leucine } \\
\text { Isoleucine } \\
\text { Valine }\end{array}$ & Methionine & Minimal & Leucine & Isoleucine & $\begin{array}{c}\text { Isoleucine } \\
\text { Valine }\end{array}$ \\
\hline K & 1.0 & 0.67 & 0.66 & 0.63 & 0.41 & 0.58 & 0.61 \\
\hline RNA/P & 0.50 & 0.52 & 0.50 & 0.38 & 0.38 & 0.38 & 0.38 \\
\hline
\end{tabular}

Minimal $=\mathrm{M}-9$ salts $+0.5 \%$ glycerol $+10 \mathrm{\mu g} / \mathrm{ml}$ uracil.

Amino acids were present at initial concerilration of $50 \mathrm{\mu g} / \mathrm{ml}$.

$\mathrm{K}=$ generations per hour .

$\mathrm{RNA} / \mathrm{P}=\frac{\mu \mathrm{g} \text { RNA } / \mathrm{ml}}{\mu \mathrm{g} \text { protein } / \mathrm{ml}}$

To determine whether the effect of casamino acids on RNA syrithesis was attributable to the presence, of methionine in casamino acids, shift-down experiments were done by transferring cells abruptly from casamino acids to minimal medium and medium supplemented only with methionine. The differential plot of Figure 1, shows RNA synthesis as a function of protein synthesis for these conditions. The cells maintained in casamino acids show an RNA/protein ratio of $0.5 \mathrm{\mu g} \mathrm{RNA} / \mathrm{\mu g}$ protein (curve A). Cells shifted to minimal medium (curve $C$ ) showed a lag of 0.6 generations, and then RNA resumed synthesis at the rate characteristic of growth in a minimal medium. Cells shifted to methionine medium (curve B) showed a similar lag. When the se cells resumed RNA synthesis, it was at a rate characteristic for cells growing in casamino acid's even though the rate of growth was much lower (Table 1). These results indicated that the methio- ' nine effect is not identical with the effect of addition of casamino acids. 


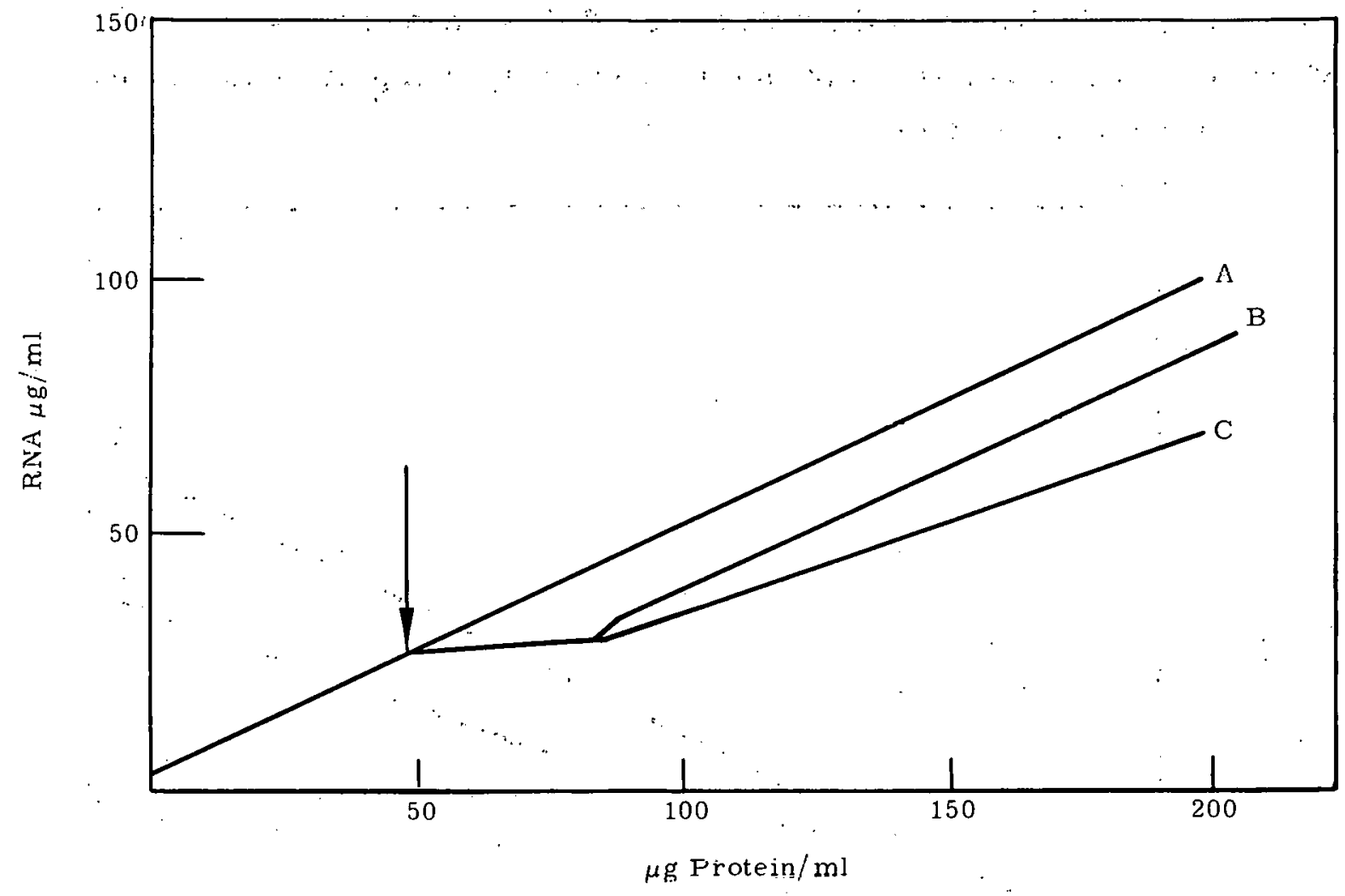

"FIGURE 1:" Shiftdöwn from Cásamino Acids

( $A=$ cells shifted to fresh casamino acids medium;

$B=$ cells shifted to methionine medium;

$\mathrm{C}=$ cells shifted to minimal medium.

Arrow indicates shift.)

When cells which had been grown in methionine were shifted to minimal medium (Figure 2), there was a lag before resumption of RNA. synthesis at the rate characteristic for minimal medium. The shift from methionine to minimal was in many respects similar to the shift from casamino acids to minimal medium. The main difference was that no appreciable change in the rate of growth was involved in the shift from methionine to minimal medium (Table 1).

These studies, even though quite preliminary, do indicate that the rate of synthesis of RNA may be increased markedly by the addition to the medium of the single amino acid, methionine. It is significant that the 
increase in relative rate of synthesis of RNA, occasioned by the addition of methionine, is not accompanied by a corresponding increase in the rate of growth of the cells.

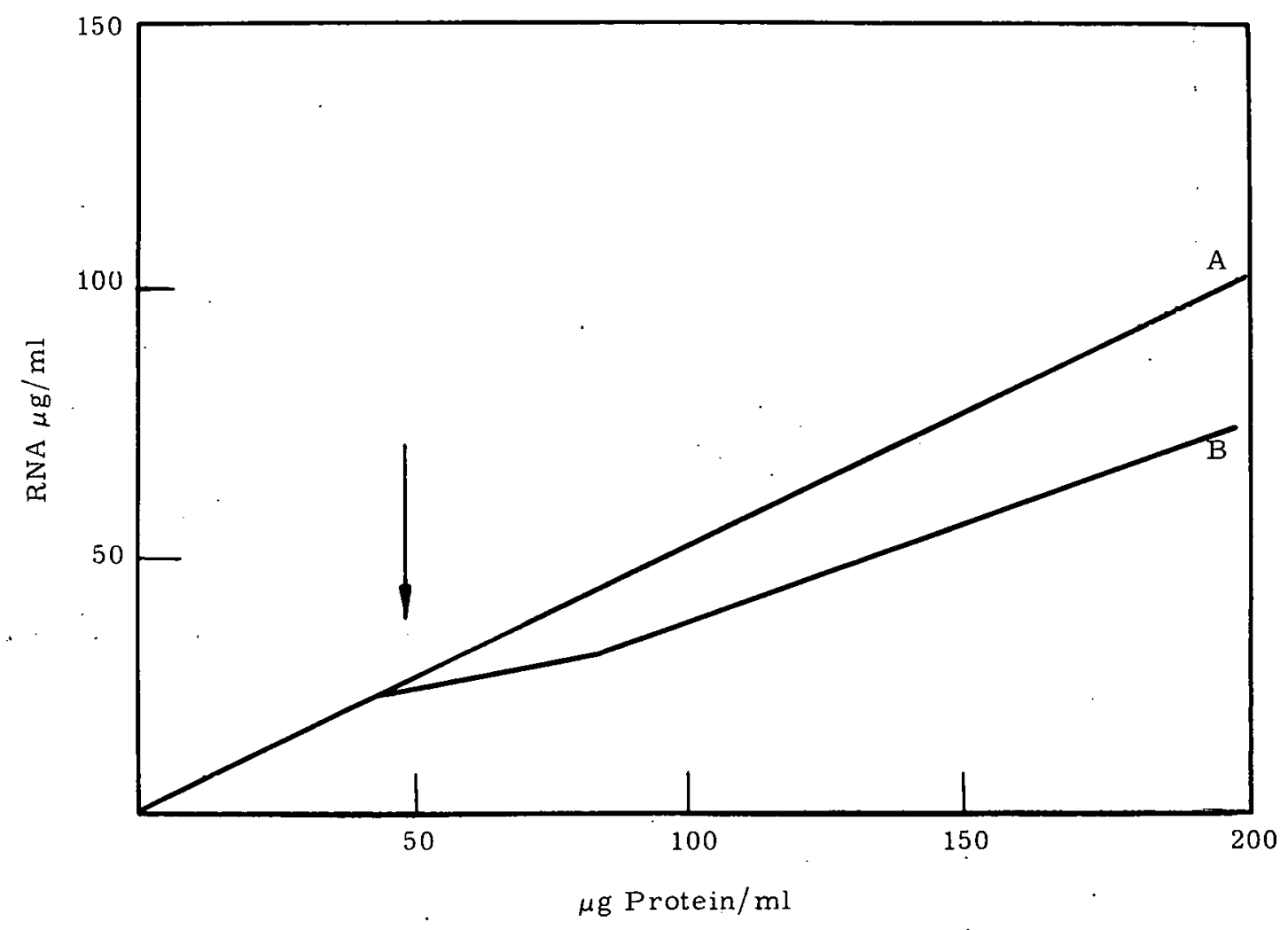

FIGURE 2. Shiftdown from Methionine to Minimal

$(A=$ cells shifted to fresh methionine medium;

$B=$ cells shifted to fresh minimal medium.)

These results suggest to us that methionine may play some peculiar role in regulating the rate of synthesis of RNA. It is possible, for example, that methionine may act, in vivo, as a nonspecific substrate for the reactions involved in charging of S-RNA molecules. Methionine is an excellent methyl group donor, and may exert control over RNA synthesis by controlling the availability of methyl groups for the synthesis of methylated bases. We plan to examine the RNA synthesized in response to methionine from. these points of view. 


\section{THE ROLE OF INDOLEPYRUVIC ACID IN THE METABOLISM}

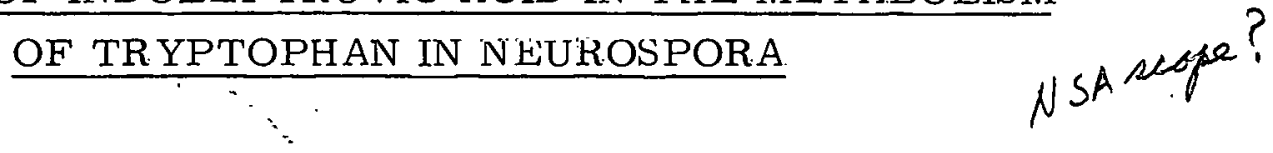

W. H. Matchett

In Neurospora, externally supplied tryptophan is, in part, converted to indolepyruvic acid by tryptophan mutants. Indolepyruvic acid is reversibly accumulated in filtrates of the se mutants and will satisfy their growth requirement in the absence of tryptophan. Growth, which takes place after mutants have exhausted externally supplied tryptophan, occurs at the expense of the previously accumulated indolepyruvic acid.

Certain classes of tryptophan mutants give considerably less final growth when cultured at $23{ }^{\circ} \mathrm{C}$ than when cultured at $33{ }^{\circ} \mathrm{C}$ even though growth is limited in each case by the same quantity of tryptophan.

The work described in this report shows that at $33^{\circ} \mathrm{C}$ a small but significant fraction of the externally supplied tryptophan is converted to indolepyruvic acid, and that this compound is reversibly accumulated in the filtrate. This compound serves as an ancillary source of tryptophan for tryptophan auxotrophs. Its presence at $33{ }^{\circ} \mathrm{C}$ and absence at $23{ }^{\circ} \mathrm{C}$ gives rise to the apparent differences in efficiency of auxotrophic utilization of tryptophan mentioned above.

The curves in Figure 1 show the rates and final amounts of protein synthesis observed in cultures of a tryptophanless mutant growing auxotrophically in minimal media supplemented with tryptophan. The arrows indicate the times at which external tryptophan disappeared from each culture. From these curves, it is clear that cultures grown at the lower temperature synthesize considerably less protein per micromole of tryptophan originally supplied ( $15 \mu$ moles $/ 20 \mathrm{ml}$ culture). than those grown at the higher temperature. .

A salient feature of these results is that although cultures grown at $23,{ }^{\circ} \mathrm{C}$ cease net synthesis of protein abruptly, shortly after the disappearance of external tryptophan, cultures grown at $33^{\circ} \mathrm{C}$ continue to synthesize protein for many hours after the exhaustion of external 


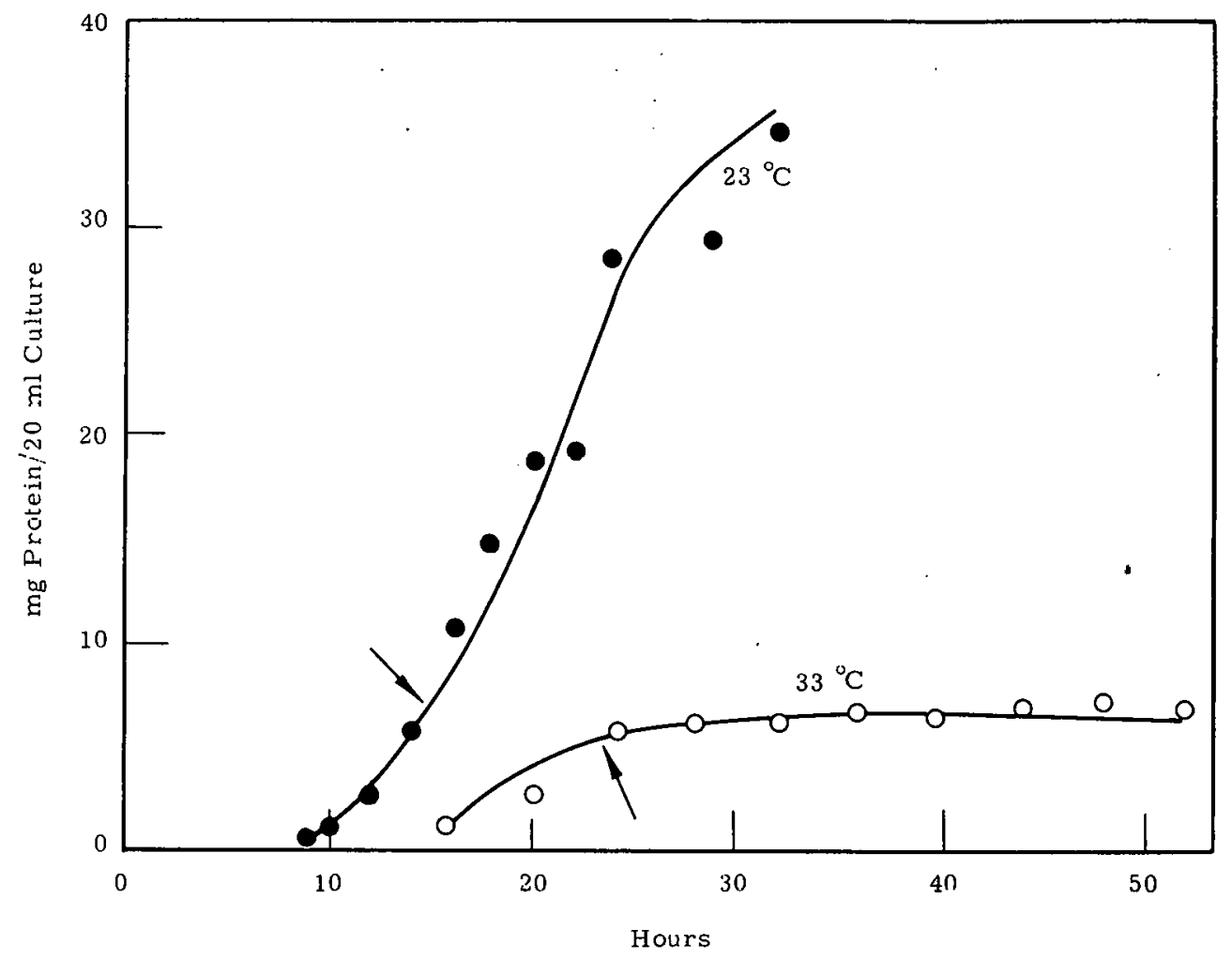

FIGURE 1. Effect of Temperature on Protein Synthesis by Mutants in $20 \mathrm{ml}$ Cultures

[Conidia were innoculated in-minimal medium ( $2 \%$ sucrose, $0.75 \mu$ moles $/ \mathrm{ml} \mathrm{L}$-tryptophan). Samples $(20 \mathrm{ml})$ of innoculated medium were transferred to conical flasks $\left(125 \mathrm{~cm}^{3}\right)$ and these were incubated in a gyrotory shaker bath at the indicated temperature. Arrows indicate times at which tryptophan disappeared from each culture.]

tryptophan. Tryptophan disappears from cultures at either temperature after the synthesis of essentially equal amounts of protein. This situation eliminates the possibility of a temperature dependent difference in the relative rate of utilization of tryptophan. Neither genetic "leakage" nor tryptophan in the intracellular pool is sufficient to account for the extra growth observed at $33{ }^{\circ} \mathrm{C}$.

The growth experiment described in Table 1 shows that the mutant growing at $33{ }^{\circ} \mathrm{C}$ accumulates a compound which will satisfy the tryptophan requirement of the strain. For this experiment the mutant was grown $14 \mathrm{hr}$ at $33{ }^{\circ} \mathrm{C}$ in medium supplemented with tryptophan. After $14 \mathrm{hr}$, 
samples of mycelia were harvested and subcultured under the conditions indiçated in the tahle. Subcultures rcceiving tryptophan or indole grew well. Cells placed, in minimal medium did not grọ. Cells placed in "used filtrate". (i.e., filtrate from which they were haṛvested) grew well even though tryptophan was demonstrably absent. Subcultures receiving any of the known or presumed catabolites of tryptophan listed at the bottom of the table did not grow.

TABLE 1. Growth Response of Mutant Mycelia

\begin{tabular}{|c|c|c|}
\hline Culture & Additions & $\begin{array}{l}\text { Increase in dry weight } \\
\text { during } 7 \mathrm{hr} \text { incubation } \\
(\mathrm{mg})\end{array}$ \\
\hline 1 & $\begin{array}{l}100 \text { ml minimal medium } \\
\quad+10 \text { mmoles L-tryptophan }\end{array}$ & 80 \\
\hline 2 & $\begin{array}{c}100 \text { ml minimal medium } \\
+10 \text { moles indole }\end{array}$ & 72 \\
\hline $3^{3 k}$ & $100 \mathrm{ml}$ minimal medium & 0 \\
\hline 4 & $100 \mathrm{ml}$ "used filtrate" & 97 \\
\hline
\end{tabular}

* Addition of any of the following compounds to culture number 3 gave no growth:

Anthranilic acid

Formylanthranilic acid

Kynurenine

Formylkynurenine
Tryptamine Indolepropionic acid Indoleacetic acid

Mutant was grown at $33^{\circ} \mathrm{C}$ for $14 \mathrm{hr}$. At this time cells were harvested and subcultured as indicated above. "Used filtr"ate" means filtrate from which cells were harvested and from which tryptophan was exhausted.

As shown in Table 2, addition of indolepyruvic acid did result in growth of the subcultures. Enzymic and nutritional studies showed clearly that tryptophan and indolepyruvic acid were interconverted by a transaminase of nonspecific origin. The presence of indolepyruvic acid in filtrates of the mutant was confirmed by standard-methods of qualitative analysis.

The curves of Figure 2 illustrate the relationship of protein synthesis, uptake of tryptophan, and accumulation and utilization of indolepyruvic acid by the mutant. At $23^{\circ} \mathrm{C}$, protein synthesis stops almost immediately after the disappearance of tryptophan from the filtrate. At 
$33{ }^{\circ} \mathrm{C}$, when tryptophan disappears, about $5 \mathrm{mg}$ of protein have been formed by the culture. At this time, $2.0 \mu$ moles of indolepyruvic acid had accumulated in the culture. Continued synthesis of protein occurs apparently at the expense of this compound. Theoretically, $2.0 \mu$ moles of this compound should support the synthesis of about $20 \mathrm{mg}$ of protein. This is very close to the amount of protein which is, in fact, synthesized after the disappearance of tryptophan and during the uptake of the previously accumulated indolepyruvic acid.
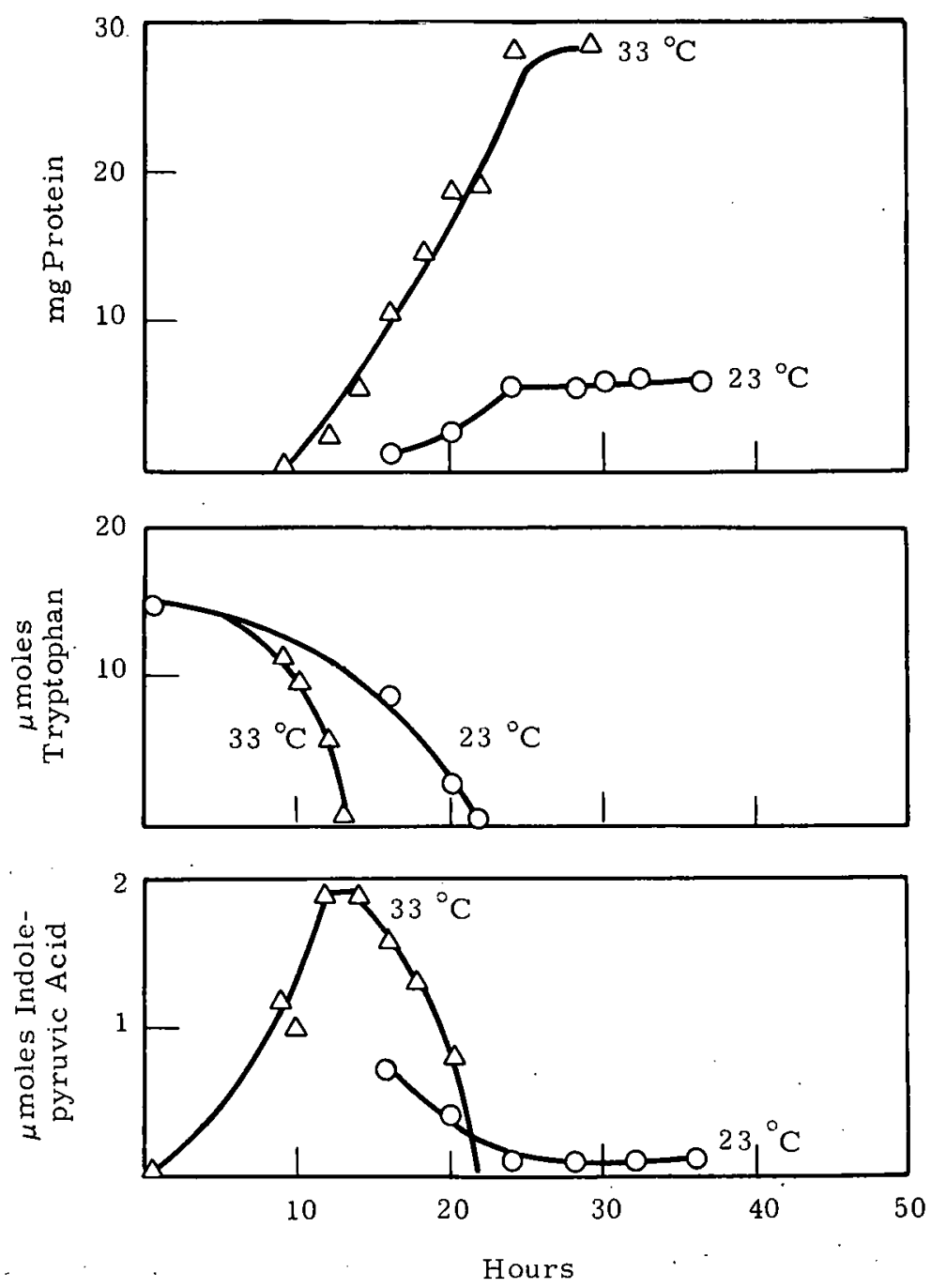

FIGURE 2. Relationship of Protein Synthesis to Utilization of Supplied and Accumulated Compounds (Mutant was grown at 33 and $23{ }^{\circ} \mathrm{C}$. Indolepyruvate was measured with the $\mathrm{FeCl}_{3}$ reagent.) 
The tryptophan cycle described by Matchett and DeMoss (Biochem. Biophys. Acta 3: 632, 1963) appears to be valid only for cell.s growing at $23{ }^{\circ} \mathrm{C}$....At $33{ }^{\circ} \mathrm{C}$, a significant fraction of the originally supplied tryptophan is converted to indolepyruvic acid (Figure 3 ). This compound is accumulated in the filtrate and after the disappearance of tryptophan from the filtrate is taken up by the cells and converted to tryptophan. In: the mutant described here, the tryptophan arising from indolepyruvic acid is the only tryptophan available for protein synthesis after exhaustion of tryptophan from the filtrate. At $23{ }^{\circ} \mathrm{C}$, protein synthesis stops when filtrate tryptophan is gone; at $33{ }^{\circ} \mathrm{C}$, protein synthesis continues even though filtrate tryptophan is gone. This continued synthesis of protein occurs at the expense of the ancillary source of tryptophan, namely indolepyruvic acid, which is present at $33{ }^{\circ} \mathrm{C}$ but absent at $23{ }^{\circ} \mathrm{C}$. It seems clear, therefore, that the effects of temperature of growth upon the apparent efficiency of utilization of tryptophan by Neurospora are mediated by the presence or absence of indolepyruvic acid in the growth filtrate at the time of disappearance of tryptophan.

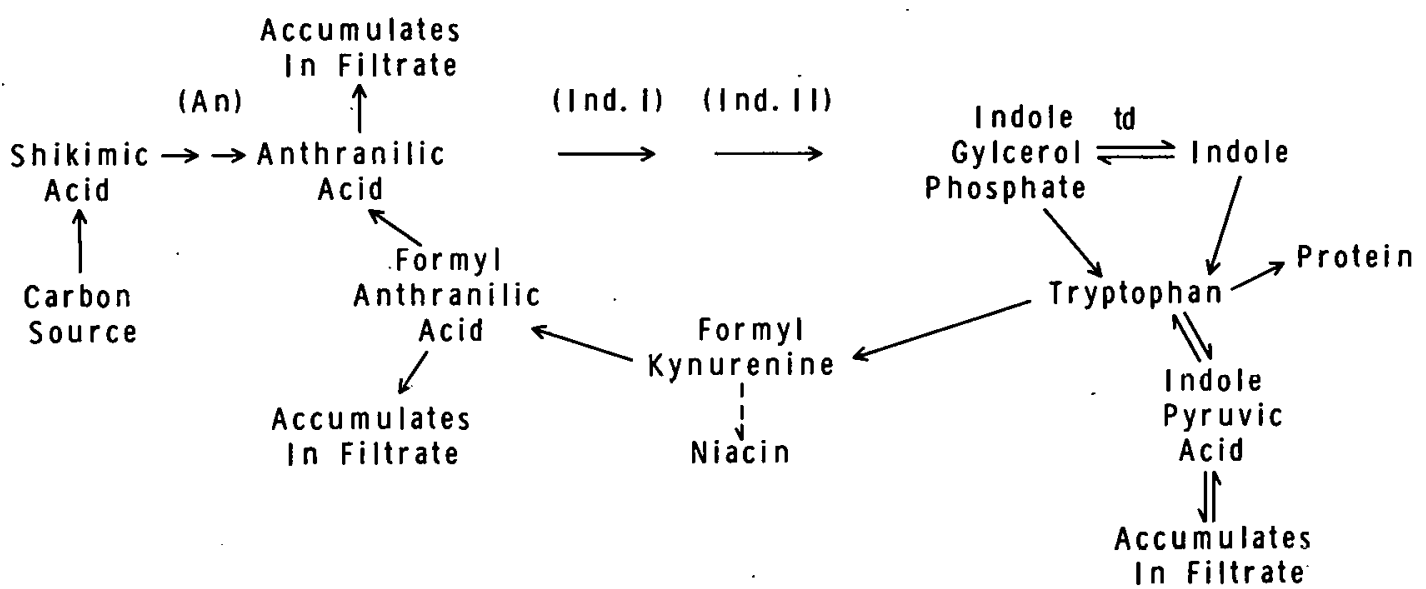

FIGURE 3. The Tryptophan Cycle

The reason why indolepyruvic acid is accumulated at $33{ }^{\circ} \mathrm{C}$ but not at $23{ }^{\circ} \mathrm{C}$ is not clear. Experiments with extracts have shown that cells grown at $23{ }^{\circ} \mathrm{C}$ have at least as much transaminating activity as cells grown at $33{ }^{\circ} \mathrm{C}$. It seems likely that the level of the intracellular pool of tryptophan, which is two- to threefold higher at $33{ }^{\circ} \mathrm{C}$ than at $23{ }^{\circ} \mathrm{C}$, is implicated in this response. 
159

BNWL- 122

It will be of interest to examine the fate of tryptophan biosynthesized via the transaminase route from the point of view of physiological channeling. From previous experience, it is known that externally supplied tryptophan enters an "expandable" pool preferentially, and that tryptophan biosynthesized from indole preferentially enters a "metabolic" pool. Future work may reveal the distribution of tryptophan arising from indolepyruvic acid to these metabilically distinct pool. 
Optimum incorporation of $\mathrm{C}^{14}$-labeled dcetate into longchain fatty acids by rat lung tissue homogenate requires. the addition of ATP, CoA, NADH, and NADPH. Disrupted lung mitochondria preparations are avidin insensitive and do not require $\mathrm{HCO}_{3}^{-}$. Although the relative subcellular . contributions of the mitochondrial fraction in the incorporation of $\mathrm{C}^{14}$-labeled acetate into long-chain fatty acids is more important in lung than in liver tissue, the mechanisms of incorporation appear to be similar.

Lung surfactants are important for the stability of alveolar radii during expiration and they assist the osmotic forces acting across the alveolar membrane. Studies on the mechanisms and site of synthesis of lung surfactants were initiated because of their possible relationship to the toxicity of inhaled radioactive particles. As a first step in our studies we examined the lung tissue synthesis of long-chain fatty acids which are constituents of lung phospholipids (Brown. Am. J. Physiol. 207: 402, 1964).

Our earlier experiments showed that the mitochondrial fraction in rat lung tissue was the most important subcellular fraction for the incorporation of $\mathrm{C}^{14}$ acetate into long-chain fatty acids (Science 146:1180;1364). Similar experiments with rabbit lung gave essentially the same results (Table 1).

The rat lung mitochondrial system was further examined to determine requirements for incorporation of acetate into long-chain fatty acids and the mechanisms involved in this incorporation. The basic incubation mixture was composed of 60 umoles adenosine triphosphate (ATP), 3 mmoles

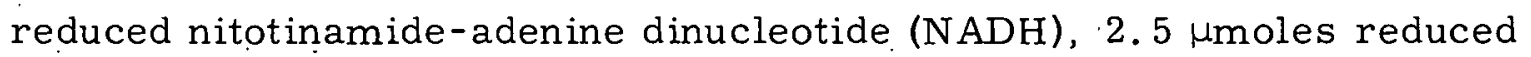
nicotinamide-adenine dinucleotide phosphate (NADPH), 2. 4 umoles CoA,

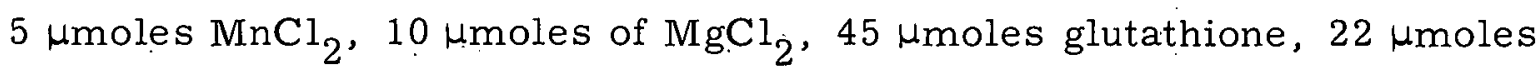
glucose-6-P. 30 mmoles isocitrate, and 10 moles of acetate in 
161

BNWL- 122

TABLE 1. Acetate-1- $\mathrm{C}^{14}$ Incorporation into Long-Chain Fatty Acids by the Subcellular Fractions of Rabbit Lung Tissue

\begin{tabular}{lc}
\hline \multicolumn{1}{c}{ Fraction tested } & $\begin{array}{c}\text { Acetate }-1-\mathrm{C}^{14} \text { incorporated } \\
\text { into fatty acids } \\
\text { (nmoles } / \mathrm{mg} \text { of protein) } \\
\text { (40 min incubation) }\end{array}$ \\
\hline Mitochondria & 2.06 \\
Supernatant & 0.63 \\
Microsomes & 0.18 \\
Mitochondria + supernatant & 0.73 \\
Mitochondria + microsomes & 0.44 \\
\hline
\end{tabular}

glycylglycine buffer pH 7.4, total volume $2.5 \mathrm{~cm}^{3}$. Table 2 gives the requirements for optimum incorporation of acetate into long-chain fatty acids. The lung mitochondrial fraction required ATP, NADH, NADPH, and CoA. .

TABLE 2. Factors Affecting the Incorporation of Acetate-1-C'14 into Long-Chain Fatty Acids by the Rat Lung Mituchundrial Fraction

\begin{tabular}{|c|c|c|c|c|}
\hline \multirow[b]{2}{*}{ Experiment. } & \multirow{2}{*}{$\begin{array}{l}\text { Omissions } \\
\text { from basic incubation } \\
\text { mixture } \\
\end{array}$} & \multicolumn{3}{|c|}{$\begin{array}{l}\text { Acetate }-1-\mathrm{C}^{14} \text { incorporated } \\
\text { into long-chain fatty acids } \\
\text { (nmoles } / \mathrm{mg} \text { of protein) }\end{array}$} \\
\hline & & 10 & 20 & 40 \\
\hline 1 & $\begin{array}{l}\text { None. } \\
\text { NADH, NADPH } \\
\text { NADH }\end{array}$ & $\begin{array}{l}0.91 \\
0.11 \\
0.20\end{array}$ & $\begin{array}{l}1.31 \\
0.72\end{array}$ & $\begin{array}{l}1.7 \\
0.19 \\
0.90\end{array}$ \\
\hline 2 & $\begin{array}{l}\text { None } \\
\text { NADPH }\end{array}$ & $\begin{array}{l}0.26 \\
0.45\end{array}$ & $\begin{array}{l}1.2 \\
0.75\end{array}$ & \\
\hline 3 & $\begin{array}{l}\text { None } \\
\text { ATP }\end{array}$ & $\begin{array}{l}0.22 \\
0.20\end{array}$ & $\begin{array}{l}0.33 \\
0.21\end{array}$ & $\begin{array}{l}1.10 \\
0.30\end{array}$ \\
\hline 4 & $\begin{array}{l}\text { None } \\
\text { CoA }\end{array}$ & $\begin{array}{l}0.75 \\
0.33\end{array}$ & $\begin{array}{l}1.75 \\
0.32\end{array}$ & $\begin{array}{l}2.0 \\
0.7\end{array}$ \\
\hline
\end{tabular}

It is known that acetate is first activated to form acetyl-CoA and then may be synthesized into long-chain fatty acids by two main mechanisms. One mechanism proceeds through malonyl- $\mathrm{CoA}$, requires $\mathrm{HCO}_{3}^{-}$and biotin and 
is extremely sensitive to avidin (which binds biotin). In the other mechanism acetyl-CoA elongates the chain of pre-existing fatty acids without proceeding through malonyl-CoA. This system does not require $\mathrm{HCO}_{3}^{-}$ or biotin and it is avidin insensitive. Table 3 shows the results of experiments testing for the mechanisms of fatty acid synthesis by the lung miluchondriall fraction. In these experiments avidin did not alter the incorporation of acetate into long-chain fatty acids while $\mathrm{HCO}_{3}^{-}$was slightly inhibitory. This is interpreted to mean that the acetate more probably elongates pre-existing fatty acids and that the incorporation in lung mitochondria does not follow the malonyl-CoA pathway for fatty acid synthesis. If in additional experiments the $\mathrm{HCO}_{3}^{-}$inhibition is substantiated then this may contribute to an explanation of surfactant deficiency observed after $\mathrm{CO}_{2}$ poisoning.

TABLE 3. Effect of Avidin and Carbonate on the Incorporation of Acetate-1-C ${ }^{14}$ into Long-Chain Fatty Acids by Disrupted Rat Lung Mitochondria

\begin{tabular}{lc}
\hline $\begin{array}{c}\text { Additions } \\
\text { to }\end{array}$ & $\begin{array}{c}\text { Acetate-1-C } \\
\text { into long-chain fatty acids } \\
\text { (nmoles } / \mathrm{mg} \text { of protein) }\end{array}$ \\
\hline None & $\frac{0.90}{(20 \mathrm{~min} \text { incubation) }}$ \\
Carbonate + biotin & 0.55 \\
Avidin & 0.70 \\
\hline
\end{tabular}

From these data we conclude that, although the relative subcellular contribution of the mitochondrial fraction for the incorporation of acetate into long-chain fatty acids is more important in lung than in liver, the mechanisms for incorporation in lung appear to be similar to those reported for liver (Wakil, S. J.; J. Lipid Res., 2: 1, 1961). 
ABSORPTION AND TRANSLOCATION

OF $\mathrm{Rb}^{+}$AND I- B.Y INTACT PLANTS

BNWL- 122

R. L. Uhiler

Transportation rates of $\mathrm{Rb}^{+}, \mathrm{I}^{-}$, and water were compared. under a variety of conditions. Iodide transport is more rapid than $\mathrm{Rb}^{+}$and can be shown to be less dependent on transpiration than $\mathrm{Rb}^{+}$transport. Evidence for metabolic media-. tion of transport is insufficient.

The Hanford Biology Annual Report for 1963 discussed some factors pretinent to the accumulation of iodide by intact plants from nutrient solutions. The accumulation of iodide was found to be a linear function of time and an exponential function of substrate concentration which was suggestive of a physical phenomenon or an unsaturated metabolically mediated process. The present report will discuss this accumulation further and, in some instances, will compare iodide to rubidium accumulation.

The absorption of $\mathrm{I}^{-}$by barley plants, 14-19, days old, increases with age as does transpiration, and dry matter. During this time, the dry weight of roots alld shoots increased threefold-both growth rates are exponential: Transpiration is linear and the daily rate doubled in five days. The accumulation rate of $\mathrm{I}^{-}$in the shoots increases but at a slower rate than growth or transpiration. Because of the unequal rates of growth and $\mathrm{I}^{-}$accumulation, there is an apparent decline in tissue concentration, i.e., g-atoms $\mathrm{I}^{-} / \mathrm{g}$ tissue. Depletion of substrate is insignificant since it amounts to: less than $2 \%$. With the exception of very young plants, the apparent concentration of the transpiration stream is sufficient to account for the accumulated iodide in the shoots.

When plants of equivalent age are transferred from a $24^{\circ} \mathrm{C}$ photo environment to a $5{ }^{\circ} \mathrm{C}$ nycto environment during the absorption period, transpiration is reduced $95 \%$ and accumulation rates of $\mathrm{I}^{-}$are reduced 75-90\%. Under these conditions, hydraulic drag of the transpired water is insufficient to account for the $I^{-}$translocated to the shoots.

When intact plants are exposed to a $4 \mathrm{hr}$. pretreatment of metabolic poisons, the accumulation of $\mathrm{I}^{-}$in the shoots is inhibited. The degree of inhibition obtained was dependent upon drug concentration in the substrate. 
BNWL- 122

Both azide and dinitrophenol were equally effective at higher concentrations, i.e., 10 to $1000 \mu \mathrm{M}$. At $1 \mu \mathrm{M}$ levels, there was no inhibition with DNP whereas azide reduced shoot accumulation $40 \%$. This difference is believed due to the more rapid rate of azide absorption and hence greater internal concentration. Within 30 min plants exposed to the highest azide concentration exhibited wilt symptoms; DNP plants showed similar symptoms an hour later.

'T'hus azide and DNF, which are known to induce metabolic malfunctions and interfere with salt absorption in various plant and animal tissues, also inhibit water transport. The transpiration rate was reduced $75 \%$ and exudation from detopped plants normally observed at harvest was absent on azide- and DNP-treated plants. The effects of azide and DNP upon I' accumulation, transpiration, and exudation were quite similar to those obtained when roots were killed by immersion in boiling water or liquid nitrogen; however, wilting was not observed during corresponding time periods in plants with killed roots.

The phytotoxicity of these drugs and the inhibition of transpiration, which is usually assumed to be passive, precludes an interpretation invoking an active process for $\mathrm{I}^{-}$transport. The $\mathrm{I}^{-}$present in leaves may be accounted for by hydraulic drag in spite of the differences in degree of inhibition of transpiration and $\mathrm{I}^{-}$accumulation rates.

In contrast to azide and DNP, pretreatment with chloramphenicol (CAP), while markedly reducing $\mathrm{I}^{-}$absorption, does not materially affect transpiration under equivalent conditions. The sensitivity of salt absorption to CAP was examined further with respect to time and rates of $\mathrm{Rb}^{+}$ and $\mathrm{I}^{-}$absorption. With equal transpiration rates, the rate of $\mathrm{I}^{-}$accumulation in the leaves is several times that of $\mathrm{Rb}^{+}$in the presence or absence of CAP. In experiments in which CAP pretreatment was varied, the rate of rubidium accumulation was reduced $70 \%$ within $1 \mathrm{hr}$. The CAP inhibition of $\mathrm{I}^{-}$absorption was delayed $2 \mathrm{hr}$ and then reduction was about $20 \%$; at $10 \mathrm{hr}$ the inhibition was $40 \%$. The dissimilarity between rates of $\mathrm{Rb}^{+}$ and $\mathrm{I}^{-}$absorption and response to $\mathrm{CAP}$, at concentrations not affecting 
transpiration, is evidence that transpiration and salt absorption are not directly.linked and the inhibition is more than a nonselective alteration of membrane permeability.

Differential rates of water and salt absorption may be obtained by inhibiting photosynthesis which was done by extending the nycto period. During periods of extended darkness, transpiration rates decline to $10 \%$ of the photo-rate after $48 \mathrm{hr}$ of darkness. In the absence of light, plants lose turgor and exhibit symptoms of wilting although the roots are bathed in aerated nutrient solution. Upon restoration of light the transpiration rate returns to $80 \%$ of the previous rate. Rates of $\mathrm{Rb}^{+}$and $\mathrm{I}^{-}$absorption also decline in darkness but the degree of change is quite different. Recovery of $\mathrm{I}^{-}$accumulation rate after light restoration is several times. the $\mathrm{Rb}^{+}$rate but slower than transpiration. Hydraulic drag could account for $\mathrm{Rb}^{+}$content in leaves but not $\mathrm{I}^{-}$.

In other experiments, the distribution of $\mathrm{Rb}^{+}$and $\mathrm{I}^{-}$within plant tissues (Red Kidney beans) was determined as a function of light. After $2 \mathrm{hr}$ in light, $70 \%$ of the $\mathrm{Rb}^{+}$accumulated is found in the leaves. The content (g-atoms/leaf) of heart leaves $>1$ st $>2$ nd $>3 \mathrm{rd}>4$ th trifoliate leaves. This acropetal gradient decrease in leaf content also holds for $\mathrm{I}^{-}$and is not affected by CA.P. This pattern is dependent upon the method of expression. On a concentration basis, i.e., g-atoms/g tissue, the gradient is basipetal from the third trifoliate leaf ( $80 \%$ expanded). The nycto-gradient of $\mathrm{Rb}^{+}$and $\mathrm{I}^{-}$is basipetal regardless of method of expression. It would appear that this transport of $\mathrm{Rb}^{+}$and $\mathrm{I}^{-}$is transpiration independent or at least largely so. During darkness, both ions accumulate in the stems and petioles; only about $30 \%$ is transported to the leaves. Rubidium, during ascent, equilibrates readily between wood (xylem) and bark (phloem), and wood/bark ratios are near unity. Iodide does not equilibrate readily and wood/bark ratios are 4 or more. The distribution between wood and bark is not affected by light or CAP.

By manipulation of the plant's environment, it is possible to distinguish between rates of $\mathrm{Rb}^{+}, \mathrm{I}^{-}$, and water movement and to depress these rates to differing degrees. Conventional interpretation of changes resulting from the use of metabolic inhibitors to invoke an active transport process for salt movement does not appear logical in view of the effects on transpiration. 
EFFECTS OF MOISTURE AND AIR TEMPERATURE ON DEPOSITION AND RETENTION OF I ${ }_{2}^{131}$ ON PLANTS AND SOIL

J. F. Cline and $F_{::} \cdot P$. Hungate

Inci-asing dir temperature accelerated the loss of $I_{2}^{131}$ from leaf and other surfaces. Moist surfaces accumulated 1.2 to 2.3 times more $\mathrm{I}_{2}$ than did corresponding dry.surfaces." The amount of $\mathrm{I}_{2}^{131}$ accumulated on a soil was dependent on the physical characteristics of the soil.

Laboratory studies were initiated to supplement field studies described in the Hanford Biology Report of 1963. The effects of air temperature and moisture on the deposition and retention of $\mathrm{I}_{2}$ on various surfaces were investigated.

Iodine-131 gas or $\mathrm{I}_{2}^{131}$ sorbed to dust wäs passed in a measured air flow over the plants and other surfaces inside a cylindrical exposure chamber. The samples were removed from the chamber after a 30 min exposure and counted by typical whole-body counting procedures. The loss of $\mathrm{I}_{2}^{131}$ from each plant was followed by daily counting of the intact plant.

High temperätures increased the loss of deposited $\mathrm{I}_{2}^{131}$ from plant leaves as shown by representative data in Figure 1. Plants maintained at $38{ }^{\circ} \mathrm{C}$ for seven days lost approximately $13 \%$ more $\mathrm{I}_{2}^{131}$ than those kept at $25{ }^{\circ} \mathrm{C}$. No observed loss of iodine, other than physical decay, was observed on plant leaves contaminated with $\mathrm{NaI}^{131}$ solution and kept at $25{ }^{\circ} \mathrm{C}$. The effect of heat was probably due to increased sublimation of $\mathrm{I}_{2}$ since heat was not effective in removing $\mathrm{NaI}^{131}$ from plants.

Paper sheets, leaf surfaces, and soil moistened with water accumulated more $\mathrm{I}_{2}^{131}$ than did an equal area of the same dry material. Moist-todry surface ratios for paper, leaves, and soil were 2.3, 2.2, and 1.2, respectively.

Table 1 shows the deposition on washed coarse sand was less by a factor of 10 than on the Cinebar loam soil, presumably due to the differences in particle sizes or the total surface area exposed. 


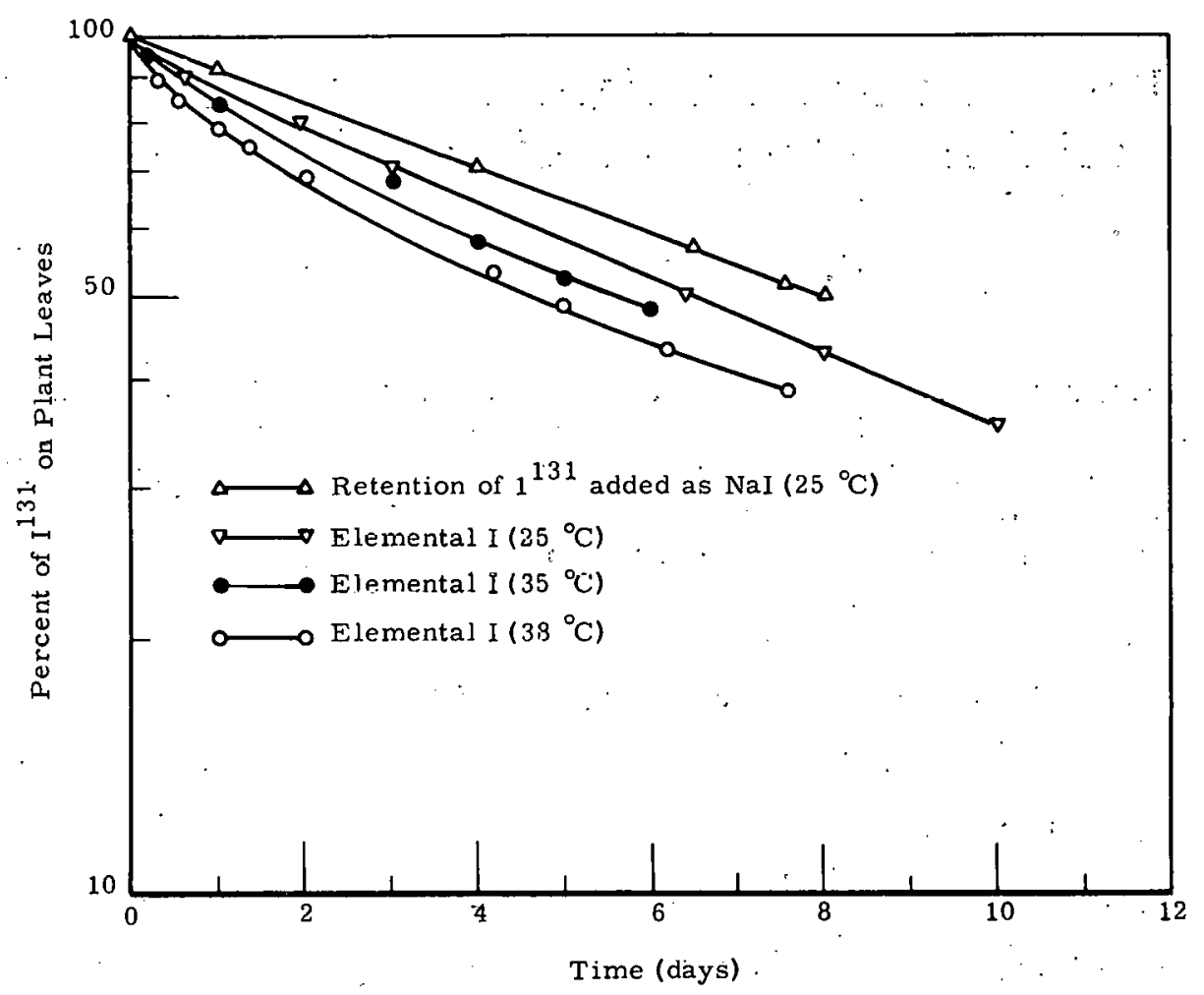

FIGURE 1. Effect of Air Temperature on Retention of Depusited Dlcmental Iodine on I.Paves

TABLE 1. Deposition of $\mathrm{I}_{2}^{131}$ on Different Soil Types

\begin{tabular}{lc}
\hline \multicolumn{1}{c}{ Soil type } & $\mathrm{nCi} \mathrm{I}^{131} / \mathrm{cm}^{2}$ \\
\hline Cinebar loam & $8.7 \pm 0.5$ \\
Ringold clay loam & $7.2 \pm 0.5$ \\
Sagemoor sandy loam & $5.2 \pm 0.5$ \\
Bentonite powder & $5.7 \pm 0.9$ \\
White washed sand & $0.6 \pm 0.02$
\end{tabular}

\pm One standard deviation. 


\section{- INFLUENCE OF SOIE SODIUM ON PLANT UPTAKE}

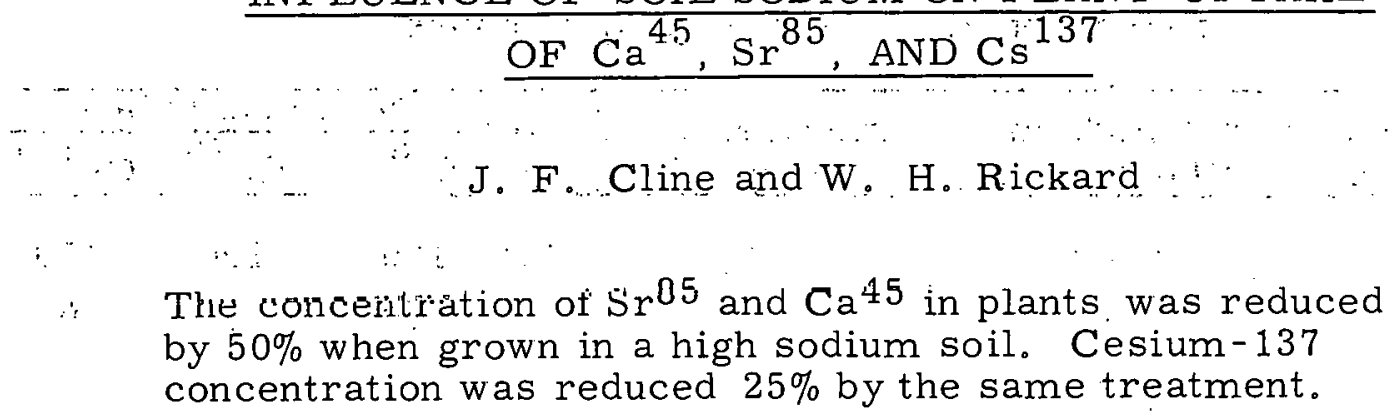

A local, sandy loam soil nearly saturated with sodium was mixed in various ratios with the similar but normal calcareous Ritzville soil (Hanford Biology Annual Report for 1953) of this area. These mixtures were spiked with $\mathrm{Sr}^{85}$ and $\mathrm{Ca}^{45}$, placed in pots and planted to barley for a 25 day growing period during which time moisture was maintained at near field capacity by daily watering. Cesium-137 uptake was obtained from barley grown on aliquots of the same soil mixtures using a Neubauer technique. Barley plants were harvested, dried and digested and $\mathrm{Ca}^{45}$ activity determinations were made using a beta counter. A NaI(Ti) welltype crystal was used to count the $\mathrm{Sr}^{85}$ and $\mathrm{Cs}^{137}$.

Strontium-85 and $\mathrm{Ca}^{45}$ concentrations in plant tissues were reduced by $50 \%$ as the ratio of sodium soil increased and as the calcareous soil decreased in the mixture (Table 1). The decreased $\mathrm{Ca}^{45}$ and $\mathrm{Sr}^{85}$ concentration in tissue as the calcium content of the soil decreased is the opposite expected based on an isotopic dilution concept. Apparently the soil $\mathrm{Ca}^{45}$ and $\mathrm{Sr}^{85}$ was made unavailable by the increased substrate sodium and possibly by the high $\mathrm{pH}$ found in the sodium soil.

Cesium-137 uptake was reduced by the same high concentration of the sodium soil, but to a lesser extent than the other isotopes. 
BNWL- 122

TABLE 1. Effect of High Sodium and Normal Soil Mixtures on the Uptake of Several Radioisotopes

\begin{tabular}{|c|c|c|c|c|c|c|}
\hline $\begin{array}{l}\% \text { Sodium soil } \\
\text { in mixture }\end{array}$ & $\begin{array}{l}\text { meq Sodium/ } \\
100 \mathrm{~g} \text { soil }\end{array}$ & $\begin{array}{c}\text { meq Calcium/ } \\
100 \mathrm{~g} \text { soil }\end{array}$ & $\begin{array}{c}\text { Soil } \\
\mathrm{pH}\end{array}$ & $\frac{\% 0}{\mathrm{Sr}^{85}}$ & $\frac{\max u}{\mathrm{Ca}^{45}}$ & $\frac{\text { take }}{\mathrm{Cs}^{137}}$ \\
\hline 0 & 0.08 & 9 & 6.8 & 100 & 100 & 100 \\
\hline 33 & $\therefore$ & - & - & 79 & 88 & 100 \\
\hline 50 & -- & - & - & 71. & 73 & -- \\
\hline 66 & -- & - & - & 67 & 67 & 80 \\
\hline 80 & -- & - & - & 66 & 60 & 80 \\
\hline 100 & 7.3 & $<3^{*}$ & 9.1 & 47 & 45 & 75 \\
\hline
\end{tabular}

* Combined with magnesium. 
EFFECT OF ROOT TEMPERATURES ON PLANT UPTAKE OF POTASSIUM AND CALCIUM

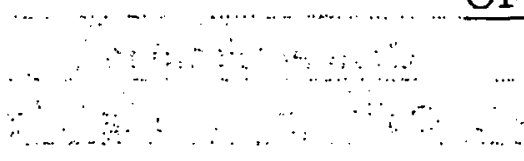

$\mathrm{J}$. F。 Cline

IIigh root temperatures showed süntle lendency to increase the uptake of calcium but had little effect on potassium uptake by bean plants grown in nutrient cultures.

High soil temperatures have been reported to increase the amount of potassium taken up by plants (Weber, J. G., et al., Soil Sci. Soc. Am. Proc: 661,1964$)$. Work in this laboratory showed that calcium uptake was reduced by increasing the potassium concentration in nutrient cultures. Therefore, it was of interest to determine if the uptake rates of these two ions could be altered by increasing the root zone temperature without change in nutrient ion concentration.

Beans were cultured in a growth chamber in modified Hoagland's nutrient solution. Root temperatures were maintained at 15, 20, 25, 28, and $31{ }^{\circ} \mathrm{C}$ by placing the culture pans in a large thermostatically controlled water bath. Each temperature treatment was triplicated.

Results in Table 1 show a general increase in the total uptake of calcium with an increase in root temperature which is only partially explained by increased yield. The means for uptake at lower temperatures $\left(15,20^{\circ} \mathrm{C}\right)$ are in most cases significantly lower than the means at higher temperatures $\left(25,28,31^{\circ} \mathrm{C}\right)$. The potassium data show no consistent temperature trend. Uptake is somewhat higher at both temperature extremes.

These results suggest that the previously reported increased potassium uptake in plants grown at high soil temperatures may be due to soilplant factors rather than to metabolic processes of the plant. 
BNWL- 122

TABLE 1. Effect of Root Temperatures on Uptake of Calcium and Potassium by Bean Plants

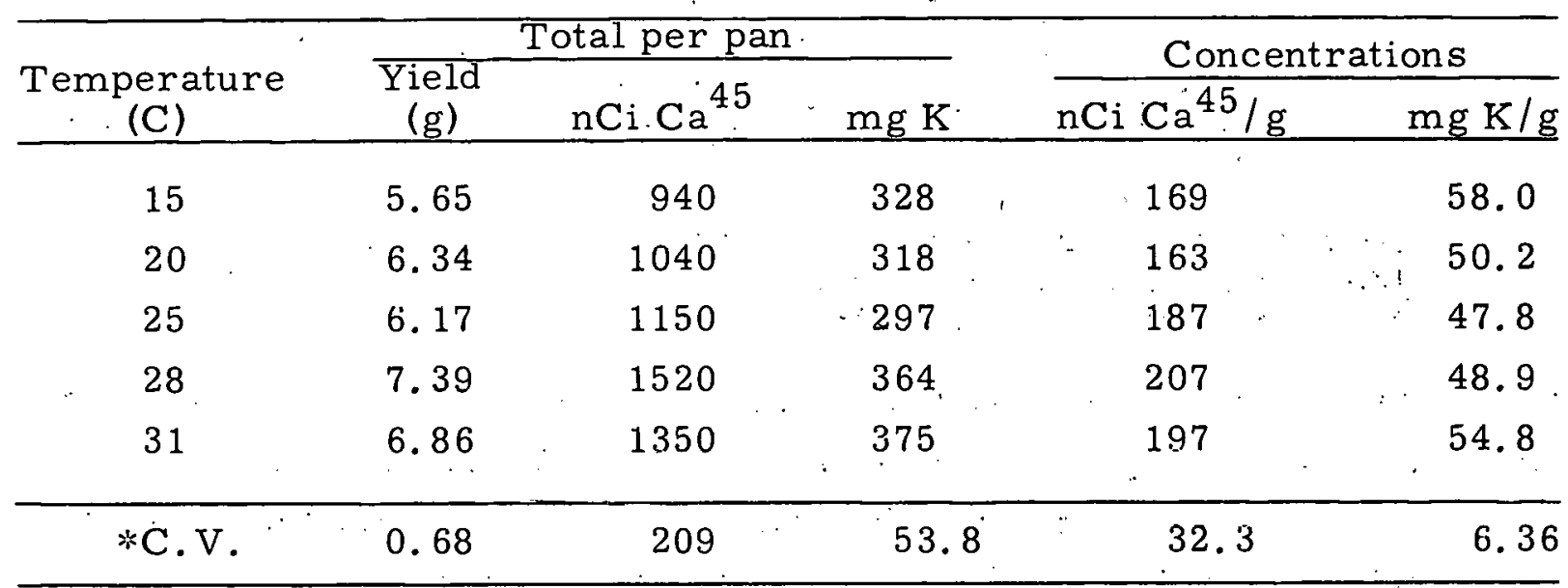

* If the absolute difference between any two means is greater than the critical value, then the means are significantly different at the 0.05 level of significance. 


\title{
RADIOACTIVITY IN NORTHERN ALASKAN NATIVES
} AND THEIR FOODS DURING 1964

\author{
W. C. Hanson, H. E. Palmer, * L. A. Braby, * \\ and B. I. Griffin ${ }^{*}$
}

\begin{abstract}
A third survey of radionuclides in northern Alaskan natives and their foods was conducted during the summer of 1964 . Cesium- 137 body burdens were about double those found in 1963 in comparable ethnic groups of natives. The maximum value $(3 \mu \mathrm{Ci})$ found in whole-body counts of 380 residents occurred in a nonnative male who consumed unusually large amounts of caribou, Seasonal variations were found in caribou flesh Cs 137 concentrations and in body burdens of natives that extensively utilized caribou as food.
\end{abstract}

A third survey of radionuclides in northern Alaskan Eskimos and Indians and their foods was conducted during the summer of 1964. Quarterly whole-body counting was accomplished at Anaktuvuk Pass to determine the seasonal cycle of $\mathrm{Cs}^{137}$ body burdens. Methods and procedures were similar to those cmployed during past years (Hanford Biology Reports for 1962 and 1963). Anaktuvuk Pass and Kotzebue were the only counting locations revisited; in addition, 58 residents of Arctic Village, an Athapascan Indian village about 200 miles east of Anaktuvuk Pass, were scanned to provide a comparison between natives who utilize moose extensively with those who rely upon caribou as their food base. A total of 380 residents of the various villages were scanned; many of them representing recounts of individuals examined in past years.

An appreciable increase in $\mathrm{Cs}^{137}$ body burdens was noted at all villages (Table 1). The various ethnic groups were ranked in much the same order as in the past, with body burdens in direct ratio to the amount of caribou or reindeer eaten. Highest $\mathrm{Cs}^{137}$ body burdens were usually found among Anaktuvuk Pass residents; however, the maximum value measured this summer $(3 \mu \mathrm{Ci})$ was that of a nonnative resident of a river village. He consumed substantially more caribou flesh than the native residents of the same region.

* Radiological Physics Group, Battelle-Northwest, Richland, Washington. 
173

BNWL-122

TABLE 1. Comparison of $\mathrm{Cs}^{137}$ Body Burdens in Adult Natives at Various Alaskan Eskimo and Indian Villages

During Summers of 1962,1963 , and 1964

\begin{tabular}{lrrrrrr}
\hline \multirow{2}{*}{ Location } & \multicolumn{5}{c}{ Mean Cs 137 body burden (nCi) } \\
\cline { 2 - 7 } Anaktuvuk Pass & 450 & $(39)^{*}$ & 640 & $(44)$ & 1330 & $(40)$ \\
Kotzebue & 150 & $(112)$ & 120 & $(102)$ & 340 & $(114)$ \\
River villages & 150 & $(35)$ & 150 & $(16)$ & 360 & $(26)$ \\
Barrow & 55 & $(248)$ & 65 & $(119)$ & - & - \\
Point Hope & 19 & $(80)$ & 40 & $(78)$ & - & - \\
Coastal villages & 100 & $(8)$ & - & - & 130 & $(2)$ \\
Little Diomede & 29 & $(15)$ & - & - & - & - \\
Fort Yukon & - & - & 37 & $(56)$ & - & - \\
Arctic Village & - & - & - & - & 640 & $(25)$
\end{tabular}

* Number of adults in sample.

Arctic Village adult residents contained about half as much $\mathrm{Cs}^{137}$ as a comparable group from Anaktuvuk Pass.

Residents of Fort Yukon were not counted this year but from records of caribou and moose consumption one would expect values to be about onefifth those at Arctic Village. In contrast to the Anaktuvuk Pass riatives, the seasonal low in $\mathrm{Cs}^{137}$ body burdens among these people is expecter to occur in late summer or fall months because they do not practice storage of caribou during summer months. Caribou killed during late summer or early autumn usually contain lower Cs ${ }^{137}$ concentrations in their flesh than at other seasons of the year, as shown by samples collected at Anakturuk Pass (Table 2).

Cesium-137 body burdens in nonnative residents of Kotzebue continued to decrease. Average values were 48, 41, and $35 \mathrm{nCi}$ during the summers of 1962, 1963, and 1964, respectively. Relatively greater variation in $\mathrm{Cs}^{137}$ values occurred in this group than among native residents of the same region because of the effect of variable amounts of caribou and. . , reindeer in their diets upon relatively low body burdens. Adult males 
TABLE $2:$ Average $\mathrm{Cs}^{137}$ Concentrations $\because$ in Caribou. Flesh.

Collected at Anakturuk Pass During 1964

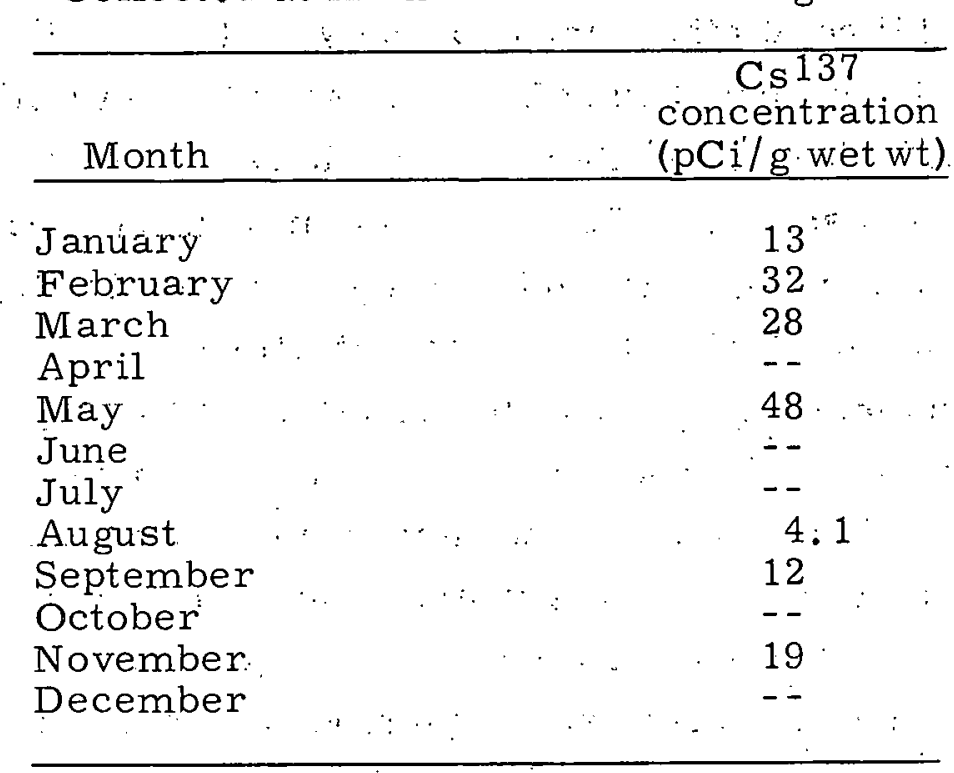

contained about four times as much $\mathrm{Cs}^{137}$ as adult females, compared to a twofold difference between adult native males and females.

A seasonal pattern of $\mathrm{Cs}^{137}$ body burdens was observed in Anaktuvuk Pass residents counted repeatedly during the year (Table 3). Minimum

TABLE 3. Cesium-137 Body Burdens in a Control Group of Anakturuk Pass Native Adults During'Various'Seasons of 1964

\begin{tabular}{lcc}
\hline $\begin{array}{c}\text { Measurement date } \\
1964\end{array}$ & $\begin{array}{c}\text { Number } \\
\text { of } \\
\text { persons }\end{array}$ & $\begin{array}{c}\text { Mean } \mathrm{Cs}^{137} \\
\text { body burden } \\
(\mathrm{nCi})\end{array}$ \\
\hline 13 January & 25 & 430 \\
30 March & 26 & 530 \\
7 July & 26 & 1260 \\
9 September & 25 & 1030 \\
13 October & 6 & 820 \\
15 November & 24 & 750 \\
\hline
\end{tabular}

* Extrapolated from a limited number of measurements with a 3 in. NaI(T1) crystal and portable counter. 
amounts occurred during January following prolonged utilization of fallkilled caribou which contained relatively lower $\mathrm{Cs}^{137}$ concentrations in flesh than those killed at other times of the year (Table 2).' A slight rise in $\mathrm{Cs}^{137}$ body burdens during March resulted from limited availability of fresh caribou from winter ranges where lichens are an important food item and a rich source of $\mathrm{Cs}^{137}$. A major seasonal kill of about 400 of these caribou returning from winter range during late May created a meat supply containing higher $\mathrm{Cs}^{137}$ concentrations. This meat was eaten throughout the summer (June through August) and was responsible for the sharp rise in human.Cs ${ }^{137}$ body burdens to the maximum measured during early July. The kill of caribou returning from summer range was made in late August, and contained comparatively low $\mathrm{Cs}^{137}$ concentrations (Table 2). This meat source had been utilized for about two weeks prior to the whole-body counts made on 9 September and resulted in a slight decrease in.Cs ${ }^{137}$. Subsequent counts in October and November showed the continuing influence of this lower $\mathrm{Cs}^{137}$ intake on human body burdens. 


\title{
RADIOACTIVITY IN ALASKAN ANIMALS
}

\section{AND FORAGE PLANTS}

\author{
D. G. Watson, L. L. Eberhardt, and W. C. Hanson
}

Cesiun-137 and $\mathrm{S}_{1} 90$ were neasured in las ge Alaskan herbivorous animals and their forage during 1963-64. In vegetation, lichens had highest concentrations of these radionuclides. The relatively high levels of $\mathrm{Cs}^{137}$ and $\mathrm{Sr}^{90}$ in reindeer and caribou were due to their consumption of lichens. Fallout concentrations in moose were about one-tenth that in caribou due to different food habits. Amounts of $\mathrm{Cs}^{13} 7$ and $\mathrm{Sr}^{90}$ have increased by a factor of four or more since 1960.

A study was begun in 1963 to investigate the geographic and species differences in the $\mathrm{Cs}^{137}$ and $\mathrm{Sr}^{90}$ content of some of the large terrestrial herbivores and their food plants. Caribou, reindeer, and moose were collected over a wide area of Alaska extending from St. Paul Island to the Canadian border, a distance of approximately $1700 \mathrm{~km}$ (Figure 1). These animals are important to the economy of the native people of northern Alaska, particularly in areas where fish and marine animals are not available.

Annual precipitation in the areas of collection is relatively low, ranging from $20 \mathrm{~cm}$ at Fort Yukon to $60 \mathrm{~cm}$ at St. Paul Island. The period of greatest rainfall is in late summer and early fall.

The concentrations of $\mathrm{Cs}^{137}$ and $\mathrm{Sr}^{90}$ in three of the important types of animal food plants, lichens, sedges, and willows, are summarized in Table 1. The lichens are an important winter food of caribou and reindeer, and the sedges and willows are utilized extensively in summer. Moose browse extensively on willows the year around. Lichens generally contained the largest amounts of $\mathrm{Cs}^{137}$ and $\mathrm{Sr}^{90}$. Mean monthly values ranged from 17 to $69 \mathrm{pCi} \mathrm{Cs}^{137} / \mathrm{g}$ dry weight, and from 5 to $15 \mathrm{pCi} \mathrm{Sr90/g}$ dry weight. The levels of these radionuclides in sedges and willows were from one-fourth to one-tenth that of lichens. Factors responsible for the higher concentrations in lichens include their long life, the year around persistence of their aerial parts, a high surface area to mass ratio, their 


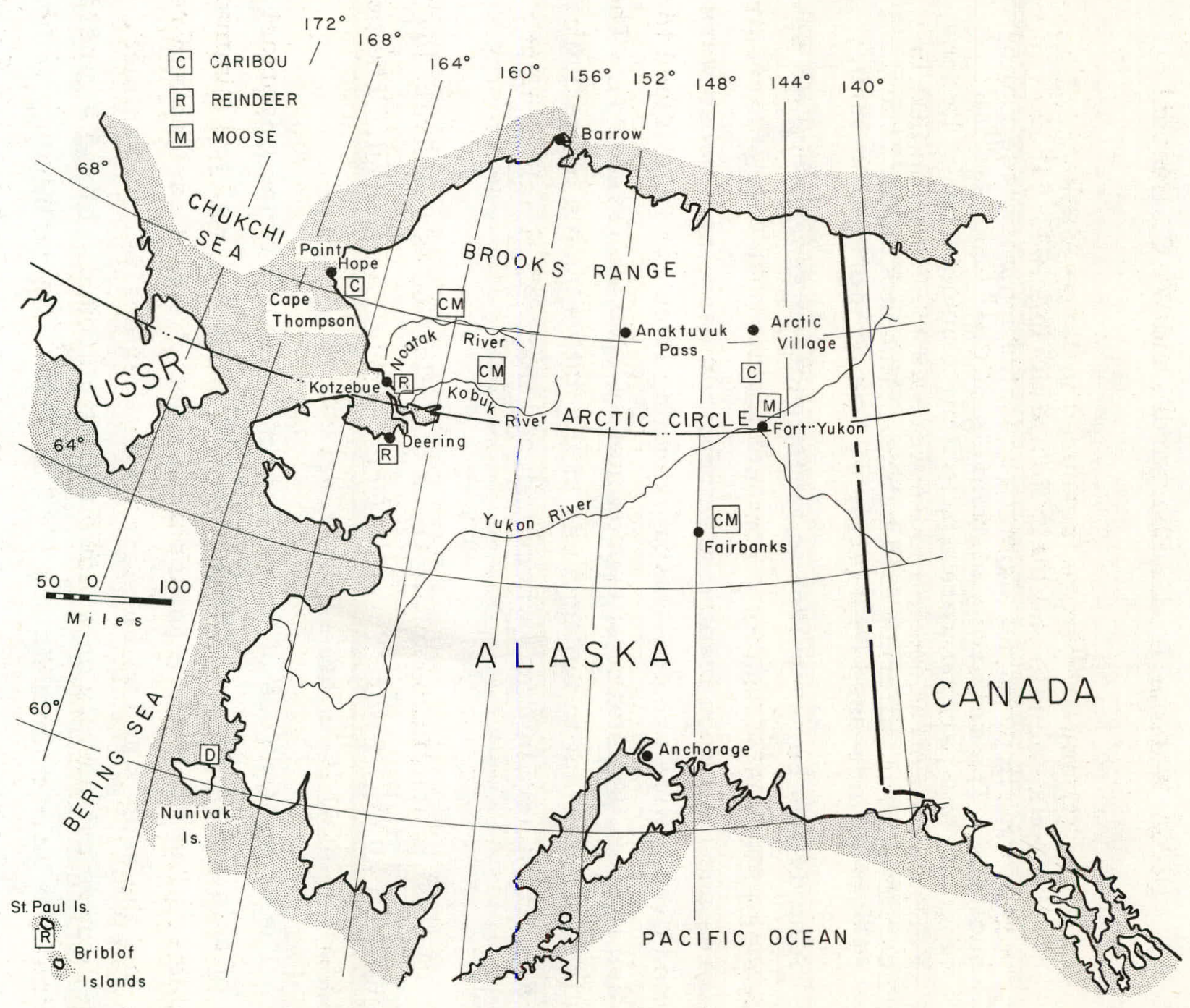

FIGURE 1. Sampling Locations 


\begin{tabular}{|c|c|c|c|c|c|c|c|c|}
\hline \multirow[b]{3}{*}{ Location } & \multirow{3}{*}{$\begin{array}{c}\text { Collection } \\
\text { Date }\end{array}$} & \multirow{2}{*}{\multicolumn{3}{|c|}{ Lichen }} & \multirow{2}{*}{\multicolumn{2}{|c|}{$\begin{array}{l}\text { pCi/g dry weight } \\
\text { Sedge-Carex spp }\end{array}$}} & \multirow{2}{*}{\multicolumn{2}{|c|}{ Willow-Salix spp }} \\
\hline & & & & & & & & \\
\hline & & $\mathrm{Cs}^{137}$ & & $\mathrm{Sr}^{90}$ & $\mathrm{Cs}^{137}$ & $\mathrm{Sr}^{90}$ & $\mathrm{Cs}^{137}$ & $\mathrm{Sr} 90$ \\
\hline Anaktuvuk Pass & $\begin{array}{l}6-63 \\
6-63 \\
1-64 \\
5-64 \\
7-64 \\
3-64\end{array}$ & $\begin{array}{l}24 \pm 2.9^{*} \\
17 \pm 1.6 \\
33 \pm 0.37 \\
28 \pm 3.2 \\
27 \pm 1.4 \\
30 \pm 0.92\end{array}$ & $\begin{array}{l}\text { (b) } \\
\text { (a) } \\
(\mathrm{a}) \\
(\mathrm{a}) \\
(\mathrm{a}) \\
(\mathrm{c})\end{array}$ & $\begin{aligned} 9.6 & \\
6.7 & \pm 3.0 \\
13 & \pm 0.61 \\
7.9 & \pm 0.27 \\
8.0 & \pm 3.3\end{aligned}$ & & & $\begin{array}{l}4.0 \pm 0.013 \\
7.5=0.20\end{array}$ & $1.7 \pm 0.059$ \\
\hline Fort Yukon & $\begin{array}{l}9-63 \\
7-64\end{array}$ & $\begin{array}{l}32 \pm 4.8 \\
52 \pm 2.0\end{array}$ & $\begin{array}{l}\text { (a) } \\
\text { (a) }\end{array}$ & $9.8 \pm 0.25$ & $2.2 \pm 0.011$ & $1.6 \pm 0.088$ & $4.8 \pm 0.59$ & $3.9 \pm 0.47$ \\
\hline Cape Thompson & $\begin{array}{l}7-63 \\
7-63 \\
7-64 \\
7-64\end{array}$ & $\begin{array}{l}33 \pm 0.79 \\
39 \pm 0.28 \\
69 \pm 7.0 \\
69 \pm 3.3\end{array}$ & $\begin{array}{l}\text { (b) } \\
\text { (c) } \\
\text { (b) } \\
\text { (c) }\end{array}$ & $\begin{array}{rr}15 & \pm 0.80 \\
4.9 & \pm 0.54\end{array}$ & $3.1 \pm 0.70$ & $3.5 \pm 0.34$ & $\begin{array}{l}1.6 \pm 0.049 \\
4.9 \pm 0.034\end{array}$ & $3.3 \pm 1.0$ \\
\hline Kobuk River & $\begin{array}{l}8-63 \\
3-64 \\
6-64\end{array}$ & $\begin{array}{l}29 \pm 0.51 \\
23 \pm 1.3 \\
61 \pm 6.1\end{array}$ & $\begin{array}{l}\text { (a) } \\
\text { (a) } \\
\text { (a) }\end{array}$ & $\begin{aligned} & 8.2 \pm 1.0 \\
& 7.5 \pm 1.4 \\
& 10 \quad \pm 1.6\end{aligned}$ & $\begin{aligned} 4.5 & \pm 0.52 \\
33 & \pm 0.37\end{aligned}$ & $2.5 \pm 0.24$ & $\begin{array}{l}5.7 \pm 0.27 \\
6.7 \pm 0.37\end{array}$ & $9.3 \pm 2.6$ \\
\hline Nunivak Island & $8-63$ & 40 & (c) & 13 & $4.0 \pm 0.53$ & $3.1 \pm 0.30$ & $6.5 \pm 1.3$ & $6.7 \pm 0.71$ \\
\hline St Paul Island & $8-63$ & & & & $8.1 \pm 0.47$ & $2.3 \pm 0.61$ & 2.7 & 4.4 \\
\hline
\end{tabular}

(a) Cladonia spp.

(b) Cornicularia spp.

(c) Cetraria spp.

* Standard error of the mean.

ability to obtain nutriment directly from the atmosphere, and their habit of growing in areas that are swept free of snow in winter, thus permitting constant exposure to the atmosphere. In contrast, the caribou and reindeer consume only the new growth of sedges and willows in summer.

The old growth of sedges often contains amounts of $\mathrm{Cs}^{137}$ comparable to that of lichen, as illustrated by the samples from Kobuk River obtained in March, 1964. These samples were comprised of dead leaves of the past summer's growth plus plant litter of earlier growing periods. Similar amounts of $\mathrm{Cs}^{137}$ have previously been observed in summer sedge samples containing both living and dead material. A limited number of rumen analyses of caribou and reindeer collected in winter indicate that this dead plant material may be an important component in the winter diet and a significant contributor of $\mathrm{Cs}^{137}$ to these animals.

No marked differences in the $\mathrm{Cs}^{137}$ and $\mathrm{Sr}^{90}$ content of plants were noted with respect to area of collection. Differences between samples taken within a limited area were often as great as those between locations several hundred kilometers apart. 
The content of $\mathrm{Cs}^{137}$ and $\mathrm{Sr}^{90}$ in animal tissues is shown in Tables 2 and 3. There were no major differences in the radionuclide burden of reindeer and caribou from similar environments. It is possible that the winter levels of $\mathrm{Cs}^{137}$ in St. Paul Island reindeer may be appreciably less than that of mainland animals due to the year around availability of green plants and the sparsity of lichens on the island.

TABLE 2. Caribou: $\mathrm{Cs}^{137}$ in Muscle, $\mathrm{Sr}^{90}$ in Bone

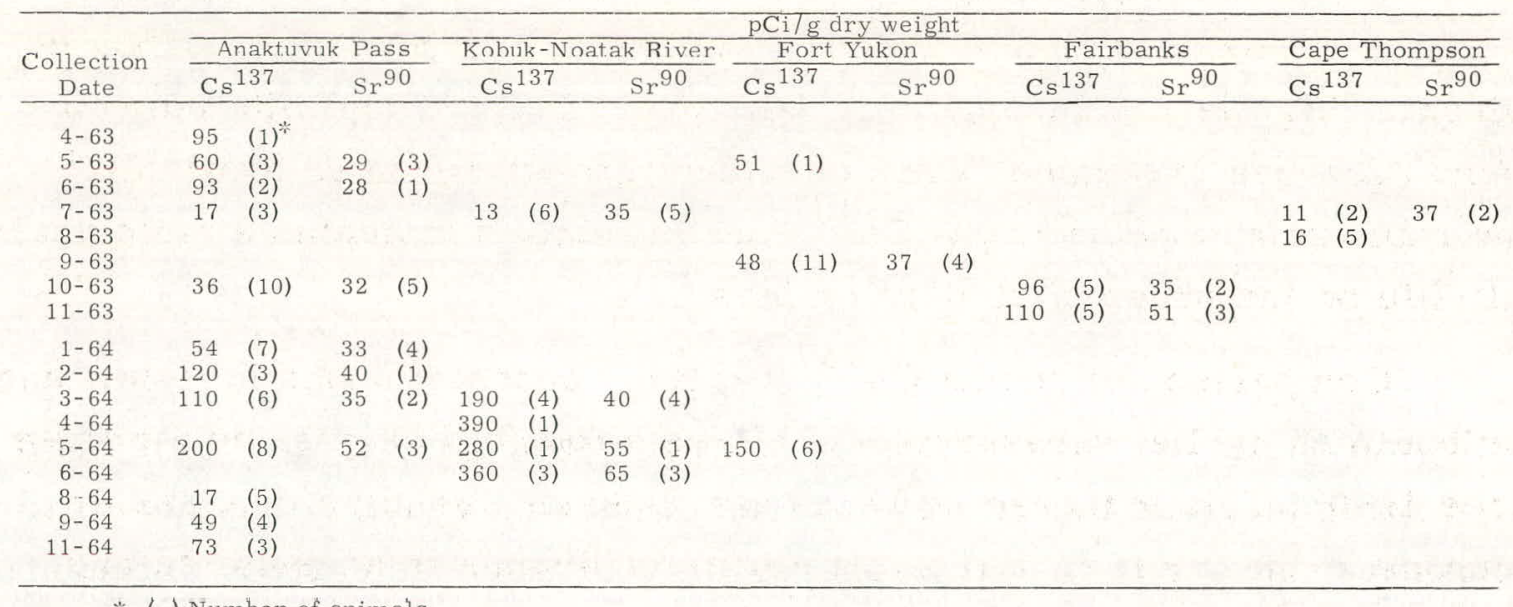

* () Number of animals

TABLE 3. Moose: $\mathrm{Cs}^{137}$ in Muscle, $\mathrm{Sr}^{90}$ in Bone

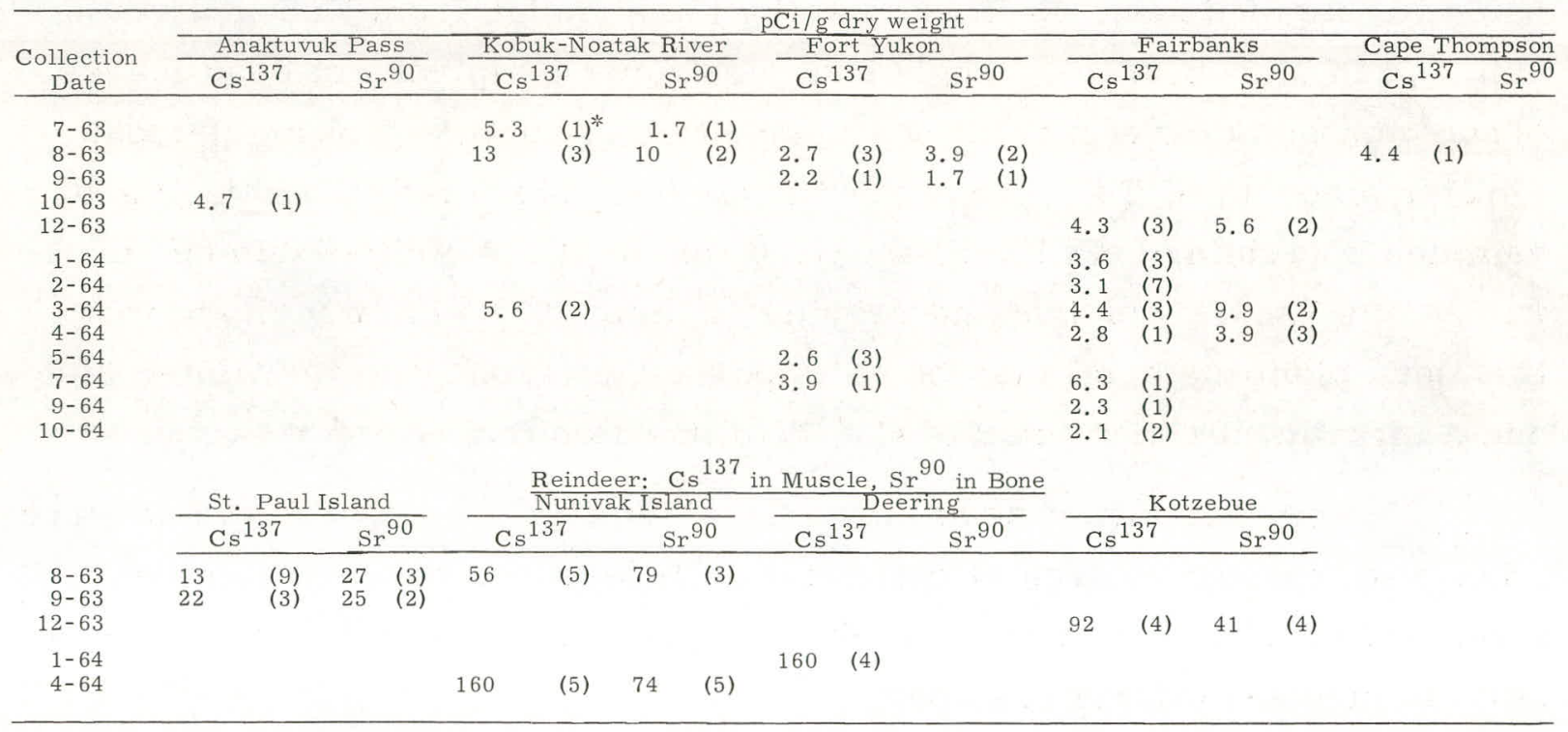

* ( ) Number of animals 
The amount of $\mathrm{Cs}^{137}$ in moose muscle and the $\mathrm{Sr}^{90}$ content of bone was about one-tenth that of caribou and reindeer. The Cs ${ }^{137}$ content of moose muscle was comparable to that of deer and elk from the State of Washington during 1963-64. The differences between the quantities of fallout radionuclides in caribou and moose tissues graphically illustrate the effect of diet on the uptake of these materials. The absence of lichen and possibly plant litter in the diet of moose are likely reasons for the lower $\mathrm{Cs}^{137}$ and $\mathrm{Sr}^{90}$ burden.

A seasonal variation in $\mathrm{Cs}^{137}$ content of reindeer and caribou is evident. High levels occur during late winter and spring followed by a sharp decrease in summer when new plant growth becomes available. The rapid rate of decrease of $\mathrm{Cs}^{137}$ in the animals indicates a biological half-life on the order of 20 days or less."

Comparison of recent $\mathrm{Cs}^{137}$ and $\mathrm{Sr}^{90}$ concentrations in lichen and caribou with earlier measurements shows a fourfold or greater increase since 1960. This increase is due to atmospheric testing of nuclear weapons in the interim, and to the ability of lichens to accumulate and retain radioactive fallout. 


\title{
STUDIES OF FALLOUT NUCLIDES IN PLANTS
} AND BROWSING ANIMALS OF WASHINGTON

\author{
L. L. Eberhardt and W. H。.Rickard
}

\begin{abstract}
A regular seriesi of samples of plants and browsing animals has been obtained over areas encompassing a wide range of precipitation and elevation. Levels of radionuclides in both plants and animals showed marked seasonal variations as well as precipitational effects.
\end{abstract}

This study was initiated in an effort to appraise the effects of season, precipitation, and elevation on fallout levels in food chains. Major study sites are on the Hanford Reservation, in the Blue Mountains (near Dayton), in the Cascade Mountains (between Yakima and Packwood), and in the vicinity of Quinault. Precipitation ranges are thus from about 6 to: $100 \mathrm{in}$. annually, and elevation from roughly 500 to $4500 \mathrm{ft}$. Very limited sampling was started in April, 1963, but intensive collections did not start until the winter of 1963. Conclusion of the intensive sampling was slated for December of 1964, but was delayed until January of 1965 .

Collections of vegetation were made on a monthly basis at three general sites (Hanford, Blues, and Cascades) with the intent of appraising seasonal changes in fallout, plant growth, and animal food habits. A variety of species were collected, but the monthly collections were largely Douglas Fir (Pseudotsuga menziesii) and bunchgrass (Agropyron spicatum). Animal collections were made on a quarterly basis, using either mule deer (Odocoileus hemionus) or elk (Cervus canadensis). These animals were chosen as being large ruminants with relatively simple food habits, and as having some value for comparative purposes in relating the study to those currently being carried on in Alaska. Precipitation collections have been made on a monthly basis at five locations representative of the three major sites, in the hope of relating fallout levels in precipitation to the accretion of fallout on plants and the subsequent transfer to animals.

Early in the study it was noted that levels of $\mathrm{Cs}^{137}$ in ruminant feces were considerably higher than those in vegetative materials in the 
diet or in the contents of the rumen. Consequently an effort. has been made to collect fresh droppings as frequently as possible in the study, and a further investigation of the relation between levels in rumen, muscle, and feces is underway in cooperation with the Experimental Animal Farm.

Many of the records from the study were damaged in a fire in November of 1964 , and it has not yet been possible at this writing to reconstitute all such records. Also, a sizable number of samples are still in the analytical process, and some small fraction of samples were lost in the fire. 'I'he longest time span of data, and the rrost complete set at the present are those from the Blue Mountains. Representative portions of these data are shown in Figure 1, and commented on below (only data for $\mathrm{Cs}^{137}$ are shown and in picocuries per gram dry weight).

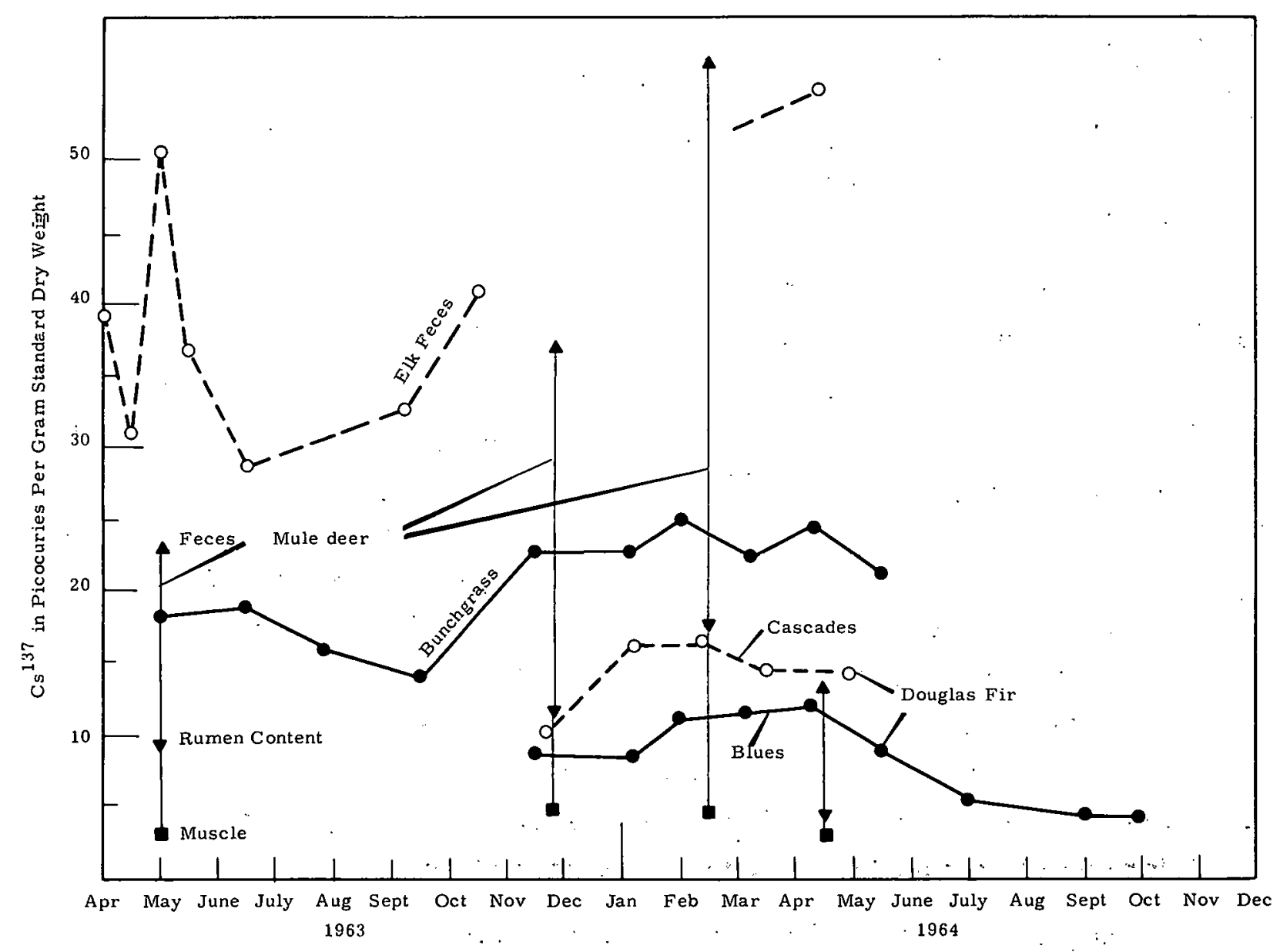

FIGURE 1. Levels of $\mathrm{Cs}^{137}$ in "Plant and Animial Samples 
The long series of bunchgrass samples shows an annual cycle of nuclide level, and little overall change from 1963 to 1964 . These samples include an accumulation of old stem material which contributes a good deal of the radionuclide burden. New growth in early summer has roughly one-third or one-fourth the levels of the composite samples.

The wide range of burden from muscle to feces (samples from the same animals) varies sharply with season, decreasing very markedly at the time (April or:May, depending on elevation) when the animals change from winter diets to the succulent green foods of the spring.

For comparative purposes, a series of levels for the Douglas Fir in the Cascade Mountains is included. Primary measurement on this species was on current growth only. Older growth shows higher levels. The effect of rather different precipitation regimes between the Cascades and the Blues is apparent in the fall and winter values shown here. The comparison is based on average values for the two areas. Individual stations stations in the Blue Mountains, ranging over some $2000 \mathrm{ft}$ of elevation show little difference in. $\mathrm{Cs}^{137}$ burden, but the Cascade stations, ranging from precipitation levels considerably lower than those of the Blues through comparable levels to over 50 in. annually at Packwood, show a threefold range in average radionuclide burden. 


\title{
RELATIONSHIP OF ANNUAL FORAGE YIELD
}

AND FALLOUT DEPOSITION IN A CHEATGRASS COMIMUNITY

\author{
W. H. Rickard
}

The concentration of $\mathrm{Cs}^{137}$ in cheatgrass was little changed in 1964 as compared to 1963 . However, the yield of cheatgrass was much greater in 1963 because of a favorable precipitational regime. Increased harvest yield resulted in a 12 -fold increase of $\mathrm{Cs}^{137}$ in the vegetation of a herbaceous plant community in 1963 as compared to 1964.

This paper presents the results of four consecutive years of cheatgrass (Bromus tectorum L.) harvests in relation to precipitational regimes and fallout radionuclides in cheatgrass.

Cheatgrass, a winter annual, was harvested from an abandoned field habitat on the Hanford Reservation, Benton County, Washington, during the years 1961-64. During the period of study the vegetation of the field consisted of a nearly pure sward of cheatgrass with only a sparse scattering of herbs, mostly Salsola kali L. and Sisymbrium altissimum L. The field was retired from agricultural use about 20 years ago and since then has been protected from livestock grazing. In 1961, three plots, each $1 \times 3 \mathrm{~m}$, were clipped of aboveground parts. In other years, 10 or 15: plots, $1 \times 1 \mathrm{~m}$, were harvested. Only new growth, i.e., the growth of each year, was harvested. Harvesting was done in late May when the plants were in fruit but before the dropping of seeds was prevalent. Yield is expressed as the oven dry weight per square meter after drying at $105{ }^{\circ} \mathrm{C}$.

The results of four years of cheatgrass harvest in relation to the precipitational regimes are shown in Table 1 . There was much variability of yield between years. The maximal yield occurred in 1963 and the minimal yield in 1964 . The minimal yield of $17 \mathrm{~g} / \mathrm{m}^{2}$ was associated with the driest precipitational regime, i.e., about one-half of the normal October to May precipitation. The months of February, March, and April, 1964 were the driest recorded in 51 years. The greatest yield was measured in 1963 when $236 \mathrm{~g} / \mathrm{m}^{2}$ of grass was harvested. An unusually moist October 
185

BNWL- 122

1962 resulted in prompt seed-germination and the early establishment of seedlings. The period of most rapid vegetative growth the following April 1963 also was favored by unusually high precipitation.

TABLE 1. Harvest Yield of Cheatgrass in Relation to Precipitational Regimes in 1961-64, Hanford Reservation, Washington

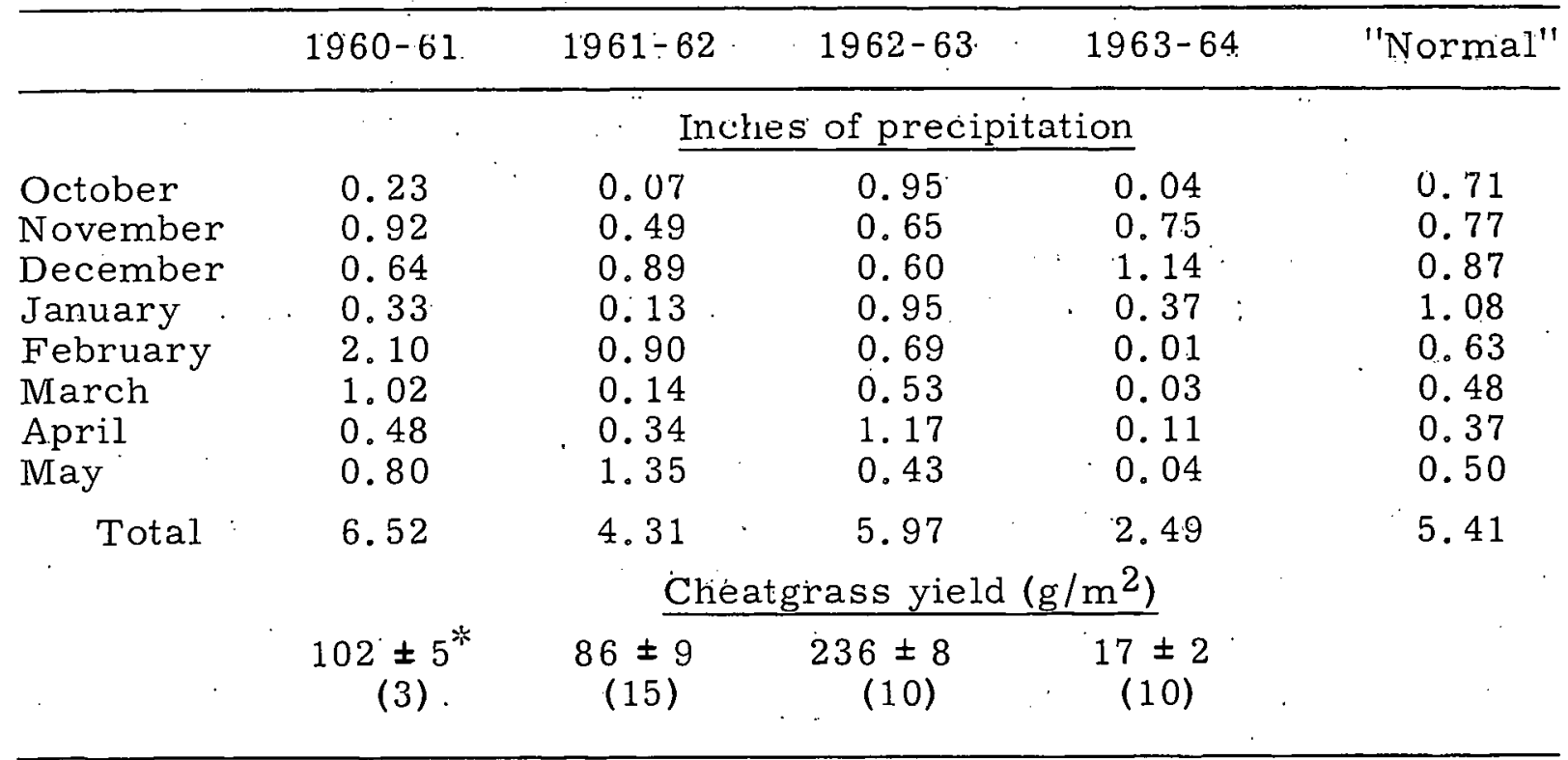

* \pm Standard error; ( ) Number of samples

Fallout gamma emitters of cheatgrass in 1963 and 1964 are showr in Table 2. In the absence of nuclear tests the C $\mathrm{e}^{144}$ content of the air sam-. pled on the Hanford Reservation was reduced about half in 1964 as compared to 1963. Cerium-144 content of cheatgrass was also reduced by about. half, i. e., $43 \mathrm{pCi} / \mathrm{g}$ dry weight in 1963 as corrupared to only $19 \mathrm{pCi} / \mathrm{g}$ in 1.964 . There was no apparent reduction of $\mathrm{Cs}^{137}$ (half-life 27 years) in cheatgrass tissues or in air samples. However, when biologic productivity was considered, there was 12 times more $\mathrm{Cs}^{137}$ available for ecologic transfer through through food chains and for microbial decomposition in 1963. 
TABLE 2: Fallout Content (Gamma Emitters) of Cheatgrass Harvested in Mid-May 1963 and 1964 on the Hanford Reservation, Benton County, Washington

\begin{tabular}{|c|c|c|c|c|c|}
\hline \multirow[b]{2}{*}{ Radionuclides } & \multicolumn{3}{|c|}{ pCi/g dry weight } & \multicolumn{2}{|c|}{$\mathrm{pCi} / \mathrm{m}^{2}$} \\
\hline & - & 1963 & $1964^{*}$ & 1963 & $1964 \%$ \\
\hline $\mathrm{Ce}^{144}, \operatorname{Pr}^{144}$ & - & 43 & 45 & 10,000 & 760 \\
\hline $\mathrm{Zr}^{95}, \mathrm{Nb}^{95}$ & & 40 & 23 & 9,000 & 390 \\
\hline $\mathrm{Ru} \mathrm{u}^{106}, \mathrm{R} \mathrm{h}^{106}$ & & 12 & 12 & 2,800 & 260 \\
\hline $\mathrm{Mn}^{54}$ & & 3.1 & 2.0 & 730 & 260 \\
\hline $\mathrm{Cs} 137$ & & 1.5 & 1.7 & 350 & 29 \\
\hline Total & & 100 & 84 & 23,000 & 1,700 \\
\hline
\end{tabular}

The entire harvest of the 1964 crop was pooled and counted in one container.

* 1964 value corrected for radiodecay. 


\title{
RADIONUCLIDE ACCUMULATION AND TRANSPORT BY PLANKTON
}

\section{IN THE COLUMBIA RIVER}

\author{
C. E. Cushing
}

Cursory:analysis of monthly averages of net plankton sam. ples revealed that $\mathrm{P}^{32}$ and $\mathrm{Zn}^{65}$ concentration ( $\mathrm{nCi} / \mathrm{g}$ dry weight) was lowest during the summer months; probably related to dilution by runoff. Transport of these radionuclides by the plankton was highest in spring and late summer, coincident with seasonal increases of the plankton. The ability of the plankton to concentrate radioisotopes from the water varied seasonally with lowest values during the summer months.

The purpose of this study was to determine the accumulation and transport of $\mathrm{P}^{32}$ and $\mathrm{Zn}^{65}$ by net plankton in the Columbia River below the Hanford reactors. Net plankton, as used in this study, is defined as the free floating organic matter retained by a No. 20 mesh plankton net (68 meshes $/ \mathrm{cm}$ ) and includes both living and dead material.

Plankton samples were collected twice monthly from several points along a transect across the river. Unequal distribution of velocity, volume, and effluent plumes dictated sampling at several points.

Data presented in this cursory report are monthly averages of the individual samples and should be interpreted with this in mind. A detailed analysis of the data awaits definition of physical characteristics of the river channel.

Figure $1 \mathrm{~A}$ shows the seasonal patterns of accumulation of $\mathrm{P}^{32}$ and $\mathrm{Zn}^{65}$ by the net.plankton. The February $\mathrm{P}^{32}$ value on all figures has been omitted because of an obvious analytical error in one sample. Lowest. values coincide.with the seasonal runoff and probably.reflect a diluting of the radioisotope concentration in the river by this increased volume with a resulting reduced uptake by the plankton.

Figure $1 \mathrm{~B}$ shows the seasonal pattern of transport of net plankton biomass and the amount of $\mathrm{P}^{32}$ and $\mathrm{Zn}^{65}$ associated with the net plankton. Fluctuations of plankton and radioactivity.are similar, although not 
entirely synchronous, with lowest values occurring during the winter months. Combination of the average monthly flow values of the Columbia with the data in Figure 1 can give crude approximations of the amount of plankton biomass, and $\mathrm{P}^{32}$ and $\mathrm{Zn}^{65}$ sorbed to the plankton and transported by the Columbia River each day at Hanford. Isotope transport values range from $0.1 \mathrm{Ci} /$ day in winter to $1.2 \mathrm{Ci} /$ day in May for $\mathrm{P}^{32}$, and $0.2 \mathrm{Ci} /$ day in February to $1.8 \mathrm{Ci} /$ day in July for $\mathrm{Zn}^{65}$. This plankton associated radioactivity amounted to roughly $1 \%$ of the total river transport of these nuclides.

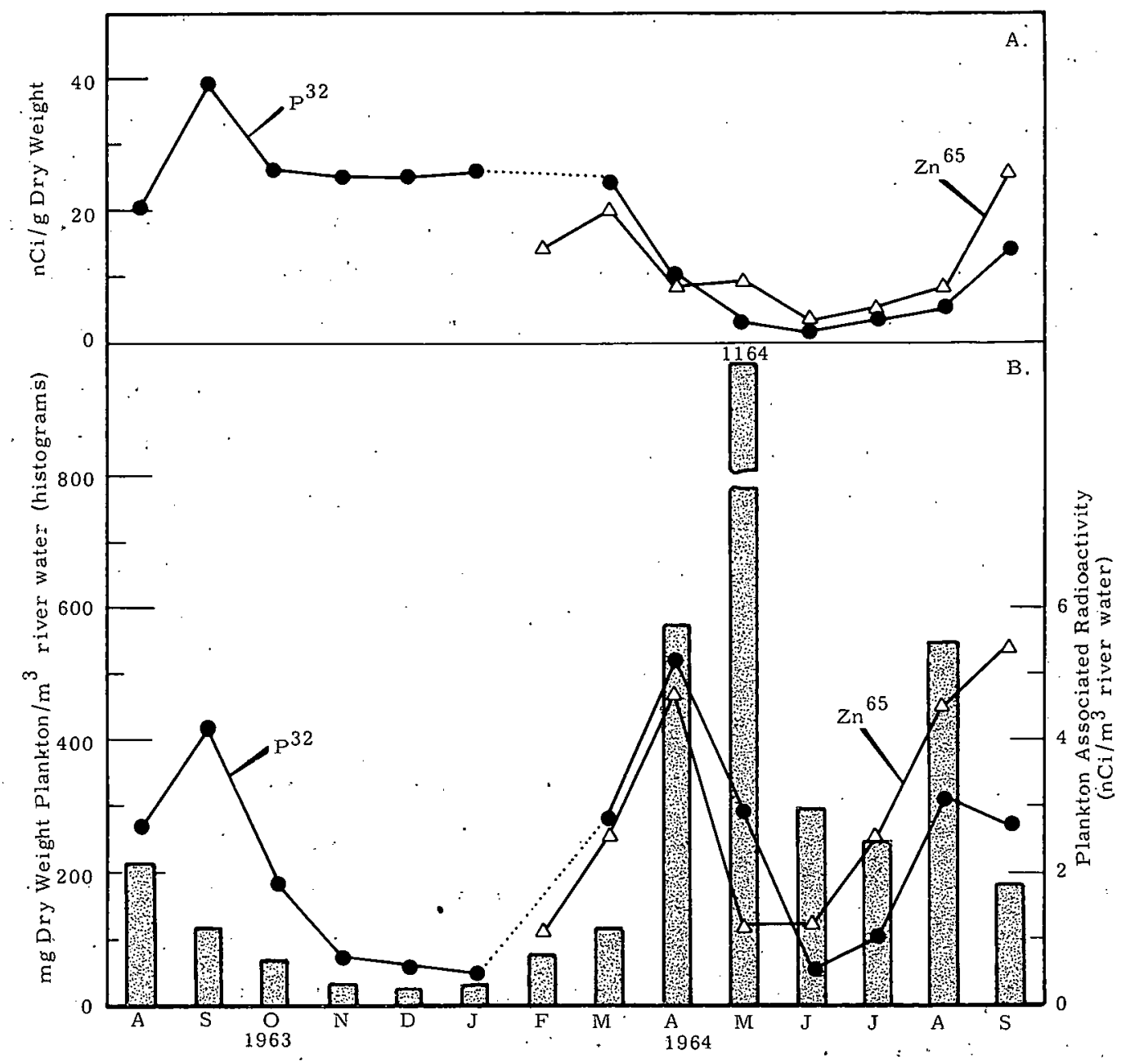

Figure 1. A. Accumulation of $\mathrm{P}^{32}$ and $\mathrm{Zn}^{65}$ : by Net Plankton B. Density of Plankton and Associated $\mathrm{P}^{32}$ and $\mathrm{Zn}^{6} 65$ in the Columbia River 
The ability of the plankton to concentrate radionuclides is expressed as the concentration factor (C.F.) and is found by dividing the concentration. of the isotope in the organism ( $\mathrm{nCi} / \mathrm{g}$ wet weight) by the concentration of the isotope in the water $(\mathrm{nCi} / \mathrm{ml})$. The present data show C.F.'s ranging from approximately 5000 to 118,000 for $\mathrm{P}^{32}$ and from 300 to 19,000 for $\cdot \mathrm{Zn}^{65}$, emphasizing the fast that therc arc seasurial varlations in the ability to concentrate radioisotopes.

It is of interest to note the seasonal relationships among these parameters. Radioisotope concentration of the net plankton declined coincident with increased runoff and plankton biomass. The lower concentrations of $\mathrm{P}^{32}$ and $\mathrm{Zn}^{65}$ in the plankton are probably the result of more organisms being exposed to a lower concentration of $\mathrm{P}^{32}$ and $\mathrm{Zn}^{65}$ in the water--a result of dilution by the runoff. Despite lower concentration of $\mathrm{P}^{32}$ and $\mathrm{Zn}^{65}$ in spring and late summer, more radiophosphorus and zinc was generally transported by the plankton due to the increased plankton biomass. 
191

BNWL- 122

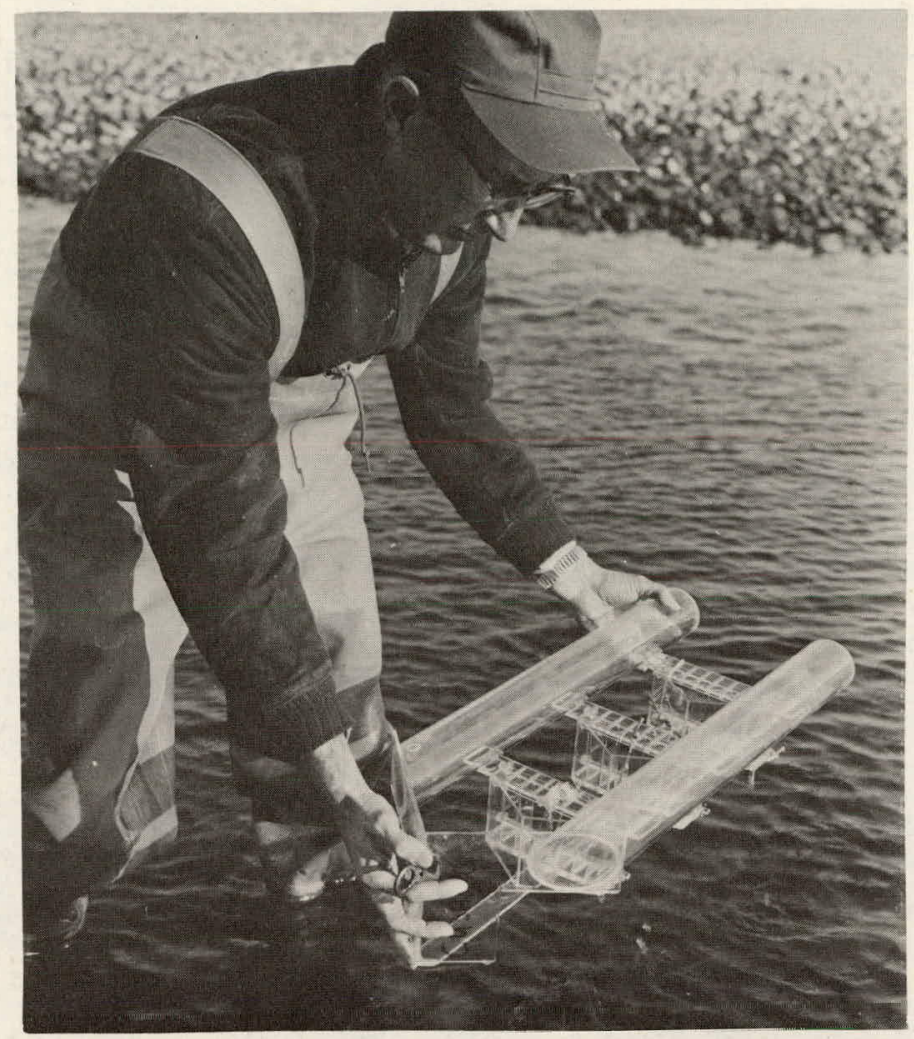

FIGURE 1. Apparatus for Exposing Experimental Slides

TABLE 1. Selected Correlation Coefficients Between Limnological Variables in the Columbia River, August 1963 to May $1964^{*}$

\begin{tabular}{|c|c|c|c|c|c|c|}
\hline$=$ & $\begin{array}{c}\text { Ash } \\
\text { weight }\end{array}$ & $\begin{array}{l}\text { Ash- } \\
\text { free }\end{array}$ & $\begin{array}{c}\text { Chlorophyll } \\
\underline{\mathrm{a}} \\
\end{array}$ & Light & $\begin{array}{c}\mathrm{Zn}^{65} \\
\text { (nCi/slide) }\end{array}$ & $\begin{array}{c}\mathrm{P}^{32} \\
\text { (nCi/slide) }\end{array}$ \\
\hline Dry weight (mg) & 0.97 & 0.89 & 0.84 & 0.71 & 0.83 & 0.94 \\
\hline Ash weight (mg) & & 0.77 & 0.85 & 0.66 & 0.90 & 0.89 \\
\hline Ash-free dry weight (mg) & & & 0.72 & 0.70 & 0.59 & 0.76 \\
\hline Light (Langleys) & & & & & 0.58 & 0.49 \\
\hline $\begin{array}{l}\text { Net Production Rate } \\
\text { (mg/dry wt. } \mathrm{cm}^{2} / \text { day) }\end{array}$ & & & 0.84 & 0.85 & & \\
\hline Chlorophyll a (abs. $664 \mathrm{~m} \mu)$ & & & & 0.66 & 0.80 & 0.71 \\
\hline River burden index & & & & & NS & NS \\
\hline
\end{tabular}

* Assuming a correlation coefficient equal to zero as a null hypothesis, all correlation coefficients are significantly different from zero at the $95 \%$ level of confidence. $\mathrm{NS}=$ not significant.

The low correlation between ash and ash-free dry weight is probably due to the seasonal changes in the composition of the community. In fall and winter, the community is dominated by diatoms, mainly Synedra 


\title{
RADIONUCLIDE ACCUMULATION AND PRODUCTIVITY OF PERIPHYTON IN THE COLUMBIA RIVER
}

\author{
C. E. Cushing
}

Best correlations among four biomass measurements of periphyton were between dry weight, ash weight, and chlorophyll a. Net Production Rate varied from 0.005 to $0.070 \mathrm{mg}$ dry weight $/ \mathrm{cm}^{2} /$ day and was closely related to chlorophyll a content and solar energy.

The accumulation of $\mathrm{P}^{32}$ and $\mathrm{Zn}^{65}$ was best related to dry and ash weight, and chlorophyll a. Low correlations were found between radionuclide accumulation and the radionuclide content of the river. The data suggested that adsorption was the dominant mode of uptake.

The periphyton community of most rivers comprises the main source of primary production. As such, the periphyton and the phytoplankton are important communities in the Columbia River in relation to radionuclide accumulation. The purposes of the present study were (1) to examine which biological and environmental factors are most influential in governing the amount of $\mathrm{P}^{32}$ and $\mathrm{Zn}^{65}$ accumulated from the river by the periphyton, and (2) to compare the relationships among the commonly used production indices and certain environmental measurements. Data on the method of sorption of these nuclides were also evaluated.

Glass slides were exposed for two-week periods in a side channel of the Columbia River below the reactors in the apparatus shown in Figure 1. Replicate slides were taken at each sampling for biomass determinations and chlorophyll extraction. Several slides were pooled for radioactivity analysis; $\mathrm{Zn}^{65}$ was counted on a single-channel gamma-ray spectrometer and $\mathrm{P}^{32}$ by differential absorber techniques. One slide was preserved for visual examination. Radionuclide content of the river was computed from analysis of water samples collected by an integrating sampler operated at the 300 Area by the Radiation Protection Department. Solar radiation was measured with an Eppley pyrheliometer.

The factors considered and their correlation coefficients are given in Table 1. 
and Melosira, which have a high ash:ash-free ratio because of their silica frustules... In spring, the filamentous green, alga Ulothrix is the dominant organism and the community would have a lower ash:ash-free ratio.

A higher correlation between light; - measured as total Langleys incident during the two-week exposure, and chlorophyll a was expected. This relationship, however, is variably influenced by such factors as detrital chlorophyll, age of the community, and prenutrition of the organisms.

The Net Production Rate (NPR) was calculated in terms of dry weight/surface area/day. The close correlation with chlorophyll a is consistent with the fact that best relationships between pigment content and productivity are usually found during periods of rapid growth. These conditions were prevalent in this study since colonization began from a bare surface. Figure 2 shows the seasonal variation in the NPR both on a dry and ash-free dry. weight basis. Since these figures represent a two week net increment from a bare surface, they are probably higher than a similar increment from an established community. The general shape of the curve is representative of the seasonal variations of many of the parameters measured in this study.

Correlations between the various biomass parameters and radionuclide accumulation were similar. The low correlation of $\mathrm{P}^{32}$ and $\mathrm{Zn}^{65}$ accumulation with solar radiation would be expected because any influence it might exert would be indirect through chlorophyll and biomass production. Low correlations were found when $\mathrm{P}^{32}$ and $\mathrm{Zn}^{65}$ were expressed as activity density and correlated with the other limnological variables.

Previous studies of the Columbia River biota revealed that the concentration of radioisotopes in the phytoplankton were more closely related to activity in the water than they were to certain environmental features. Thus, it was suspected that the radioisotope content of the river might influence the uptake by the periphyton to such a degree as to mask the effects of biological activity. In the present study, however, there appeared to be little correlation between radionuclide accumulation and 
radioisotope content of the river as measured at a point several miles downstream from where the periphyton was sampled. This anomaly is being investigated further under laboratory conditions.

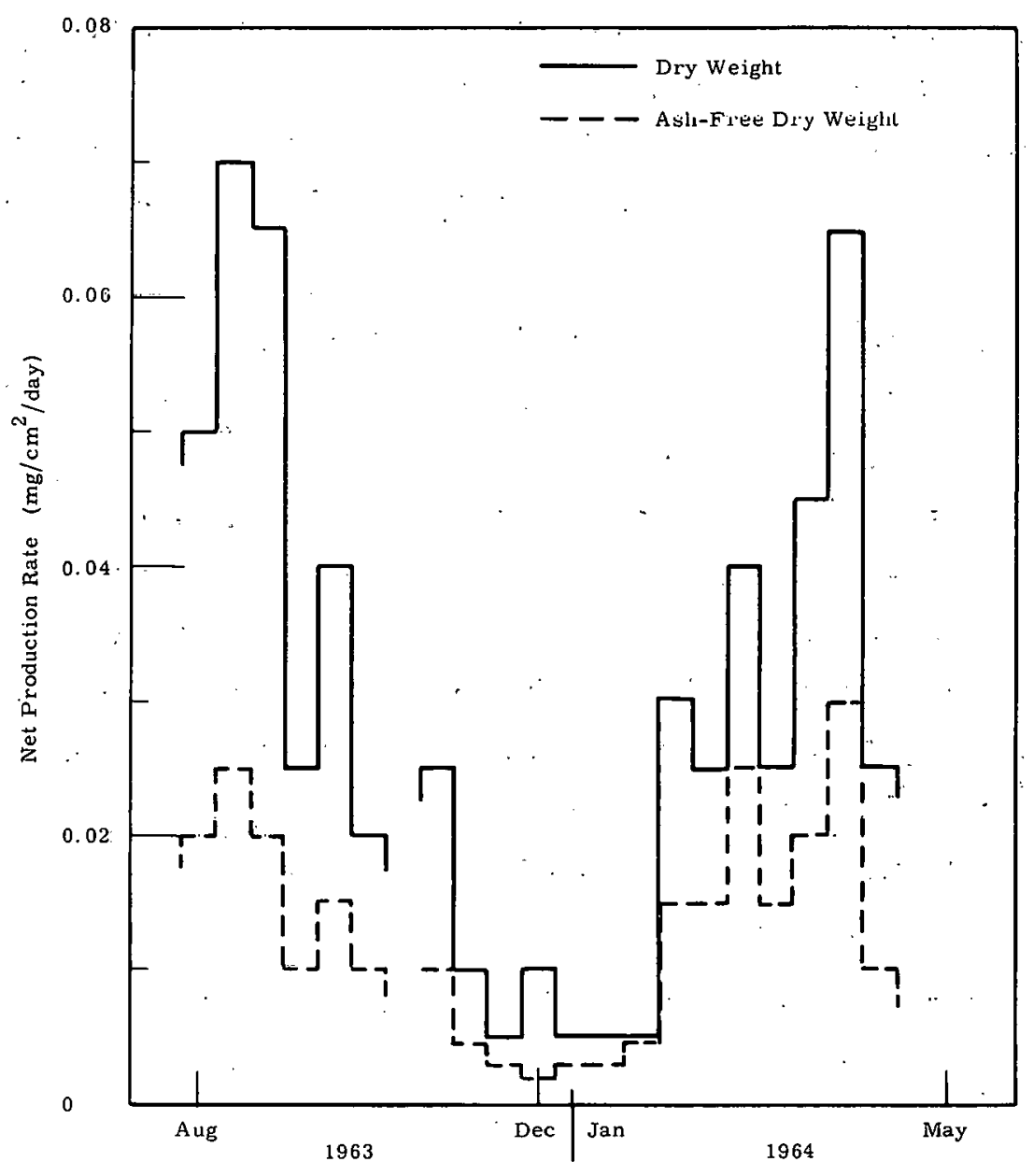

FIGURE 2. Net Production Rate of Periphyton, August 1963 to May 1964

The fact that nuclide accumulation is better related to the dry and ash weights than to ash-free dry weight, sugge'sts that the dominant mode of uptake is adsorption rather than absorption. A better correlation with the organic fraction would be expected if absorption were the prevalent method of uptake. The data further suggest that the periphyton community accumulates a certain amount of each isotope from the river and that this amount is governed not by the amount to which it is exposed, but by the physical size of the community. 


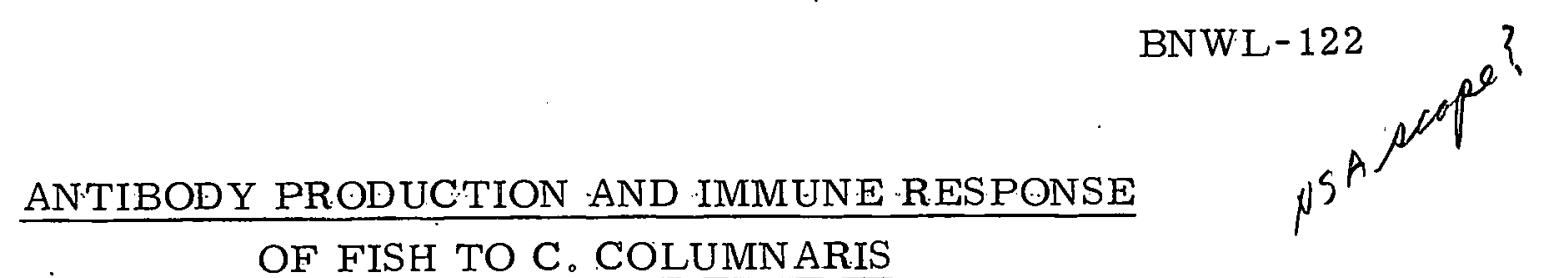
OF FISH TO C.COLUMNARIS

M. P. Fujihara, P. A. Olson", and R. E. Nakatani

Incidence of Chondrococcus columnaris in yearling rainbow trout; which were exposed to natural infection as fingerlings, suggests yearlings are immune and frequently active carriers of the organism. The maximum saline agglutinin titers induced in trout were 1:640 for vaccine and 1:5120 for Freund's adjuvant, plus vaccine. Preliminary surveys of Columbia River fish for antibody, titers suggested that a majority, of the fish had previous exposure to columnaris.

Past observations of fingerling rainbow trout held in troughs showed an abrupt rise in mortality associated with columnaris infection, followed by an equally abrupt fall and cessation of columnaris mortality. Numbers of organisms released by the fish to the water also rose sharply with mortality, but did not decline as mortality dropped to near zero (Hanford Biology Report for 1963). These observations, and the lack of columnaris mortality among yearlings and older trout, imply immune response of the fish to columnaris.

Release of organisms to water by yearling trout appears to be cyclic. Fish were removed from troughs and individually isolated in columnaris-free water for $1 \mathrm{hr}$. Plate counts provided estimates of numbers of organisms released. Figure 1 illustrates such data for two fish. Fish 1 showed three cycles over the 120 day test period with as many as $2.1 \times 10^{6}$ organisms released in an hour. Fish 2 showed one cycle over 28 days with no further release. However, when this fish was returned for two weeks to a trough holding other fish in Columbia River water, and subsequently tested, large numbers of organisms were again released. Results with other isolated fish varied from no columnaris release, a single cycle, or several cycles of release. These yearling fish are apparently immune; some rid themselves of the organisms while others act as carriers of the disease. Smears from the gills were positive, but no colonies were obtained from platings from internal organs. 


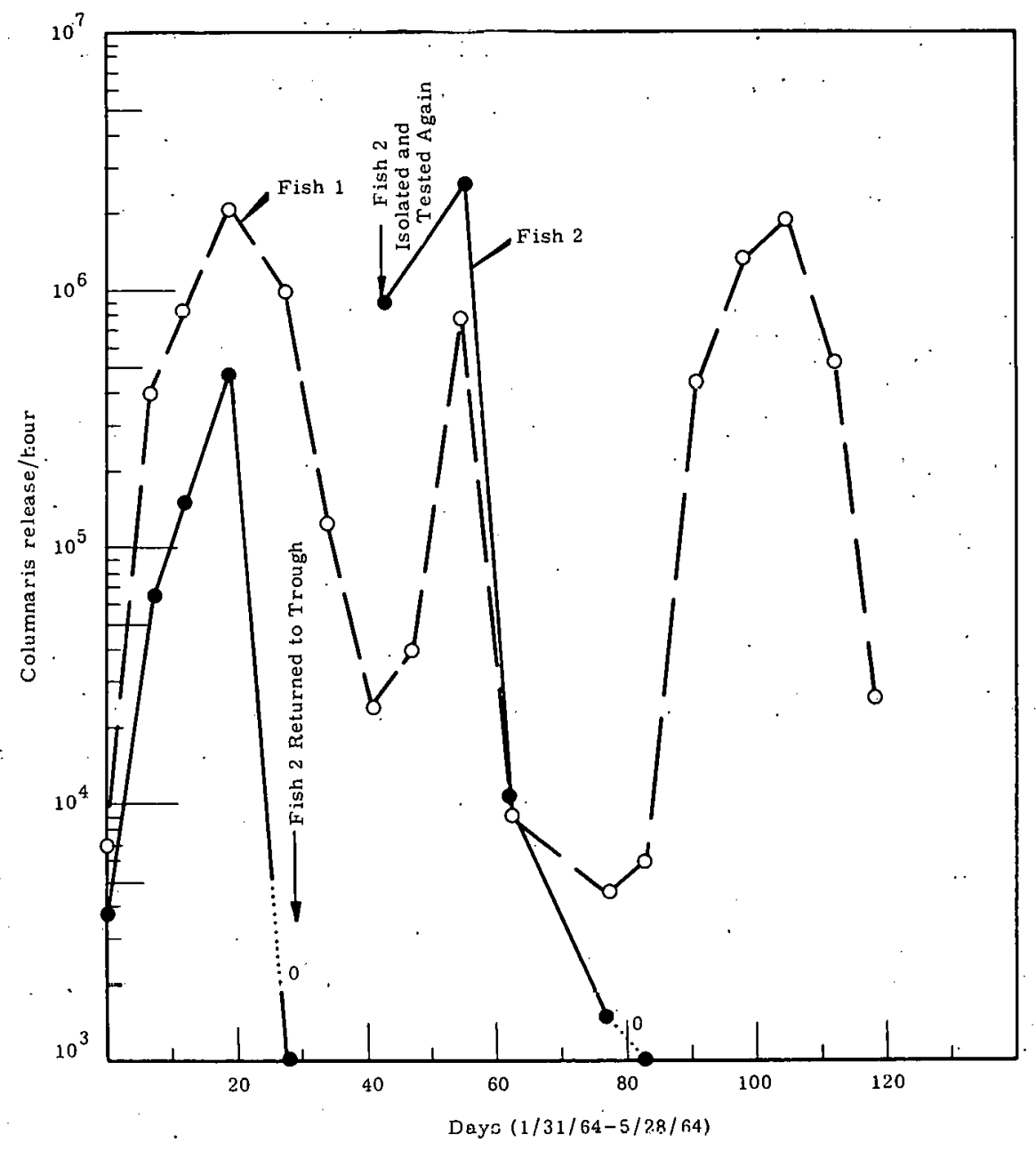

FIGURE 1. Columnaris Release from Isolated Yearling Rainbow Trout Held at $64^{\circ} \mathrm{F}$

A similar cycling of bacterial release was noted over a period of 140 days in a trough holding 25 yearling trout. At the conclusion of this holding period, 10 fish were actively releasing $\underline{C}$. columnaris while 15 were not.

The immunological characteristics of rainbow trout were investigated to determine the extent of antibody response and its value in protecting fish from disease when exposed to virulent columnaris organisms. Blood sera of trout having a known history of exposure showed agglutinin " titers against columnaris, whereas sera from imported trout with no 
history of columnaris exposure had no antibodies. Agglutinating antibodies did not react to a number of other bacterial antigens tested.

Injection of heat killed columnaris produced titers both when used alone and with Freund's adjuvant. Table 1 summarizes the results. Each titer represents the average results from 20-25 rainbow trout. Data on protective and/or immunizing values of the antigen on fish, immunity of fish of low and high titers to columnaris challenge, and effects of a single vaccine injection on production of antibody titers and the feasibility of developing an oral vaccine against columnaris are yet to be investigated.

TABLE 1. Maximum Titers Induced by $\underline{\mathrm{C}}$. columnaris Vaccine in Rainbow Trout

\begin{tabular}{|c|c|c|c|c|c|c|c|c|c|c|c|}
\hline \multirow[b]{2}{*}{ Injections } & \multirow{2}{*}{$\begin{array}{l}\text { No. } \\
\text { of } \\
\text { fish }\end{array}$} & \multicolumn{10}{|c|}{ Weeks postinjection } \\
\hline & & 0 & 1 & 2 & 3 & 4 & 5 & 6 & 8 & 10 & $\overline{12}$ \\
\hline Sham (control) & 50 & 0 & 0 & 0 & 0 & 0 & 0 & 0 & 0 & 0 & 0 \\
\hline Vaccine, intraperitoneal & 20 & 0 & 0 & 20 & 40 & 80 & 320 & 320 & 640 & 640 & 640 \\
\hline $\begin{array}{l}\text { Vaccine plus Freund's } \\
\text { Adjuvant, intraperitoneal }\end{array}$ & 25 & 0 & 20 & 40 & 80 & 160 & 640 & 640 & 1280 & 2560 & 5120 \\
\hline Vaccine, subrutaneous & 25 & 0 & 0 & 40 & 80 & 80 & 320 & 160 & 640 & 320 & 640 \\
\hline $\begin{array}{l}\text { Vaccine plus Freund's } \\
\text { Adjuvant, subcutaneous }\end{array}$ & 20 & 0 & 20 & 80 & 160 & 320 & 640 & 640 & 1280 & 2560 & 2560 \\
\hline
\end{tabular}

The above observations suggested that the frequency and magnitude of anti-columnaris titers could be used as an exposure indicator for natural populations of fish. A sampling program has demonstrated such titers in all species of Columbia River fish, except whitefish, Prosopium williamsoni. In most cases about $75 \%$ of the fish showed titers, indicating that most had been previously exposed to $\underline{\mathrm{C}}$. columnaris. It is clear that many fish survive such exposurc. It is not clear how many may have died from exposure.. Neither is it certain that all fish having an exposure history will subsequently show a persistent titer. 
CHINOOK SALMON SPAWNING NEAR HANFORD - 1964

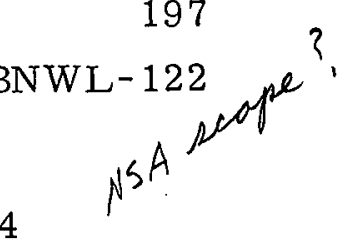

\author{
D.G.Watson
}

The number of chinook salmon nests observed in the vicinity of Hanford was only slightly less than the 18 year maximum. Surcess of the local salmon population appears to be better than that of the overall fall run in the Columbia.River.

Three aerial surveys of locally spawning chinook salmon were conducted on the Columbia River from Richland to Priest Rapids during : the period October 21 to November 16. Spawning had just started before the first survey and was completed by the last.

The year's total of 1443 salmon nests approaches the 18 year maximum of 1485 observed in 1958. The success of the local fall chinook salmon population is better than the overall fall run in the Columbia River. A comparison of the first five-year period (1947-51) to the last five-year period (1960-64) of this study shows that local nesting increased nearly threefold while the number ascending Bonneville Dam was nearly halved. This apparent success of the local population is presumed to be related to the partial barrier effect of Priest Rapids Dam. During the 12 years prior to the completion of the dam an average of $17 \%$ of the total number of nests was observed in the spawning area immediately downstream from the dam; since then an average of $43 \%$ of the total was in this area.

Diurnal fluctuations in river level, produced by regulation of flow by the dam, were great. The average daily fluctuation in river elevation during the spawning season was 7.1 feet in 1964 compared with 5.2 feet in 1963. This rapid change in water level intermittently exposed some salmon nests to the air. The effect of this on the survival of the deposited salmon eggs is unknown. 


\title{
REACTOR EFFLUENT MONITORING - 1964
}

\author{
P. A. Olson and R. E.. Nakatani
}

Comparisons between groups of chinook fingerlings reared in regular and cooled reactor efflient showed the importance of the accumulative effect of small temperature increments. Higher mortalities were observed in the present studies with local stock chinooks than in past studies with Puget Sound chinooks, due, perhaps, to physiological differences in racial stocks.

Since monitoring of Hanford's reactor effluent started in 1945, the biological effects of the primary factors (heat, chemical toxicity, and radiation) have been defined in terms of growth and mortality for young chinook salmon. In most of these studies, however, the test subjects were not the local stock of fall run chinooks. The practical unavailability of the local stock in past years left no alternative but to use other stocks such as the Green River. chinooks of Puget Sound. Because physiological differences between racial stocks are important variables, the results of the 1964 test with the progeny of the chinooks captured locally are of special interest. The test was designed not only to monitor regular reactor effluent in terms of the usual growth and mortality data but also to evaluate the accumulative effect of a relatively small temperature increment by comparing fish reared in regular and cooled effluent.

Eight groups, each with 500 chinook fingerlings, were reared in effluent concentrations of $0,2,4$, and $6 \%$. Four groups were maintained at river temperatures (cooled effluent) and the second four groups at river temperatures, plus the heat contributed by the warm effluent (regular effluent). Growth was followed by biweekly weight measurements and mortality scored daily. The accumulation of $\mathrm{P}^{32}$ and $\mathrm{Zn}^{65}$ directíy from effluent water was estimated by radioanalysis of the fish at the end of the 10 weeks.

Figure 1 illustrates the cumulative mortality for each group. Clearly, the 4 and $6 \%$ reactor effluent groups suffered higher mortalities of 11 and $20 \%$, respectively. The mortalities in all other lots, including 


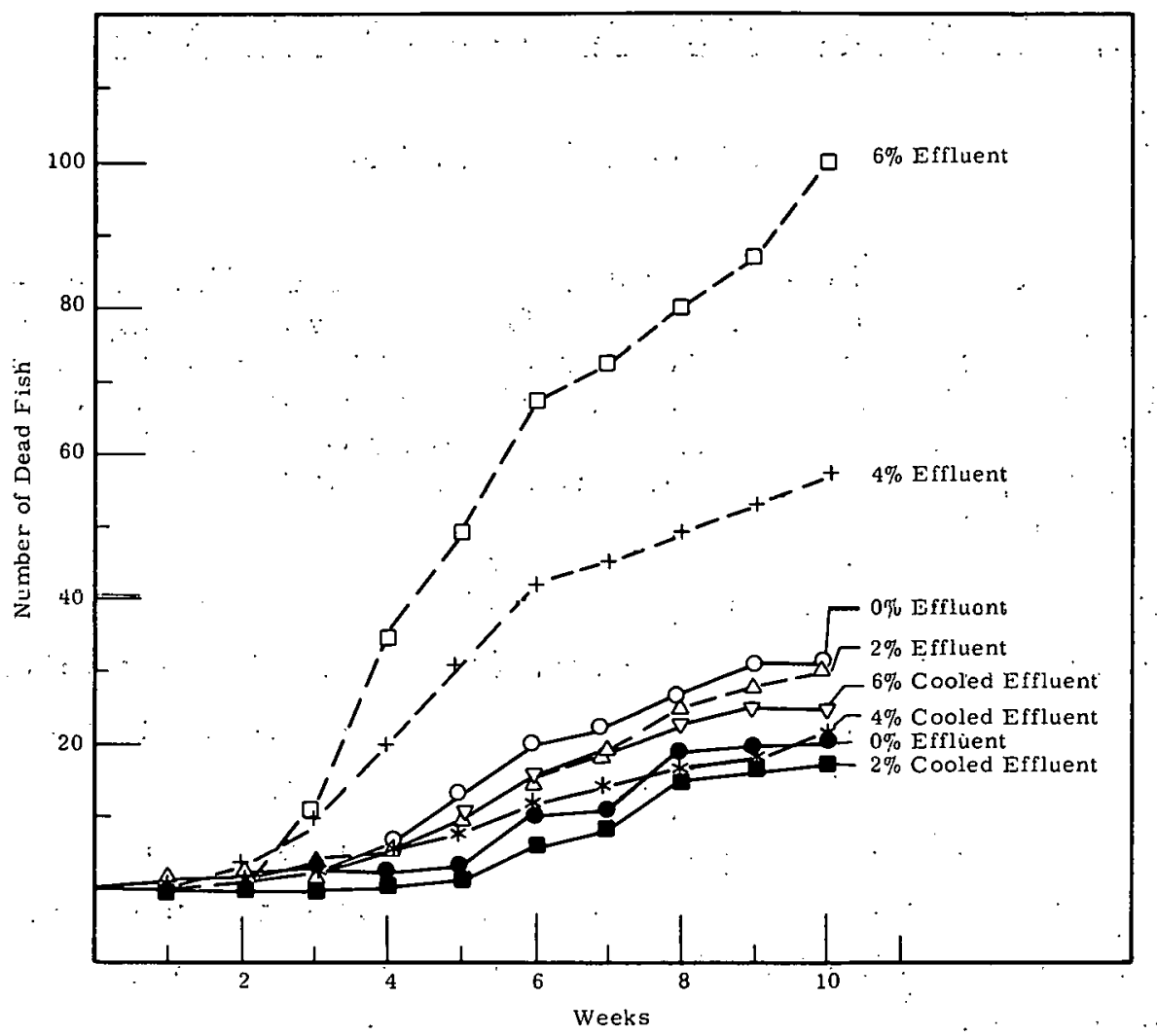

FIGURE 1. Mortality Curves of Chinooks

'Reared Under Various Effluent Conditions, 500 Fish/Group

the 4 and $6 \%$ cooled effluent, were lower, ranging from 3 to $6 \%$. The effect of 4 and $6 \%$ regular effluent on mortalities is striking. Past data would have predicted no markedly increased mortality at the $4 \%$ concentration; especially when the fish are exposed to effluent as late fingerlings for only 10 weeks. The local stock fingerlings may possibly be more sensitive than the stocks used in the past.

The growth in body weight illustrated in Figure 2 was similar for all groups with the exception of the 4 and $6 \%$ regular effluent groups. Warmer waters caused by the addition of effluent accelerated growth. The length-weight relationship was analyzed by using the following model: $\mathrm{W}=\mathrm{aL} \mathrm{b}^{\mathrm{b}}$, where $\mathrm{W}=$ weight; $\mathrm{a}=\mathrm{a}$ constant; $\mathrm{L}=$ standard length; and $\mathrm{b}=$ an exponent; usually about 3 for salmonids. Analysis of covariance 


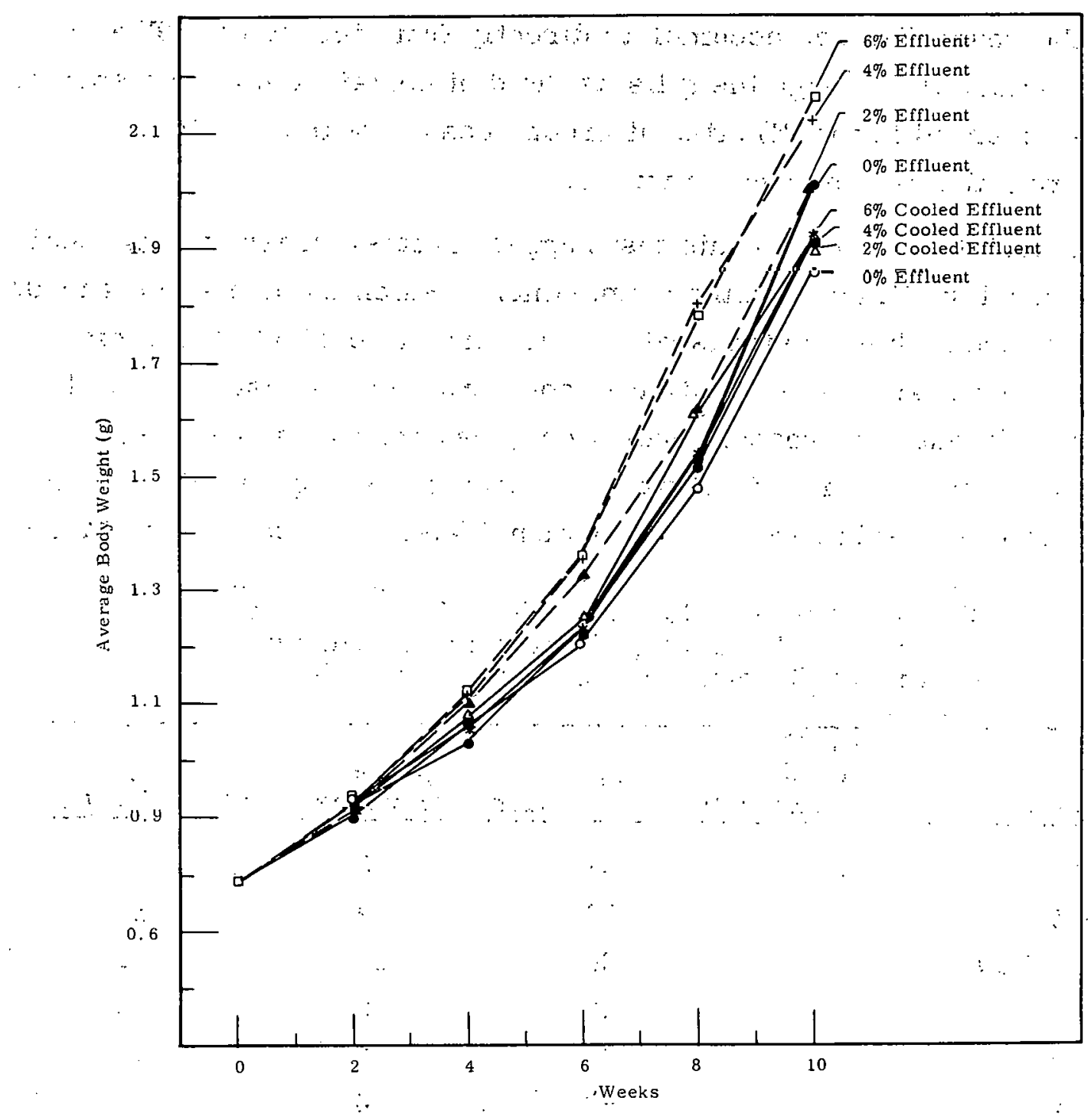

FIGURE 2. Growth in Body Weight of Chinooks Reared Under Various Effluent Conditions

inferred no statistical difference between the treatment groups in lengthweight relationships. The computed overall mean value of $b$ was 3.0380 .

Table 1 summarizes the results of the radioanalysis for $\mathrm{P}^{32}$ and $\mathrm{Zn}^{65}$ in fish reared in regular effluent for 10 weeks. Because of the small size of the fish, 6 fish for $\mathrm{P}^{32}$ and 14-19 fish for $\mathrm{Zn}^{65}$ were pooled for each sample. The presented values estimate roughly the amount of $\mathrm{P}^{32}$ 
and $\mathrm{Zn}^{65}$ the young fish can accumulate directly from the water. The mode of entry is primarily through the gills as the diet contained no radioisotope. Activity is observed in the $0 \%$ effluent group because of the reactors upstream from the hatchery water intake.

Although the results of this test suggest greater sensitivity of local chinook to reactor effluent, 'further experiments which include simultaneous testing of different chinook stocks will be required to evaluate the racial factor. Current results are not strictly comparable with past data partly because of differences in reactor operations, reactor tubes, and temperature regime. The biological importance of even a few degrees difference in the temperature regimen is clearly demonstrated in these trough studies.

TABLE 1. Average Concentration of $\mathrm{P}^{32}$ and $\mathrm{Zn}{ }^{65}$ in Chinook Fingerlings Reared for 10 Weeks in Various Concentrations of Reactor Effluent

\begin{tabular}{|c|c|c|c|c|c|}
\hline $\begin{array}{c}\text { Treatment } \\
\text { groups }\end{array}$ & $\begin{array}{l}\text { No. of } \\
\text { pooled } \\
\text { samples }\end{array}$ & $\mathrm{pCi}_{\mathrm{A}} \mathrm{P}^{32} / \mathrm{g}$ fish & $\begin{array}{l}\text { No. of } \\
\text { pooled } \\
\text { Samples }\end{array}$ & $\mathrm{pCi} \mathrm{Zn}^{65}$ & $\% \mathrm{~g} \mathrm{fish}$ \\
\hline $0 \%$ Effluent & 5 & 27 & 9 & $\because$, & \\
\hline $2 \%$ Effluent & 5 & 28 & 9 & 11 & \\
\hline $2 \%$ Cooled effluent & 5 & 28 & 10 & 15 & \\
\hline $4 \%$ Effluent & 5 & 43 & 9 & 15 & \\
\hline $4 \%$ Cooled effluent & 5 & 26 & 10 & 11 & \\
\hline $6 \%$ Effluent & 8 & 42 & 8 & 9 & \\
\hline $6 \%$ Cooled effluent & - & -- & 10 & 19 & \\
\hline
\end{tabular}




\section{PUBLICATIONS}

\section{Documents}

Staff of Biology Laboratory. 1964. Hanford Biology Research Annual Report for 1963. HW-80500 (Hanford Laboratories, Richland, Washington) .

Kornberg. H. A. 1964. Progrcss in Biulugical Research - A Summary of Hanford Laboratories Achievements Under These Programs Under General Electric. HW-83613 (Hanford Laboratories, Richland, Washington).

\section{Open Literature}

Bair, W. J. 1964. Inhaled radioactive particles and gases. Science 146:440-444.

Bair, W. J. 1964. Conclusion and acknowledgements - Hanford symposium on inhaled radioactive particles and gases. Health Physics 10:1259.

Bair, W. J., B. O. Stuart, J. F. Park, and W. J. Clarke. 1964. Factors affecting retention, translocation and excretion of radioactive particles, p. 253-274. In Radiological Health and Safety in Mining and Milling of Nuclear Materials, Vol. 1. IAEA, Vienna, Austria.

Ballou, J.E. 1964. Distribution and retention of plutonium-239 and neptunium-237 in the rat adrenal. Radiation Research 22:81-94.

Bustad, L. K. 1964. Hanford symposium on biology of radioiodine. Atompraxis 10:119-121.

Bustad, L. K., N. M. Gates, A. Ross, and L. D. Carlson. 1964. Effects of prolonged low-level gamma irradiation on mice. (Abstr.) Radiation Research 22:174.

Clarke, W. J. and W. J. Bair. 1964. Plutonium inhalation studies. VI. Pathologic effects of inhaled plutonium particles in dogs. Health Physics 10:391-398.

Clarke, W. J., J. F. Park, J. L. Palotay, and W. J. Bair. 1964. Bronchioloalveolar tumors of the canine lung following inhalation of plutonium particles. Am. Rev. of Respiratory Diseases 90:963-967.

Eberhardt, L. L. 1964. Variability of the strontium-90 and caesium-137 burden of native plants and animals. Nature 204:238-240.

Erdman, H. E. 1964. Dominant lethal proportions modified by X-radiation, temperatures and co-habitation in single- and mixed-species populations of flour beetles, Tribolium confusum and T. castaneum. (Abstr.) Radiation Research 22:023.

Erdman, H. E. 1964. Research notes. Tribolium Information Bulletin $7: 57-59$. 
Erdman, H. F. 1964. Sexual precocity of the male flour beetle, Tribolium castaneum Herbst, and the influence of temperatures on reproduction during early adult life. The Canadian Entomologist 96:657-659.

Hackett, P. L. 1964. Toxicity of copper administration and X-irradiation in rats: Thesis. Washington State University, Pullman, Washington.

Hanson, W: C. and H. E. Palmer. 1964. Accumulation of fallout cesium137 in Alaskan natives. North American Wildlife and Natural Resources Conference, trans., 29th, p. 215-225.

Hanson, W. C., H. E. Palmer, and B. I. Griffin. 1964. Radioactivity in northern Alaskan Eskimos and their foods, summer 1962. Health Physics 10:421-429.

Kornberg, H. A. 1964. A comparison of approaches to radiation and general toxicology. (Abstr.) Toxicology and Applied Pharmacology $6: 351$.

Kornberg, H. A. 1964. Introduction - Hanford symposium on inhaled radioactive particles and gases. Health Physics 10:861.

McClanahan, B. J. 1964. Zinc-cadmium interrelationships in rats and sheep. Thesis. Washington State University, Pullman, Washington.

McClellan, R. O. 1964. Calcium-strontium discrimination in miniature pigs as related to age. Nature 202:104-106.

McClellan, R. O. and L. K. Bustad. 1964. Metabolism of some SNAP radionuclides in miniature swine. (Abstr.) Aerospace Medicine 35:276.

McClellan, R. O. and L. K. Bustad. 1984. Tuxicity of cignificant radinnuclides in large animals. Annals N.Y. Acad. Sci. 111, Art. 2:793-811.

McClellan, R. O.o. W. J. Clarke, and Glenda S. Vogt. 1964. Acute toxicity of $\mathrm{Sr}^{90}$ in miniature swine. (Abstr.) Toxicology and Applied Pharmacology 6:353.

McClellan, R。O., J. L. Palotay, W. J. Clarke, and G. S. Vogt. 1964. Ectopic myelopoiesis and other hematological changes in miniature swine ingesting $\mathrm{Sr}^{90}$ daily. (Abstr。). Proceedings of the Xth Congress of the International Society of Haematology, Stockholm, Sweden, August 30-September 4, 1964.

McClellan, R. O., Glenda S. Vogt, R. E. Kane, and F. F. Hahn. 1964. Endotoxin-induced leukocyte response of miniature swine ingesting Sr90 daily. (Abstr.) Radiation Research 22:213.

McClellan, R。O., Glenda S.Vogt, R. E。 Kane, and F. F. Hahn. 1964. Endotoxin-induced neutrophil response in miniature swine ingesting strontium-90 daily. Nature 201:721-722.

Mahlum, D. D: 1964. Effect of $\mathrm{Np}^{237}$ on lipid metabolism.: (Abstr.). Toxicology and Applied Pharmacology 6:354.

Noyan, A. 1964. Water absorption from the intestine via portal and lymphatic pathways in rats. Proc. Soc. Exptl. Biol. and Med. 117: 317-320. 
O'Brien, R. T. 1964. Effect of $\mathrm{D}_{2} \mathrm{O}$ on uptake in yeast. Proc. Soc. Exptl.Biol. and Med.117:555-558.

Palmer, H. E., W. C. Hanson, B. I. Griffin, and D. M. Fleming. 1964. Radioactivity measurements in Alaskan Eskimos in 1963. Science 144: 859-860。

Palmer, H. E.,.R. W. Perkins, and B. O. Stuart. 1964. The distribution and deposition of radon daughters attached to dust particles in the respiratory oystem of humars exposed to uranium mine atmospheres. Health Physics 10:1129-1135.

Palmer, R. F. and R. C. Thompson. 1964. Strontium-calcium interrelationships in the growing rat. Am. J. Physiol. 207:561-566.

Park, J. F., W. J. Bair, and W. J. Clarke. 1964. Chronic toxicity of inhaled plutonium in dogs. (Abstr.) Radiation Research 22:222.

Park, J.F., W. J. Clarke, and W. J. Bair. 1964. Chronic effects of inhaled plutonium in dogs. Health Physics 10:1211-1217.

Ragan, H. A., W. J. Clarke, V. G. Horstman, R. O. McClellan, B. J.. McClanahan, and L.K. Bustad. 1964. Effects of plutonium on swine skin. (Abstr.) Health Physics 10:588.

Rickard, W.H. 1964. Spring precipitation and the strontium-90 contamination of wheat in the semi-arid regions of Idaho and Montana. Nature 201:309-310.

Rickard, W. H. 1964. A vagrant occurrence of the black phoebe in southeastern Washington. The Condor 66:162.

Rickard, W. H. 1964. Bird surveys in cottonwood-willow communities in winter. The Murrelet 45:22-25.

Rickard, W. H. 1964. Demise of sagebrush through soil changes. Bio-Science 14:43-44.

Smith, V. H. 1964. Prevention of plutonium deposition by desferrioxamine- $\beta$. Nature 204:899-900.

Stuart, B. O. 1964. Distribution and excretion of inhaled and intravenously administered Pm 147 . (Abstr.) Toxicology and Applied Pharmacology 6:360.

Stuart, B. O., H. W Casey, and W. J. Bair. 1964. Acute and chronic effects of inhaled ${ }^{144} \mathrm{CeO}_{2}$ in dogs. Health Physics 10:1203-1209.

Sullivan, M. F. and R.C. Thompson. 1964. The influence of fractionated $\mathrm{X}$-irradiation on the intestine of rats protected by cysteine and partial body shielding. Radiation Research 23:551-563.

Tombropoulos, E. G。 1964. Fatty acid synthesis by subceliular fractions of lung tissue. Science 146:1180-1181.

Tombropoulos, E. G. 1964. Review of therapeutic procedures for removal of inhaled radioactive materials. Health Physics 10:1251-1257. 
Tombropuulos, E. G. and W.J. Bair. 1964. Effect of the form of inhaled cerium dioxide on its removal by diethylenetriamine pentaacetic acid. (A.bstr。) Health Physics 10:587.

Watson, D. G.; W. C. Hanson, and J. J. Davis. 1964. Strontium-90 in plants and animals of Arctic Alaska, 1959-61. Science 144:1005-1009.

West, J.E. and W. J. Bair. 1964。 Plutonium inhalation studies. V. Radiation syndrome in beagles after inhalation of plutonium dioxide: Radiation Research 22:489-506. 


\section{LECTURES}

Papers Presented at Society Meetings and Symposia

Sullivan, M. F。 Bile salt influence in intestinal radiation injury.: Symposium on Intestinal Function. San.Juan, Puerto Rico. January 15-18, 1964 .

Hungate, F. P. I.ife in Greecc. Irealth Physics Society, Richland, Washington: January $31,1964$.

Hanson, W. C. The accumulation of fallout cesium-137 in northern Alaskan natives. Wildlife Conference, Las.Vegas, Nevada, March 9, 1964 .

Eberhardt, L. L. Sampling ecosystems for fallout radionuclides. Wildlife Conference, Las Vegas, Nevada. March 9, 1964.

Kornber'g, H. A. A comparison of approaches to radiation and general toxicology. Society of Toxicology,.Williamsburg, Virginia. March 10, 1964 .

Mahlum, D.D. Effect of $\mathrm{Np}^{237}$ on lipid metabolism. Society of Toxicology, Williamsburg, Virginia. March 10, 1964.

McClellan, R. O. Acute toxicity of $\mathrm{Sr}^{90}$ in miniature swine. Society of Toxicology, Williamsburg;" Virginia。 March 10, 1964.

Stuart, B. O. Distribution and excretion of inhaled and intravenously administered $\mathrm{Pm}^{147}$. Society of Toxicology,. Williamsburg, Virginia. 'March 10, 1964.

Dean, J. M. Instrumentation in Biology at Hanford. Pacific Fishery Biologists Annual Meeting, Ocean Shores, Washington. March 25-27, 1964.

Nakatani, R. E. Chairman of Panel on Instrumentation in Fisheries. Pacific Fishery Biologists Annual Meeting, Ocean Shores, Washington. March 25-27, 1964。

O'Brien, R. T. Effects of deuterium oxide on attainable growth of Saccharomyces cerevisiae. American Society of Microbiology, Washington, D. C. May 3, 1964.

Symposium on Inhaled Radioactive Particles and Gases, Hanford Laboratories, General Electric Company, Richland, Washington, Maý 4-6, 1964.

Palmer, H。 E., R. W. Perkins and B..O. Stuart. The distribution and deposition of radon daughters attached to dust particles in the $\because:$ respiratory system of humans exposed to uranium mine atmospheres.

Engel, S. (read by W. J. Clarke). Comparative anatomy and pulmonary air-cleansing mechanisms in man and certain experimental animals.

Park, J.F...W. J. Clarke, and W. J. Bair. Chronic effects of inhaled plutonium in dogs. 
Stuart, B. O., H. W. Casey, and W. J. Bair. Acute and chronic effects of inhaled $\mathrm{Ce}^{144} \mathrm{O}_{2}$ in dogs.

Tombropoulos, E. G. Review of therapeutic procedures for removal of inhaled radioactive materials.

McClellan, R. O., L.K. Bustad, and R. F. Keough. Metabolism of some SNAP radionuclides in miniature swine. Aerospace Medical Association Meeting, Miami Beach, Florida. May 11-14, 1964.

Park, J. F., W. J. Bair, and W.J. Clarke. Chronic toxicity of inhaled plutonium in dogs. Radiation Research Society, Miami Beach, Florida. May 18-20, 1964.

Erdman, H. E. Dorrinant lethal proportions modified by X-radiation, temperatures, and cohabitation in single- and mixed-species populations of flour beetles, Tribolium confusum and $T$. castaneum. Radiation Research Society, Miami Beach, Florida. May 18-20, 1964.

McClellan, R. O. Endotoxin-induced leukocyte response of miniature swine ingesting $\mathrm{Sr}^{90}$ daily. Radiation Research Society, Miami Beach, Florida. May 18-20, 1964.

Sullivan, M. F. Measurement of intestinal damage from neutrons, X rays or nitrogen mustard treatment. Radiation Research Society, Miami Beach, Florida. May 18-20, 1964.

Bair, W. J. Effect of the form of inhaled cerium dioxide on its removal by diethylenetriamine-pentaacetic acid. Health Physics Society, Cincinnati, Ohio. June 14-18, 1964.

Ragan, H. A., et al. Effects of plutonium on swine alkin. Health Physics Society, Cincinnati, Ohio. June 14-18, 1964.

Keoügh, R. F. Flame spectrophotometric determination of calcium after strontium oxalate coprecipitation. American Chemical Society, Spokane, Washington. June 15, 1964.

Cline, J.F. Effect of climatic, physical, and biological conditions on deposition and retention of $\mathrm{I}^{13}$ on plants. American Society of Plant Physiologists, A.A.A.S. Western Section, University of British Columbia, Vancouver, B.C. June 22-25, 1964.

Ragan, H. A., et al. Application of miniature goats in ruminarit.research. Annual Meeting of the American Veterinary Medical Association, Chicago, Illinois. July 19-23, 1964.

Bustad, L. K., R. O. McClellan, and J. Garner. Significance of radionuclide contamination in ruminants. Second International Symposium on the Physiology of Digestion in the Ruminant. Ames, Iowa. August 19-21, 1964!

Cushing, C. E. Productivity and radionuclide accumulation of periphyton in the Columbia River. AIBS Meetings - Ecological Society of America, Boulder, Colorado. August 23, 1964.

Rickard, W. H. Mineral uptake by greasewood and hopsage. AIBS Meetings - Ecological Society of America, Boulder, Colorado. August 23, 1964. 
Nakatani, R. E. Toxicity and metabolism of zinc -65 in trout. AIBS. Mëetings. - Ecological Society of America; : Boulder, Colorado. August $26 ; 1964$.

Bair, W. J. Deposition, retention, and excretion of inhaled particles. Pacific Northwest American Industrial Hygiene Association, . Richland, Washington. August 28, 1964.

Clarke, W. J. Histopathology and autoradiography of the lung following plutonium inhalation. Pacific Northwest Amer.ican Industrial Hygiene Association., Richland, Washington. August 28, 1964.

Palotay, J. L. Anatomy and physiology of the mammalian lung. Pacific Northwest American Industrial Hygiene Association, Richland, Washington. August 28, 1964 .

Park, J. F. Biological effects of inhaled aerosols. Pacific Northwest American Industrial Hygiene Association, . Richland, Washington. August 28, 1964.

McClellan,.R. O., et al. Ectopic myelopoiesis and other hematologic changes in miniature swine ingesting Sr 90 daily. Xth Congress of the International Society of Hematology, Stockholm, Sweden. August 30September 4, 1964.

Hungate, F. P. Radionuclides in Alaska Eskimos. 15th Alaskan Science Conference, Fairbanks, Alaska (AAAS). September 1-4, 1964.

Matchett, W. H. Utilization of tryptophan by Neurospura. American Suclety for Microbiology, Moscow, Idaho. October 2, 1964.

Watson,.D. G. Cesium-137 and strontium-90 in Alaskan animals and forage plants. 4th Symposium on Radioactivity in Scandinavia, Risö, Denmark. October 5-6, 1964.

Society for Experimental Biology and Medicine (Northwest Section Annual Meeting) Seattle, Washington, October 24, 1964:

Berlin, J.D. and C. C. Bowen. Flagellar initiation and centrioles in Albugo.

Fujihara, M. P. The effects of radiation and $\mathrm{D}_{2} \mathrm{O}$ on cichlid fish. Hsieh, J. J. C. The mechanism of iodine gas absorption by leaves. Liu, D. H. W. and W. J.Clarke. Sites of zinc deposition in the gastrointestinal tract of trout.

Matchett, W. H. Utilization of tryptophan by Neurospora.

McClanahan, B. J. The zinc-cadmium interrelationships.

Smith, V. H. Cooperative action of desferrioxamine- $\beta$ with diethylenetriamine-pentaacetic acid in removal of plutonium from rats.

Erdman, H. E. Fast neutron irradiation effects on reproduction and the influence of temperature and sex-exposed for day-old flour beetles, Tribolium castaneum Herbst. Annual Meeting of Entomological Society of Canada, Vancouver, B.C. October 19-21, 1964. 
209

BNWL- 122

McClanahan, B. J. Milk secretion of zinc and cadmium in the ruminant. IAEA-sponsored Symposium on the U.se of Radioisotopes in Animal

Nutrition and Physiology, Prague, Czechoslovakia. November 23-27, 1964. 
Off-Site and Locál Seminars.

Park, J. F. Biological effects of inhaled radioactive particles: U.S. Naval Research Unit, Washington State University, 'Pullman, , " : Washington. January. 6, 1964.

Matchett, W.H. Some aspects of tryptophane metabolism in Neurospora. Washington State University, Pullman,..,Washington. (Exchange Seminar Program). February 19, 1964.

Eberhardt, L. L. Kadiation in relation to plants and animals. Washington State Department of Game, Olympia, Washington. February 27, 1964.

Park, J.F. Toxicity of inhaled plutonium. 6516 U.S. Army: Reserve and Development Unit, Pasco, Washington. March 2, 1964.

O'Brien, R. T. Physiological effects of heavy water on microorganisms. Washington State Univerisity, Pullman, Washington (Exchange Seminar Program). March 6, 1964.

McClellan, R. O. Some hematological effects of daily ingestion of $\mathrm{Sr}^{90}$ in miniature swine. Department of Medicine, University of Washington, Seattle, Washington. March 18, 1964.

McClellan, R. O. Some measurements of damage in miniature swine ingesting $\mathrm{Sr}^{90}$. Industrial Physicians: Meeting, Richland, Washington. March 19, 1964.

Dean, J. M. Effects of tempcrature acclimation on some aspects of carbohydrate metabolism of Crustacea. Washington State University, Pullman, Washington. (Exchange Seminar Program). March 23, 1964.

Dean, J. M. "Physiological effects of temperature acclimation in Crustacea. Biology Department, DePaul University", Chicago," Illinois, April 18, 1964.

Sullivan, M. F. Effect of radiation on the intestine. University of Washington, Seattle, Washington. May 7, 1964.

Kornberg, H. A. Biology at Hanford. Battelle Memorial Institute, Columbus, Ohio. May 14, 1964.

Bair, W. J. Inhalation of radioactive particles. University of Washington Radiological Sciences, Seattle, Washington. May 28, 1964.

McClellan, R. O. Radiostrontium metabolism and toxicity in miniature swine. University of Oregon Dental School, Portland, Oregon. June 4, 1964 .

Mahlum, D. D. Cellular effects of radiation. Biochemical effects of radiation. University of Washington Summer Institute for Radiation Biology, Seattle, Washington. June 21, 1964.

Hungate, F. P. Genetics. University of Washington Summer Institute for Radiation Biology, Seattle, Washington. June 26, 1964. 
Bustad, L. K. Physiopathology of irradiation. University of Washington. Summer Institute for Radiation Biology, Seattle, Washingtion. June 29 and $30, . .1964$.

Rickard, W. H. : Radioecology. Montana Stäte University Summer Institute for Radiation Biology, Yellow Bay, Montana. July 13, 1964.

Park, J. F. Inhalation of radioactive particles. : University of Utah : Radiobiology Summer Institute, Salt Lake City; Utah. Jüly 14, 1964.

Rickard, W. H. Radioecology. Montana State University Summer Institute, Missoula; Montana. July 14, 1964.

University of Washington Summer Institute for Radiation Biology, Richland, Washington:

August 12, 1964

Mahlum, D. D. Heavy metals and liver metabolism.

Bustad, L. K. Radioiodine in domestic animals and man.

Mc Clellan, . R: O. " $\mathrm{Sr}^{90}$ metabólism in pigs.

August 14, 1964

Erdman, H. E. Radiation studies with flour beetles.

Hanson, W. C. Alaskàn studies.

Nakatani, R. E. Effluent monitoring and fish research.

Park, J. F. Inhalation of rádioàctive particles.

Bustad, L. K. and R. U. MeClellan. Radinnuclide toxicity in domestic animals. College of Veterinary Medicine, . Washington State University, Pullman, Washington. October 30, 1964. 


\section{Biology :Department Seminars}

Park, J. F. Chronic toxicity of inhaled $P_{1}$ in dogs. January 8, 1964. Liu, D. H. W: Toxicity of industrial chemicals to fish. January 1.5, 1964 .

Eastlick, H. L., Department of Zoology, Washington State University, Pullman, . Washington (Exchange Seminar Program). Methyl chloranthrene induction of neoplasma in chickens. J January 17, 1964.

Wilson, D. O. Deposition of $\mathrm{I}^{131}$ on plants and soil under simulated fallout conditions. January 22, 1964.

Ballou, J. E. Plutonium deposition in soft tissues. January 29, 1964.

Mahlum, D.:D. Neptunium-237 and lipid metabolism. February 5, 1964.

Silverman, M. S., Head, Microbiology and Immunology, USNRDL், San Francisco, California. Effect of radiation on infection and the role of infection on radiation injury. February $7,1964$.

Olson, P. A. Further studies on columnaris disease. February 12, 1964.

Leader, TR. W. Associate Professor of Veterinary Pathology, Washíngton State University, Pullman, Washington. Antibody - friend or foe. February 14, 1964.

Dean, J. M. Effects of temperature acclimation on some aspects of carbohydrate metabolism of Crustacea, February.10, 1964.

Mrcclellian, R. O. Measures of damage in miniature swine ingesting $\mathrm{Sr}^{90}$. February 26, 1964.

Klontz, G. W., Western Fish Disease Laboratory, Seattle, Washington. Diseases of fish: problems and their solution. February 27, 1964.

Clarke; W. J. Bronchiolo-alveolar tumors of the canine lung following: plutonium particle inhalation. March 4, 1964.

Sullivan, M. F. Biological effects of neutron irradiation. March 11, 1964.

Hecht, A., Department of Botany, Washington State University, Pullman,

- Washington. Experimental modification of genetic incompatibility. March 13, 1964.

Cushing, C...E. Plankton and water chemistry. March 18, 1964.

Ragan, H. A. Effect of plutonium on swine skin. March 18, 1964.

Vanderbeek, J. W. New production reactor (100-N Department). March 19, 1964.

Hungate, F. P: Transmutation effects in biological systems. March 25, 1964 .

Price, K. R. Root distribution in Artemesia as measured by $\mathrm{I}^{131}$ uptake. March 25, 1964. 
Bair, W. J. Experiments on inhaled radioactive particles and cigarette. ; smoke. April 8, 1964.

Hart, J. Sanford, National Research Council, Canada. Energetics of temperature regulation of birds and small mammals. April 10, 1964.

Cline, J. F. Cesium toxicity in pea roots. April 15, 1964.

Wood, D. H: Neptunium toxicity in sheep. April 15, 1964.-

Buschbom, R. Use of computers in Biology. April 22, 1964.

Tombropoulos, E. G. Lipid metabolism of lung tissue. April 29, 1964.

Harvey, R. A., Physics and Instruments Laboratory, Hanford Laboratories. Use of analog.computcrs in Biology. May 13, 1964.

Todd, P., Donner Laburatory; University of California, Berkeley,

California. The relative biological effectiveness of heavy ion radiation. in tissue culture cells. May 15, 1964. -

Hackett, P. L. Comparison of copper and radiation toxicity... May 20, 1964.

McClanahan, B. J, Zinc and cadmium interrelationships in rats. May 20, 1964.

Spencer, H., Chief, Metabolic Section, Veteran's' Administration, : Edward Hines, Jr. Hospital, Hines, Illinois. Radiostrontium metabolism in. man. June 22, 1964.

Wiley, W. R., Department of Bacteriology and Public Health, Washington State University, Pullman, Washington. The requirements of an alka-' line $\mathrm{pH}$ and $\mathrm{NH}_{4}$ ions for membrane transport by Bacillus pasteurii. June 29, 1964.

Pierce, M., Chairman, Department of Zoology, Vassar College, Poughkeepsie, New York, Ecology - basis of modern weed control in aquatic environments. July 17, 1964:

Stienhardt, M. D., Department of Genetics, University of Washington, Seattle, Washington. An inquiry into the mechanism of information transfer from DNA to messenger RNA. October 5, 1964.

Cushing; C. E. Productivity and radionuclide accumulation by periphyton. October 14, 1964.

McKenney, J. R. Transport of Ca and P in the isolated rat intestine. October 20, 1964.

Erdman, H. E. Dose ratio of $250 \mathrm{kvp} X$-rays and 4.6 mev fast neutrons for induction of $50 \%$ dominant lethals. October $28 ; 1964$.

Berlin, J. D. Fine structure of centrioles and flagella in Albugo. November $12,1964$.

Pekas, J. C. Gross and cellular aspects of $\mathrm{Zn}^{65}$ metabolism. November $19,1964$. 
Uyeki, E. M. Graft-host response in bone marrow transplantation. November 25, 1964.

Sullivan, M.F. Bile salt absorption in the irradiated rat. December 2, 1964.

Matchett, W. H. Metabolism of tryptophan in Neurospora crassa. December 9, 1964.

A.braham, S., Department of Physiology, University of Berkeley, Berkeley, California. The role of microsomes in fatty acid synthesis. December 15, 1964.

Palotay, J. L. Information systems. December 16, 1964.

Taber, R. D. and T. J. Nimlos, School of Forestry, IMontana State University, Missoula, Montana. Alpine ecosystems of the Northern Rocky Mountains. December 18, 1965.

Clarke, W. J. The use of cell organ culture and cytochemical techniques in toxicological research. December $23,1964$.

McClellan,. R. O. Strontium-90 induced hematopoietic tissue neoplasms. December $30,1964$. 


\section{ONSITE DISTRIBUTION}

Copy Number

Pacific Northwest Laboratory

F. W. Albaugh

W. J.Bair

C. A. Bennett

S. H. Bush.

$\because$ L:K. Bustad

W. J. Clarke

G. M. Dalen

R. F. Dickerson

S. L. Fawcett

R. F. Foster

W. E. Foust

J. J. Fuquay

E. P. Galbraith

F. P. Hungate

R. L. Junkins

A. R. Keene

H. A. Kornberg

W. H. Matchett

R. E. Nakatani

C. E. Newton

J. M. Nielsen

R. F. Palmer

J. L. Palotay

H. M. Parker

R. S. Paul

D. W. Pearce

P. M. Potter

W. C. Roesch

G. M. Rolph.

A. J. Stevens

M. F. Sullivan

R. C. Thompson

C. R. Tipton, Jr.

M. T. Walling, Jr.

Biology Library

Extra Copies (H.A. Kornberg)

Technical Publications, 300 Area

Technical Publications, 700 Area

Technical Information Files

Douglas "Unitè,d Nuclear.

Hanford Occupational Health Foundation

W. D. Norwood 
216

BNWLL- 122

\section{ONSITE DISTRIBUTION}

Copy Number

398

Isochem

Richland Operations Office

399

400-405

406- 407

P. G. Holsted

C. L. Robinson, Jr.

408 Techrical Information Library

U.S. Testing 